\title{
The Isolation and Structure Elucidation of Secondary Metabolites from Tongan Marine Invertebrates
}

\section{Victoria UNIVERSITY OF WELLINGTON Te Whare Wānanga o te Ūpoko o te Ika a Māui

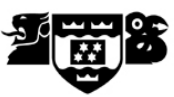

\author{
A thesis \\ submitted to Victoria University of Wellington \\ in fulfilment of the requirements for the degree of \\ Master of Science \\ in Chemistry.
}




\section{Abstract}

During the course of this study, Tongan marine organisms were investigated for new secondary metabolites. A combination of reversed-and normal-phase chromatographic techniques and NMR spectroscopy was employed, to aid in the isolation and structure elucidation of the five known and four new compounds isolated in this study.

A brief investigation into the antifungal activity of Tongan holothurian saponins was instigated in order to compare the activity against saponins isolated from the common New Zealand sea cucumber, Australostichopus mollis. A yeast-based chemical genetics study, determined the antifungal activity, for four partially purified Tongan holothurian extracts, against Saccharomyces cerevisiae, to be similar to neothyonidioside (44), a saponin from $A$. mollis. This result suggested the antifungal activity to be a common characteristic to sea cucumber saponins.

Further interest in secondary metabolites from Tongan marine organisms led this study towards the investigation of Tongan marine sponges. Five sponges were selected for screening, and two chosen for further study which yielded five known compounds (51-53, 61, 62) and four new fascaplysin derivatives; 7-bromoreticulatine, 10-bromo-6,7-dimethoxyhomofascaplysin C, 10-bromo-6,7-dimethoxyhomofascaplysin D, and 10-bromohomofascaplysin A (63-66, respectively).

Although 63 and 66 are new members of the fascaplysin family solely due to the position of the bromine, it appears that bromination on the A-ring is comparatively rare, with only three of the 24 literature examples displaying A-ring bromination. On the other hand, 64 and 65 present a new sub-class of fascaplysin derivatives due to the presence of a dimethoxy functionality. Both 7-bromoreticulatine (63) and 10-bromohomofascaplysin A (66) were found to be potently cytotoxic in the HL-60 cell line, exhibiting $\mathrm{IC}_{50}$ values of 33.8 and 498 $n M$, respectively. 10-Bromo-6,7-dimethoxyhomofascaplysins C (64) and D (65) were significantly less cytotoxic with respective $\mathrm{IC}_{50}$ values of 2.7 and $6.0 \mu \mathrm{M}$. 

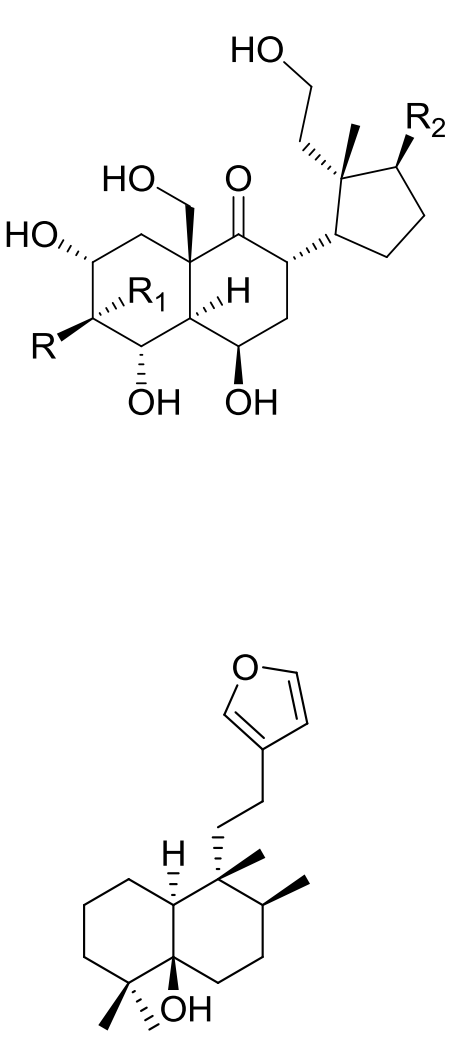

61

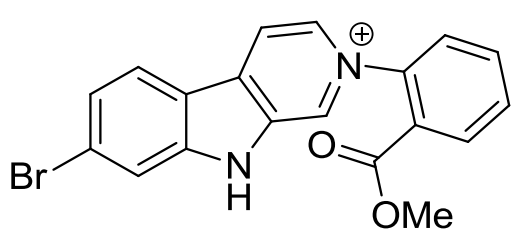

63

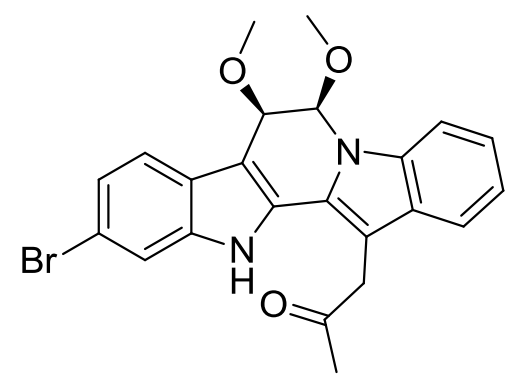

65
$51 \mathrm{R}=\mathrm{OH} \quad \mathrm{R}_{1}=\mathrm{H} \quad \mathrm{R}_{2}=$

$52 \mathrm{R}=\mathrm{OH} \quad \mathrm{R}_{1}=\mathrm{H} \quad \mathrm{R}_{2}=$

$53 \mathrm{R}=\mathrm{H} \quad \mathrm{R}_{1}=\mathrm{OH} \quad \mathrm{R}_{2}=$

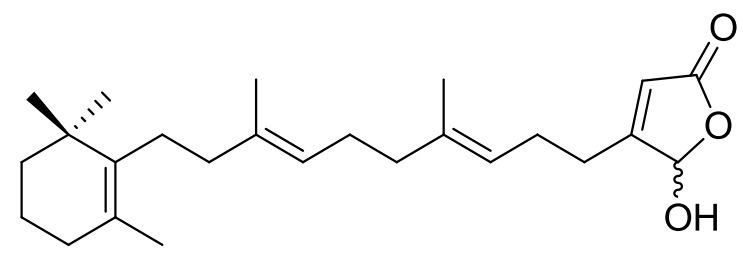

62<smiles>CO[C@H]1c2c([nH]c3cc(Br)ccc23)-c2c(C=O)c3ccccc3n21</smiles>

64

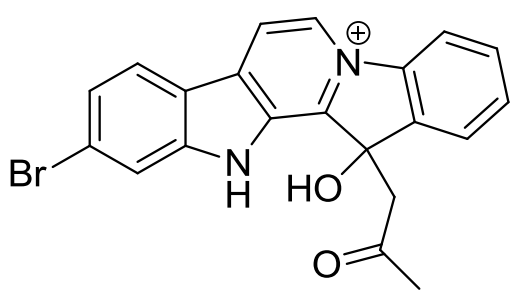

66 


\title{
Acknowledgements
}

\author{
'He aha te mea nui o te ao? \\ He tangata, he tangata, he tangata!' \\ Translation: 'What is the most important thing in the world? \\ It is people, it is people, it is people!'
}

The renowned Maori proverb quoted above describes the most important contributing factor towards not only the completion of this thesis, but to all my achievements to date. Without the support from many, these accomplishments, without a doubt would not have been possible.

First of all, I would like to thank my incredible supervisor, Associate Professor Peter Northcote for his time, patience, guidance, expertise and support through my MSc. You have been amazingly understanding and your enthusiasm for natural products chemistry has well and truly been contagious! All the sleepless nights from my excitement and eagerness to analyse NMR data has definitely been worth it. Thank you Peter, I have thoroughly enjoyed natural products chemistry and could not have wished for a better supervisor!

Through my time in the lab I have had the greatest pleasure of working with many fantastic people. To Jonathan Singh 'Jono', Jacqueline Barber and Bryan Northover, you have been excellent lab buddies. Thanks particularly to Jono and Jacqui who were never hesitant whenever I required their help which seemed like always. Jacqui, you often referred to me as 'lab mum' (which always amused me especially considering the extreme height difference between us) I believe you deserve that title in recognition of all the assistance you have provided me. To Jono, thank you for sharing your vast knowledge in this subject, even as I was writing this thesis, and especially for meticulously editing my thesis. Also, Jacqui and my cousin Mel, I extend thanks to you both for your contribution towards editing this thesis. I would like to thank the members of our brother laboratory, the 'Aquavino lab', Dr Rob Keyzers who I have often approached for his advice and expertise, and Peter Clark, Nathaniel Dasyam, and Emma Aitken for being great friends. Thank you also to John Ryan and Ian Vorster for all the technical help you both provided with NMR.

I extend my sincere gratitude to the entire academic and support staff of the School of Chemical and Physical Sciences. Thanks especially to Professor John Spencer and Professor Kate McGrath for your complete understanding and support during a time when I thought I could not continue with my MSc. Thank you also, to Professor Brian Halton for all your help with Spartan. To Teresa Gen and Jackie King, thank you so much for all the help you have given me over the years, you have both been awesome. 
Thanks to Professor John Miller and Ariane Chan from the Cell Biology Research group at the School of Biological Sciences for kindly performing the biological assays on my compounds.

To the staff of the Science faculty, in particular Celia Simpson and Shona de Sain, thank you.

I would like to give a huge thank you to the Te Roopu Awhina Whanau, particularly Liz Richardson, who always offered an immense amount of support, guidance and encouragement throughout my time at university. Also, thank you for providing me with the chance to gain an insight into postgraduate research studies while I was an undergraduate. I never would have considered an MSc had I not had that opportunity.

Financial assistance received during my MSc from Te Roopu Awhina, Simon and Jonathan Cave, the He Huarahi Tamariki Trust, the Zonta club of Mana, and the Curtis-Gordon Research Scholarship in Chemistry is gratefully acknowledged.

And finally to my friends and family I owe special thanks. To Susan and David Baragwanath, my thanks expand back to the first day I set foot in the door of the old top tavern in Cannons Creek. At that time, I was happy if I could do art all day and as you know, not so happy when you insisted that I study other important subjects. Now, I am absolutely grateful to you for having done that as I am not sure how far I would have made it at university, or if I ever would have decided to enrol. What I am sure about, is that the old top tavern door opened so many other doors which provided opportunities I never dreamt or thought about when I was 16, thank you. Thank you for all your overwhelming support, for your extreme generosity and kindness and for overall always being there for me. Also to Juliet and Neil Bellingham, thank you for being such great mentors, teachers, for supporting and encouraging me but specifically for igniting my passion for science and setting me on the beginning of a journey that led me to where I am today. To Sarah Derenzy, I have often approached you for assistance with so many things and without hesitation you have always been more than happy to help! Thank you so much, you have constantly been there for me and your support, guidance and encouragement has and will forever be greatly appreciated. I would also like to thank others from He Huarahi Tamariki who have helped to pave the way, including Glenis Levack, Helen Webber, Heather Te Huia, Pam and David Oughton, the late Austin Brookes and Clifton Buck and the members of the He Huarahi Tamariki Trust. Most importantly, to my amazing family, Mum, Kor, Rocky, Ruta, my son and my honey, thank you for being exceptionally patient, having faith in me, for the tremendous amount of encouragement and your unconditional support through the ups and the downs. I am immensely grateful to you all. My dear 'mujah' without you especially, none of this would have ever been possible and words cannot truly express my gratitude and appreciation towards everything you have done and continue to do for the kids and I. Thank you, and love you always. 


\section{Table of Contents}

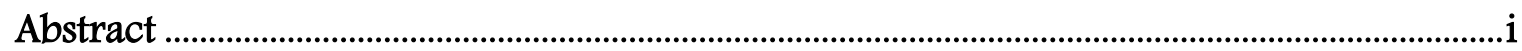

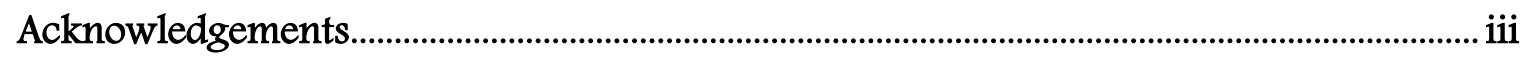

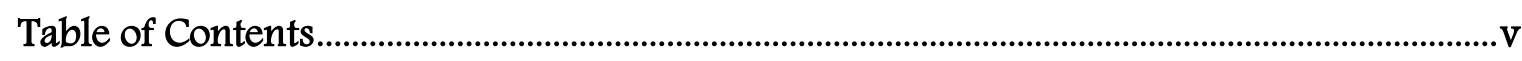

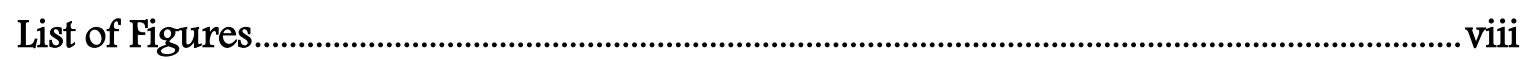

List of Schemes

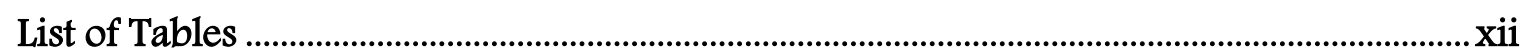

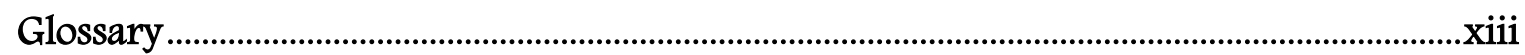

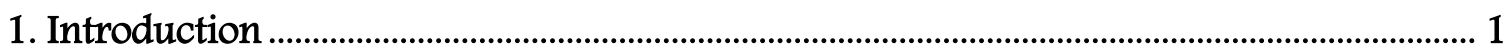

1.1 Chemical History of Natural Products..................................................................... 1

1.2 The Marine Environment and Marine Natural Products ......................................... 3

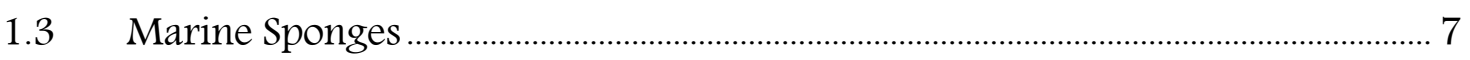

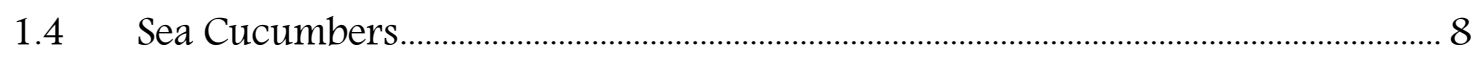

1.5 The Kingdom of Tonga and Marine Natural Products.............................................. 9

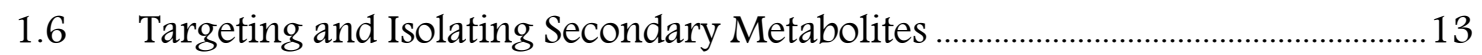

1.7 Marine Natural Products, VUW Screening Methods ................................................. 18

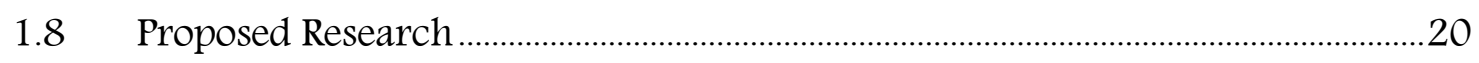

2. Screening Tongan Marine Organisms.................................................................................22

2.1 Comparison of Antifungal Activity between Tongan Holothurians and Australostichopus mollis.. 
2.1.1 Triterpene Glycosides from Australostichopus mollis.

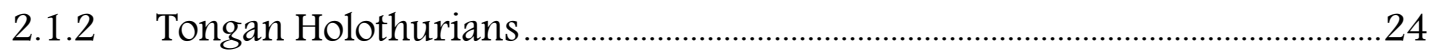

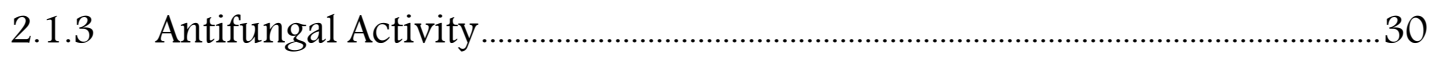

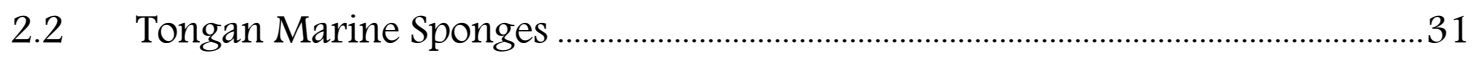

3. New Fascaplysin Congeners from a Sponge of the Order Dictyoceratida ........................39

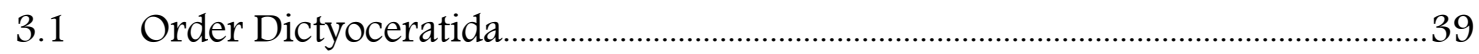

3.2 The Isolation of Known and New Compounds …………………..............................40

3.2.1 10-Bromohomofascaplysin A........................................................................... 43

3.2.2 10-Bromo-6,7-dimethoxyhomofascaplysin D .................................................49

3.2.3 10-Bromo-6,7-dimethoxyhomofascaplysin C....................................................56

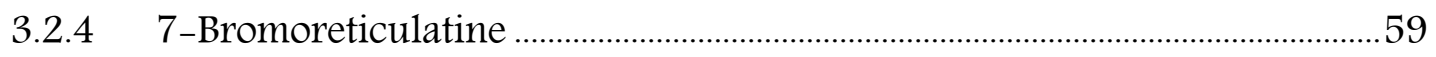

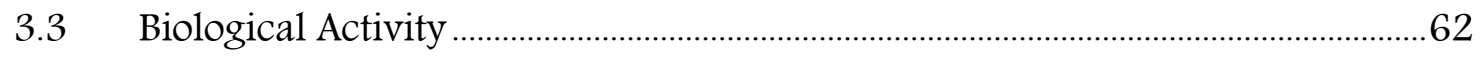

3.4 Hemiaminal Ether Functionality: Spectral Characteristics ………........................62

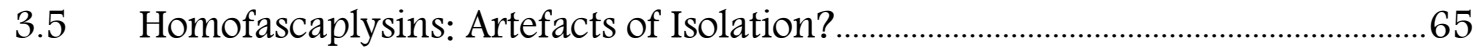

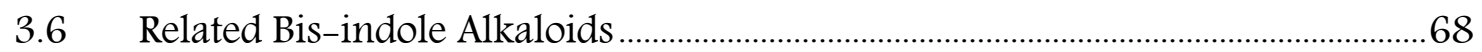

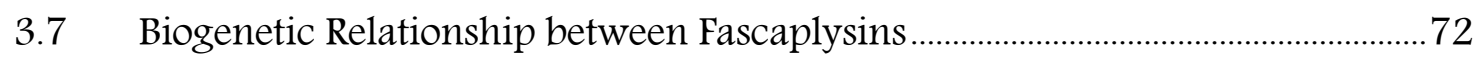

4. Conclusion

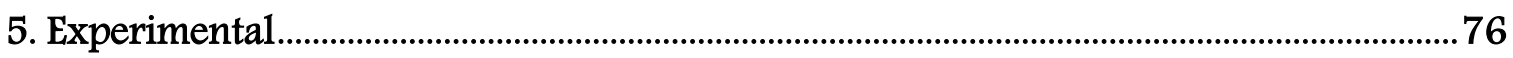

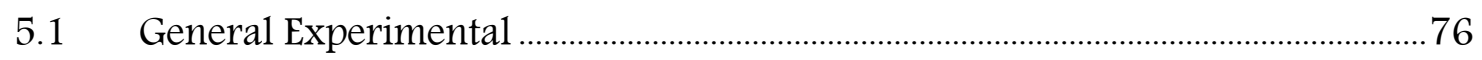

5.2 Isolation of Euryspongiols A1, A2 and B from an Unidentified Sponge .............77

5.3 Isolation of Bis-indole Alkaloids from a Dictyoceratid Sponge................................78

5.3.1 Re-extraction of a Specimen of Sponge PTN4_08B in the Search for

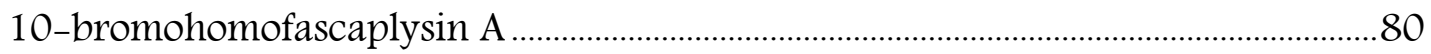

Appendix A. Existing Marine Screening Protocol ..........................................................................82 
Appendix C. 7-Bromoreticulatine Spectra

Appendix D. 10-Bromo-6,7,-dimethoxyhomofascaplysin C Spectra.

Appendix E. 10-Bromo-6,7,-dimethoxyhomofascaplysin D Spectra 103

Appendix F. 10-Bromohomofascaplysin A Spectra 107

References Error! Bookmark not defined. 


\section{List of Figures}

1.1. Map of the Kingdom of Tonga.

1.2. Schematic showing the mass distribution in a typical marine sponge extract.

1.3. Cyclic loading procedure.

1.4. (a) Digital HSQC mask (contains 160 sponges). (b) Common correlations in the HSQC mask

1.5. (a) An uninteresting sponge screen. (b) An interesting screen

2.1. Surface photo of PTN3_13D

2.2. ${ }^{1} \mathrm{H} \mathrm{NMR}\left(\mathrm{CD}_{3} \mathrm{OD}, 600 \mathrm{MHz}\right)$ screen spectrum of the $75 \% \mathrm{Me}_{2} \mathrm{CO} / \mathrm{H}_{2} \mathrm{O}$ fraction of PTN3_13D

2.3. $\mathrm{HMBC}\left(\mathrm{CD}_{3} \mathrm{OD}, 600 \mathrm{MHz}\right)$ screen spectrum of the $75 \% \mathrm{Me}_{2} \mathrm{CO} / \mathrm{H}_{2} \mathrm{O}$ fraction of PTN3_13D

2.4. Surface photo of PTN3_13F

2.5. Surface photo of PTN3_13G

2.6. ${ }^{1} \mathrm{H}$ NMR $\left(\mathrm{CD}_{3} \mathrm{OD}, 600 \mathrm{MHz}\right)$ screen spectrum of the $75 \% \mathrm{Me}_{2} \mathrm{CO} / \mathrm{H}_{2} \mathrm{O}$ fraction of PTN3_13F

2.7. $\mathrm{HMBC}\left(\mathrm{CD}_{3} \mathrm{OD}, 600 \mathrm{MHz}\right)$ screen spectrum of the $75 \% \mathrm{Me}_{2} \mathrm{CO} / \mathrm{H}_{2} \mathrm{O}$ fraction of PTN3_13F

2.8. ${ }^{1} \mathrm{H} \mathrm{NMR}\left(\mathrm{CD}_{3} \mathrm{OD}, 600 \mathrm{MHz}\right)$ screen spectrum of the $75 \% \mathrm{Me}_{2} \mathrm{CO} / \mathrm{H}_{2} \mathrm{O}$ fraction of PTN3_13G

2.9. $\mathrm{HMBC}\left(\mathrm{CD}_{3} \mathrm{OD}, 600 \mathrm{MHz}\right)$ screen spectrum of the $75 \% \mathrm{Me}_{2} \mathrm{CO} / \mathrm{H}_{2} \mathrm{O}$ fraction of PTN3_13G

2.10. Surface photo of PTN3_13H

2.11. ${ }^{1} \mathrm{H}$ NMR $\left(\mathrm{CD}_{3} \mathrm{OD}, 600 \mathrm{MHz}\right)$ screen spectrum of the $75 \% \mathrm{Me}_{2} \mathrm{CO} / \mathrm{H}_{2} \mathrm{O}$ fraction of PTN3_13H

2.12. $\mathrm{HMBC}\left(\mathrm{CD}_{3} \mathrm{OD}, 600 \mathrm{MHz}\right)$ screen spectrum of the $75 \% \mathrm{Me}_{2} \mathrm{CO} / \mathrm{H}_{2} \mathrm{O}$ fraction of PTN3_13H 
2.14. Surface photo of PTN4_O8B.

2.15. ${ }^{1} \mathrm{H}$ NMR $\left(\mathrm{CD}_{3} \mathrm{OD}, 600 \mathrm{MHz}\right)$ screen spectra of the $75 \% \mathrm{Me}_{2} \mathrm{CO} / \mathrm{H}_{2} \mathrm{O}$ fraction of PTN4_05C (blue) and PTN4_08B (black)....

2.16. $\mathrm{HMBC}\left(\mathrm{CD}_{3} \mathrm{OD}, 600 \mathrm{MHz}\right)$ screen spectrum of the $75 \% \mathrm{Me}_{2} \mathrm{CO} / \mathrm{H}_{2} \mathrm{O}$ fraction of PTN4_05C

2.17. Surface photo of PTN3_13A

2.18. ${ }^{1} \mathrm{H} \mathrm{NMR}\left(\mathrm{CD}_{3} \mathrm{OD}, 600 \mathrm{MHz}\right)$ screen spectrum of the $75 \% \mathrm{Me}_{2} \mathrm{CO} / \mathrm{H}_{2} \mathrm{O}$ fraction of PTN4_13A.

2.19. $\mathrm{HMBC}\left(\mathrm{CD}_{3} \mathrm{OD}, 600 \mathrm{MHz}\right)$ screen spectrum of the $75 \% \mathrm{Me}_{2} \mathrm{CO} / \mathrm{H}_{2} \mathrm{O}$ fraction of PTN4_13A..

2.20. Surface photo of PTN4_14B.

2.21. ${ }^{1} \mathrm{H} \mathrm{NMR}\left(\mathrm{CD}_{3} \mathrm{OD}, 600 \mathrm{MHz}\right)$ screen spectrum of the $75 \% \mathrm{Me}_{2} \mathrm{CO} / \mathrm{H}_{2} \mathrm{O}$ fraction of PTN4_14B.

2.22. $\mathrm{HMBC}\left(\mathrm{CD}_{3} \mathrm{OD}, 600 \mathrm{MHz}\right)$ screen spectrum of the $75 \% \mathrm{Me}_{2} \mathrm{CO} / \mathrm{H}_{2} \mathrm{O}$ fraction of PTN4_14B.

3.1. Surface photo of PTN4_10B

3.2. ${ }^{1} \mathrm{H}$ NMR $\left(\mathrm{CD}_{3} \mathrm{OD}, 600 \mathrm{MHz}\right)$ screen spectrum of the $100 \% \mathrm{Me}_{2} \mathrm{CO}$ fraction from the sponge PTN4_1OB

3.3. COSY and HMBC correlations establishing the connectivity between $\mathrm{C}-4 \mathrm{a}$ and $\mathrm{C}-13$ in 10-bromohomofascaplysin A

3.4. COSY and HMBC correlations establishing the connectivity between $\mathrm{C}-13$ and $\mathrm{C}-16$ in 10-bromohomofascaplysin A

3.5. COSY and HMBC correlations establishing the connectivity between $\mathrm{C}-7 \mathrm{~b}$ and C-11a in 10-bromohomofascaplysin A.

3.6. Key COSY, HMBC, and NOESY correlations between the substructures providing the structure of 10-bromohomofascaplysin A

3.7. COSY and $\mathrm{HMBC}$ correlations establishing the connectivity between $\mathrm{C}-4 \mathrm{a}$ and $\mathrm{C}-13$ in 10-bromo-6,7-dimethoxyhomofascaplysin D. 
3.8. COSY and HMBC correlations establishing the connectivity between $\mathrm{C}-13$ and $\mathrm{C}-16$ in 10-bromo-6,7-dimethoxyhomofascaplysin D

3.9. $\mathrm{COSY}$ and $\mathrm{HMBC}$ correlations establishing the connectivity between $\mathrm{C}-7 \mathrm{~b}$ and C-11a in 10-bromo-6,7-dimethoxyhomofascaplysin D

3.10. COSY and HMBC correlations establishing the connectivity between C-6 and C-12 in 10-bromo-6,7-dimethoxyhomofascaplysin D

3.11. Calculated dihedral angle between the vicinal protons of possible configurations as deduced from the ${ }^{3} J_{\mathrm{HH}}$ coupling constants for $\mathrm{H}-6$ and $\mathrm{H}-7$

3.12. Key HMBC and NOESY correlations establishing the structure of 10-bromo-6,7-dimethoxyhomofascaplysin D

3.13. COSY, HMBC, and key NOESY correlations establishing the structure of 10-bromo-6,7-dimethoxyhomofascaplysin C

3.14. COSY and $\mathrm{HMBC}$ correlations establishing the connectivity between $\mathrm{C}-10$ and $\mathrm{CH}_{3-17}$ in 7 -bromoreticulatine .60

3.15. COSY, HMBC and key NOESY correlations establishing the structure of 7-bromoreticulatine. .60 


\section{List of Schemes}

2.1. Isolation procedure for compounds $\mathbf{5 1}-\mathbf{5 3}$ from PTN4_14B

3.1. Isolation procedure for compounds 61-66 from PTN4_10B

3.2. Nucleophilic addition of acetone to 10-bromofascaplysin. . .65

3.3. Putative biogenetic relationship between fascaplysin derivatives.. .73 


\section{List of Tables}

3.1. ${ }^{13} \mathrm{C}(150 \mathrm{MHz})$ and ${ }^{1} \mathrm{H}(600 \mathrm{MHz})$ NMR data $\left(\mathrm{CDCl}_{3}\right)$ for 10-Bromohomofascaplysin A

3.2. ${ }^{13} \mathrm{C}(150 \mathrm{MHz})$ and ${ }^{1} \mathrm{H}(600 \mathrm{MHz})$ NMR data $\left(\mathrm{CD}_{3} \mathrm{OD}\right)$ for 10-Bromohomofascaplysin A

3.3. ${ }^{13} \mathrm{C}(150 \mathrm{MHz})$ and ${ }^{1} \mathrm{H}(600 \mathrm{MHz})$ NMR data $\left(\mathrm{CDCl}_{3}\right)$ for 10-Bromo-6,7-dimethoxyhomofascaplysin D

3.4. ${ }^{13} \mathrm{C}(150 \mathrm{MHz})$ and ${ }^{1} \mathrm{H}(600 \mathrm{MHz})$ NMR data $\left(\mathrm{d}_{6}-\mathrm{DMSO}\right)$ for 10-Bromo-6,7-dimethoxyhomofascaplysin D

3.5. ${ }^{13} \mathrm{C}(150 \mathrm{MHz})$ and ${ }^{1} \mathrm{H}(600 \mathrm{MHz})$ NMR data $\left(\mathrm{CDCl}_{3}\right)$ for 10-Bromo-6,7-dimethoxyhomofascaplysin C .58

3.6. ${ }^{13} \mathrm{C}(150 \mathrm{MHz})$ and ${ }^{1} \mathrm{H}(600 \mathrm{MHz})$ NMR data $\left(\mathrm{CDCl}_{3}\right)$ for 7 -Bromoreticulatine 61

3.7. Calculated Difference in the ${ }^{1} \mathrm{H}$ and ${ }^{13} \mathrm{C}$ NMR Chemical Shifts at Positions 6 and 7 between $64,65,67$ and 68 


\section{Glossary}

$\boldsymbol{\delta} \quad$ Chemical shift (ppm)

${ }^{13}$ C NMR Carbon-13 Nuclear Magnetic Resonance

${ }^{1}$ H NMR Proton Nuclear Magnetic Resonance

Ac $\quad\left(\mathrm{CH}_{3} \mathrm{C}(\mathrm{O})-\right)$

br $\quad$ Broad

$\mathrm{C}_{18} \quad$ Octadecyl derivatised silica gel

$\mathrm{CD}_{3} \mathrm{OD} \quad$ Deuterated methanol

$\mathrm{CDCl}_{3} \quad$ Deuterated chloroform

$\mathrm{CH}_{2} \mathrm{Cl}_{2} \quad$ Dichloromethane

COSY Correlation spectroscopy $\left({ }^{1} \mathrm{H}\right.$ to ${ }^{1} \mathrm{H}$ correlations depicted by $)$

d Doublet

$\mathrm{d}_{6}$-DMSO Deuterated DMSO

dd Doublet of doublets

DIOL 2,3-Dihydroxy-1-propoxypropyl derivatised silica gel (derivatised silica gel)

DMSO Dimethyl sulfoxide

EEZ Exclusive Economic Zone

EtOAc Ethyl acetate

$\mathrm{H}_{2} \mathrm{O} \quad$ Water

$\mathrm{HCOOH} \quad$ Formic acid

HMBC Heteronuclear Multiple Bond Correlation $\left({ }^{1} \mathrm{H}\right.$ to ${ }^{13} \mathrm{C}$ correlations

depicted by $\longrightarrow$ )

HP20 PSDVB stationary support

HPLC High Pressure Liquid Chromatography

HRESIMS High Resolution Electro-Spray Ionisation Mass Spectrometry 


\begin{tabular}{|c|c|}
\hline HSQC & Heteronuclear Single Quantum Coherence \\
\hline $\mathrm{IC}_{50}$ & Concentration that is inhibitory in $50 \%$ of test subjects \\
\hline$J$ & Scalar coupling constant \\
\hline $\mathrm{m}$ & Multiplet \\
\hline$m / z$ & Mass to charge ratio \\
\hline MIC & Minimum inhibitory concentration \\
\hline $\mathrm{MNP}$ & Marine Natural Products \\
\hline $\mathrm{Me}_{2} \mathrm{CO}$ & Acetone \\
\hline $\mathrm{MeCN}$ & Acetonitrile \\
\hline $\mathrm{MeOH}$ & Methanol \\
\hline MS & Mass Spectrometry \\
\hline NMR & Nuclear Magnetic Resonance \\
\hline NOESY & $\begin{array}{l}\text { Nuclear Overhauser Enhancement Spectroscopy }\left({ }^{1} \mathrm{H} \text { to }{ }^{1} \mathrm{H}\right. \\
\text { correlations depicted by } \longleftrightarrow)\end{array}$ \\
\hline pet. ether & Petroleum ether (hexanes) \\
\hline pos. & Position \\
\hline ppm & Parts per million \\
\hline PSDVB & Poly(styrene-divinylbenzene) \\
\hline s & Singlet \\
\hline SCUBA & Self-contained underwater breathing apparatus \\
\hline $\mathbf{t}$ & Triplet \\
\hline TLC & Thin Layer Chromatography \\
\hline VUW & Victoria University of Wellington \\
\hline
\end{tabular}




\section{Chapter 1}

\section{Introduction}

\subsection{Chemical History of Natural Products}

Historically, mankind has exploited and relied on natural resources for clothing, shelter foodstuffs, and perhaps the most intriguing, for medicines. Plants have been utilised as a major source for traditional medicines for thousands of years. The earliest ancient Egyptian medicine dates back to 2900 BC, although the "Ebers Papyrus", dating from 1500 BC represents the most notable Egyptian pharmacopoeia documenting over 700 "drugs". It was not until the 1800s, however, that the plant components responsible for the remedy of human illness were actively sought and in 1826 morphine (1) became the first commercially available pure natural product. ${ }^{1}$ These naturally-derived, biologically active compounds are now known to be secondary metabolites; chemical substances not essential to life as they are not required for the normal growth, development or reproduction of an organism. ${ }^{2}$ Initially regarded as waste products, these complex and frequently toxic chemicals are recognised as a means for interactions between organisms, often for defense. ${ }^{3}$ Ever since, secondary metabolites have captivated natural products chemists, who continue to pursue these fascinating molecules for both their interesting chemical structures and their potential as therapeutic agents for the treatment of human disease.<smiles>CN1CC[C@H]2C=C[C@H](O)[C@@H]3Oc4c(O)ccc5c4[C@@]23CCN1C5</smiles> 
Since initial investigations in the early 1800s, natural products chemistry has been fundamental to drug discovery and development, with plant and microbial derived drugs constituting a crucial role in the increased average human life span during the $20^{\text {th }}$ century alone. ${ }^{4}$ The renowned antibiotic, penicillin G (2) and the chemotherapeutic drug, paclitaxel (Taxol, 3), are two such examples of medically important, naturally-derived drugs. Alexander Fleming's discovery of penicillin G (2) from Penicillium notatum in 1928 incited extensive microbial natural products research between the 1940s and 1970s. Microbes were found to be prolific producers of antibiotic compounds, providing a vast number of structurally diverse bioactive metabolites. ${ }^{1,4}$ Many of these microbial derived antibiotics still hold significance in the pharmaceutical industry, although the emergence of new pathogens and the continual development of drug-resistant bacteria drives the search for new antibacterial agents. ${ }^{5}$ Paclitaxel (3), originally isolated from the stem bark of the Western Yew tree, Taxus brevifolia, is an antitumour agent used in the treatment of ovarian, breast, lung and prostate cancer. ${ }^{6}$ Specific parts of a variety of species within the genus Taxus were used historically by several Native American tribes in their traditional medicines. ${ }^{1}$ The road to pharmaceutical success for Taxol (3) was lengthy, taking 21 years before the U.S Food and Drug Administration (FDA) approved the drug for clinical use. ${ }^{6 b}$ Between 1981 and 2008, almost two thirds of drugs approved by the FDA were natural products or derivatives thereof. ${ }^{3}$<smiles>CC1(C)SC2[C@@H](NC(=O)Cc3ccccc3)C(=O)N2[C@H]1C(=O)O</smiles>

2

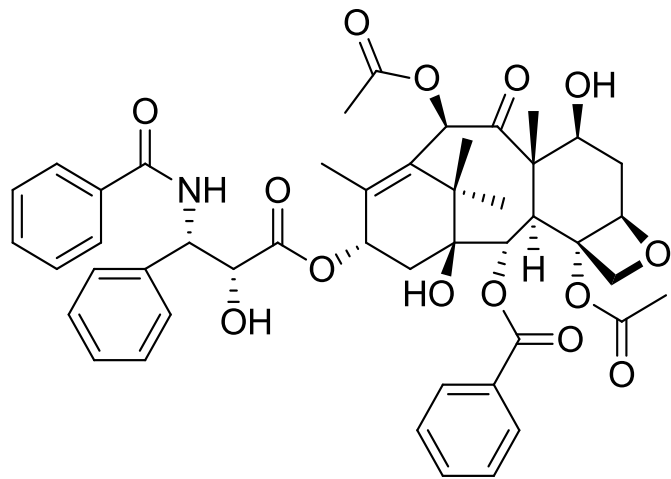

3

Despite the successful contribution of natural products research to medicine, many pharmaceutical companies began to downsize or completely dismantle their natural products facilities in the early 1990 s. $^{7}$ Combinatorial chemistry ${ }^{\dagger}$ was introduced as a faster and cheaper alternative to natural products isolation, and thus was rapidly embraced by the pharmaceutical industry. 8 By the early 2000s, however, researchers were met with disappointment as combinatorial chemistry failed to provide the anticipated number of drug

\footnotetext{
${ }^{\dagger}$ Combinatorial chemistry in its origin involved the use of a single compound in a variety of reactions in order to synthesise every possible combination of compounds that could be produced from it.
} 
leads. ${ }^{9}$ Attempts to build large libraries containing thousands to millions of synthetic compounds (high-throughput screening) using a single scaffold ${ }^{*}$, often resulted in simplistic and topologically similar compounds, very few of which were biologically active. ${ }^{9,} 10$ Only one drug resulting from this method has been reported; sorafenib mesylate (Nexavar, 4), approved by the FDA in 2005 as an antitumour drug used for the treatment of advanced renal cancer. ${ }^{11}$ The concept of combinatorial chemistry has since shifted towards the production of small to medium-sized libraries, using multiple scaffolds. This amendment recognises the significance of natural products, as researchers aim to synthesise compounds which are more "natural product-like" using scaffolds based on biologically active, naturallyderived compounds. ${ }^{10,11}$<smiles>CNC(=O)c1cc(Oc2ccc(NC(=O)Nc3ccc(Cl)c(C(F)(F)F)c3)cc2)ccn1</smiles>

While the modified method is expected to be more productive than its earlier version, the lack of success from combinatorial chemistry has begun to steer pharmaceutical companies back towards natural product discovery programmes. ${ }^{12}$ Certainly, technological advancements in isolation and spectroscopic techniques have made experimental analyses of natural products easier to carry out and interpret and have further contributed to the resurgence of interest in natural products research. For instance, a modern nuclear magnetic resonance (NMR) instrument can now routinely provide excellent data with sub-milligram samples. ${ }^{13}$

\subsection{The Marine Environment and Marine Natural Products}

The therapeutic use of medically important drugs such as morphine, penicillin, quinine, digitoxin, and aspirin demonstrates the important role plants and micro-organisms have played in medicine and indeed in the increased human life expectancy observed today. ${ }^{14}$ Much potential remains to be offered by the terrestrial environment in the search for biologically active metabolites, although the advent of SCUBA (self-contained underwater breathing apparatus) has enabled explorations to extend into the marine environment. Marine environmental conditions are considerably different to terrestrial environments and it was assumed that the chemical characteristics of compounds from marine organisms would also be different. ${ }^{7}$

\footnotetext{
*A compound used as a template for the development of compound libraries in combinatorial chemistry.
} 
The oceans cover more than two thirds of the Earth's surface and approximately $90 \%$ of the world's species are represented in the marine environment. ${ }^{15}$ Experts estimate that certain marine ecosystems, such as coral reefs, contain a greater level of biological diversity than tropical rainforests. ${ }^{16}$ This large marine biodiversity, the majority of which is found within the ocean fringe, has led to the assumption of a high chemical diversity of secondary metabolites. Much of the marine life consists of soft-bodied, sessile or slow-moving organisms which have either acquired toxic secondary metabolites from marine microorganisms, or have evolved to biosynthesise them. ${ }^{16 a}$ These organisms utilise the compounds to paralyse prey, deter predators, or keep competitors at bay. ${ }^{17}$ Not surprisingly, marinederived toxins are often potent since they are rapidly diluted upon release. ${ }^{17}$ Chemical diversity, high toxicity, and not to mention the unique and often complex chemical structures are factors which contribute to the promising biological activities displayed by marinederived metabolites, hence their pursuit by marine natural product researchers. ${ }^{18}$

Spongothymidine (5) and spongouridine (6), discovered in the 1950 s by Bergmann and coworkers from the Caribbean sponge Tethya crypta, are believed to be the earliest marinederived natural products reported. ${ }^{19}$ Further interest led to compounds $\mathbf{5}$ and $\mathbf{6}$ being used as prototypes for the development of the anti-HIV compound azidothymidine (AZT, 7), the antiviral drug adenine arabinoside (Vira-A, 8), and the anticancer agent cytosine arabinoside (Cytosar-U, 9) ${ }^{20}$ Although the discovery of compounds $\mathbf{5}$ and $\mathbf{6}$ prompted the interest of other natural products researchers, it was not until the 1970s when the marine environment was more seriously considered as a resource for potentially useful natural products and the term marine natural products was formally coined. ${ }^{166,21}$
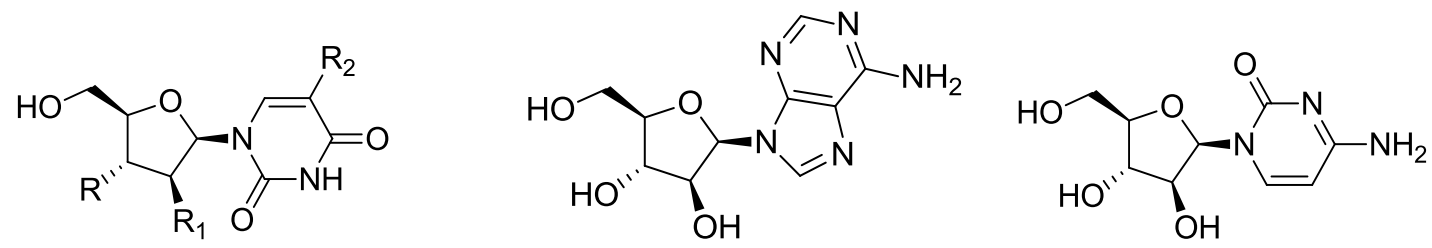

$$
\begin{array}{llll}
5 & \mathrm{R}=\mathrm{OH} & \mathrm{R}_{1}=\mathrm{OH} & \mathrm{R}_{2}=\mathrm{CH}_{3} \\
\mathbf{6} & \mathrm{R}=\mathrm{OH} & \mathrm{R}_{1}=\mathrm{OH} & \mathrm{R}_{2}=\mathrm{H} \\
7 & \mathrm{R}=\mathrm{N}_{3} & \mathrm{R}_{1}=\mathrm{H} & \mathrm{R}_{2}=\mathrm{CH}_{3}
\end{array}
$$

8

$$
9
$$

The marine environment has since proved to be a very fruitful resource for the isolation of many interesting biologically active compounds. Before 1995, approximately 6,500 marine-derived compounds had been isolated; ${ }^{17}$ that figure has increased almost four-fold to more than $24,000 .{ }^{22}$ Some examples of interesting molecules from marine organisms include maitotoxin, palytoxin and symbiodinolide (10-12 respectively). With remarkably complex chemical architectures, compounds 10-12 are among the most extraordinary of those 
isolated from nature. They are commonly referred to as "super carbon-chain compounds" as a result of their highly oxygen-functionalised, long-chain carbon backbone and are purported to be the largest natural products isolated besides biopolymers such as nucleic acids, proteins and polysaccharides. Maitotoxin (10), and palytoxin (11) induce extreme toxicity in mice, while symbiodinolide (12) exhibits biological activity against human neuroblastoma cells. ${ }^{23}$

Currently, ten marine natural products (or derivatives thereof) are at various stages of clinical development, while ziconotide (Prialt, 13), trabectedin (Yondelis, 14), and eribulin mesylate (Halaven, 15) join compounds 7-9 in the ensemble of approved marine-derived pharmaceuticals. ${ }^{24}$ Ziconotide (13) is the synthetic equivalent of the 25-amino acid peptide, $\omega$-conotoxin MVIIA which was isolated from the marine cone snail, Conus magus. Approved by the US FDA in 2004, 13 is a potent analgesic presently used for the management of chronic pain in cancer and AIDs patients and is considered more effective than opiates as the patient does not develop a dependency. ${ }^{25}$ Trabectedin (14), a tetrahydroquinoline alkaloid, was isolated from the tunicate, Ecteinascidia turbinata. In 2007, the European Union approved 14 for use against soft tissue carcinoma. ${ }^{25}$ The most recent addition, eribulin mesylate (15) is derived from halicondrin B (16), a marine natural product originally isolated from the sponge Halichondra okadai. ${ }^{24,} 26$ Eribulin mesylate (15) is approved for the treatment of metastatic breast cancer. ${ }^{27}$

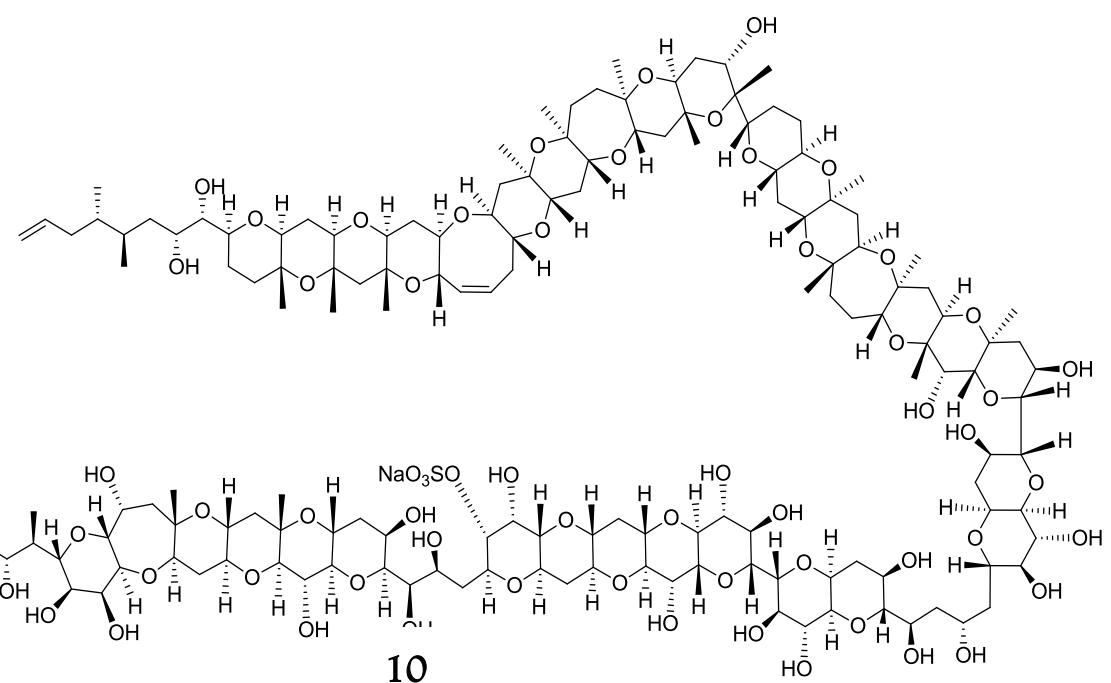




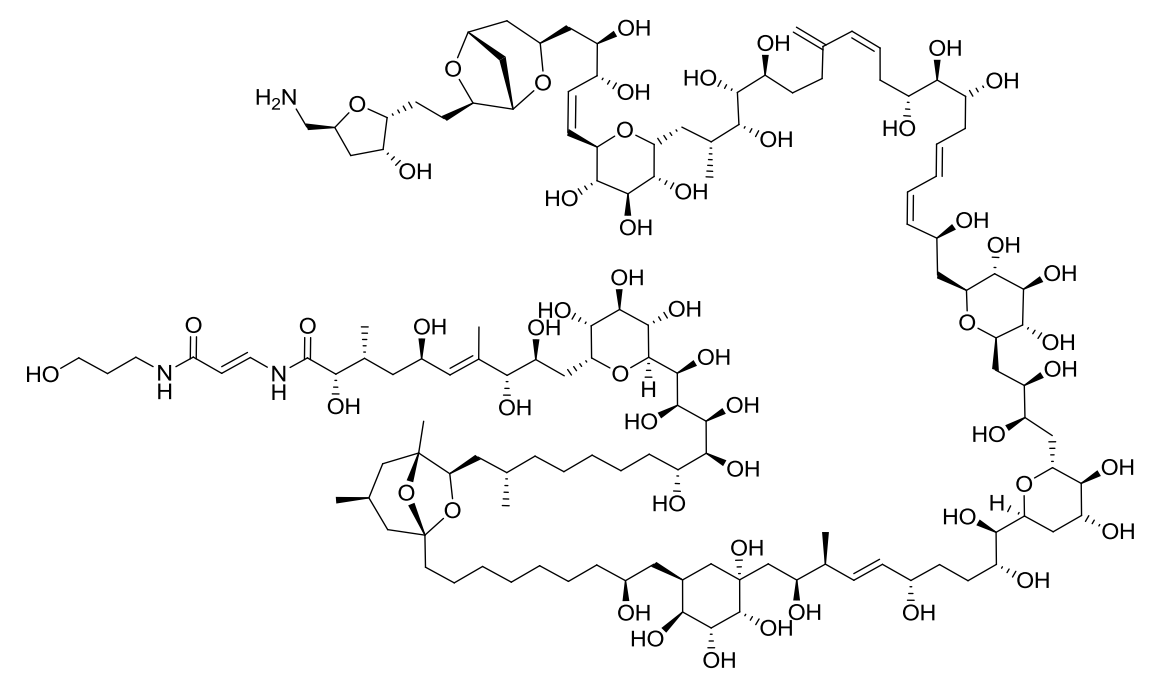

11

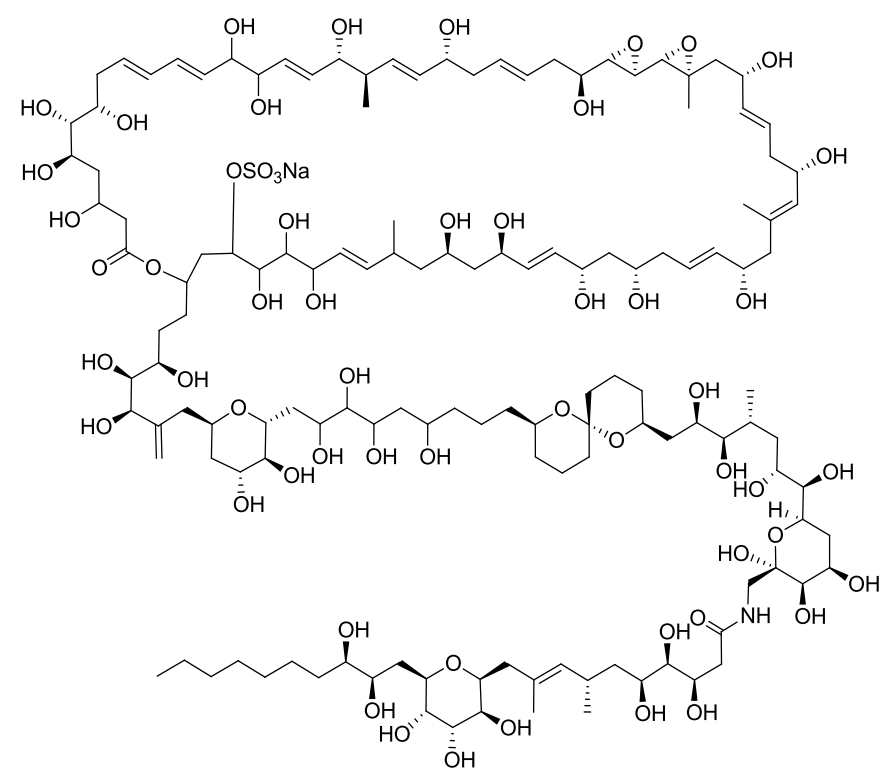

12

$\mathrm{H}_{2} \mathrm{~N}$-Cys-Lys-Gly-Lys-Gly-Ala-Lys-Cys-Ser-Arg-Leu-Met-Tyr-Asp-Cys-Cys-Thr-Gly-Ser-Cys-Arg-Ser-Gly-Lys-Cys-CONH ${ }_{2}$

13

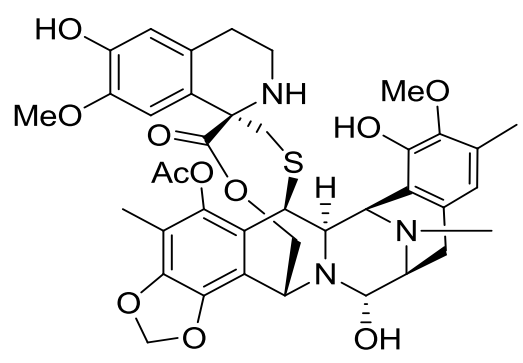

14

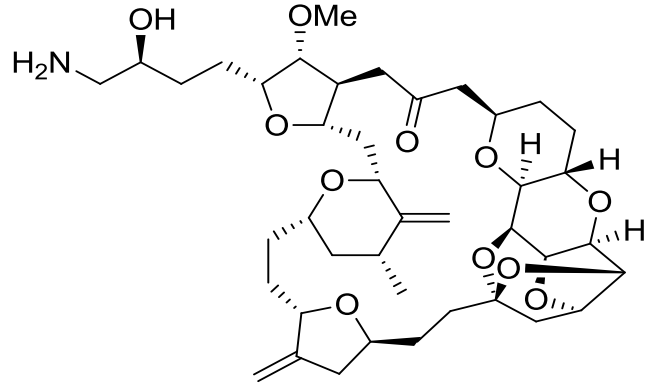

15 


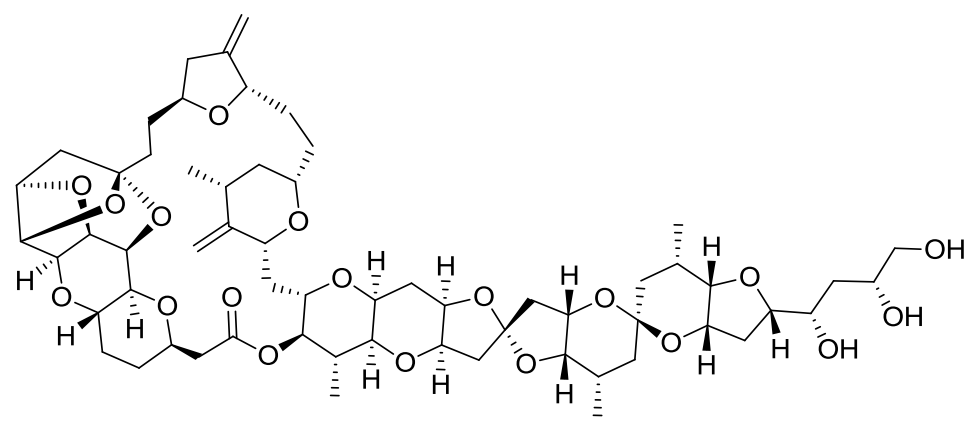

16

\subsection{Marine Sponges}

Among the variety of marine organisms noted for producing secondary metabolites, sponges are a particularly prolific source of chemically diverse, biologically active compounds. ${ }^{28}$ The emergence of novel sponge metabolites remains steady, constituting close to $30 \%$ of marine natural products described between 2008 and $2010 .^{29}$

Sponges are multicellular, filter feeding organisms lacking true tissue organisation which places them among the most primitive of animals. The phylum Porifera is made up exclusively by sponges, containing the three classes Hexactinellida, Calcarea and the largest, Demospongiae, which comprises around $90 \%$ of sponge species. Sponges are taxonomically classified depending on morphological features and the types of spicules (skeletal element) present within the sponge; some sponges lack spicules which can cause difficulty when taxonomic classification is concerned. There are currently around 15,000 extant species and it is believed another 30,000 are yet to be described. ${ }^{30}$

Sponges are soft bodied sessile organisms, that produce toxic or distasteful secondary metabolites to deter predators, keep neighbouring competitors at bay, or prevent parasitic infection or overgrowth of fouling organisms. ${ }^{28}$ A greater frequency of toxic compounds have been isolated from sponges that occupied space in a competitive environment or those that inhabited areas exposing them to predators. For example, sponges within coral reefs, where the level of biodiversity is high, often yield bioactive metabolites. ${ }^{31}$ Temporal and spatial variations have also been found to contribute to the concentration of mycalamide A (17) in Mycale hentsheli and salicylihalamide A (18) in Haliclona sp. ${ }^{32,33}$ Sponges from tropical environments where more predation occurs and temperatures are warmer, have been found to contain high concentrations of toxic secondary metabolites. ${ }^{34,35}$ The reason for this phenomenon is uncertain, but it is proposed that predation and competition pressures cause an increased investment by the sponge, into the production of chemical defences, thus resulting in increased levels of toxic metabolites in tropical sponges. ${ }^{31,34,35}$ Regardless, there is no doubt that sponges as a whole, have given rise to a variety of natural products which 
exhibit a wide range of biological activities from antitumour, antiviral, and antiinflammatory to immunosuppressive and neurosuppressive activity, all of which have potential as pharmaceuticals. ${ }^{20 a, 29 a, 29 b, 36}$

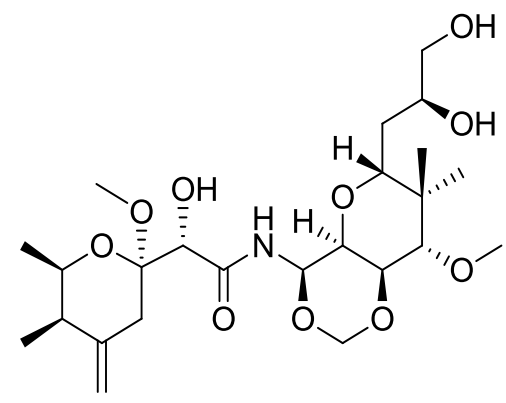

17

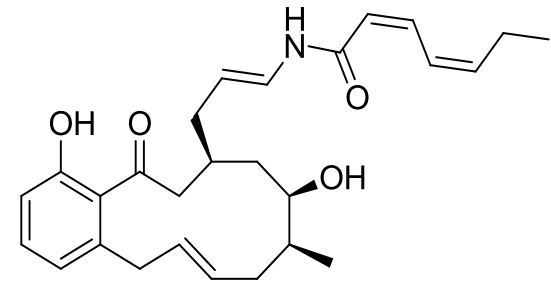

18

\subsection{Sea Cucumbers}

Sea cucumbers (holothurians) belong within the phylum Echinodermata, which also includes organisms such as star fish and sea urchins. The phylum contains six extant orders of holothurians and approximately 1300 species, widespread throughout the world's oceans. In $90 \%$ of sea cucumbers, the endoskeleton is reduced to microscopic skeletal structures called ossicles, which are embedded in the dermis. Typically composed of calcium carbonate, ossicle shapes vary quite remarkably and are species specific which can be used to assist with taxonomic classification of holothurians. ${ }^{37}$

As slow moving organisms, sea cucumbers are susceptible to predation and are therefore equipped with defensive mechanisms to aid in their survival. Physical defences can include the expulsion of strong adhesive threads (Cuvierian tubules) that act to instantly foul any object, and the evisceration and rapid regeneration of body organs. ${ }^{38}$ Often, these physical defences are complemented by chemical defences in the form of toxic secondary metabolites. ${ }^{37,39}$ The most commonly found secondary metabolites from sea cucumbers are saponins; high molecular weight compounds consisting of a sugar moiety bound to an aglycon usually referred to as the genin or sapogenin. ${ }^{40}$ The term 'saponin' results from their surfactant properties, as they typically exhibit detergent-like characteristics such as the ability to cause foaming in water. ${ }^{41}$ Saponins can be found in all parts of the body within sea cucumbers. ${ }^{42}$

Depending on the type of aglycon present, saponins can be grouped into three main classessteroid glycosides, steroid-alkaloid glycosides, and the most predominantly isolated, triterpene glycosides. ${ }^{41,43}$ The earliest sea cucumber saponin described in the literature is the 
triterpene glycoside, holothurin A (19). ${ }^{44}$ Isolated in 1959 from Actinopyga agassizi, 19 has been found to possess neurolytic, hemolytic, and cancerostatic properties. ${ }^{44}$ Two decades later, holothurin B (20) was reported as an isolate from the sea cucumber Holothuria luecospilota Brandt. ${ }^{45}$ Recent examples of biologically active triterpene glycosides from sea cucumbers are pentactasides B (21) and C (22), isolated from Pentacta quadrangularis. These compounds displayed moderate in vitro cytotoxicity against a range of human cancerous cell lines. ${ }^{46}$

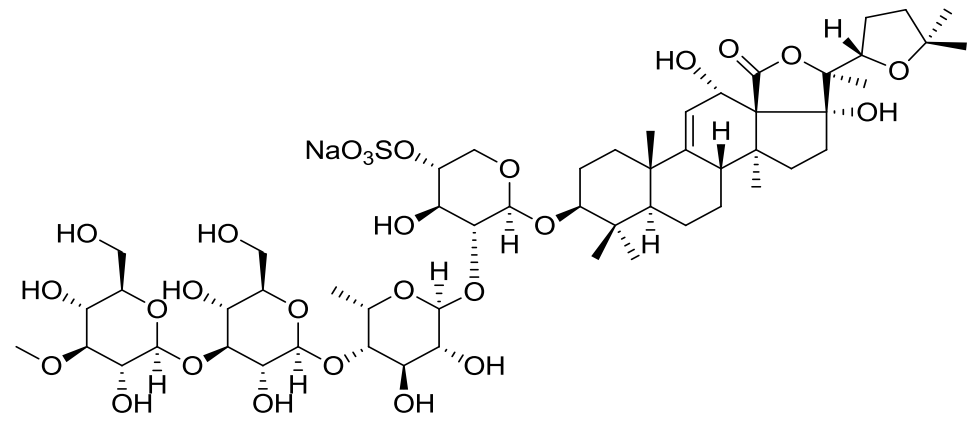

19

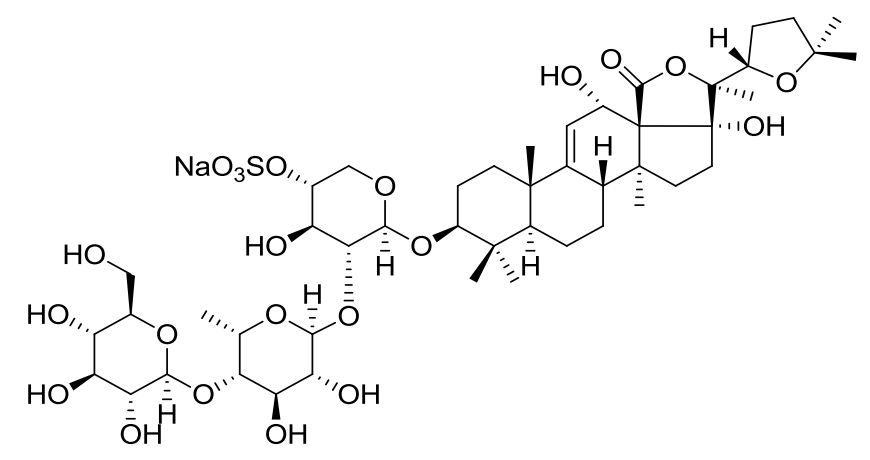

20

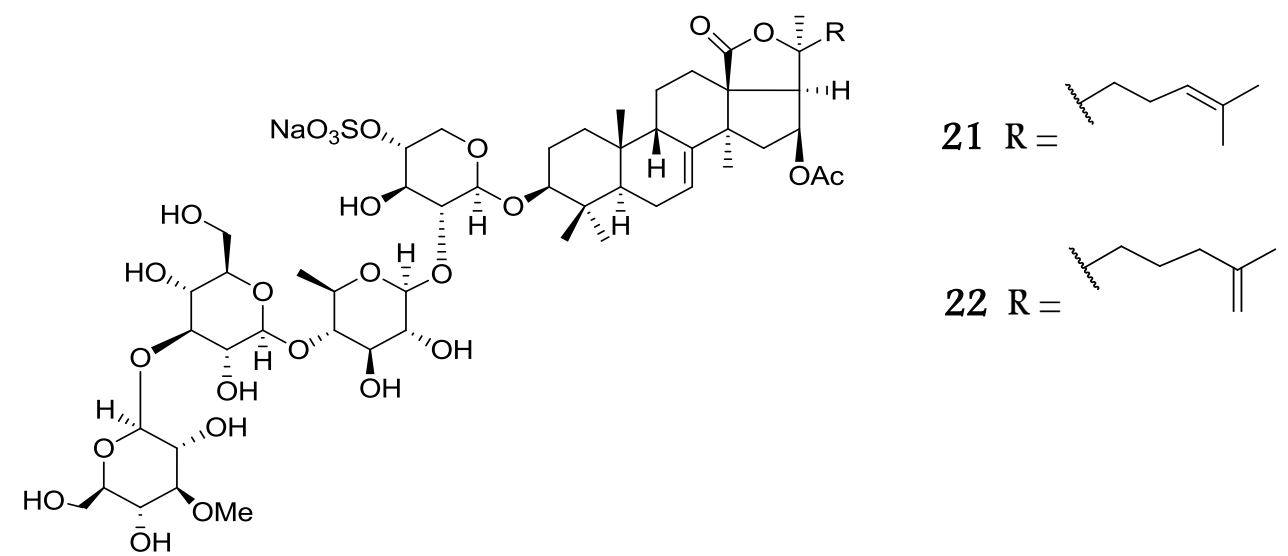

\subsection{The Kingdom of Tonga and Marine Natural Products}

Tropical sponges produce higher quantities of secondary metabolites compared with those from temperate environments. ${ }^{34,35}$ This has certainly been observed for samples obtained 
from Tongan marine organisms in the MNP laboratory (VUW), to quite a significant degree when compared against New Zealand marine natural products. As mentioned earlier, competition and predation pressures are thought to contribute to this phenomenon. ${ }^{31,35,34,72}$

Located in the South Pacific Ocean, north-east of New Zealand, the Kingdom of Tonga is an archipelago with an Exclusive Economic Zone (EEZ) of approximately 700,000 $\mathrm{km}^{2}$. This large area encompasses 171 islands, of which only 48 are inhabited and is divided into five main groups: Vava'u, Tongatapu, 'Eua, Ha'apai and the Nuias (Figure 1.1).

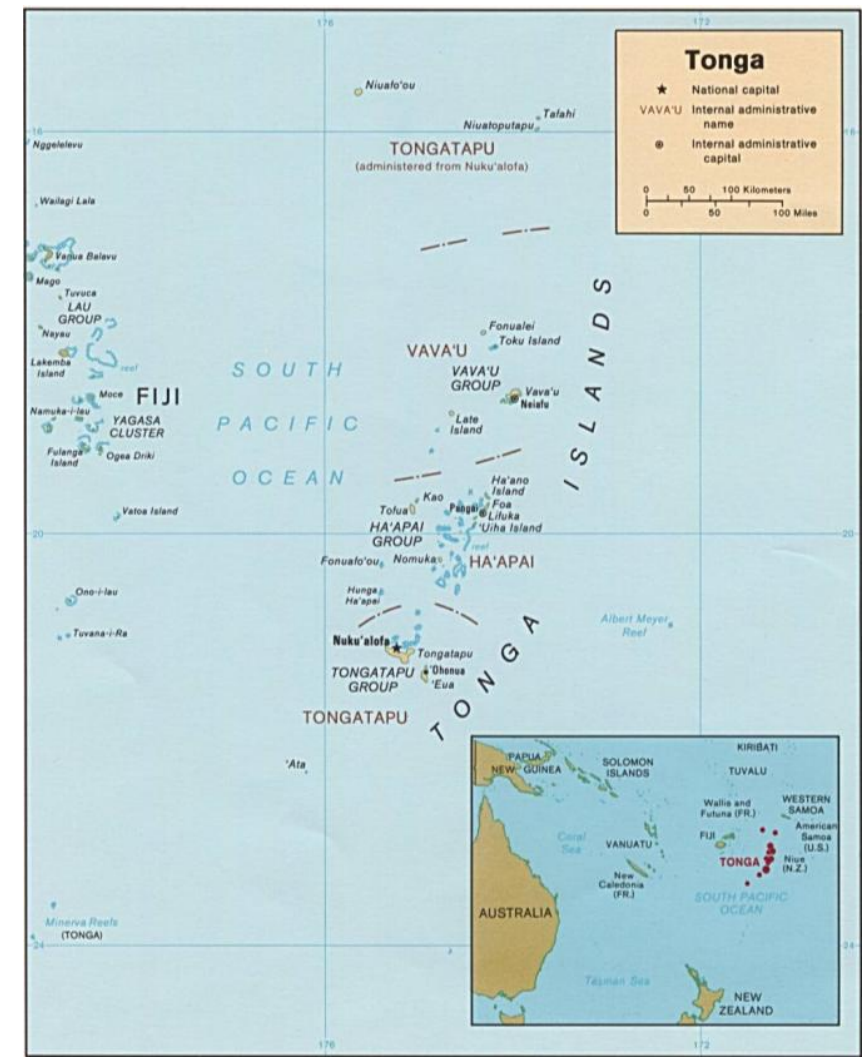

Figure 1.1. Map of the Kingdom of Tonga. Courtesy of the University of Texas Austin Libraries.

The literature documents many reports by leading MNP researchers of secondary metabolites from Indo-Pacific marine organisms but very few are reported from Tongan waters. Additionally, those which describe metabolites from Tongan marine organisms are from the 1980 s and methods of isolation were typically bioassay guided. ${ }^{47}$ The bioassay guided method of natural products isolation is target specific, homing in on the compound or compounds exhibiting activity in the particular assay used while neglecting all others. This means that many other minor, potentially biologically active chemical constituents may have been overlooked. As such, further investigations using the NMR screening methods employed by the VUW MNP laboratory (see Chapter 1.6) are justifiable as there remains potential for the discovery of new compounds. 
Crews and Quiñoá reported the collection of a Psammaplysilla sp. from Tonga and the subsequent isolation of 3-bromo-4-hydroxyphenylacetonitrile (23) and psammaplin A (24)a compound which exhibits in vitro cytotoxicity in mice. ${ }^{48}$ Psammaplin A (24) was described as the first disulfide compound isolated from marine biota. Methyl nuapapuanoate (25) was isolated from a Prianos sp. collected from Tongan coral reefs and is believed to be the first report of a norditerpene from sponges. ${ }^{47}$ A Tongan collection of the sponge Hyrtios erecta yielded the norsesterterpenoid hyrtial (26) along with several scalarane sesterterpenes (27$35) .{ }^{49,} 50$

Investigations into Tongan marine natural products chemistry, by members of the VUW MNP research group, have led to the isolation of a variety of interesting biologically active secondary metabolites. A study of a Plakortis sp. sponge, resulted in the isolation of seven new polyketides, lehualides E-K (36-42). ${ }^{51}$ Lehualides I (40) and J (41) present a methyl sulphide and methyl sulfoxide functionality, respectively and are believed to be the first report of such moieties within isolates from the Plakortis genus. Lehualides F (37), G (38) and I (40) inhibited the growth of drug-sensitive mutant strains of Saccharomyces cerevisiae (bakers yeast) at $100 \mu \mathrm{M}$ concentrations, but were inactive against wild-type yeast. Compounds 37-40 were also tested against the human promyelocytic leukemia (HL-60) cell line and were found to exhibit cytotoxicity with $\mathrm{IC}_{50}$ values of $6.2,5.4,14.6$ and $10.8 \mu \mathrm{M}$, respectively. ${ }^{51}$ An investigation of the sponge Cacospongia mycofijiensis yielded zampanolide (43), ${ }^{52}$ although 43 was originally reported from a Japanese collection of the sponge Fasciospongia rimosa in $1996 .{ }^{53}$ As a result of this recent isolation, 43 was discovered to be a microtubule stabilising agent, after exhibiting potent cytotoxicity against the HL-60 $\left(\mathrm{IC}_{50} 4.3 \mathrm{nM}\right.$ ) and $1 \mathrm{~A} 9$ (ovarian carcinoma; $\mathrm{IC}_{50} 14.3 \mathrm{nM}$ ) cell lines. Interestingly, 43 was found to be equally cytotoxic as paclitaxel (3) against the A2780 (ovarian cancer) cell line $\left(\mathrm{IC}_{50} 7.1 \mathrm{nM}\right)$ and remained cytotoxic against the paclitaxel-resistant $\mathrm{A} 2780 \mathrm{AD}$ cell line $\left(\mathrm{IC}_{50} 7.5 \mathrm{nM}\right){ }^{52}$<smiles>N#CCc1ccc(O)c(Br)c1</smiles>

23<smiles>O=C(NCCSSCCNC(=O)/C(Cc1ccc(O)c(Br)c1)=N/O)/C(Cc1ccc(O)c(Br)c1)=N\O</smiles> 


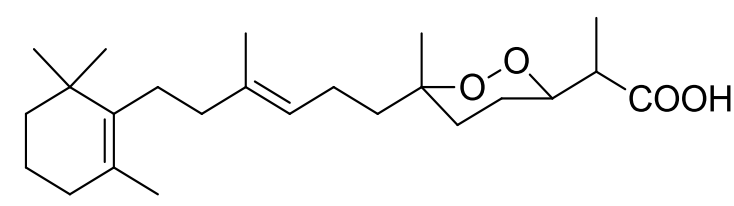

25
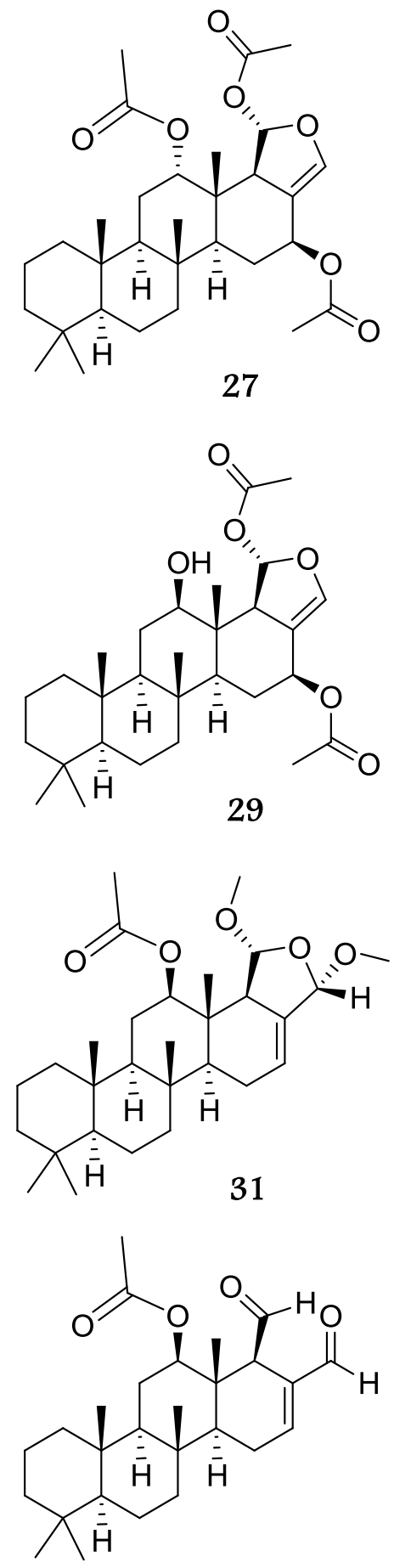

33

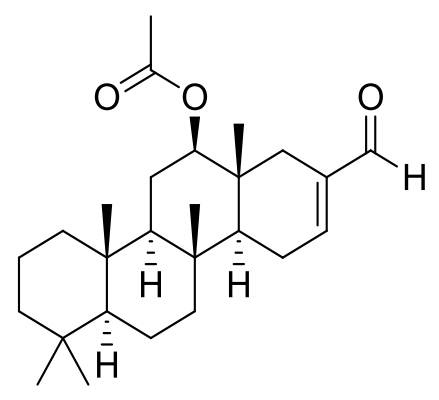

26
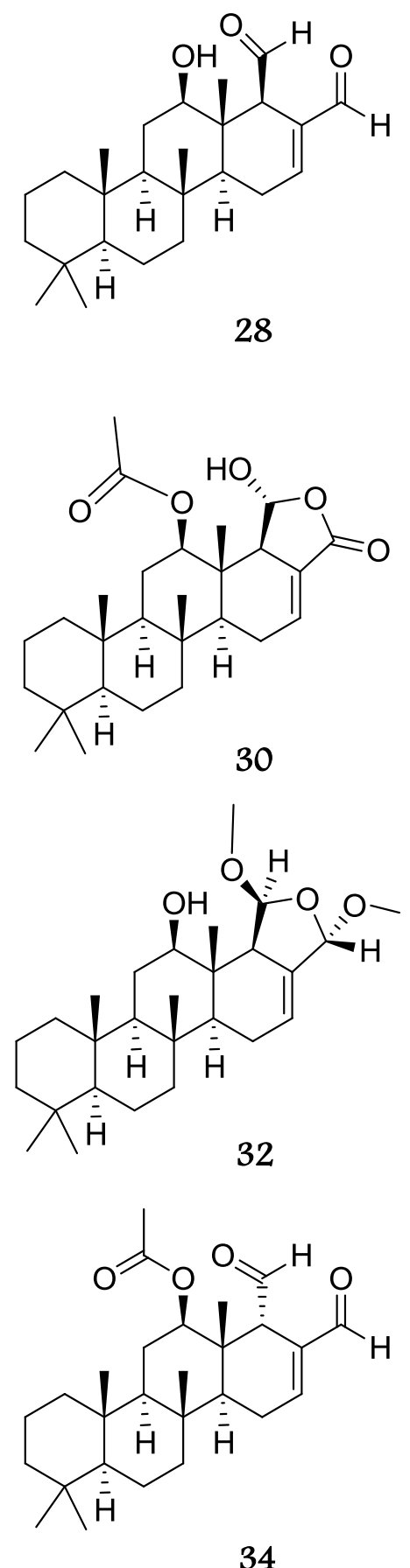

34 
<smiles>CC(=O)C[C@H]1C[C@H]2[C@@H]3CC[C@H]4C(C)(C)CCC[C@]4(C)[C@H]3C[C@H](O)[C@]2(C)c2cocc21</smiles>

35<smiles>[R]Oc1c(C)c(C/C=C(\C)CCCCCCc2ccccc2)oc(=O)c1OC</smiles>

$36 \mathrm{R}=\mathrm{CH}_{3}$

$37 \quad \mathrm{R}=\mathrm{H}$<smiles>[R]SCCCCCCCCCCc1oc(=O)c(OC)c(OC)c1C</smiles><smiles>COc1c(C)c(CCCCCCCCCS(C)=O)oc(=O)c1OC</smiles><smiles>COc1oc(=O)c(CCCCCCCCCCCCCCCCCSSCCCCCCCc2oc(=O)c(OC)c(OC)c2C)c(C)c1OC</smiles>

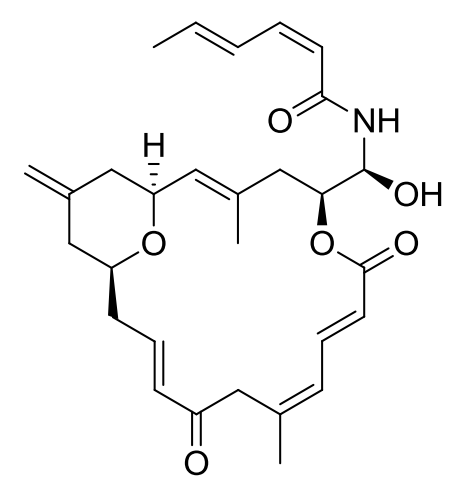

\subsection{Targeting and Isolating Secondary Metabolites}

As secondary metabolites are not essential to life and are metabolically expensive to produce, they are often present within the manufacturing organism in low quantities. Generally, crude extracts of a given organism contain a large range of non-polar and polar materials ${ }^{54}$ which constitute high concentrations of primary metabolites and salts, and only low concentration 
of secondary metabolites. Secondary metabolites typically comprise both polar and non-polar functionalities, essentially giving them an amphiphilic nature. This allows the compounds to transverse hydrophilic and hydrophobic environments, enabling partial solubility in water and more importantly in terms of biological activity, the ability to transport across the cell membrane to interact with the substrate. ${ }^{55}$

Due to the vast array of compounds (possessing a range of polarities) present in a crude extract, solubility issues are often encountered. Thus, preliminary purification steps are common practice in a natural products laboratory before screening a crude extract. The hypothetical diagram shown in Figure 1.2 illustrates the relative masses of compounds within a crude extract, against the elution profile from reversed-phase column chromatography. A large proportion of the mass elutes from the column at the beginning (high polarity compounds such as carbohydrates) and the end (low polarity compounds such as lipids and steroids). The intermediate region or 'mass window' implicated in Figure 1.2, tends to contain the compounds of interest (i.e. secondary metabolites) and therefore provides an ideal target in preliminary purification stages of a crude extract.

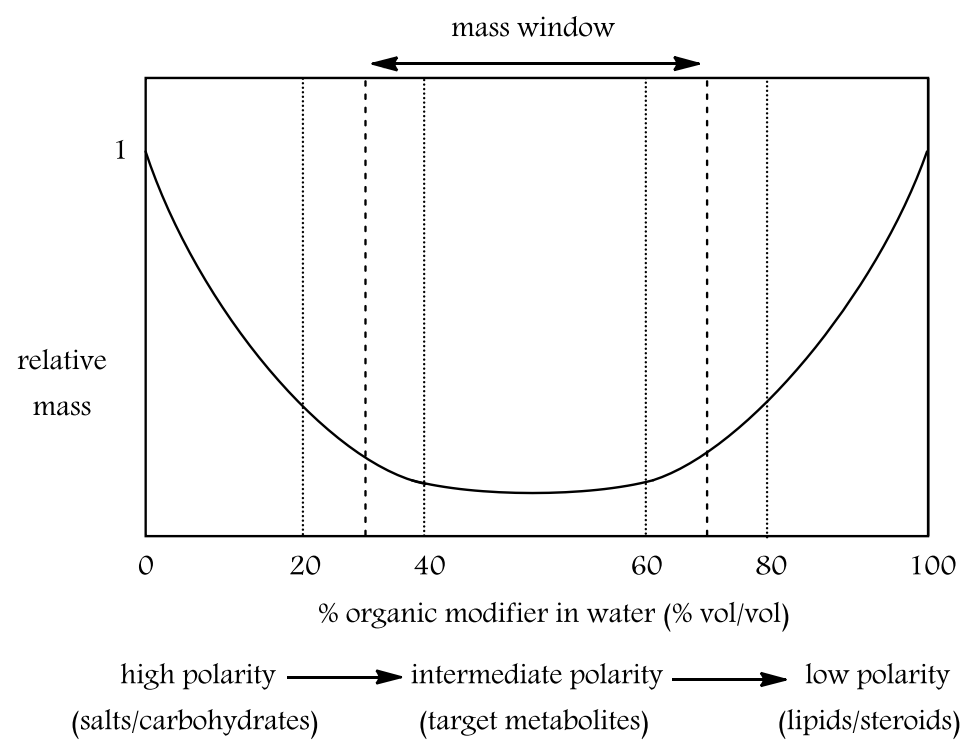

Figure 1.2. Schematic showing the mass distribution in a typical marine sponge extract.

\section{Liquid-liquid Partitioning}

The isolation of natural products typically comprises a variety of separation techniques, which depend on a range of factors such as solubility, stability, and volatility of the compounds to be separated. Liquid-liquid partitioning is one of the most commonly used methods for the fractionation of crude extracts. The method employs the use of two immiscible solvents, increasing the polarity at each subsequent step, as the process is carried out. Separation is achieved by distribution of the compounds into the different fractions 
according to their polarity. ${ }^{54,56}$ Although this technique is straightforward and has been used successfully, it requires large volumes of solvents, many of which are environmentally unfriendly, such as halogenated solvents. Furthermore, some extracts may form stable emulsions, leading to incomplete partitioning of the extract and target compounds can spread out into multiple fractions, introducing additional complications in the purification process. $^{56}$

\section{Column Chromatography}

Column chromatography is a universal purification method used in natural products laboratories. Normal-phase column chromatography is a technique best suited for the separation of non-polar compounds. Once the sample has been loaded onto the column, elution is carried out beginning with a non-polar solvent and the polarity of the mobile phase is gradually increased with incremental additions of a polar solvent. Usually, silica gel is used in normal phase chromatography. ${ }^{17}$ In the case of medium to high polarity compounds, however, silica gel is problematic; owing to the polarity and Brønsted acidity of the silanol groups, polar compounds often irreversibly bind to, or chemically react with the sorbent. Consequently, separation and product recovery is often very low. ${ }^{57}$ Functionalised silica can provide additional benefits which help to overcome this problem.

The efficient separation of medium to highly polar compounds can be carried out using reversed-phase column chromatography. Octadecyl derivatised silica gel $\left(C_{18}\right)$ is an example of a reversed-phase stationary medium initially used by Blunt et al. for the fractionation of a sponge extract. ${ }^{56}$ The crude extract is mixed with a small amount of $C_{18}$ sorbent and concentrated under reduced pressure. Once dry, it is then transferred as a slurry onto a column containing $\mathrm{C}_{18}$ and eluted with solvent mixtures of decreasing polarity. ${ }^{56}$ As with normal-phase silica gel, this chromatographic technique also has its limitations. Repeated use, particularly with highly aqueous solutions, tends to 'strip' the octadecyl chains from the column, thereby exposing silanol groups to the sample. ${ }^{58}$

\section{Cyclic Loading}

Cyclic loading (Figure 1.3), developed by Northcote and West at Victoria University of Wellington (VUW), is a technique used for the fractionation of crude extracts from marine organisms. ${ }^{57}$ The technique uses poly(styrene-divinylbenzene) (PSDVB) as the stationary phase and like $\mathrm{C}_{18}$, is also a reversed-phase solid support, though it has many more advantages. PSDVB is a cross-linked polymer with a large surface area. Adsorption and 
retention of compounds can be controlled by the use of ionic buffers, as PSDVB is stable throughout the $\mathrm{pH}$ range. The absence of surface ligands eliminates any possibility of 'stripping' (as in $\mathrm{C}_{18}$ ) and therefore it remains chemically stable in aqueous solvents. As such, it can be reused repeatedly without concern. The use of inexpensive environmentally friendly solvents, such as acetone and methanol, is a further advantage. Concentration of crude extracts for loading onto columns is often problematic due to the broad mixture of polarities contained within; polar solvents cause non-polar compounds to precipitate out while nonpolar solvents have the opposite effect. The cyclic loading technique circumvents this issue by enabling an extract to be loaded directly onto the column without the need for preconcentration.

When a crude extract is passed through the column containing PSDVB, most non-polar compounds adsorb to the stationary phase. The eluent is diluted with $\mathrm{H}_{2} \mathrm{O}$ (typically $100 \%$ $\mathrm{v} / \mathrm{v}$ ) and recycled through the column - this step is repeated until a three-fold dilution of the extract has been achieved. Addition of $\mathrm{H}_{2} \mathrm{O}$ increases the polarity of the eluent and thus each 'cyclic loading' step means the compounds of slightly higher polarity (than those already adsorbed onto PSDVB) will have a greater affinity for the stationary phase, ensuring adsorption of these compounds. Elution of the column is sequentially carried out with organic modifier $/ \mathrm{H}_{2} \mathrm{O}$ mixtures of decreasing polarity.

Although the cyclic loading process is relatively straightforward, the resulting fractions containing water have a tendency to froth when concentrating under reduced pressure. A modified cyclic loading process described as back loading, is next employed to remove the water from fractions and thus avoid the aforementioned problem. This process involves diluting the fraction with $\mathrm{H}_{2} \mathrm{O}$, 'back loading' onto PSDVB, collecting and diluting the eluent once more, recycling onto PSDVB, after which the column is eluted with $100 \%$ organic modifier. The eluent can be subsequently concentrated under reduced pressure without difficulty.

Cyclic loading, to its disadvantage, is a very time consuming process, as large quantities of solvent are passed through the column; beginning with $200 \mathrm{~mL}$ of crude extract, a total of 4.1 L of solvent is passed through the column (through both cyclic loading and back loading procedures). However, this issue is surpassed by the aforementioned advantages. Additionally, cyclic loading has been further developed for large-scale extractions (of specimens up to 1 $\mathrm{kg}$ ) which can be automated using an HPLC pump system. 


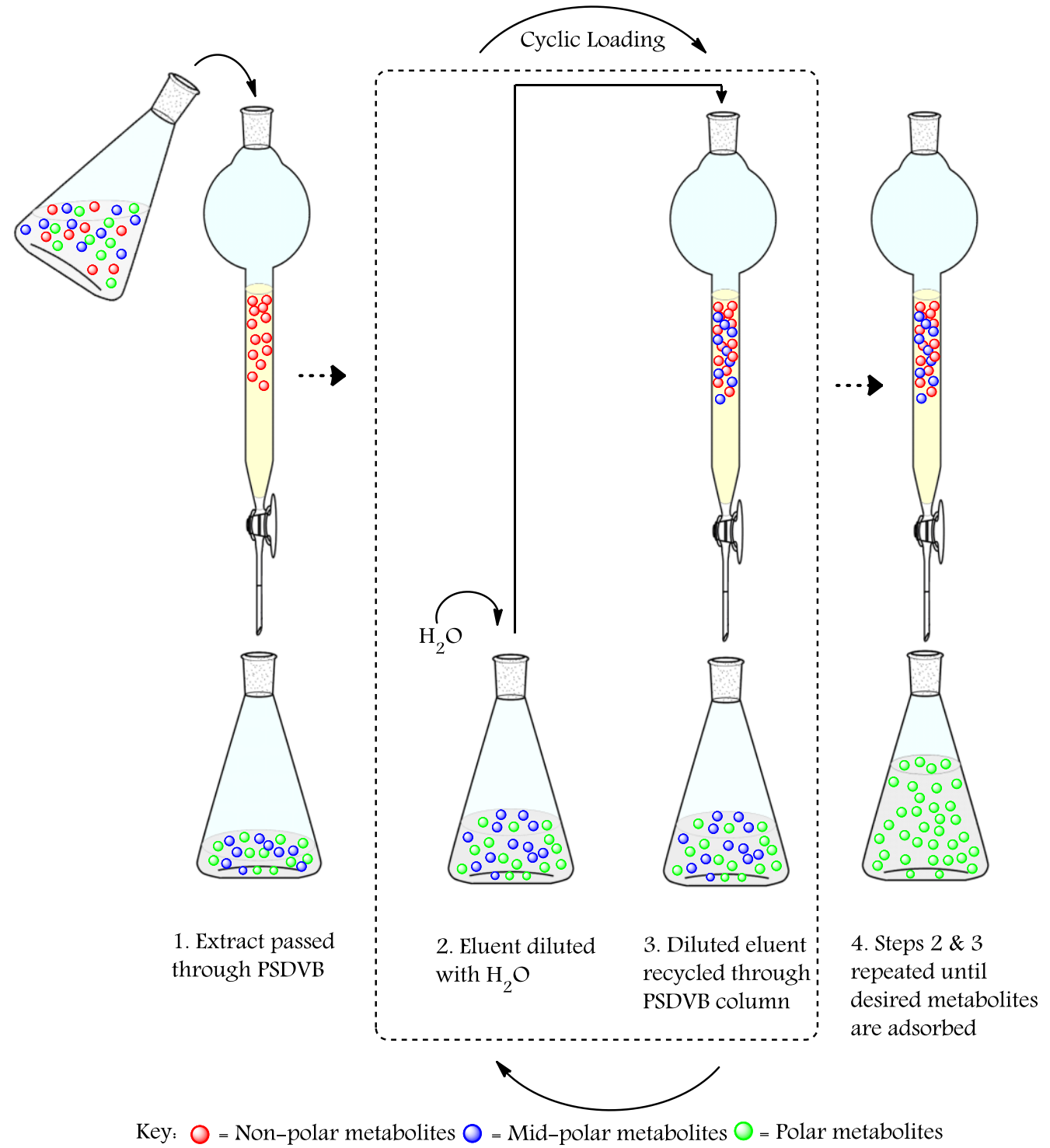

Figure 1.3. Cyclic loading procedure. Adapted from West. ${ }^{57}$

\section{Bioassay-Guided Screening}

Secondary metabolites are created to interact with biological systems, and consequently, high selectivity and specificity towards a biological target are characteristics that are often exhibited by natural products. These characteristics have been utilised in the search for biologically active secondary metabolites, whereby the traditional approach to guide the isolation of such compounds has been via bioassay-guided screening methods. ${ }^{59}$ In this method, selection of a source organism is determined by whether the extract returns a positive result for a target biological activity. Subsequent to a positive result, purification processes are carried out and tracked by testing each daughter fraction against the same biological assay. Only biologically active fractions are further progressed through purification procedures. Detection by testing against a specific biological activity therefore 
leads to the isolation and purification of compounds of potential pharmaceutical interest. In addition, important data about the mechanism of action is acquired at an early stage. ${ }^{3}$

Although this screening method results in the isolation of biologically active compounds, it is narrowly focused on a single biological activity and can inadvertently mask minor biologically active compounds which pass through undetected. It is a highly sensitive technique utilising micromolar samples in bioassays, though it is also destructive as compounds are unrecoverable once biological activity is tested. ${ }^{55} 60$

\section{NMR-Based Screening}

Since the early 1980s, NMR spectroscopy has been used for the detection of ligand-protein binding to targets. However, it was in the 1990s when the technique was used to as a screening tool in natural products for drug discovery. ${ }^{61}$ The increase in NMR field strength, advances in micro-coils and cryogenic systems, and the development of capillary and microprobes has greatly improved the NMR sensitivity, enabling the structure elucidation of submilligram quantities of natural product compounds. ${ }^{13}$ Compared with bioassay-guided screening, however, NMR-based screening is relatively insensitive as the sample sizes required for NMR experiments are still higher. On the other hand, advanced NMR techniques circumvent the problems often encountered with bioassay-guided fractionation. Preparation of NMR samples is relatively fast and experiments are comparatively quick to run. Additionally, NMR spectroscopy is non-destructive, meaning that samples can be used to easily and readily recover compounds at the end of the experiment. Successive chromatographic techniques for further purification can be optimised as a result of information obtained in regards to chemical functionality. For example, prior knowledge of functional groups such as acidic or basic moieties could lead to the use of ion-exchange media or $\mathrm{pH}$ buffers to provide a more efficient separation and purification of the fraction. Although this method of screening does not provide information on biological activity, the perception is that structural novelty frequently leads to interesting bioactivity. ${ }^{60}$

\subsection{Marine Natural Products, VUW Screening Methods}

Our laboratory employs an NMR-based screening method to analyse semi-purified extracts of marine organisms, and to guide the isolation of potentially new secondary metabolites. Following the extraction of a selected specimen and the subsequent cyclic loading of the extract onto PSDVB, the column is eluted using solutions of i) $30 \% \mathrm{Me}_{2} \mathrm{CO} / \mathrm{H}_{2} \mathrm{O}$ ii) $75 \%$ $\mathrm{Me}_{2} \mathrm{CO} / \mathrm{H}_{2} \mathrm{O}$ iii) $\mathrm{Me}_{2} \mathrm{CO}$. The $30 \%$ and $75 \%$ fractions are then backloaded onto separate 
PSDVB columns as outlined earlier, and then each column is eluted with $\mathrm{Me}_{2} \mathrm{CO}$. Once the fractions have been concentrated under reduced pressure, they are analysed by NMR spectroscopy. The intermediate region depicted in the mass window of Figure 1.2, would therefore represent the $75 \%$ fraction and should theoretically contain the majority of the secondary metabolites.

NMR screening in the MNP (VUW) laboratory has been used for several years to screen semipurified extracts. In regards to speed of screening, economic implications, and accuracy of results, it has become the preferential method of screening. Initially, the $1 \mathrm{D}{ }^{1} \mathrm{H}$ NMR experiment was the screening tool used, however the level of structural data acquired was extremely limited. Furthermore, signals belonging to secondary metabolites were masked at resonances between 0.5 and $5.5 \mathrm{ppm}$, by any primary metabolites present in the fraction. ${ }^{57}$ The initial NMR screening protocol was further developed to include the 2D COSY and HSQC experiments so that resonances could be separated using the second dimension. Spectra obtained from these two experiments were originally used to generate a paper mask however manual interpretation of complex spectra was not without difficulty and prone to error. Due to the additional information regarding chemical group functionality provided by the HSQC experiment, further development of the paper mask idea, led to the generation of a digital HQSC mask. ${ }^{55,60,62}$

The HSQC digital mask is a compilation and superimposition of HSQC spectra obtained from the $75 \% \mathrm{Me}_{2} \mathrm{CO} / \mathrm{H}_{2} \mathrm{O} \mathrm{HP} 20$ fraction (Figure 1.4). The development of the mask involved electronically exporting, adding together and overlaying the HSQC spectra. Valuable information can be obtained by comparing peak correlations within the mask to that of the screen whereby common correlations appear as strong peaks and are easily identified from uncommon correlations which are generally weak by comparison (Figure 1.5). ${ }^{55,60,62}$

Two HSQC masks were developed for New Zealand marine organisms: one for sponges and the other for algae. ${ }^{55,60,62}$ The development of the algae HSQC mask was instigated, after discovering an incompatibility between the algae and sponge HSQC spectra; all correlations in the algae HSQC screen spectra appeared unusual and thus interesting, when applied to the sponge HSQC mask. ${ }^{55}$ A further implication of this, is that the HSQC mask is unsuited for screening Tongan marine organisms and indicated that another mask was needed. Currently, the development of an HMBC mask is in progress which will be used for the screening of Tongan marine organisms. ${ }^{63}$ The HMBC experiment was selected, as it provides information on non-protonated functional groups which the HSQC experiment does not offer. 
Furthermore, the multiple-bond correlations enable the determination of chemical motifs and the derivation of compound substructures.
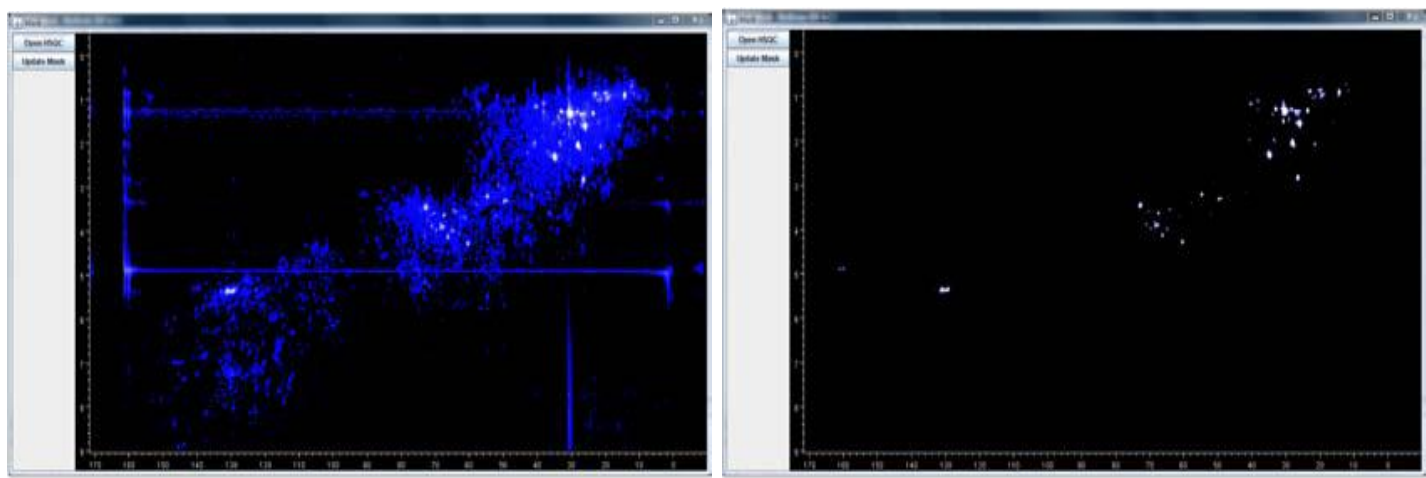

(a)

(b)

Figure 1.4. (a) Digital HSQC mask (contains 160 sponges). (b) Common correlations in the HSQC mask.

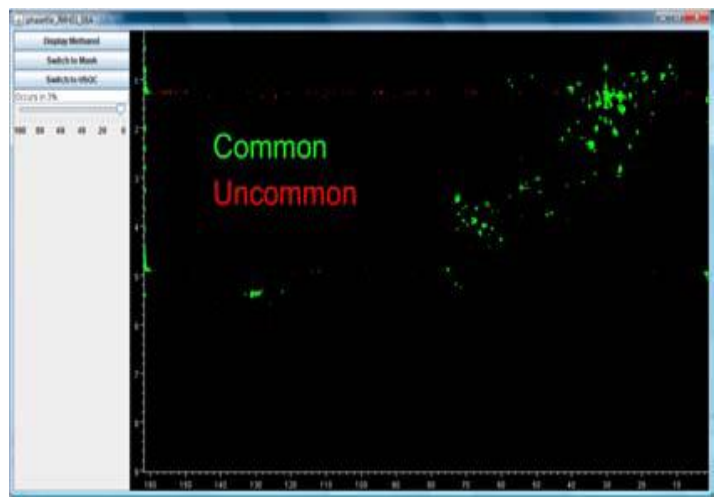

(a)

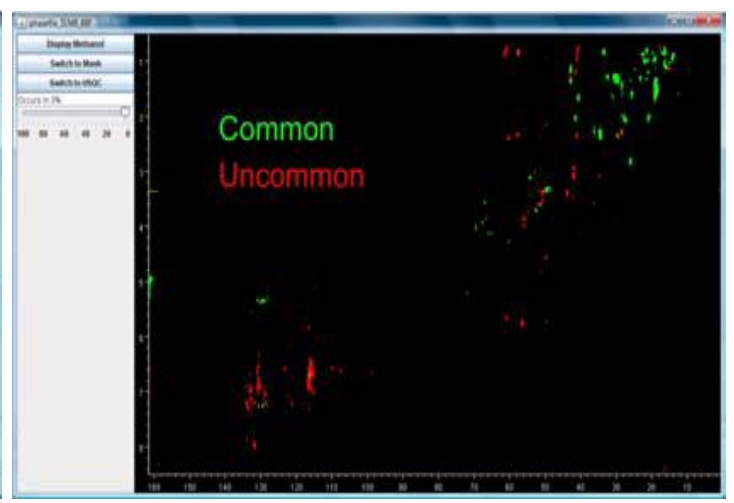

(b)

Figure 1.5. (a) An uninteresting sponge screen. (b) An interesting screen

\section{$1.8 \quad$ Proposed Research}

Interesting antifungal activity observed for triterpene glycosides obtained from the common New Zealand sea cucumber, Austalostichopus mollis, prompted curiosity as to the whether this activity is unique to the compounds of A. mollis. In order to answer this, Tongan sea cucumbers will be extracted, and partially purified samples will be tested for antifungal activity at the School of Biological Sciences, VUW. This project will additionally investigate Tongan marine sponges with the aim of isolating new, potentially biologically active, secondary metabolites. Purification techniques will involve the use of a combination of reversed- and normal-phase chromatography. Partially purified extracts will be initially analysed by 1D and 2D NMR experiments in order to evaluate fractions of further interest, and the pursuit of any compounds of interest will be guided by NMR spectroscopy. NMR 
spectroscopy and HRESIMS will be utilised in the structure elucidation of compounds and all new compounds will be submitted to the School of Biological Sciences, VUW, to test for biological activity. 


\section{Chapter 2}

\section{Screening Tongan Marine Organisms}

\subsection{Comparison of Antifungal Activity between Tongan Holothurians and Australostichopus mollis}

Sea cucumbers are a prolific source of saponins, and in particular of triterpene glycosides. Triterpene glycosides are metabolites commonly found in plants and it is rare to observe them from animals, yet they are regularly isolated from sea cucumbers and surprisingly their isolation has also been reported from sponges. ${ }^{64}$ A broad biological profile has been noted for compounds of this type, including antifungal, cytostatic, cytotoxic, hemolytic and immunomodulatory activities. ${ }^{65}$

\subsubsection{Triterpene Glycosides from Australostichopus mollis}

Australostichopus mollis, the most common sea cucumber of New Zealand, was investigated by Greta Moraes, which led to the isolation of one known (neothyonidioside, 44) and six new triterpene glycosides, mollisosides $\mathrm{A}, \mathrm{B}_{1}, \mathrm{~B}_{2}, \mathrm{C}-\mathrm{E}$ (45-50, respectively). ${ }^{40,58,66}$ A partially purified sample containing these compounds, exhibited antifungal activity against Rhizopus sp. with $90-100 \%$ inhibition at concentrations of $100 \mu \mathrm{g} / \mathrm{mL}^{40}$ This interesting activity profile prompted curiosity as to whether the antifungal activity was specific to the saponins from $A$. mollis or a commonality to saponins from sea cucumbers in general. As A. mollis represents the most common sea cucumber found in New Zealand, such investigations aimed at answering this question could not proceed without access to other specimens. An expedition to Tonga for the collection of marine organisms provided an opportunity for other sea cucumbers to be investigated therefore enabling a comparison of the antifungal activity between saponins from Tongan sea cucumbers and A. mollis. 


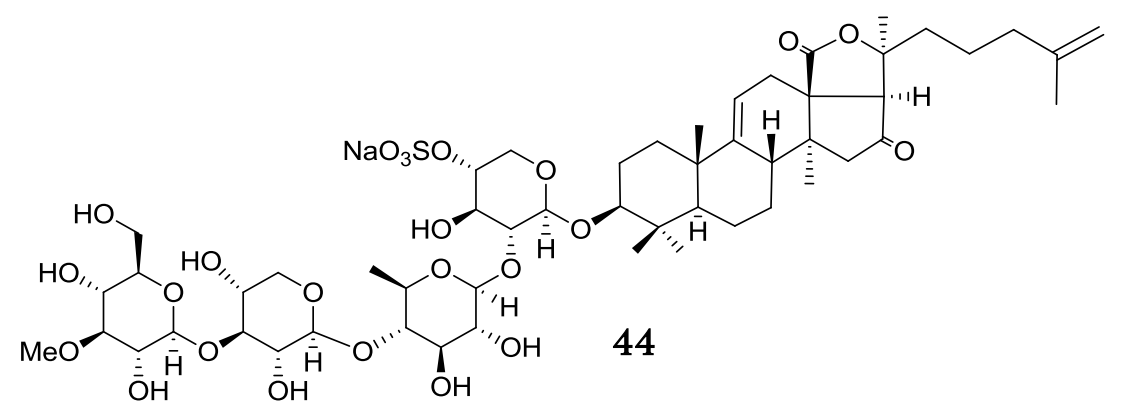

(n)
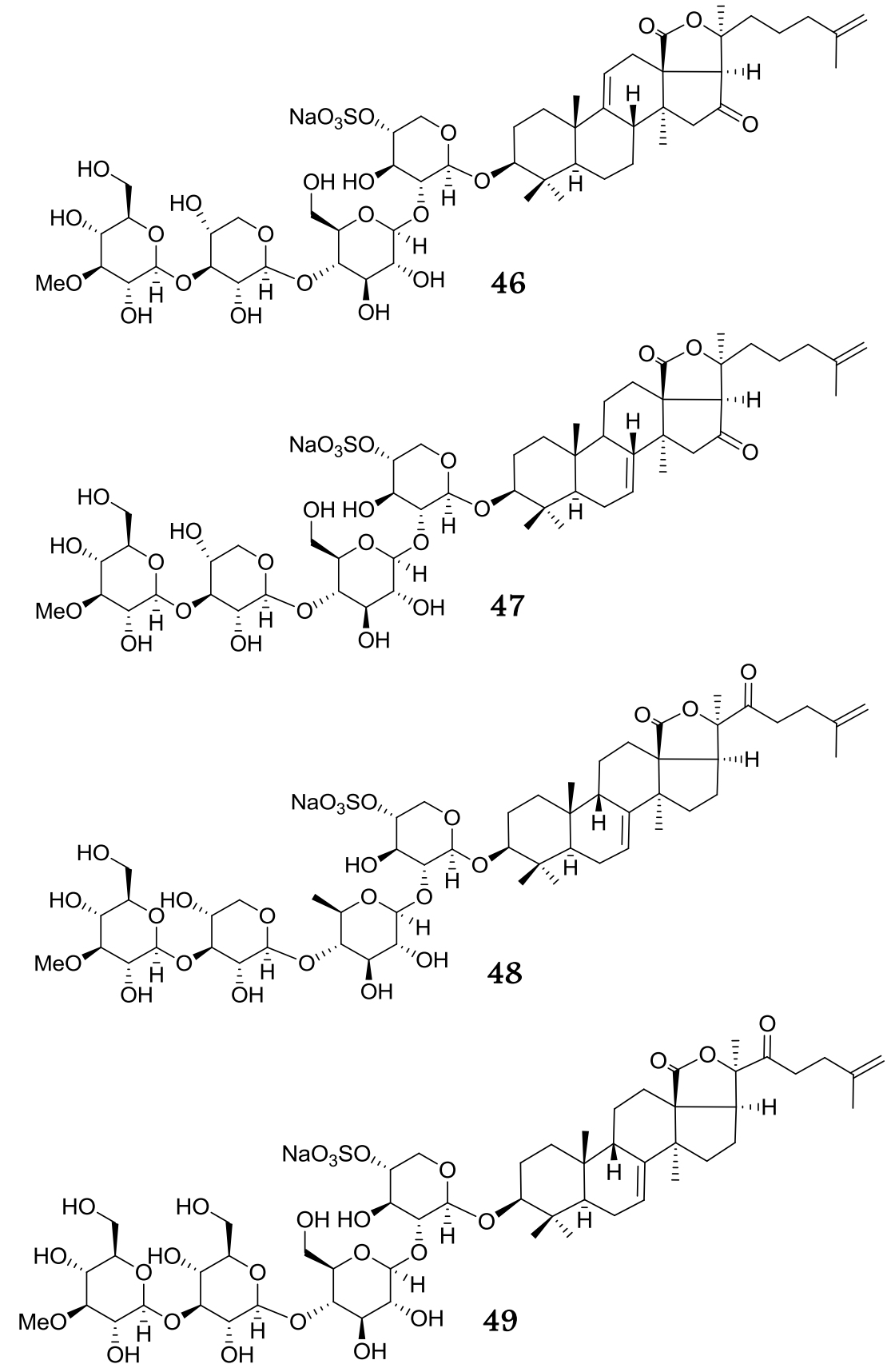


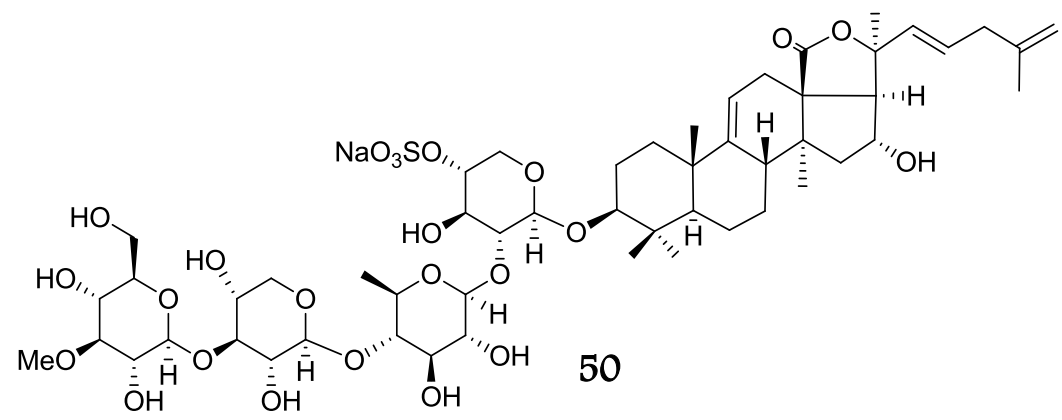

\subsubsection{Tongan Holothurians}

The opportunity to collect marine organisms from Tonga allowed for the collection of a variety of common Tongan sea cucumbers. During a snorkel collection in late 2008, a total of eight different common species of holothurians were obtained, from Popua Beach, Tongatapu, Tonga. As these were common Tongan sea cucumbers, comparisons made against pictures of Tongan sea cucumbers facilitated with their identification. Four of these were selected for investigation.

\section{PTN3_13D}

PTN3_13D (Figure 2.1) has a jet black, leathery epidermis, and is tentatively identified as Stichopus chloronotus. A total mass of $537 \mathrm{~g}$ was collected, from which $70 \mathrm{~g}$ was extracted. Following HP2O cyclic loading and back loading, the $75 \% \mathrm{Me}_{2} \mathrm{CO} / \mathrm{H}_{2} \mathrm{O}$ fraction was obtained $(235.6 \mathrm{mg})$ as a creamy white powder. Although the ${ }^{1} \mathrm{H}$ NMR spectrum did not provide a great deal of information (Figure 2.2), the $\mathrm{HMBC}$ screen spectrum of the $75 \% \mathrm{Me}_{2} \mathrm{CO} / \mathrm{H}_{2} \mathrm{O}$ fraction showed correlations that were consistent with saponin-like compounds (Figure 2.3).

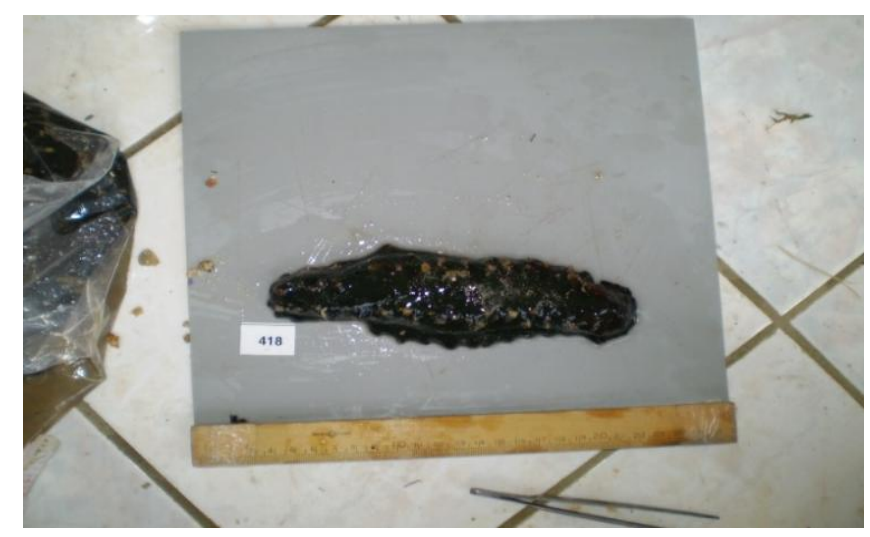

Figure 2.1. Surface photo of PTN3_13D 


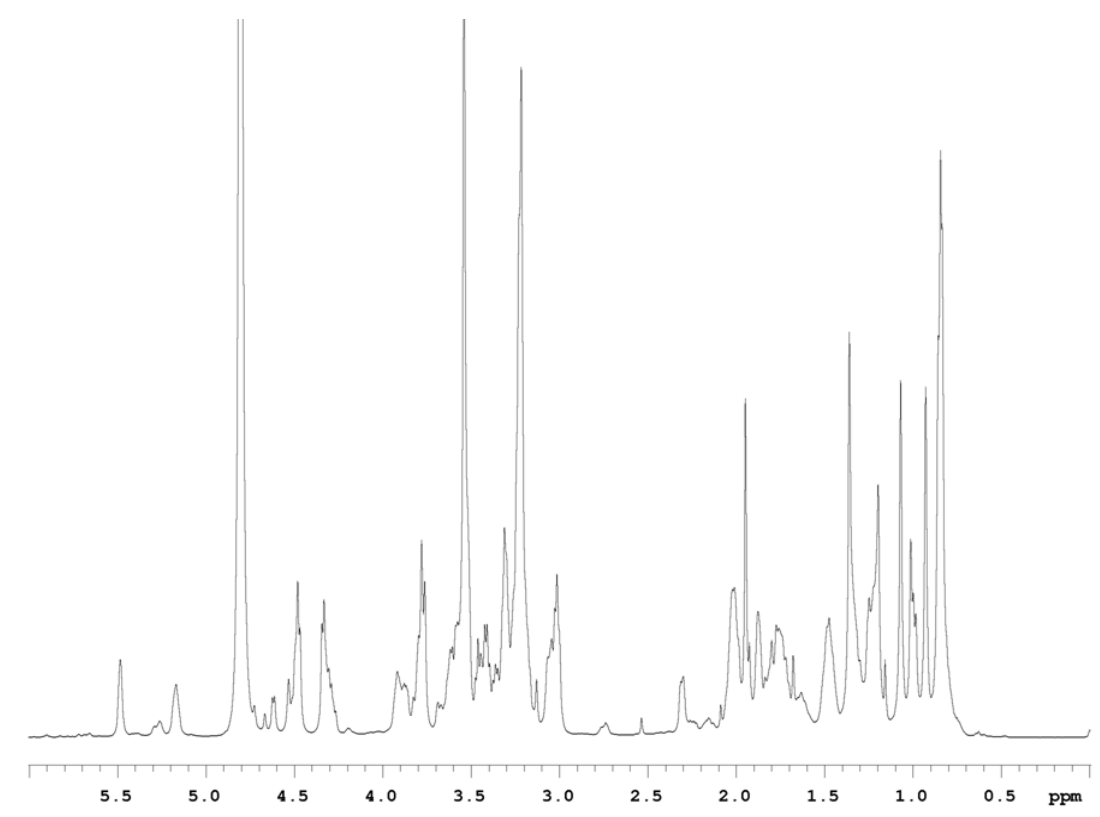

Figure 2.2. ${ }^{1} \mathrm{H} \mathrm{NMR}\left(\mathrm{CD}_{3} \mathrm{OD}, 600 \mathrm{MHz}\right)$ screen spectrum of the $75 \% \mathrm{Me}_{2} \mathrm{CO} / \mathrm{H}_{2} \mathrm{O}$ fraction of PTN3_13D.

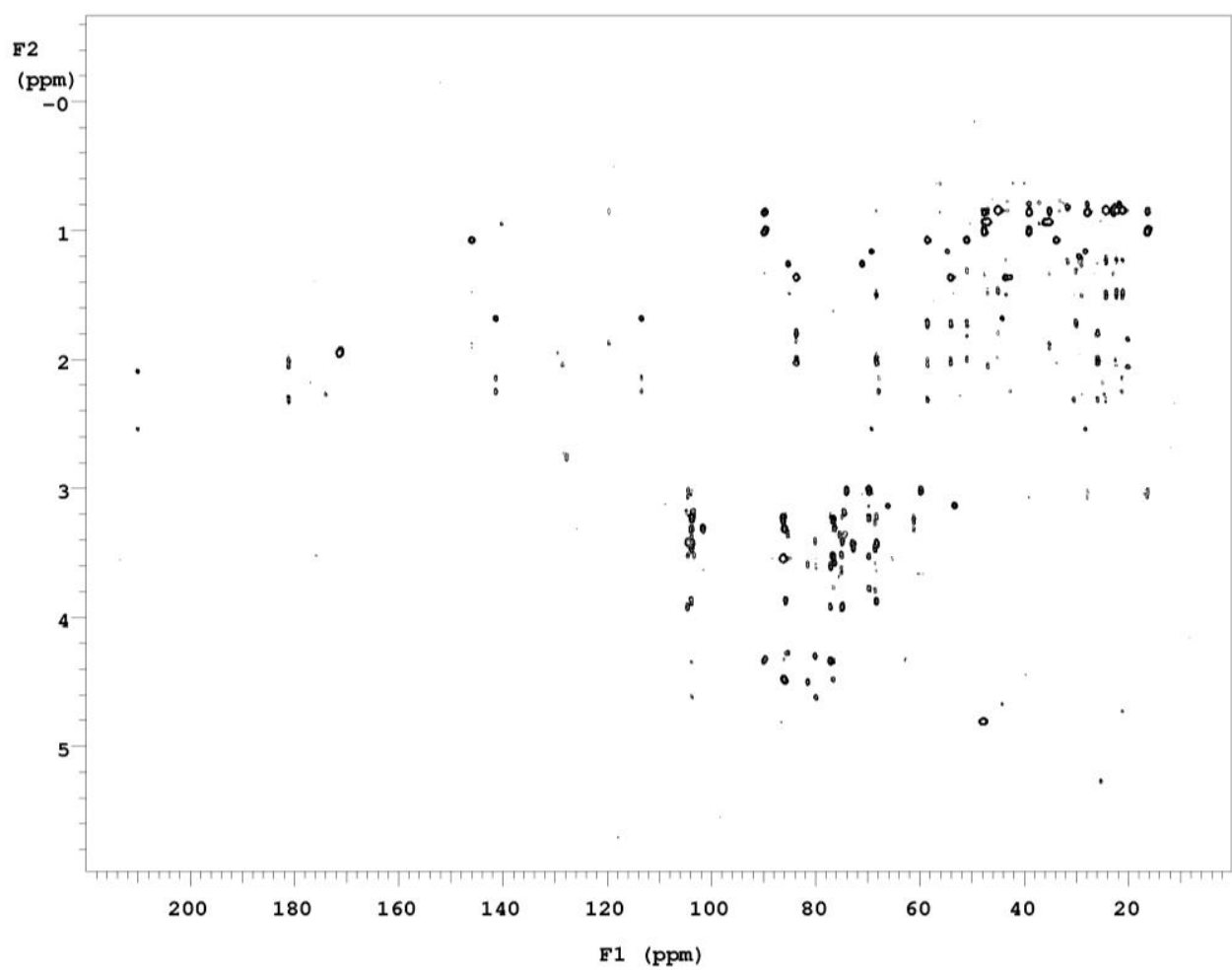

Figure 2.3. $\mathrm{HMBC}\left(\mathrm{CD}_{3} \mathrm{OD}, 600 \mathrm{MHz}\right)$ screen spectrum of the $75 \% \mathrm{Me}_{2} \mathrm{CO} / \mathrm{H}_{2} \mathrm{O}$ fraction of PTN3_13D. 


\section{PTN3 13F}

PTN3_13F (Figure 2.4) was tentatively identified as Holothurea sp. (either $H$. edulus or $H$. atra). A total of $320 \mathrm{~g}$ was collected and $38 \mathrm{~g}$ was extracted. During backloading, the $75 \%$ $\mathrm{Me}_{2} \mathrm{CO} / \mathrm{H}_{2} \mathrm{O}$ eluent began to foam as $\mathrm{H}_{2} \mathrm{O}$ was added. This observation indicated the presence of saponins. A total of $77.1 \mathrm{mg}$ of the $75 \% \mathrm{Me}_{2} \mathrm{CO} / \mathrm{H}_{2} \mathrm{O}$ fraction was obtained as a white powder. Although, the observed foaming suggested the presence of saponins, this could not be ascertained with certainty from NMR data due to broad resonances in the ${ }^{1} \mathrm{H}$ NMR spectrum (Figure 2.6) and very few correlations observed in the HMBC spectrum (Figure 2.7).

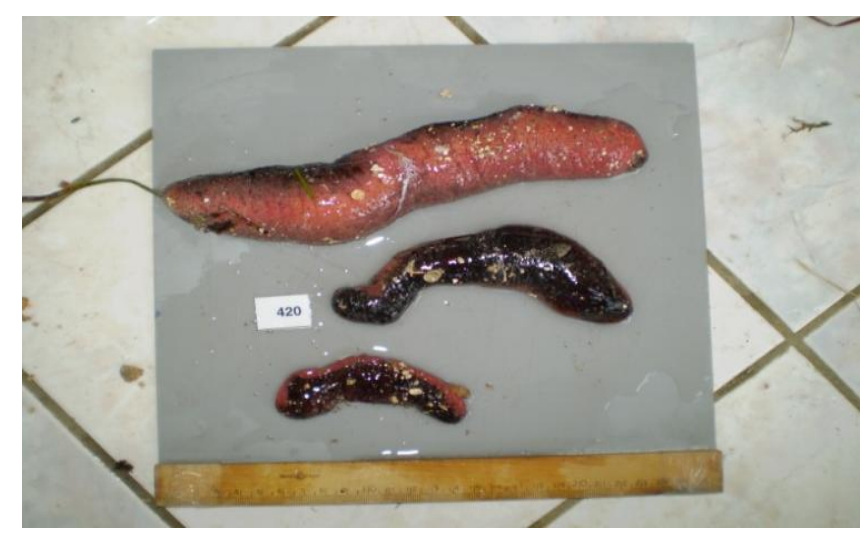

Figure 2.4. Surface photo of PTN3_13F

\section{PTN3_13G}

PTN3_13G (Figure 2.5) is tentatively identified as a Bohadschia sp. (either B. argus or B. simils). A total mass of $470 \mathrm{~g}$ was collected and $50 \mathrm{~g}$ was extracted. The initial dilution of the $75 \% \mathrm{Me}_{2} \mathrm{CO} / \mathrm{H}_{2} \mathrm{O}$ eluent for back loading also formed a foaming solution, again indicating the presence of saponins. A total of $39.6 \mathrm{mg}$ was obtained as a white powder from the $75 \%$ $\mathrm{Me}_{2} \mathrm{CO} / \mathrm{H}_{2} \mathrm{O}$ fraction. In addition to the observed foaming of the eluent, the NMR data also suggested the presence of saponins (Figures 2.8 and 2.9).

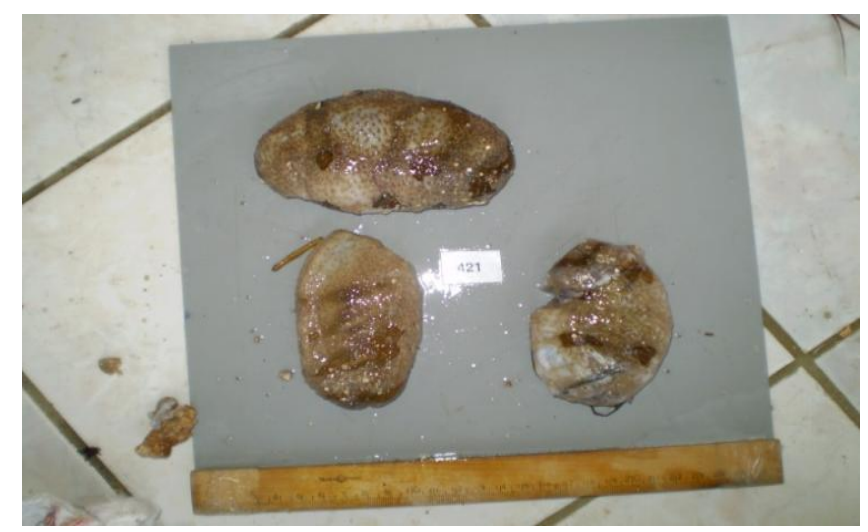

Figure 2.5. Surface photo of PTN3_13G 


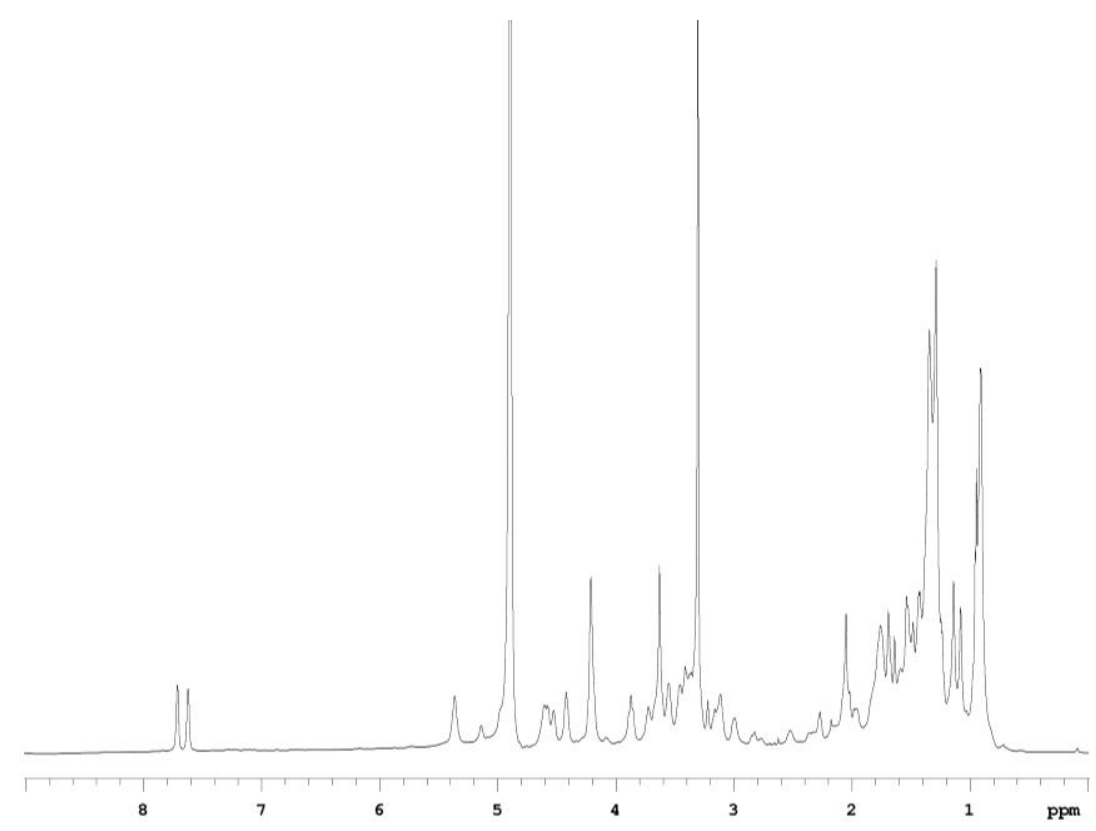

Figure 2.6. ${ }^{1} \mathrm{H} \mathrm{NMR}\left(\mathrm{CD}_{3} \mathrm{OD}, 600 \mathrm{MHz}\right)$ screen spectrum of the $75 \% \mathrm{Me}_{2} \mathrm{CO} / \mathrm{H}_{2} \mathrm{O}$ fraction of PTN3_13F.

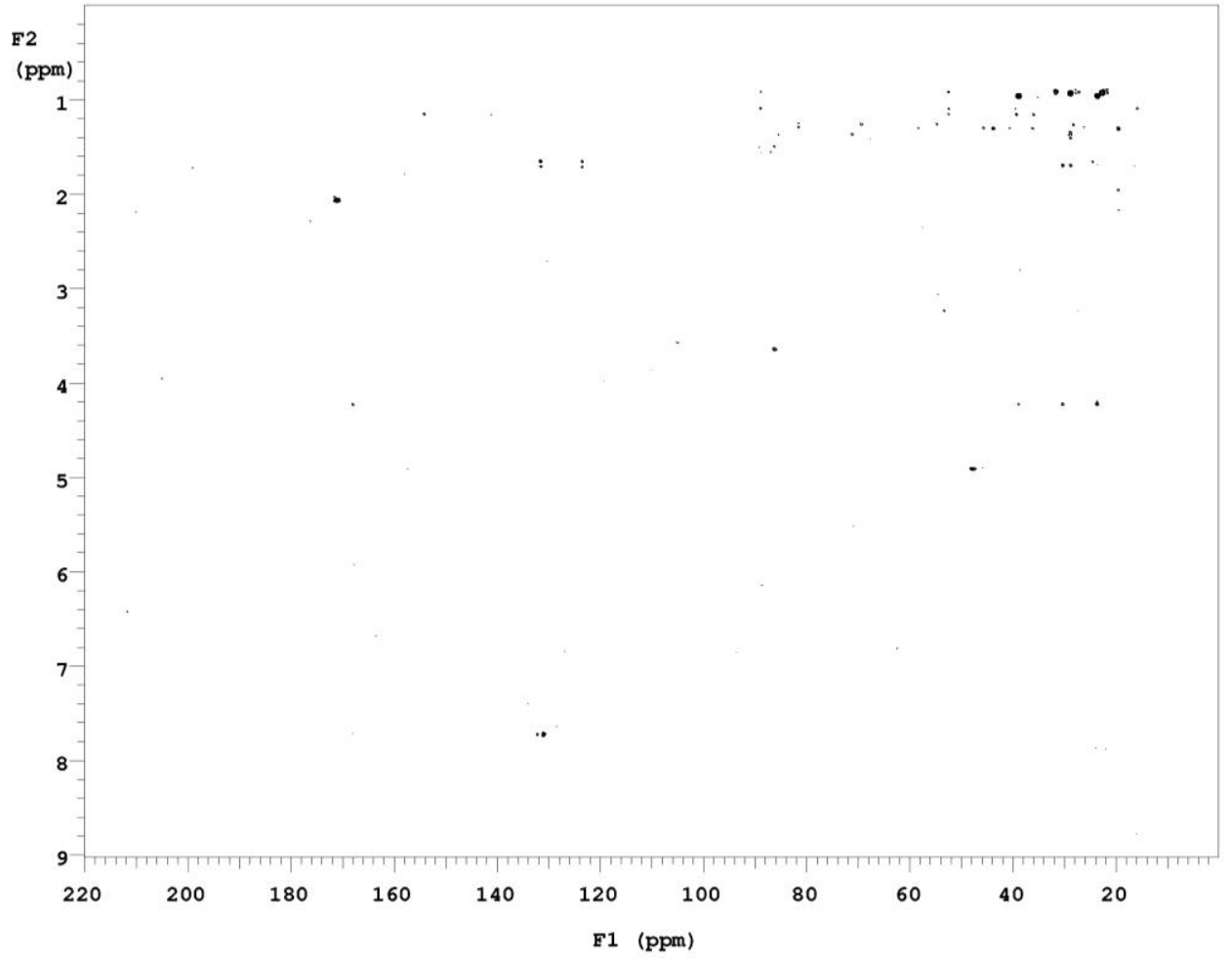

Figure 2.7. $\mathrm{HMBC}\left(\mathrm{CD}_{3} \mathrm{OD}, 600 \mathrm{MHz}\right)$ screen spectrum of the $75 \% \mathrm{Me}_{2} \mathrm{CO} / \mathrm{H}_{2} \mathrm{O}$ fraction of PTN3_13F. 


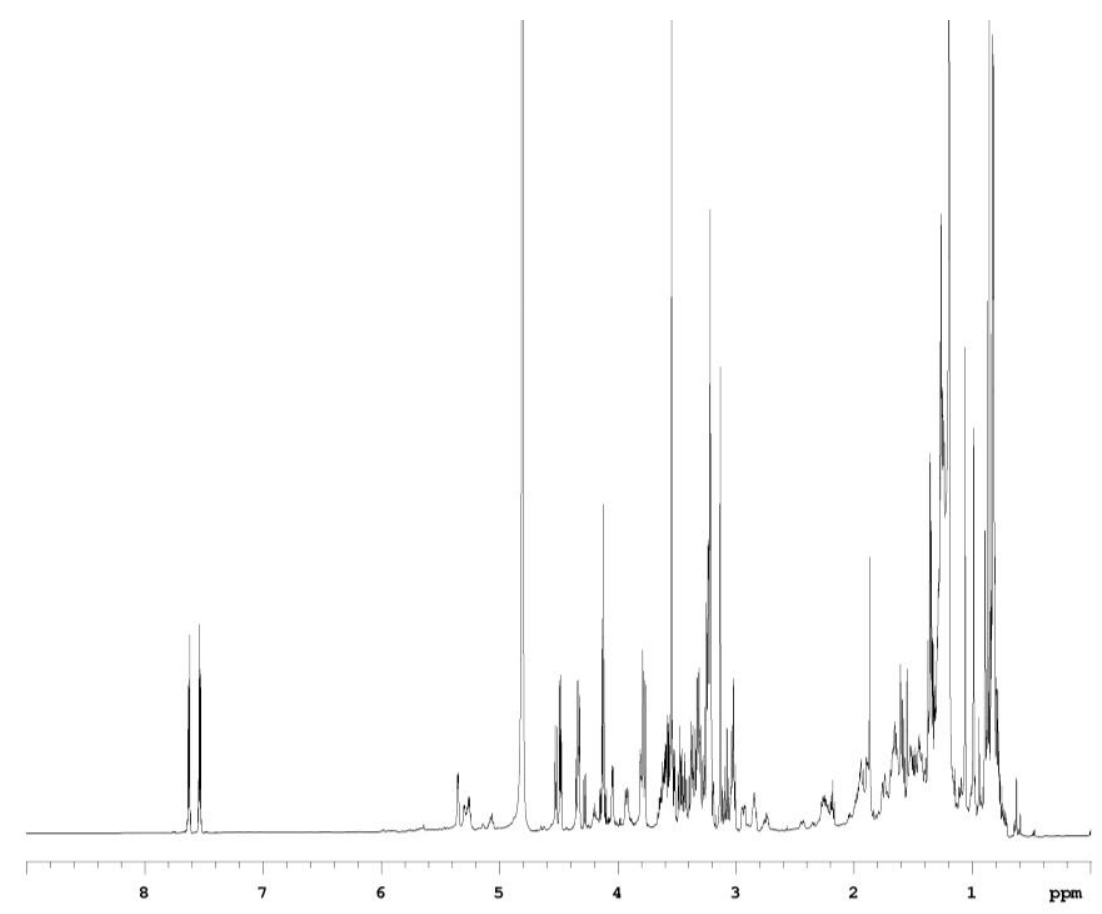

Figure 2.8. ${ }^{1} \mathrm{H} \mathrm{NMR}\left(\mathrm{CD}_{3} \mathrm{OD}, 600 \mathrm{MHz}\right)$ screen spectrum of the $75 \% \mathrm{Me}_{2} \mathrm{CO} / \mathrm{H}_{2} \mathrm{O}$ fraction of PTN3_13G.

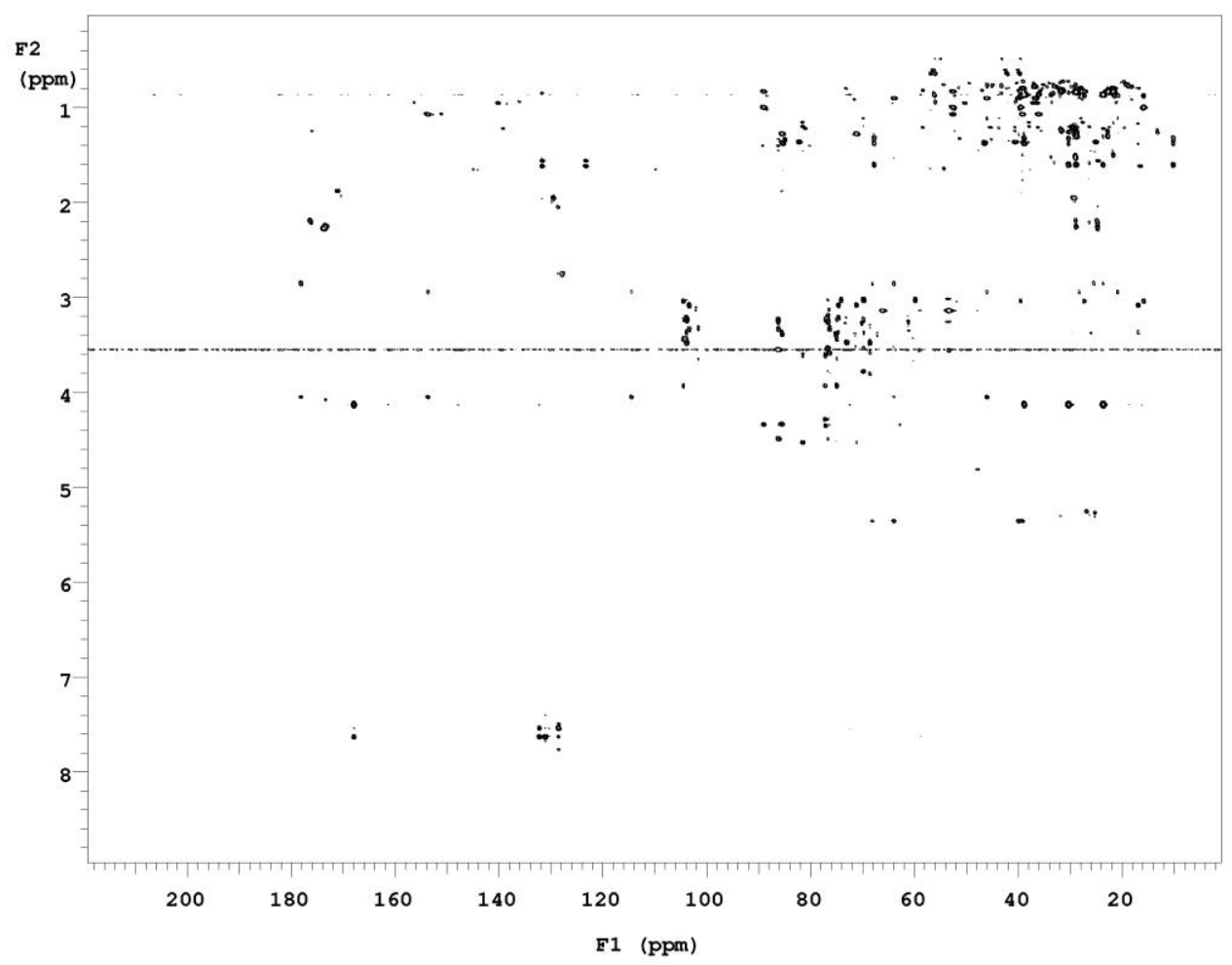

Figure 2.9. $\mathrm{HMBC}\left(\mathrm{CD}_{3} \mathrm{OD}, 600 \mathrm{MHz}\right)$ screen spectrum of the $75 \% \mathrm{Me}_{2} \mathrm{CO} / \mathrm{H}_{2} \mathrm{O}$ fraction of PTN3_13G. 
PTN3_13H

PTN3_13H (Figure 2.10) possesses a dark brown exterior and has tentatively been identified as Bohadschia vitiensis. A mass of $70 \mathrm{~g}$, out of a total $252 \mathrm{~g}$ was extracted. Following cyclic and back loading, the $75 \% \mathrm{Me}_{2} \mathrm{CO} / \mathrm{H}_{2} \mathrm{O}$ fraction concentrated to dryness under reduced pressure to afford a creamy white powder. The NMR screen spectra indicated the presence of saponins (Figures 2.11 and 2.12).

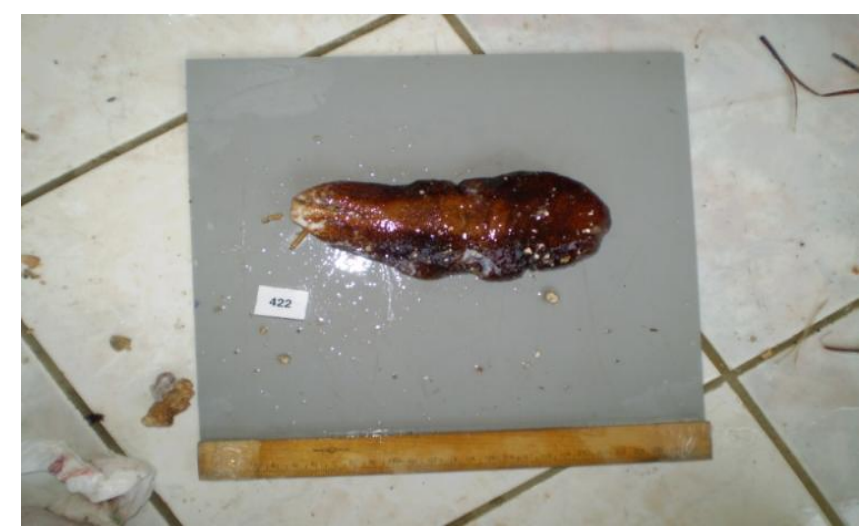

Figure 2.10. Surface photo of PTN3_13H

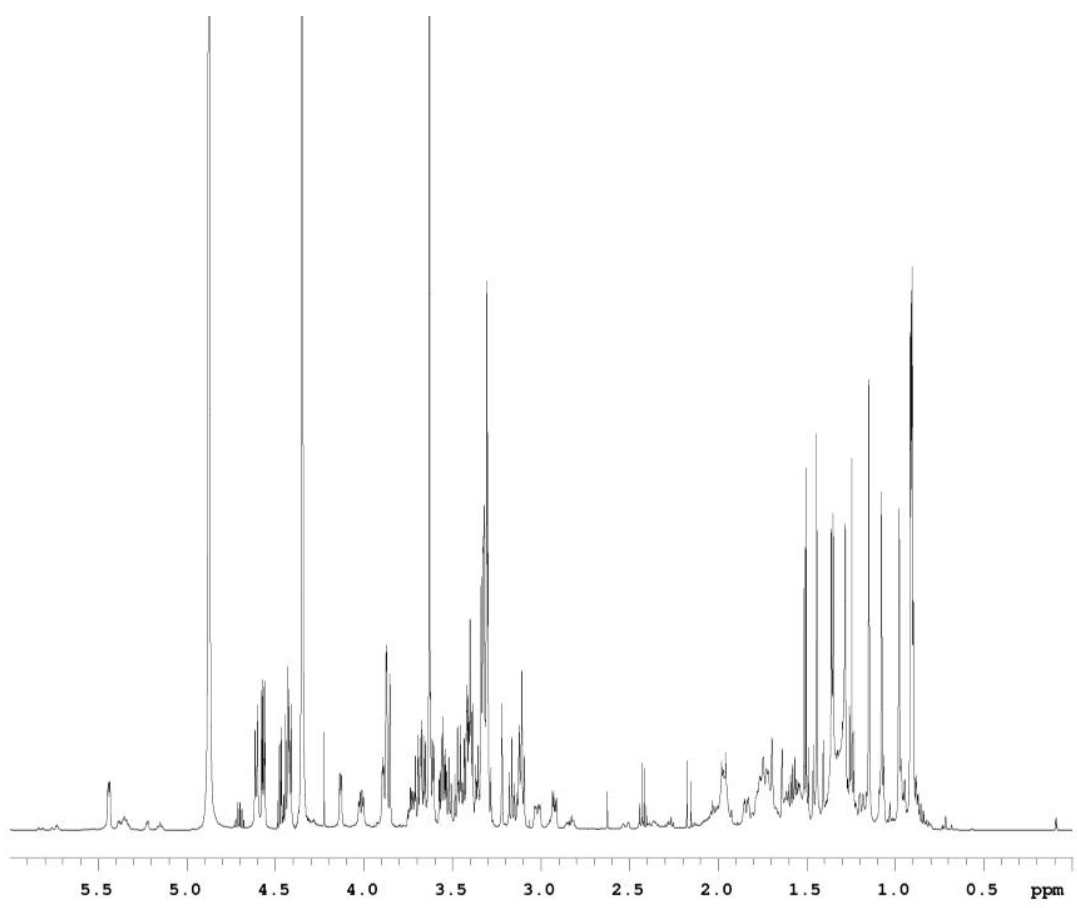

Figure 2.11. ${ }^{1} \mathrm{H} \mathrm{NMR}\left(\mathrm{CD}_{3} \mathrm{OD}, 600 \mathrm{MHz}\right)$ screen spectrum of the $75 \% \mathrm{Me}_{2} \mathrm{CO} / \mathrm{H}_{2} \mathrm{O}$ fraction of PTN3_13H. 


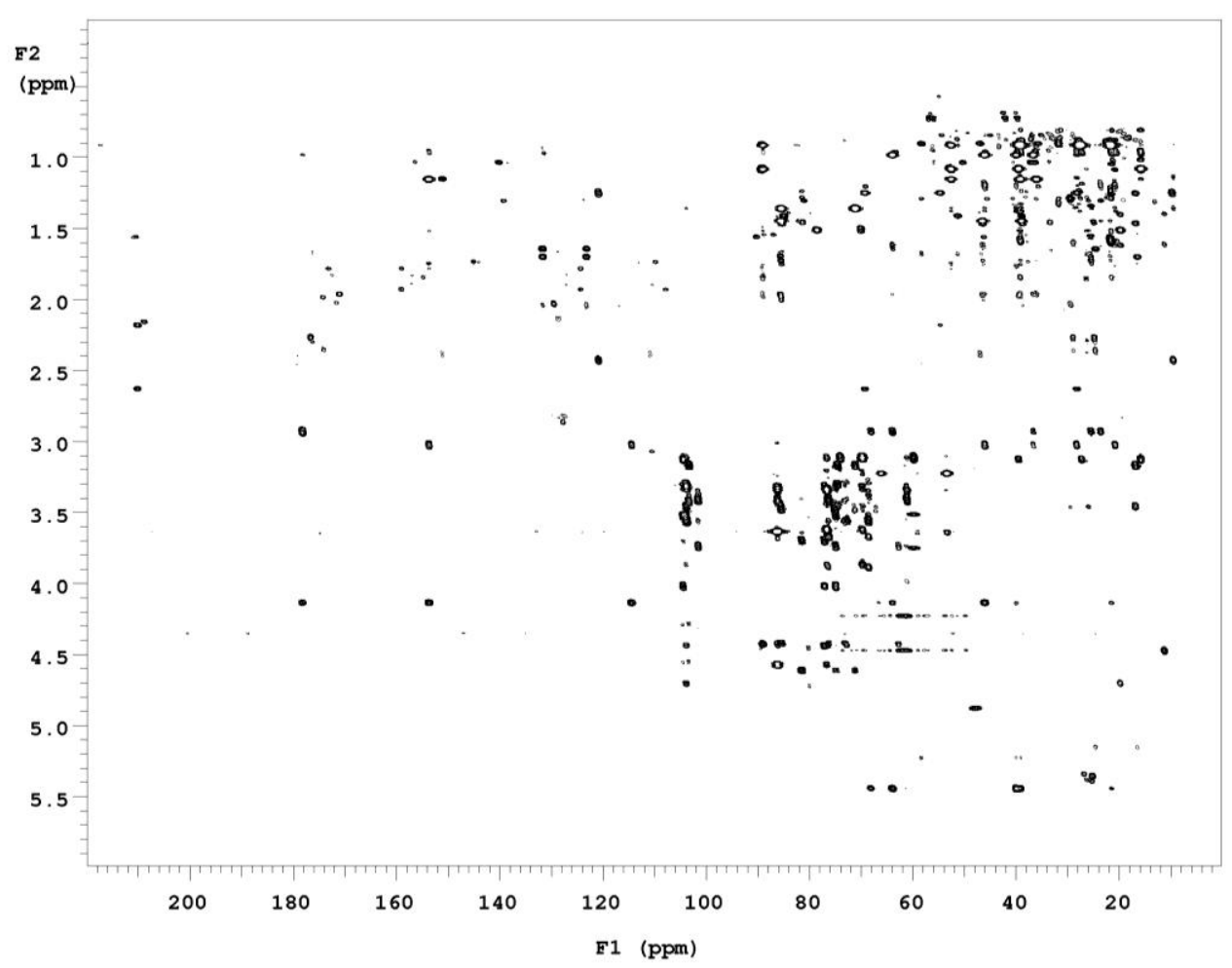

Figure 2.12. $\mathrm{HMBC}\left(\mathrm{CD}_{3} \mathrm{OD}, 600 \mathrm{MHz}\right)$ screen spectrum of the $75 \% \mathrm{Me}_{2} \mathrm{CO} / \mathrm{H}_{2} \mathrm{O}$ fraction of PTN3_13H.

\subsubsection{Antifungal Activity}

Subsamples of each of the $75 \% \mathrm{Me}_{2} \mathrm{CO} / \mathrm{H}_{2} \mathrm{O}$ fractions were submitted to the School of Biological Sciences, VUW where antifungal activity against Saccharomyces cerevisiae was tested. The antifungal activity of the semi-purified extracts from Tongan sea cucumbers, appeared to be comparatively similar, to that observed for neothyonidioside (44), which has a minimum inhibitory concentration (MIC) of $1 \mu \mathrm{M}(1.1 \mu \mathrm{g} / \mathrm{mL})$ against $S$. cerevisiae. ${ }^{67}$ Close to $93 \%$ growth inhibition was observed for the sample from PTN3_13D at $1.1 \mu \mathrm{g} / \mathrm{mL}$, and PTN3_13H at $3.3 \mu \mathrm{g} / \mathrm{mL}$, and between $60-65 \%$ growth inhibition at $11 \mu \mathrm{g} / \mathrm{mL}^{\S}$ for both samples obtained from PTN3_13F and PTN3_13G. Furthermore, neothyonidioside resistant yeast strains showed resistance to all four Tongan sea cucumber samples. These results suggested that the antifungal activity of the $A$. mollis saponins is not specific, but is rather a generic feature of holothurian saponins.

The antifungal mechanism of action of neothyonidioside (44) was recently published. ${ }^{67}$ Neothyonidioside (44) binds directly to ergosterol ${ }^{* *}$ in a dose-dependent manner, thereby disrupting the cell membrane. This study suggests that other sterol-binding antifungal 
agents, operate in this manner. ${ }^{67}$ In view of these results, the comparable antifungal activity observed between the Tongan sea cucumber samples and the A. mollis triterpene glycosides is not surprising, since saponins are known to bind to sterols. ${ }^{68}$ It is likely that the saponins within the Tongan sea cucumber samples may be operating by the same mechanism within yeast.

Holothurians have been extensively investigated for secondary metabolites and these are well represented in the literature. As our interest was purely in the comparable antifungal activity, Tongan sea cucumbers were not investigated any further and the focus of this project moved towards the investigation of new secondary metabolites from Tongan marine sponges.

\subsection{Tongan Marine Sponges}

A total of 260 sponges was collected during two collection trips to Tonga in 2008 and 2009. Many of these included multiple specimens of the same sponge, which have been collected from different geographical locations in Tonga as this can often be important in determining the level and type of metabolites within the organism. Sponges were collected from various locations in Tongatapu, 'Eua, and the Vava'u group. Five sponges, all collected from Vava'u, were selected for screening and two were chosen for further analyses.

\section{PTN4_05C}

PTN4_05C (Figure 2.13) is a soft, biscuit-beige coloured, unidentified sponge. The exterior of the sponge was covered with algae. The sponge was screened (22 g) and revealed both the $75 \% \mathrm{Me}_{2} \mathrm{CO} / \mathrm{H}_{2} \mathrm{O}$ and the $100 \% \mathrm{Me}_{2} \mathrm{CO}$ fractions to contain one major compound, identified as steroidal, with olefinic signals clearly defined. No further analysis was performed. The ${ }^{1} \mathrm{H}$ NMR and HMBC screen spectra are provided in Figures 2.15 and 2.16, respectively.

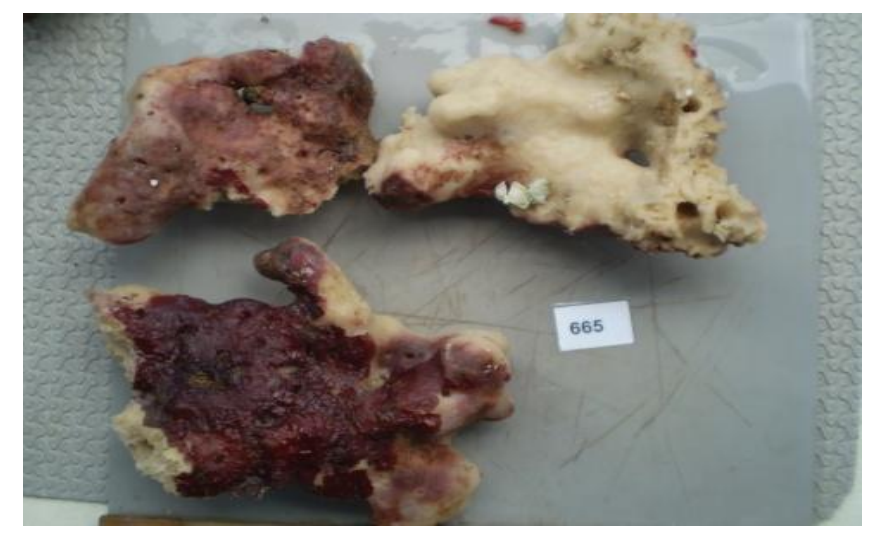

Figure 2.13. Surface photo of PTN4_O5C 


\section{PTN4_08B}

PTN4_08B (Figure 2.14) was a soft, beige coloured unidentified sponge. The screen of a $19 \mathrm{~g}$ sponge specimen revealed it to be the same as PTN4_O5C as the spectra of both the $75 \%$ $\mathrm{Me}_{2} \mathrm{CO} / \mathrm{H}_{2} \mathrm{O}$ and $100 \% \mathrm{Me}_{2} \mathrm{CO}$ fractions were identical. Further investigations were discontinued. The ${ }^{1} \mathrm{H}$ NMR screen spectrum is given in Figure 2.15.

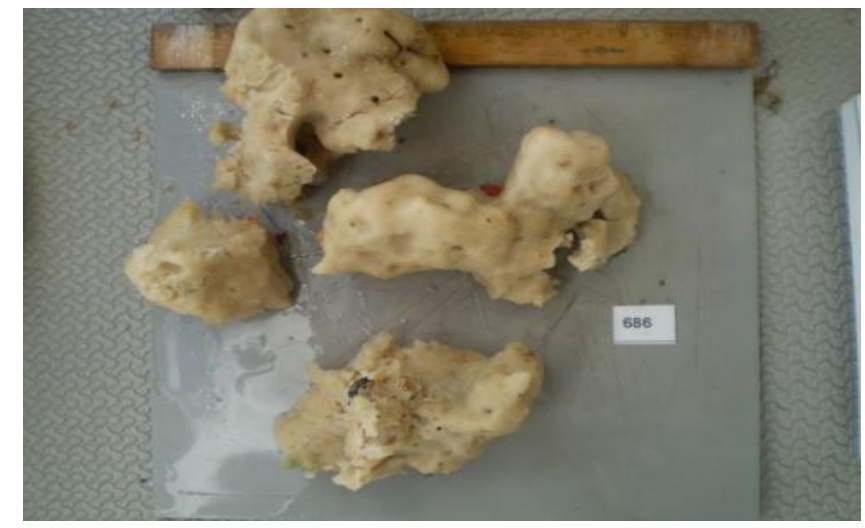

Figure 2.14. Surface photo of PTN4_08B

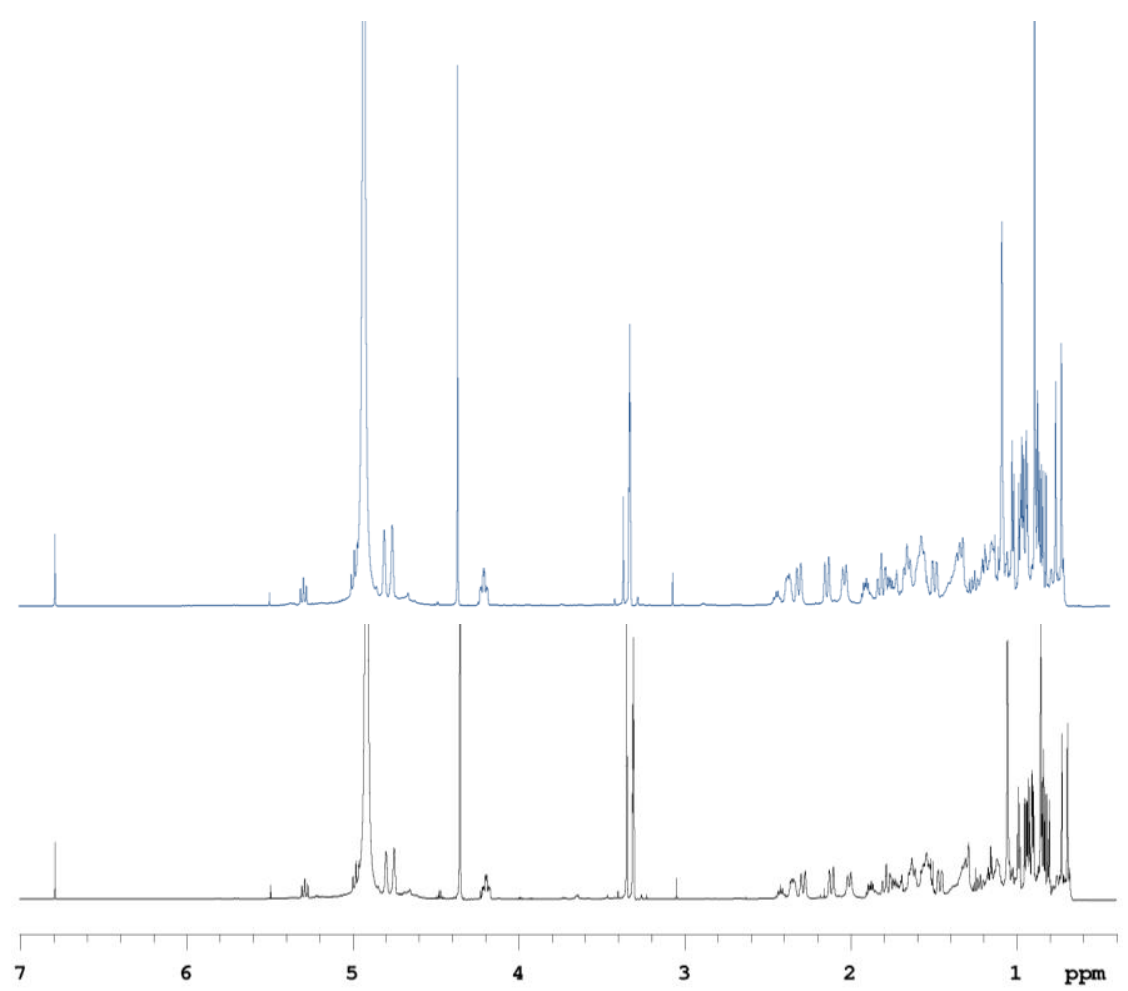

Figure 2.15. ${ }^{1} \mathrm{H} \mathrm{NMR}\left(\mathrm{CD}_{3} \mathrm{OD}, 600 \mathrm{MHz}\right)$ screen spectra of the $75 \% \mathrm{Me}_{2} \mathrm{CO} / \mathrm{H}_{2} \mathrm{O}$ fraction of PTN4_05C (blue) and PTN4_08B (black). 


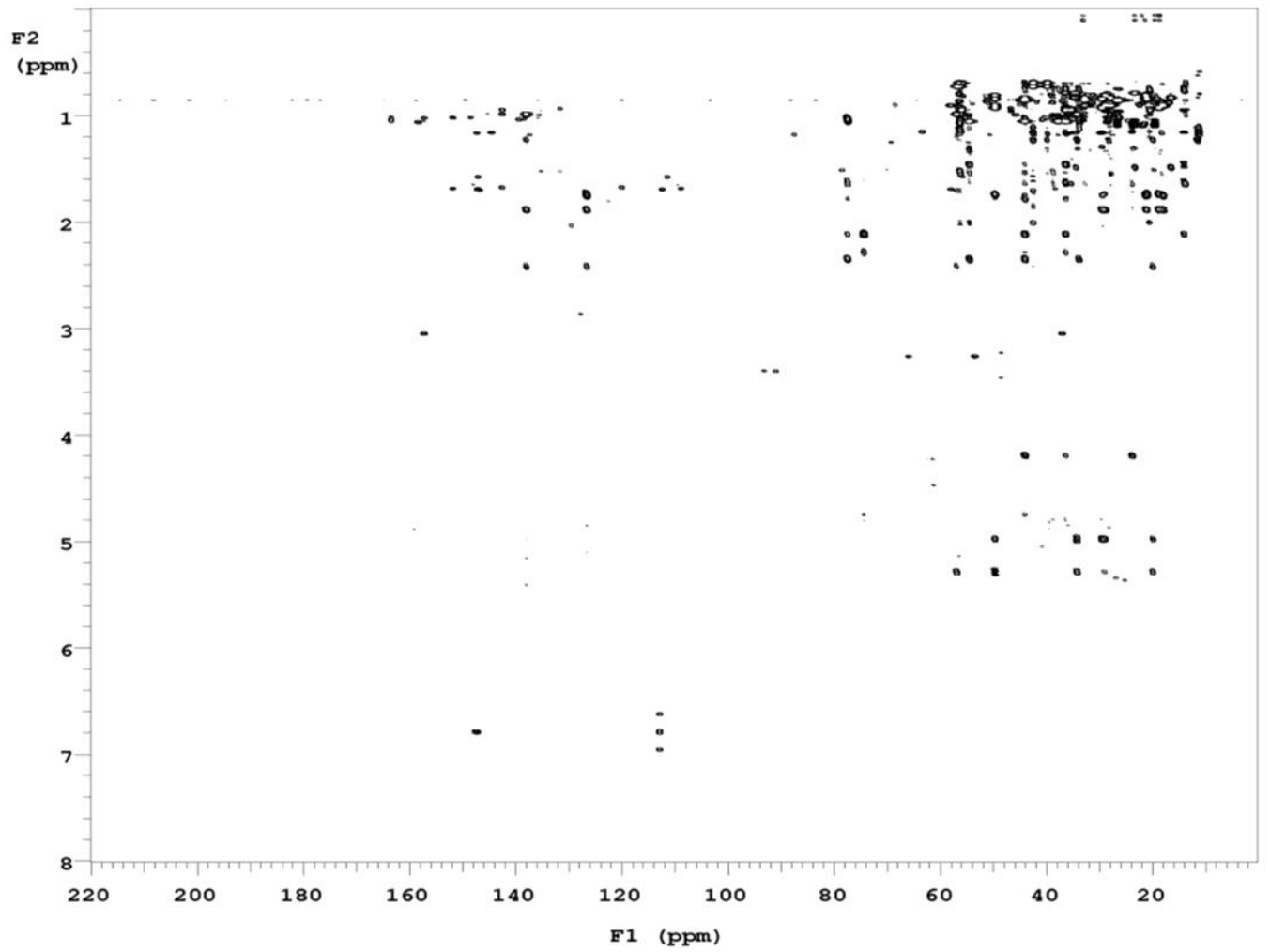

Figure 2.16. $\mathrm{HMBC}\left(\mathrm{CD}_{3} \mathrm{OD}, 600 \mathrm{MHz}\right)$ screen spectrum of the $75 \% \mathrm{Me}_{2} \mathrm{CO} / \mathrm{H}_{2} \mathrm{O}$ fraction of PTN4_05C.

\section{PTN4_13A}

PTN4_13A (Figure 2.17) is a white, unidentified sponge with an irregular smooth surface. Upon exposure to air the exterior of the sponge began to oxidise to a purple colour. Compared to other Tongan sponge specimens, PTN4_13A provided samples of considerably low mass and solubility issues were encountered. The screen NMR spectra revealed uninteresting resonances (Figures 2.18 and 2.19) and as such no further analysis was performed.

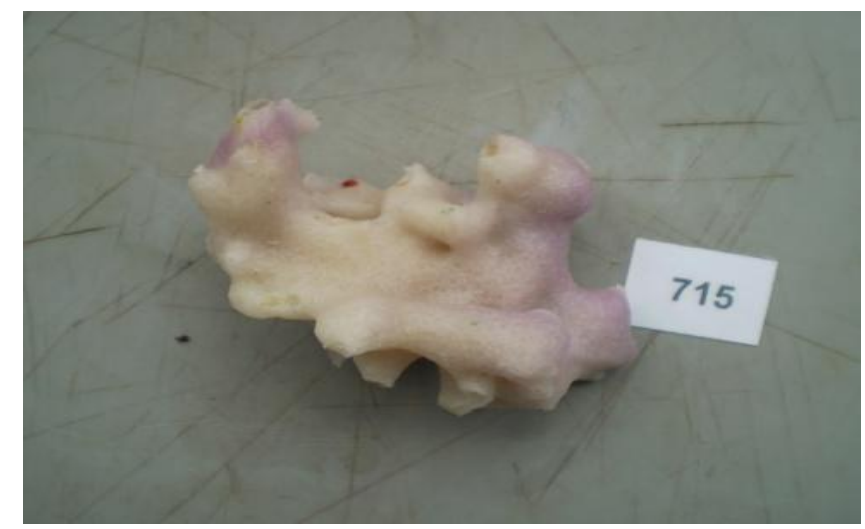

Figure 2.17. Surface photo of PTN3_13A 


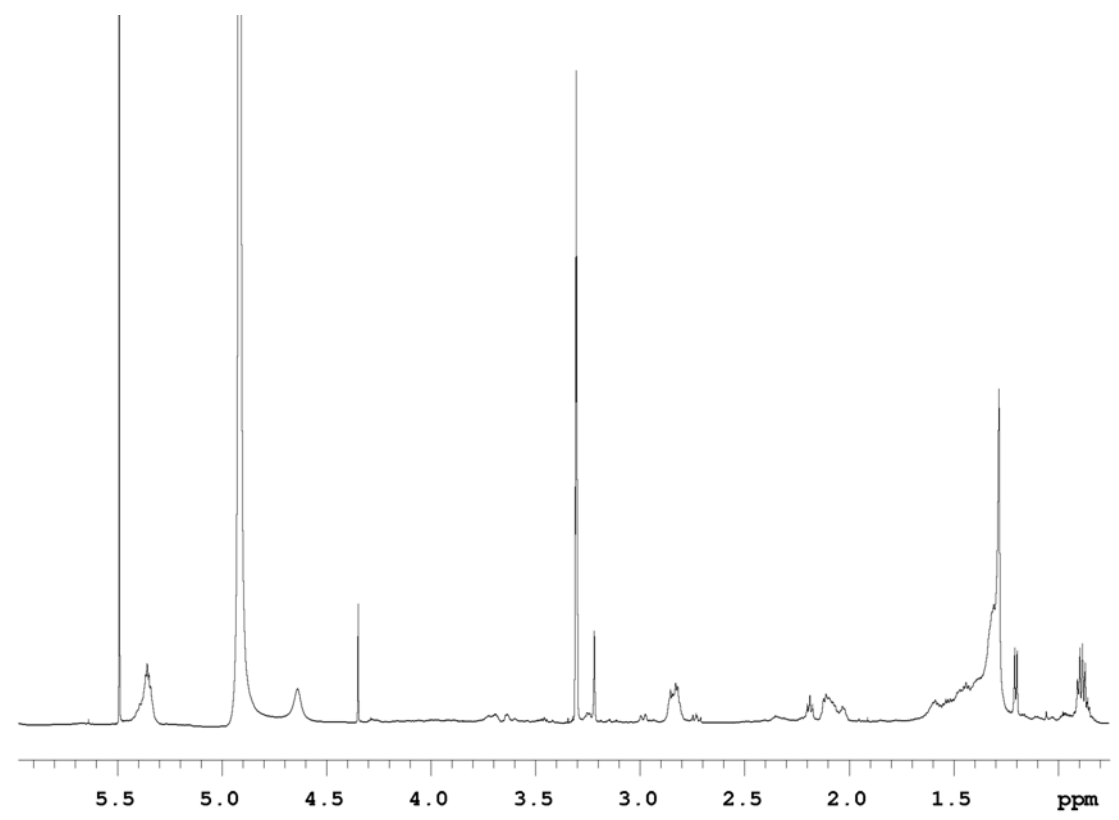

Figure 2.18. ${ }^{1} \mathrm{H}$ NMR $\left(\mathrm{CD}_{3} \mathrm{OD}, 600 \mathrm{MHz}\right)$ screen spectrum of the $75 \% \mathrm{Me}_{2} \mathrm{CO} / \mathrm{H}_{2} \mathrm{O}$ fraction of PTN4_13A

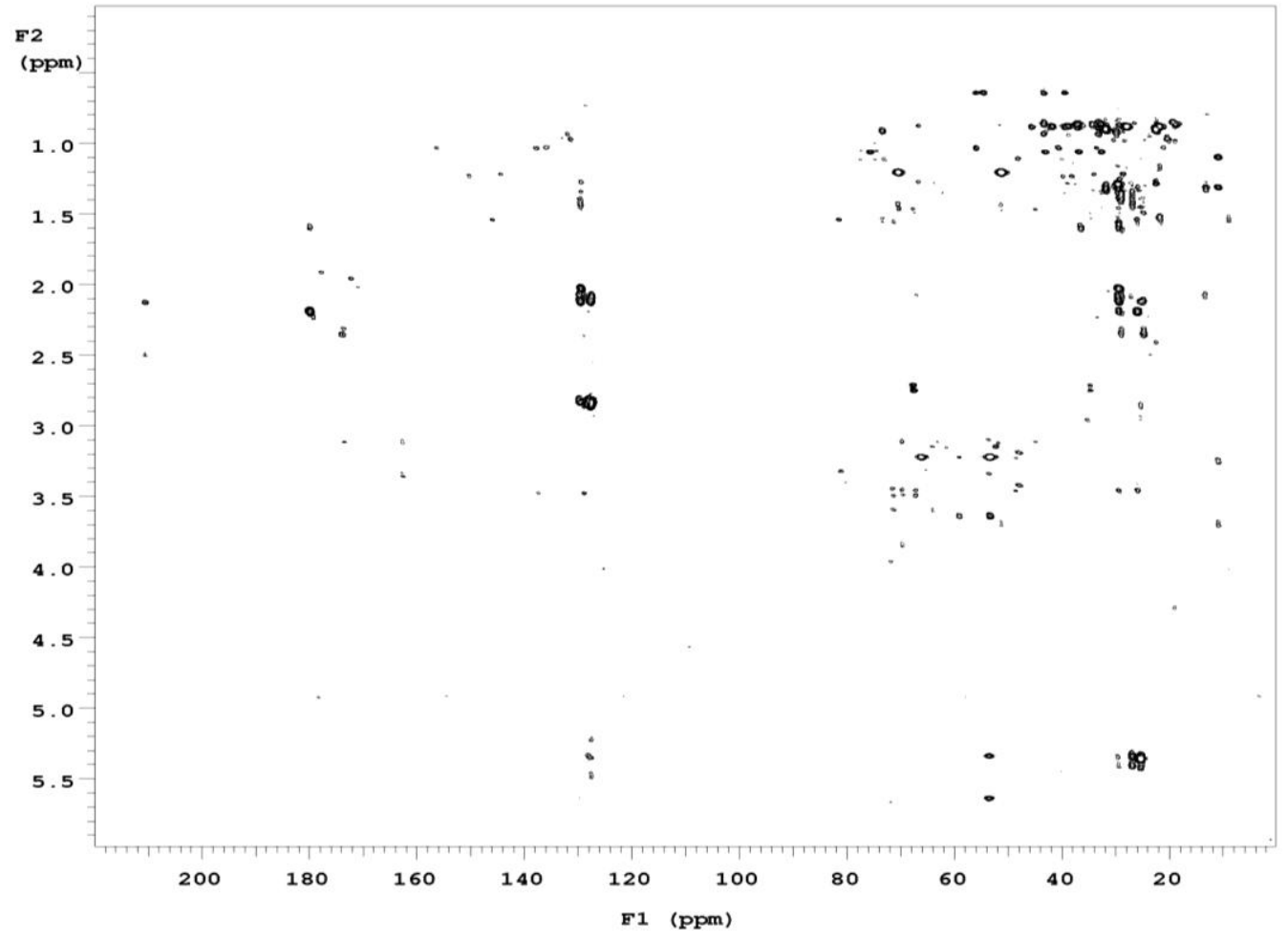

.Figure 2.19. $\mathrm{HMBC}\left(\mathrm{CD}_{3} \mathrm{OD}, 600 \mathrm{MHz}\right)$ screen spectrum of the $75 \% \mathrm{Me}_{2} \mathrm{CO} / \mathrm{H}_{2} \mathrm{O}$ fraction of PTN4_13A. 
PTN4_14B (Figure 2.20) is a hard, porous unidentified sponge with a honey-comb shape. The exterior is lilac in colour and highly reticulated. Underwater, the sponge appeared whitish blue. A small specimen (22 g) of the sponge was screened and the $75 \% \mathrm{Me}_{2} \mathrm{CO} / \mathrm{H}_{2} \mathrm{O}$ fraction was selected for further investigation due to the $\mathrm{HMBC}$ screen spectrum revealing a variety of proton resonances correlating to carbonyl and olefinic carbons (Figure 2.22). Figure 2.21 displays the ${ }^{1} \mathrm{H}$ NMR screen spectrum.

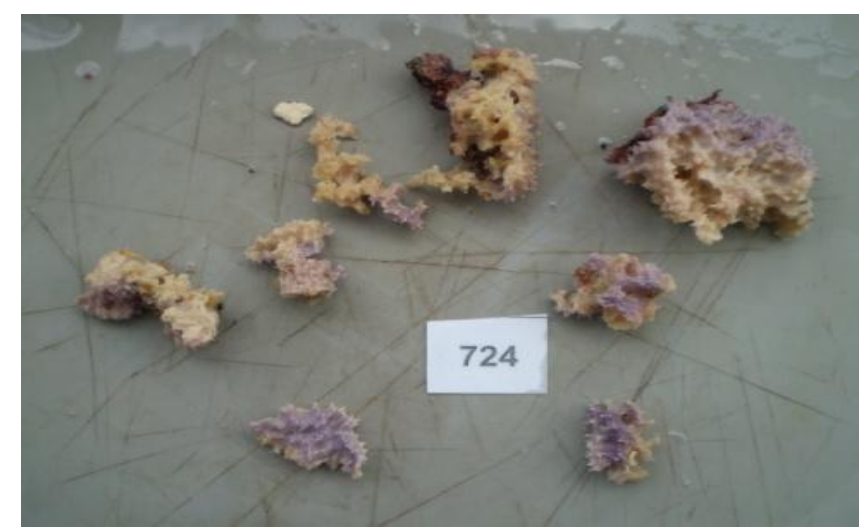

Figure 2.20. Surface photo of PTN4_14B

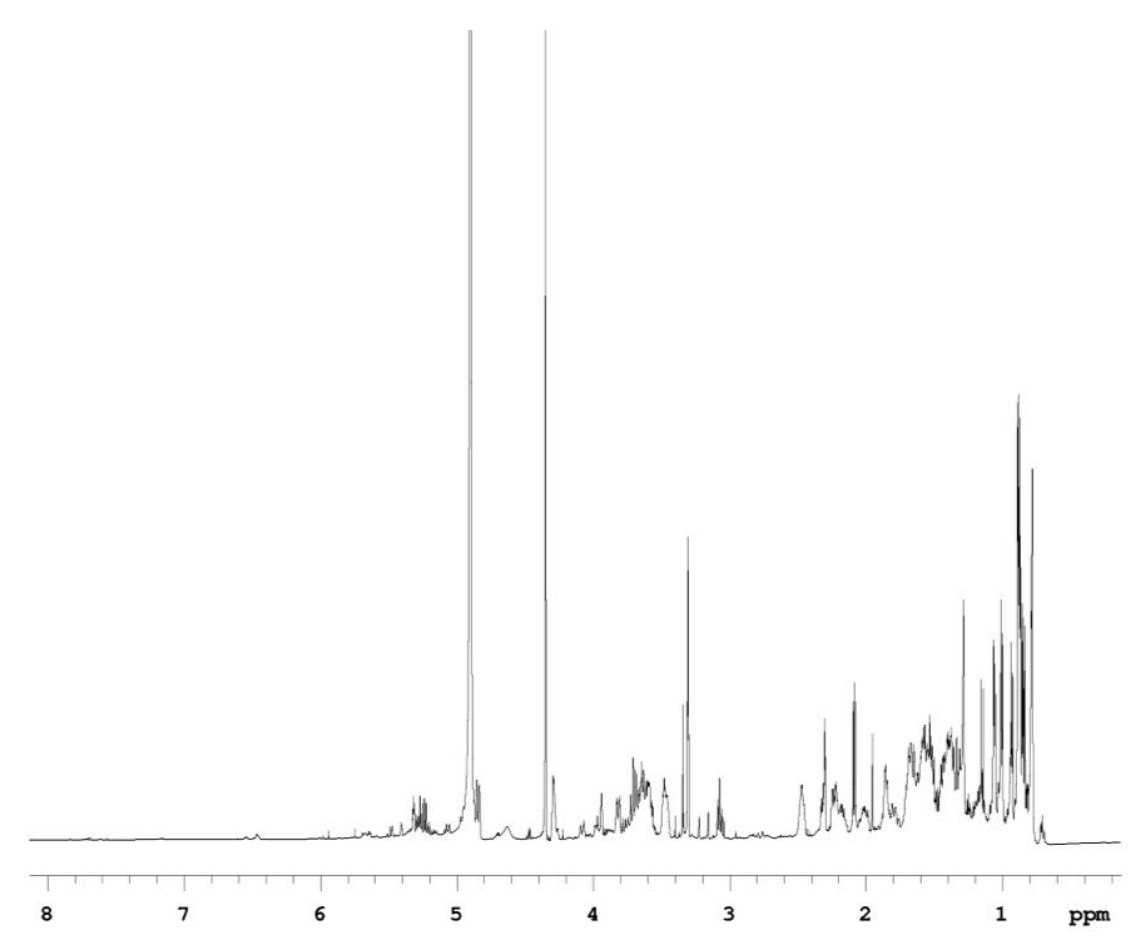

Figure 2.21. ${ }^{1} \mathrm{H} \mathrm{NMR}\left(\mathrm{CD}_{3} \mathrm{OD}, 600 \mathrm{MHz}\right)$ screen spectrum of the $75 \% \mathrm{Me}_{2} \mathrm{CO} / \mathrm{H}_{2} \mathrm{O}$ fraction of PTN4_14B. 


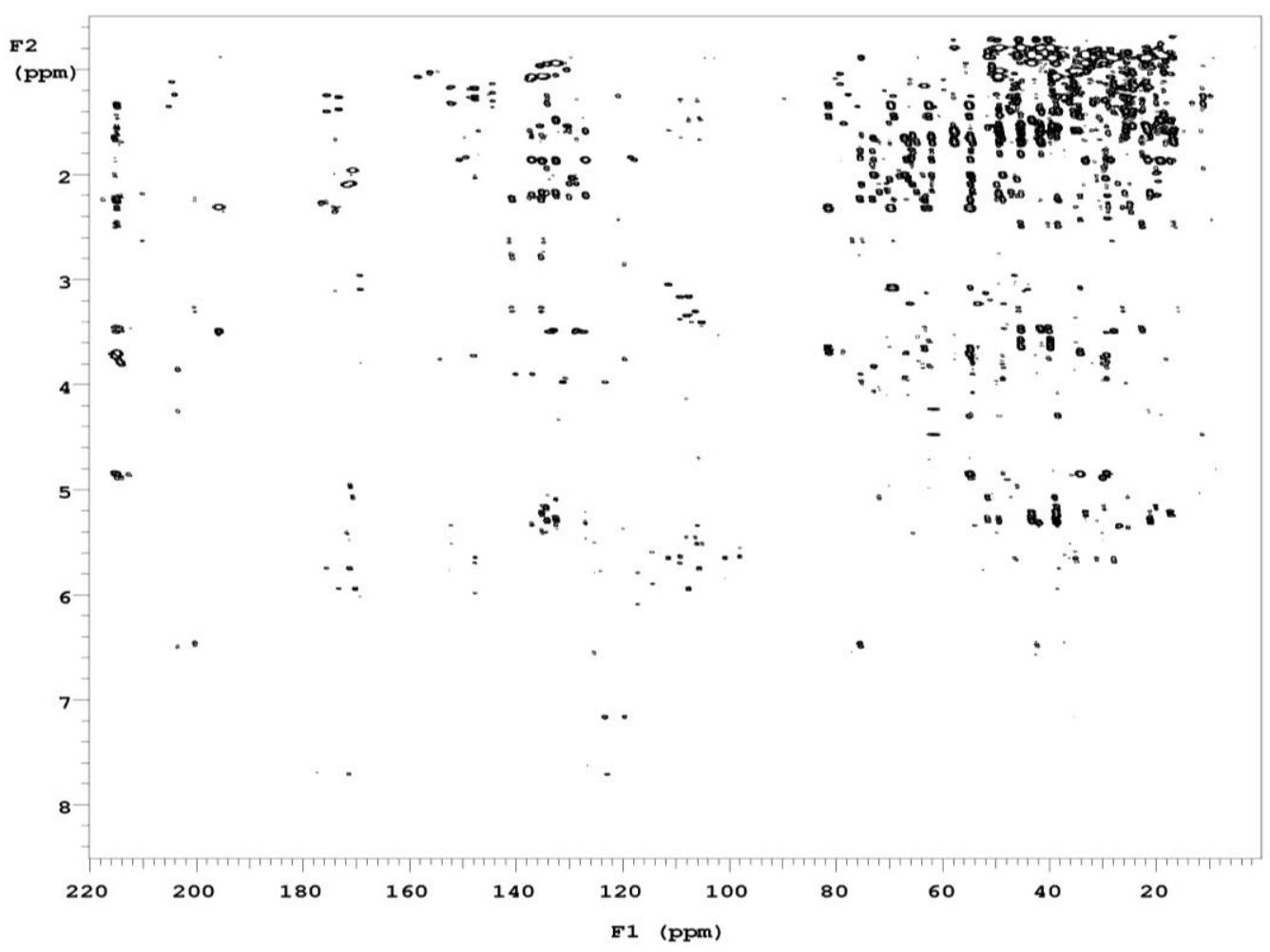

Figure 2.22. $\mathrm{HMBC}\left(\mathrm{CD}_{3} \mathrm{OD}, 600 \mathrm{MHz}\right)$ screen spectrum of the $75 \% \mathrm{Me}_{2} \mathrm{CO} / \mathrm{H}_{2} \mathrm{O}$ fraction of PTN4_14B.

Continued purification methods using HP2Oss, DIOL, and reversed-phase HPLC $\mathrm{C}_{18}$ (Scheme 2.1) resulted in the isolation of three known hexahydroxylated 9,11-secosteroids: euryspongiols A1, A2, and B (51-53, respectively). The ${ }^{1} \mathrm{H}$ NMR and HSQC spectra of the sample containing euryspongiol A1 (51) revealed the presence of another closely related compound comprising approximately one third of the sample. The structure of the minor component of the sample could not be elucidated as the signals were either too weak or absent in the HMBC spectrum. Euryspongiol A2 (52) was present together with euryspongiol B (53), with 52 being the major component of the sample by approximately $70 \%$. The stereochemistry of the chiral centres present in the side chain of compounds 51-53 is undetermined due to the compounds existing as mixtures.

Compounds 51-53 were originally isolated from a New Caledonian sponge Euryspongia sp., along with seven other euryspongiol congeners (54-60). ${ }^{69}$ The large number of euryspongiols reported in the literature meant that the isolation of new euryspongiol derivatives would be unlikely. In addition, no other fractions generated during the purification of 51-53 were of any interest. As a result, further studies on this sponge were discontinued. 


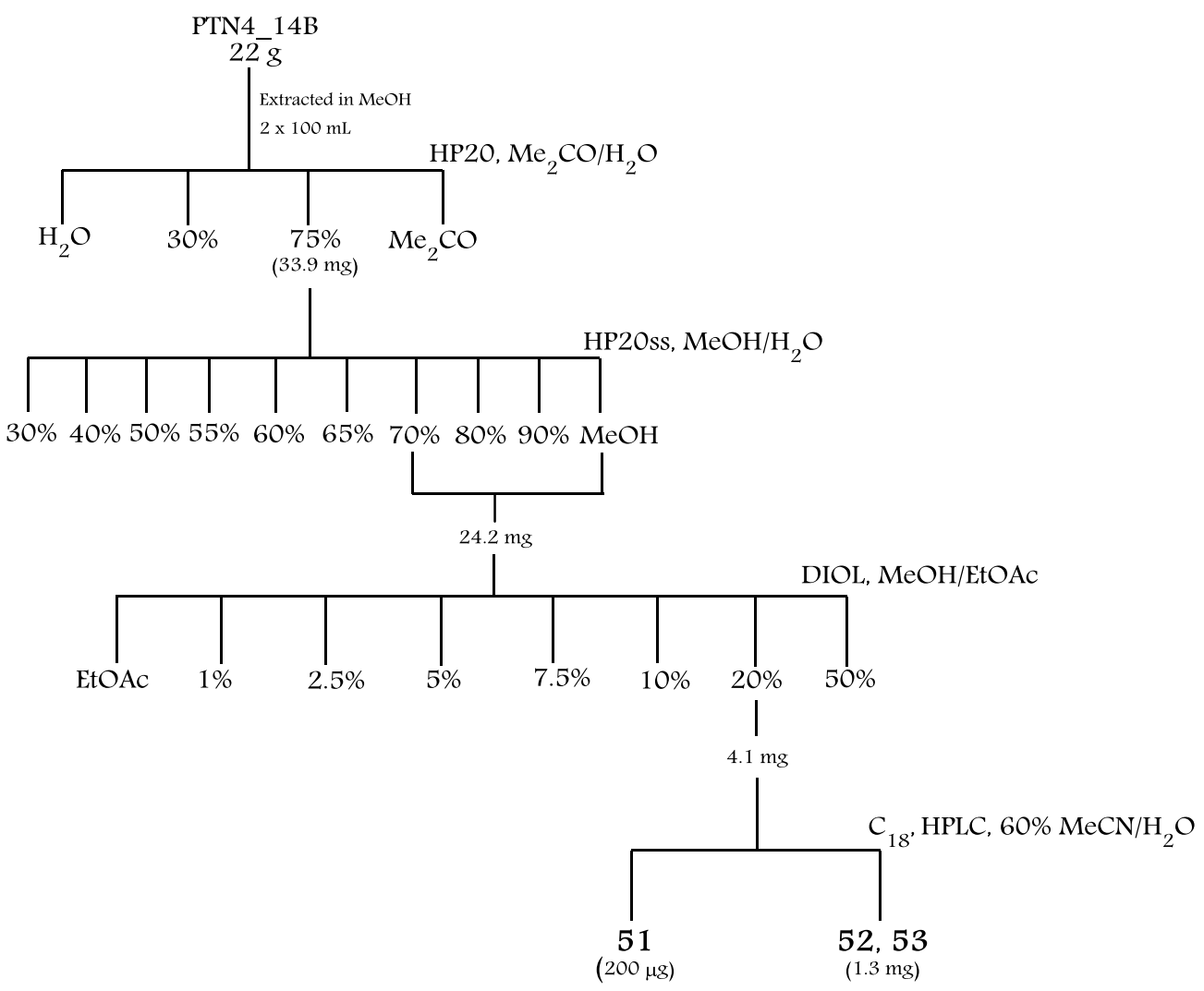

Scheme 2.1. Isolation procedure for compounds 51-53 from PTN4_14B.

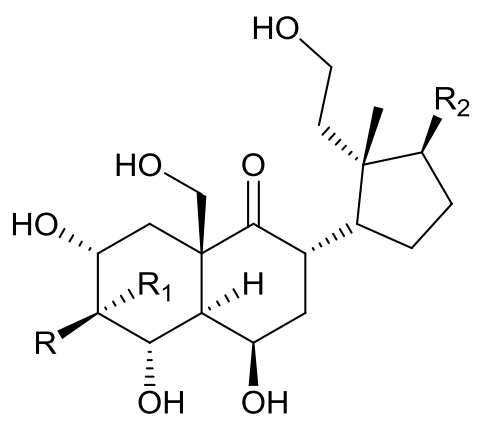

51<smiles>[R]OO</smiles>

52 $\mathrm{R}=\mathrm{OH} \quad \mathrm{R}_{1}=\mathrm{H} \quad \mathrm{R}_{2}=$ unm<smiles>CC(C)CCCC(C)C</smiles>

$53 \mathrm{R}=\mathrm{H}$<smiles>CC1CC2CC1C2C#[R1]O</smiles><smiles>C=CC(C)C(C)C</smiles>

$54 \mathrm{R}=\mathrm{OH} \quad \mathrm{R}_{1}=\mathrm{H} \quad \mathrm{R}_{2}=$

$55 \mathrm{R}=\mathrm{OH} \quad \mathrm{R}_{1}=\mathrm{H} \quad \mathrm{R}_{2}=$ mons
$56 \mathrm{R}=\mathrm{OH} \quad \mathrm{R}_{1}=\mathrm{H} \quad \mathrm{R}_{2}=$ antur.

$57 \mathrm{R}=\mathrm{H}$
$58 \mathrm{R}=\mathrm{H}$

$\mathrm{R}_{1}=\mathrm{OH}$<smiles>CC(C)CCC[C@@H](C)[C@H](C)C=[W]</smiles>

$59 \quad \mathrm{R}=\mathrm{H} \quad \mathrm{R}_{1}=\mathrm{OH} \quad \mathrm{R}_{2}=$<smiles>CC(C)/C=C/C(S)C(C)C</smiles> 


\section{PTN4-10B and PTN4_08E}

PTN4_10B and PTN4_08E (identical sponge) (Figure 3.1) was firm but springy with a dark brown exterior, a green-brown interior and an odour slightly reminiscent of garlic. The screen of the $100 \% \mathrm{Me}_{2} \mathrm{CO}$ fraction showed interesting signals in the aromatic region of the spectrum and was selected for further investigation accordingly. The study of this sponge and isolated compounds will be discussed in Chapter 3.

NMR spectroscopy has been used effectively to identify sponge extracts with interesting chemical characteristics and those with less interesting chemical profiles, early in the investigation. Despite this, it is important to note that the use of the HMBC mask as a screening tool in the future, will greatly increase the ease and efficiency by which extracts can be evaluated in order to determine sponges containing interesting secondary metabolites. PTN4_05C and PTN4_08B were initially considered as different sponges due to the fouling algae accumulated on the surface of PTN4_05C. Through NMR screening, these two sponges were discovered to be identical very early on in the study. This may not have been recognised as early in the investigation if a bioassay guided screening protocol had been utilised. Two sponges were selected for further analysis due to interesting resonances in the NMR screen spectra, which resulted in the isolation of a mixture of known and new compounds. 


\section{Chapter 3}

\section{New Fascaplysin Congeners from a Sponge of the Order Dictyoceratida}

During the course of our groups screening of Tongan sponges, a dark brown sponge, PTN4_10B (Figure 3.1) was discovered to contain interesting aromatic resonances in the $75 \% \mathrm{Me}_{2} \mathrm{CO} / \mathrm{H}_{2} \mathrm{O}$ HP2O fraction. Further investigation of the sponge was postponed while other samples were investigated by members of the Marine Chemistry group. Interest in the aromatic resonances instigated a re-examination of the sponge, which ultimately led to the isolation of two known compounds and four new fascaplysin derivatives.

The digestion of a small sponge specimen, in concentrated $\mathrm{HNO}_{3}$ and in $\mathrm{NaOCl}$ established the sponge to be devoid of silicaceous and calcitic spicules. A search through the literature for related compounds to those isolated from PTN4_10B, revealed that the host sponges belonged to the family Thorectidae, order Dictyoceratida. Taking these into account, in addition to the texture of the sponge, PTN4_1OB has tentatively been assigned to the order Dictyoceratida and may possibly belong to the family, Thorectidae.

\subsection{Order Dictyoceratida}

The order Dictyoceratida encompasses four families of sponges, Thorectidae, Dysideidae, Spongiidae, and Irciniidae and 36 described genera, although several more are yet to be described and classed into this order. The lack of mineral (silicaeous) spicules within Dictyoceratid sponges often complicates the task of taxonomic identification. General characteristics of Dictyoceratid sponges include a tough and compressible texture which is usually conulose (the surface is manifested with conules or elevated cones). The level of flexibility of the sponge can vary depending on the density of the fibre skeleton, or whether debris is incorporated within the sponge matrix. Marked differences between the exterior and 
interior pigmentation are often observed, with the outer surface usually being very dark in colour and the inner much lighter by comparison. A diverse range of terpenoids have been found from sponges of this order and to account for them all is beyond the scope of this report. ${ }^{30}$

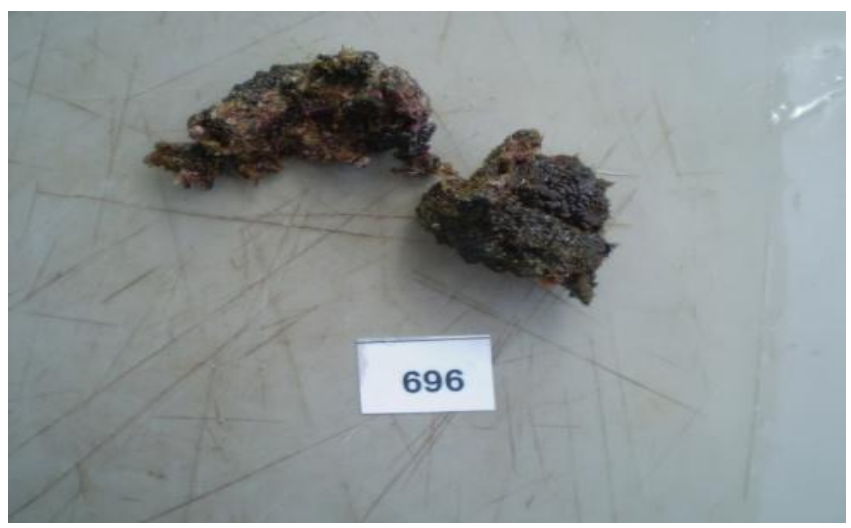

Figure 3.1. Surface photo of PTN4_10B

\subsection{The Isolation of Known and New Compounds}

PTN4_1OB (Figure 3.1) was collected by SCUBA from Fakafotula (a small island near the Port of Refuge), Vava'u, Tonga. A total of $92 \mathrm{~g}$ was extracted in $\mathrm{MeOH}$ twice overnight, and the extracts were subsequently cyclic loaded onto pre-equilibrated reversed-phase PSDVB sorbent. Upon completion of cyclic loading, the beads were consecutively batch eluted with $30 \% \mathrm{Me}_{2} \mathrm{CO} / \mathrm{H}_{2} \mathrm{O}$, $75 \% \mathrm{Me}_{2} \mathrm{CO} / \mathrm{H}_{2} \mathrm{O}$, and $100 \% \mathrm{Me}_{2} \mathrm{CO}$. Although the $75 \%$ fraction is generally the fraction of interest in regards to secondary metabolites (Figure 1.2), the ${ }^{1} \mathrm{H}$ NMR screen spectrum of the $100 \%$ fraction revealed interesting aromatic resonances between $\delta_{\mathrm{H}} 7.50-8.75$ (Figure 3.2). For this reason, the $100 \% \mathrm{Me}_{2} \mathrm{CO}$ fraction was chosen for further investigations, in pursuit of the compound responsible for the aromatic resonances.

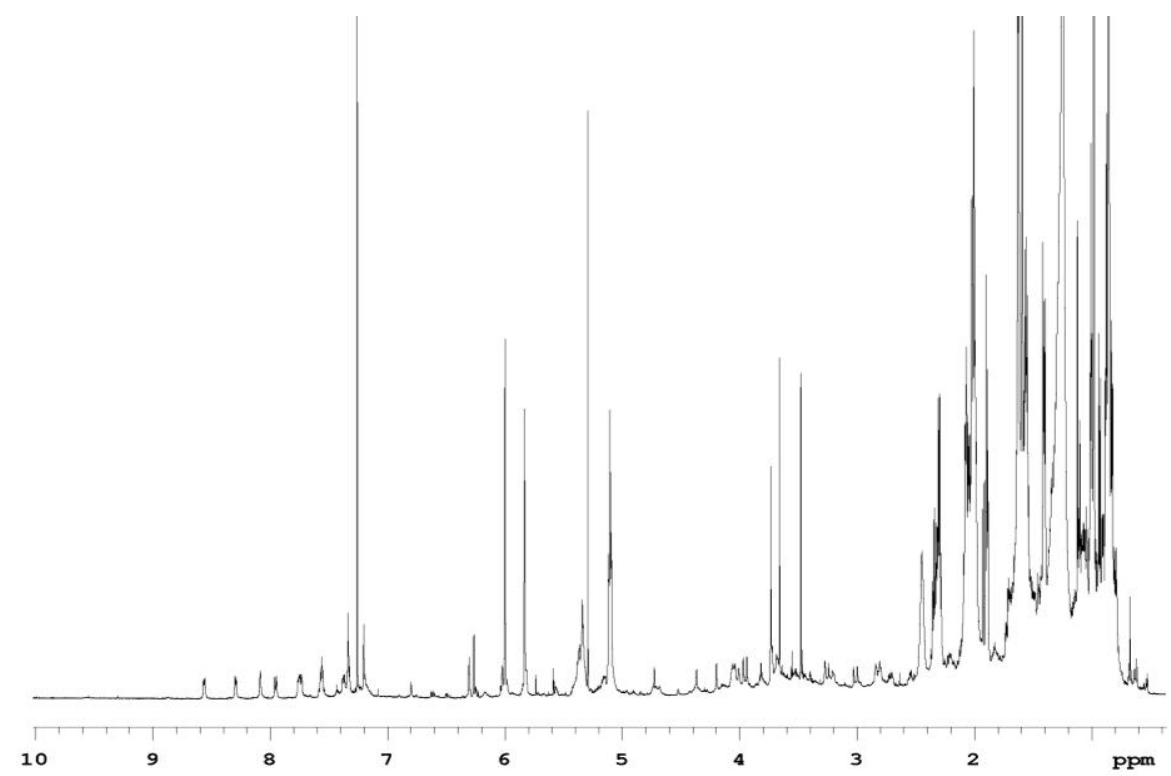

Figure 3.2. ${ }^{1} \mathrm{H} \mathrm{NMR}\left(\mathrm{CD}_{3} \mathrm{OD}, 600 \mathrm{MHz}\right)$ screen spectrum of the $100 \% \mathrm{Me}_{2} \mathrm{CO}$ fraction from the sponge PTN4_10B. 
DIOL flash column chromatography was employed as the next step for purification which afforded the known compounds ambliol B (61) from 20\% DCM/pet. ether and luffariellolide (55) from the 5\% EtOAc/DCM fraction (Scheme 3.1). Faulkner and Walker first reported the isolation of the diterpenoid ambliol B (61) from Dyisdea amblia in $1980 .{ }^{70}$ Luffariellolide (62), is a sesterterpene initially isolated from the Palauan sponge Luffariella sp. in $1987 .{ }^{71}$ Shortly thereafter, 62 was independently isolated by a separate research group from a Fijian sponge Fascaplysinopsis sp. ${ }^{72}$ Both Dysidea and Luffariella belong to the order Dictyoceratida. ${ }^{30}$

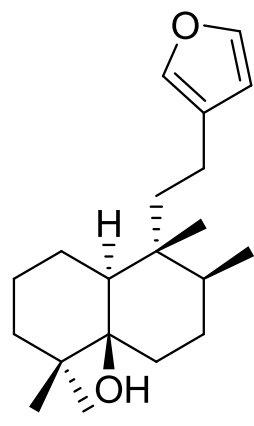

61

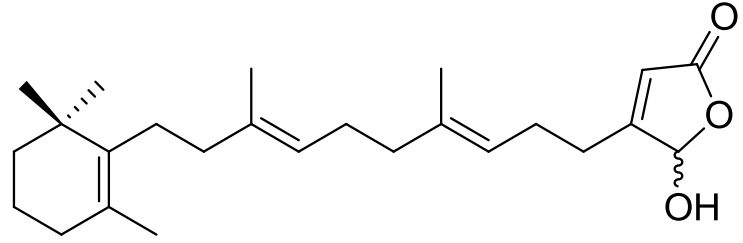

62

\section{New Compounds}

In addition to the isolation of the known compounds 61 and 62, four new fascaplysin derivatives were isolated. A fraction eluting from the DIOL column in $10 \% \mathrm{H}_{2} \mathrm{O} / \mathrm{MeOH}$ was determined by NMR spectroscopy to contain 7 -bromoreticulatine (63). The ${ }^{1} \mathrm{H}$ NMR spectrum of the $50 \% \mathrm{MeOH} / \mathrm{DCM}$ DIOL fraction showed more of the aromatic resonances that were of interest and was therefore purified further. The fraction was re-chromatographed on DIOL (flash) and the fractions analysed by NMR spectroscopy, which showed that the aromatic resonances were confined to the $20 \% \mathrm{DCM} / \mathrm{MeOH}$ fraction. Attempts to purify the sample on reversed-phase $\mathrm{C}_{18}$ HPLC using $\mathrm{MeCN}$ and $\mathrm{H}_{2} \mathrm{O}$ was unsuccessful due to streaking and altering the conditions to a lower ratio of $\mathrm{MeCN} / \mathrm{H}_{2} \mathrm{O}$ or to a $0.01 \%$ acidified solution (formic acid) proved ineffective. Consequently, the sample was chromatographed on normal-phase HPLC (DIOL, IPA/ $n$-hexane) to give three fractions. The first two fractions contained the pure compounds 10-bromo-6,7-dimethoxyhomofascaplysin C (64) and D (65), while the last contained, an impure sample of a related compound. Purification of this sample using reversedphase $\mathrm{C}_{18}$ HPLC was re-attempted using more acidic conditions $\left(30 \% \mathrm{MeCN} / 0.5 \mathrm{M} \mathrm{HCOOH}_{(\mathrm{aq})}\right)$ yielded 10-bromohomofascaplysin A (66). The isolation procedure is outlined in Scheme 3.1. 


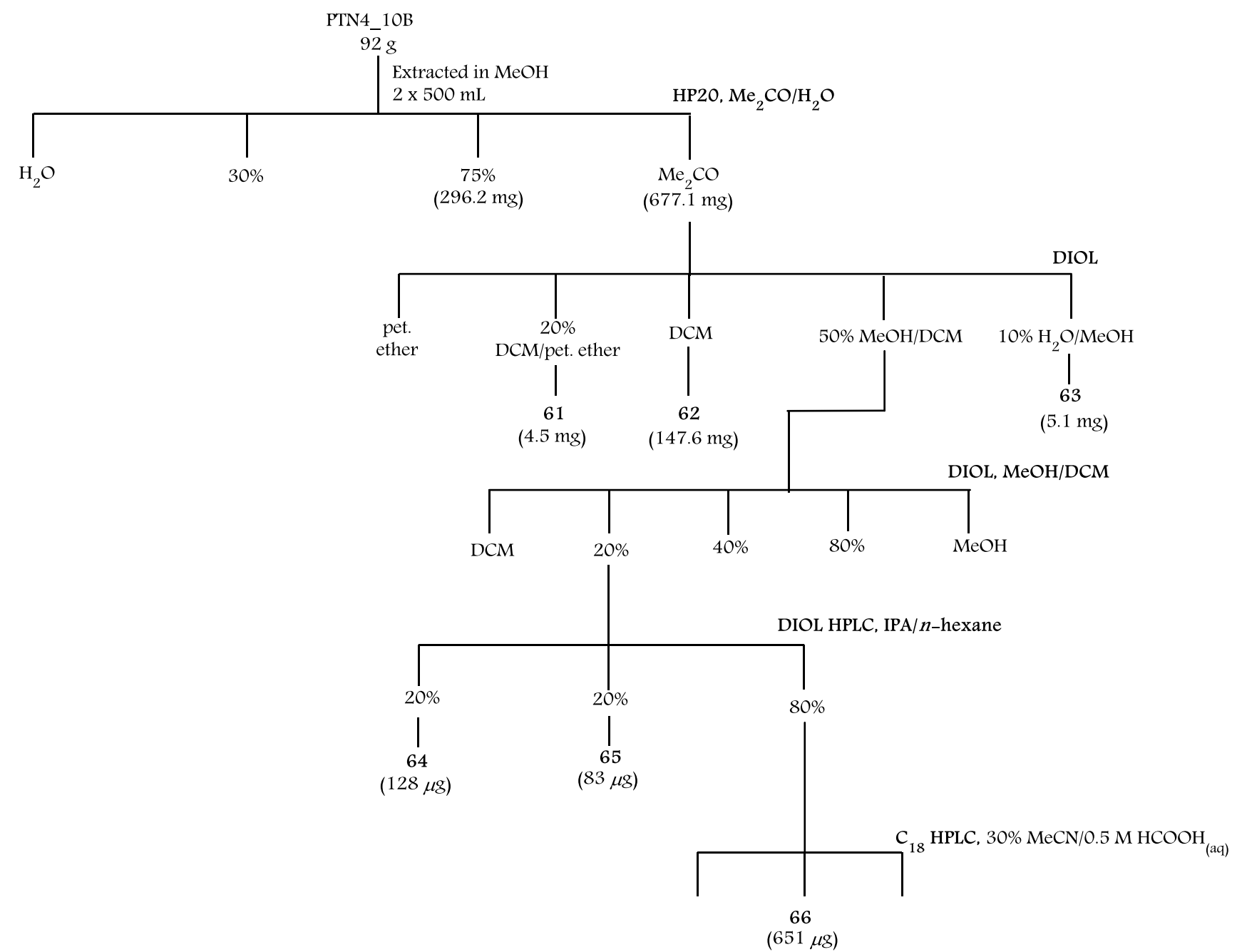

Scheme 3.1. Isolation procedure for compounds 61-66 from PTN4_10B 


\subsubsection{0-Bromohomofascaplysin A}

10-Bromohomofascaplysin A (66) was isolated as a yellow solid. The compound was isolated in conjunction with a persistent long chain alkyl moiety, identified via resonances in the ${ }^{1} \mathrm{H}$ and ${ }^{13} \mathrm{C}$ NMR spectra $\left(\delta_{\mathrm{H}} 0.84-0.87,1.25 ; \delta_{\mathrm{C}} 29.7\right.$ and 14.1$)$ and another minor impurity which displayed resonances between $\delta_{\mathrm{H}}$ 1.0-3.5. Despite many attempts, using a variety of different chromatographic methods, these impurities remained inseparable. Not surprisingly, an examination of literature supplemental data demonstrates this to be a commonly encountered feature observed among the fascaplysins. ${ }^{73}$

Positive ion mode HRESIMS revealed characteristic ion clusters $\left([M]^{+}:[M+2]^{+} ; 1: 1\right)$ indicative of the presence of bromine and consistent with a molecular formula $\mathrm{C}_{21} \mathrm{H}_{16} \mathrm{~N}_{2} \mathrm{O}_{2} \mathrm{Br}^{+}\left(\mathrm{m} / z\right.$ 407.0395, $\left.[\mathrm{M}]^{+}, \Delta 0.0 \mathrm{ppm}\right)$. With an apparent double bond equivalent of 14.5 and the observation of an $[\mathrm{M}]^{+}$in electrospray ionisation mode, the compound was determined to be a natively charged species. The ${ }^{1} \mathrm{H}$ NMR spectrum indicated only 15 of the 16 protons (one of which was observed as a broad singlet at $\delta_{\mathrm{H}} 13.73$ attributed to a $\mathrm{NH}$ proton). Lack of observation of the last proton in the ${ }^{1} \mathrm{H}$ NMR spectrum could be accounted for as another exchangeable; the presence of two exchangeable protons within the molecule is substantiated by the absence of two protonated signals from the HSQC. Inspection of the

${ }^{13} \mathrm{C}$ NMR spectrum showed 20 distinct carbon resonances accredited to the compound, while the final carbon unaccounted for was determined from observed three-bond correlations in the HMBC spectrum.

Analysis of the multiplicity-edited HSQC spectrum provided information on the direct connectivity of 14 protons to their corresponding carbons, giving nine aromatic methines, one highly deshielded diastereotopic methylene pair, and one methyl singlet. The remaining ten non-protonated carbon resonances were attributed to a ketone carbon $\left(\delta_{\mathrm{C}} 204.5\right)$, eight substituted aromatic carbons $\left(\delta_{\mathrm{C}} 145.7,143.7,140.4,136.6,134.0,130.8,127.5,118.3\right)$ and one quaternary oxygenated carbon $\left(\delta_{\mathrm{C}} 78.0\right)$.

Examination of the COSY and HMBC data, in addition to the multiplicities of the aromatic protons established the connectivity from $\mathrm{C}-1 \mathrm{a}$ through to $\mathrm{C}-4 \mathrm{a}$. COSY correlations were observed between the aromatic methine protons, $\mathrm{CH}-1\left(\delta_{\mathrm{H}} 7.65, \delta_{\mathrm{C}} 124.7\right)$ and $\mathrm{CH}-2$ $\left(\delta_{\mathrm{H}} 7.52, \delta_{\mathrm{C}} 130.6\right), \mathrm{CH}-3\left(\delta_{\mathrm{H}} 7.56, \delta_{\mathrm{C}} 130.7\right)$ and $\mathrm{CH}-4\left(\delta_{\mathrm{H}} 7.62, \delta_{\mathrm{C}} 113.2\right)$ and between CH-2 and CH-3. Prevalent correlations observed within aromatic systems in an HMBC spectrum are three-bond couplings, and when two- and four-bond couplings are present their crosspeak intensities are typically weak by comparison. ${ }^{74}$ With this in mind, HMBC data 
confirmed the connectivity ascertained using the COSY experiment and established the positions of the non-protonated aromatic carbons, to give a 1,2-disubstituted aromatic ring. Correlations in the HMBC spectrum were observed from $\mathrm{H}-4$ to $\mathrm{C}-2$ and to the nonprotonated carbon C 1a $\left(\delta_{\mathrm{C}} 136.6\right)$. H-1 correlated to both $\mathrm{C}-3$ and the non-protonated aromatic carbon, $\mathrm{C} 4 \mathrm{a}\left(\delta_{\mathrm{C}} 140.4\right)$. One additional weak $\mathrm{HMBC}$ correlation was observed from $\mathrm{H}-1$ to the quaternary carbon $\mathrm{C}-13\left(\delta_{\mathrm{C}} 78.0\right)$, deduced to be the substituent at C-1a. Threebond correlations were also evident from $\mathrm{H}-2$ to $\mathrm{C}-4$ and $\mathrm{C}-1 \mathrm{a}$, and from $\mathrm{H}-3$ to $\mathrm{C}-1$ and C-4a. The HMBC and COSY correlations are outlined in Figure 3.3.

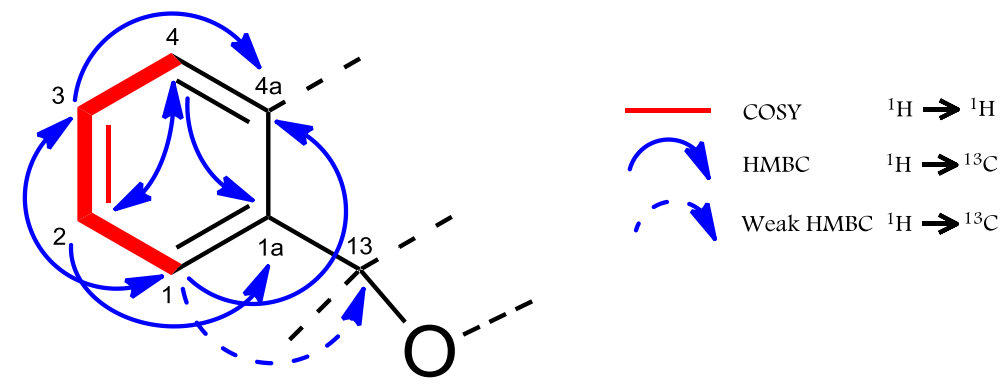

Figure 3.3. COSY and HMBC correlations establishing the connectivity between C-4a and C-13 in 10-bromohomofascaplysin A (66).

A long-range COSY correlation was observed between the methyl singlet, $\mathrm{CH}_{3}-16\left(\delta_{\mathrm{H}} 1.89\right.$, $\left.\delta_{\mathrm{C}} 30.1\right)$ and one of the two diastereotopic methylene doublet protons, $\mathrm{CH}_{2}-14\left(\delta_{\mathrm{Ha}} 3.92\right.$, $\left.\delta_{\mathrm{Hb}} 4.66, \delta_{\mathrm{C}} 51.3\right)$, indicating a close proximity between these protons. As expected, both protons on $\mathrm{CH}_{2}-14$ coupled to one another. $\mathrm{HMBC}$ correlations from $\mathrm{H}_{3^{-}}-16$ included strong correlations to $\mathrm{C}-14$ and to $\mathrm{C}-15\left(\delta_{\mathrm{C}} 204.5\right)$ and a weak correlation to $\mathrm{C}-13$, suggesting a connection between this substructure and that outlined in Figure 3.3. Confirmation of the link between the two substructures was provided by $\mathrm{HMBC}$ correlations observed from $\mathrm{H}_{2-} 14$ to $\mathrm{C}-13$, and $\mathrm{C}-1 \mathrm{a}$. Both of the protons of $\mathrm{CH}_{2}-14$ correlated to $\mathrm{C}-15$ and $\mathrm{C}-16$. One further correlation, from $\mathrm{H}_{2}-14$ to $\mathrm{C}-12 \mathrm{~b}\left(\delta_{\mathrm{C}} 143.7\right)$, indicated the placement of a non-protonated aromatic carbon adjacent to $\mathrm{C}-13$ (Figure 3.4).
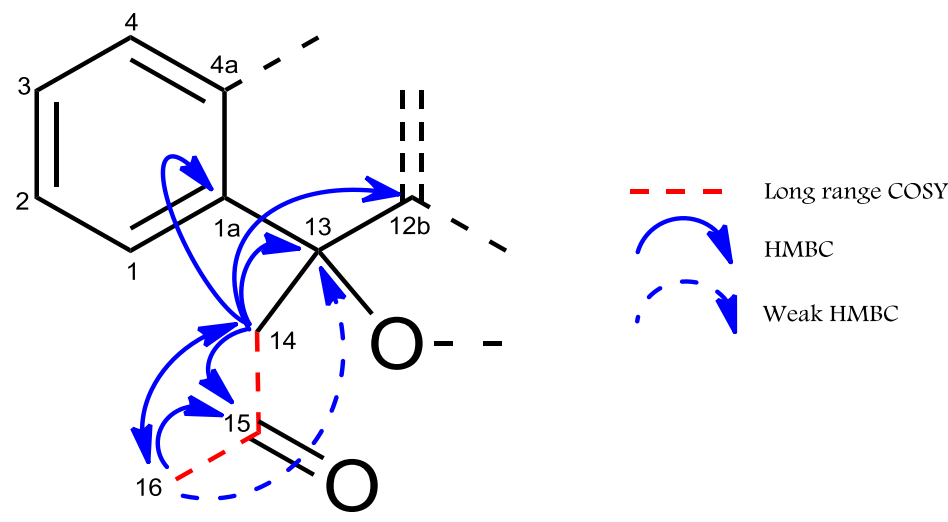

Figure 3.4. COSY and HMBC correlations establishing the connectivity between C-13 and C-16 in 10-bromohomofascaplysin A (66). 
The deshielded aromatic methine protons, $\mathrm{CH}-8\left(\delta_{\mathrm{H}} 7.81, \delta_{\mathrm{C}} 124.0\right)$ and $\mathrm{CH}-9\left(\delta_{\mathrm{H}} 7.17\right.$, $\delta_{\mathrm{C}} 125.9$ ), showed COSY correlations to each other. $\mathrm{CH}-9$ also displayed a long range COSY correlation to the relatively deshielded singlet aromatic proton, $\mathrm{CH}-11\left(\delta_{\mathrm{H}} 8.04, \delta_{\mathrm{C}} 116.5\right)$. These correlations suggested a 1,2,4-trisubstituted aromatic ring. Support for this arrangement was obtained through HMBC correlations. Both $\mathrm{H}-9$ and $\mathrm{H}-11$ displayed a correlation to the non-protonated aromatic carbon $\mathrm{C}-7 \mathrm{~b}$ and a reciprocal correlation to each other. A third weak correlation was observed from H-11 to the non-protonated aromatic carbon $\mathrm{C}-10\left(\delta_{\mathrm{C}} 127.5\right)$. The aromatic methine proton $\mathrm{H}-8$, only correlated to nonprotonated carbons; two strong HMBC correlations were observed to $\mathrm{C}-10$, and $\mathrm{C}-11 \mathrm{a}$ $\left(\delta_{\mathrm{C}} 145.7\right)$ and a weak correlation to $\mathrm{C}-7 \mathrm{a}\left(\delta_{\mathrm{C}} 134.0\right)$ was displayed. As this weak correlation did not correspond to a two-bond coupling, it was considered that the strong correlations were three-bond couplings within the aromatic ring, while the weak correlation was a three-bond coupling to the substituent on $C_{-} 7 \mathrm{~b}$. Although the positions of $C_{-}-10$ and $C_{-}-11 a$ within the aromatic ring were certainly meta- in relation to $\mathrm{CH}-8$, they remained ambiguous at this stage as they could have been on either side of the ring. They are placed correctly in Figure 3.5, however, it should be noted that this was not deduced until a later stage of the structure elucidation. Figure 3.5 illustrates the COSY and HMBC correlations.

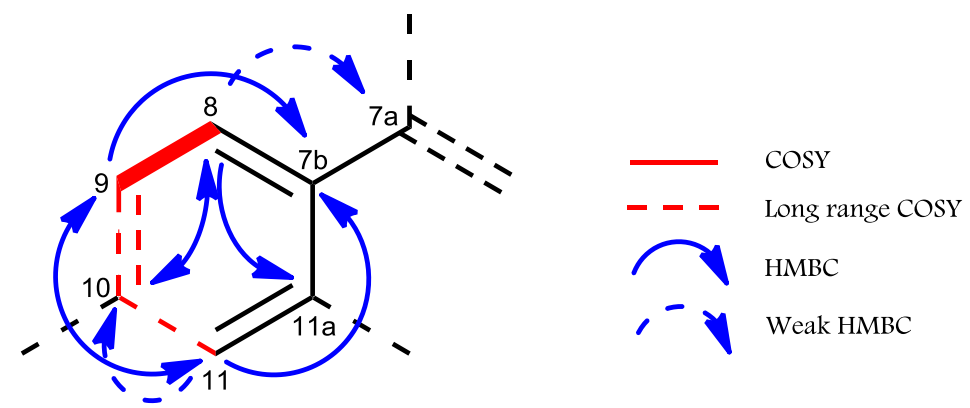

Figure 3.5. COSY and $\mathrm{HMBC}$ correlations establishing the connectivity between $\mathrm{C}-7 \mathrm{~b}$ and C-11a in 10-bromohomofascaplysin A (66).

A third aromatic ring was determined through analysis of the COSY and HMBC data. COSY data of $\mathrm{CH}-6\left(\delta_{\mathrm{H}} 8.49, \delta_{\mathrm{C}} 122.2\right)$ and $\mathrm{CH}-7\left(\delta_{\mathrm{H}} 8.29, \delta_{\mathrm{C}} 117.0\right)$ showed the two aromatic protons coupling to each other but not to any other protons. HMBC correlations were observed from H-6 to C-7 and from H-7 to C-6 and all other correlations from both protons were to non-protonated aromatic carbons, suggesting a 1,2,3,4-tetrasubstituted aromatic ring. Further $\mathrm{HMBC}$ correlations include $\mathrm{H}-7$ to $\mathrm{C}-7 \mathrm{~b}$ and $\mathrm{C}-12 \mathrm{a}\left(\delta_{\mathrm{C}} 130.8\right)$, while three correlations were observed from $\mathrm{H}-6$; one to $\mathrm{C}-4 \mathrm{a}$, another to $\mathrm{C}-7 \mathrm{a}\left(\delta_{\mathrm{C}} 134.0\right)$ and the last to $\mathrm{C}-12 \mathrm{~b}$. Specifically, these correlations to $\mathrm{C}-4 \mathrm{a}, \mathrm{C}-7 \mathrm{~b}$, and to $\mathrm{C}-12 \mathrm{~b}$ indicated an interconnection to both substructures illustrated in Figures 3.4 and 3.5 and further suggested 
the existence of a five membered ring system between this substructure, and the one outlined in Figure 3.4.

Of all the aromatic protons, H-6 and H-7 were the most highly deshielded and their ${ }^{3} J_{\mathrm{HH}}$ coupling constants were considerably lower by comparison at 5.8 and $6.2 \mathrm{~Hz}$, respectively. Furthermore, the ${ }^{1} J_{\mathrm{CH}}$ of $\mathrm{CH}-6$ (188 Hz) was significantly larger than all others. Based on this evidence, it was clear that these two aromatic protons were experiencing a disparate chemical environment to the other aromatic protons. With 14.5 double bond equivalents indicating the compound to be a positively charged species, a pyridinium cation substructure was proposed, with H-6 adjacent to the nitrogen in view of the fact that it appeared the most deshielded. As the HMBC data suggested a connection between this substructure and those illustrated in Figures 3.4 and 3.5, it was postulated that the three together must form a pentacyclic aromatic system, which could be validated if the substructure from Figure 3.5 contained an indole functionality. The proposed structure accounts for all double bond equivalents, carbons, nitrogens, oxygens and 15 of the 16 hydrogens. With only one hydrogen and the bromine left to assign, this implied that the oxygen connected to C-13 was a hydroxyl functionality and the bromine was substituted at $\mathrm{C}-10$. This highly aromatic pentacyclic ring system is not without precedence in marine natural products, belonging to the marine natural products class of compounds known as the fascaplysins. ${ }^{73 a, 75}$

Reassessment of the HMBC correlations from H-6, H-7 and H-8 in addition to NOESY data confirmed the validity of the proposed structure. Valuable information was obtained from the NOESY experiment, with the most significant observations including correlations between $\mathrm{H}-6$ and $\mathrm{H}_{-} 4, \mathrm{H}_{2}-14$ and $\mathrm{H}-1$, and $\mathrm{H}-7$ and $\mathrm{H}-8$ (Figure 3.6). $\mathrm{C}-10$ and $\mathrm{C}-11 \mathrm{a}$ were ultimately assigned to their positions based on the chemical shifts of related compounds reported in the literature. ${ }^{73,75}$ The structure of 10-bromohomofascaplysin A (66) is therefore provided in Figure 3.6 and is accompanied with NMR data in Tables $3.1\left(\mathrm{CDCl}_{3}\right)$ and 3.2 $\left(\mathrm{CD}_{3} \mathrm{OD}\right)$.
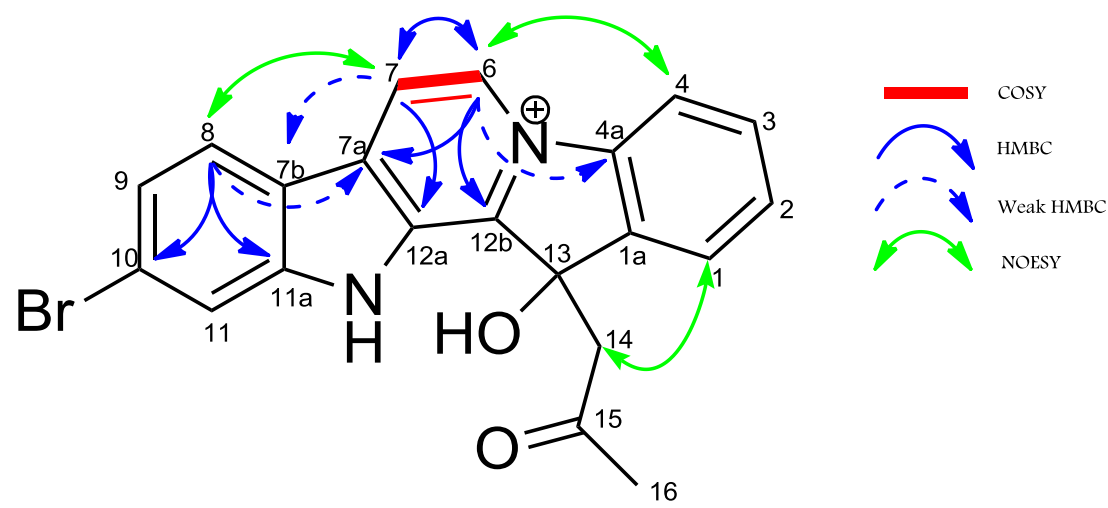

Figure 3.6. Key COSY, HMBC, and NOESY correlations between the substructures providing the structure of 10-bromohomofascaplysin A (66). 
Table 3.1. ${ }^{13} \mathrm{C}(150 \mathrm{MHz})$ and ${ }^{1} \mathrm{H}(600 \mathrm{MHz}) \mathrm{NMR}$ data $\left(\mathrm{CDCl}_{3}\right)$ for 10-Bromohomofascaplysin $\mathrm{A}(66)$.

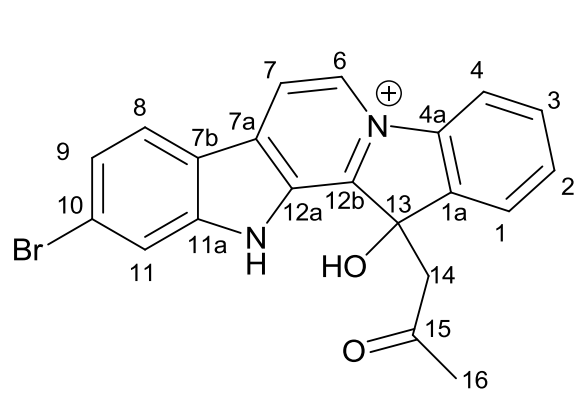

66

\begin{tabular}{|c|c|c|c|c|c|c|c|c|}
\hline \multirow[b]{2}{*}{ Pos } & \multicolumn{3}{|c|}{${ }^{13} \mathrm{C}$} & \multicolumn{3}{|c|}{${ }^{1} \mathrm{H}$} & \multirow[b]{2}{*}{$\cos Y$} & \multirow{2}{*}{$\begin{array}{c}\mathrm{HMBC} \\
\left({ }^{1} \mathrm{H} \text { to }{ }^{13} \mathrm{C}\right) \\
\end{array}$} \\
\hline & $\delta(\mathrm{ppm})$ & Mult & $J$ & $\delta(\mathrm{ppm})$ & mult & $J(\mathrm{~Hz})$ & & \\
\hline $1 \mathrm{a}$ & 136.6 & C & & & & & & \\
\hline 1 & 124.7 & $\mathrm{CH}$ & 168 & 7.65 & $d$ & 7.3 & 2 & $3,4 \mathrm{a}, 13$ \\
\hline 2 & 130.6 & $\mathrm{CH}$ & 169 & 7.52 & $t$ & 7.4 & 1,3 & $1 \mathrm{a}, 4$ \\
\hline 3 & 130.7 & $\mathrm{CH}$ & 169 & 7.56 & $t$ & 7.4 & 2,4 & $1,4 \mathrm{a}$ \\
\hline 4 & 113.2 & $\mathrm{CH}$ & 168 & 7.62 & d & 7.7 & 3 & 1a, 2 \\
\hline $4 \mathrm{a}$ & 140.4 & $\mathrm{C}$ & & & & & & \\
\hline 6 & 122.1 & $\mathrm{CH}$ & 188 & 8.49 & d & 5.8 & 7 & $4 a, 7,7 a, 12 b$ \\
\hline 7 & 117.0 & $\mathrm{CH}$ & 173 & 8.29 & $d$ & 6.2 & 6 & $6,7 \mathrm{~b}, 12 \mathrm{a}$ \\
\hline $7 \mathrm{a}$ & 134.0 & C & & & & & & \\
\hline $7 \mathrm{~b}$ & 118.3 & C & & & & & & \\
\hline 8 & 124.0 & $\mathrm{CH}$ & 166 & 7.81 & d & 8.7 & 9 & $7 \mathrm{a}, 10,11 \mathrm{a}$ \\
\hline 9 & 125.9 & $\mathrm{CH}$ & 171 & 7.17 & d & 8.5 & $8,11^{*}$ & $7 \mathrm{~b}, 11$ \\
\hline 10 & 127.5 & $\mathrm{C}$ & & & & & & \\
\hline 11 & 116.5 & $\mathrm{CH}$ & 176 & 8.04 & $\mathrm{~s}$ & & 9* & $7 b, 9,10$ \\
\hline $11 \mathrm{a}$ & 145.7 & C & & & & & & \\
\hline $12 \mathrm{a}$ & 130.8 & C & & & & & & \\
\hline $12 \mathrm{~b}$ & 143.7 & $\mathrm{C}$ & & & & & & \\
\hline 13 & 78.0 & C & & & & & & \\
\hline $14 \mathrm{a}$ & 51.3 & $\mathrm{CH}_{2}$ & 127 & 3.92 & d & 18.7 & $14 \mathrm{~b}, 16^{*}$ & $1 \mathrm{a}, 12 \mathrm{~b}, 13,15,16$ \\
\hline $14 \mathrm{~b}$ & 01.0 & $n_{1}$ & 127 & 4.66 & d & 18.7 & $14 \mathrm{a}$ & $1 \mathrm{a}, 13,15$ \\
\hline 15 & 204.5 & C & & & & & & \\
\hline 16 & 30.1 & $\mathrm{CH}_{3}$ & 128 & 1.98 & s & & $14 b^{*}$ & 14,15 \\
\hline $\mathrm{NH}$ & & & & 13.73 & brs & & & \\
\hline
\end{tabular}

\footnotetext{
* Long-range coupling
} 
Table 3.2. ${ }^{13} \mathrm{C}(150 \mathrm{MHz})$ and ${ }^{1} \mathrm{H}(600 \mathrm{MHz})$ NMR data $\left(\mathrm{CD}_{3} \mathrm{OD}\right)$ for 10-Bromohomofascaplysin $\mathrm{A}(66)$.

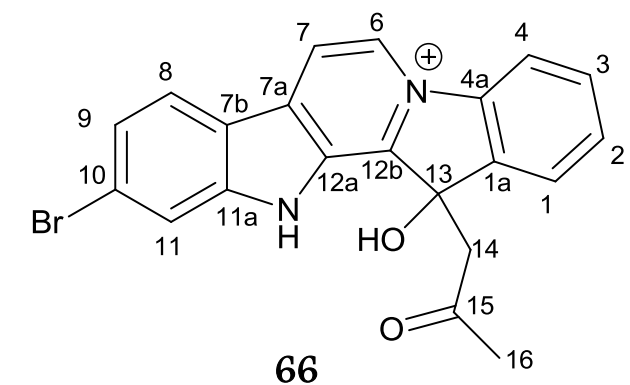

$\stackrel{+\infty}{\infty}$

\begin{tabular}{|c|c|c|c|c|c|c|c|c|}
\hline \multirow[b]{2}{*}{ Pos } & \multicolumn{2}{|c|}{${ }^{13} \mathrm{C}$} & \multicolumn{3}{|c|}{${ }^{1} \mathrm{H}$} & \multirow[b]{2}{*}{$\cos Y$} & \multirow{2}{*}{$\begin{array}{c}\mathrm{HMBC} \\
\left({ }^{1} \mathrm{H} \text { to }{ }^{13} \mathrm{C}\right)\end{array}$} & \multirow[b]{2}{*}{ NOESY } \\
\hline & $\delta(\mathrm{ppm})$ & mult & $\delta(\mathrm{ppm})$ & mult & $J(\mathrm{~Hz})$ & & & \\
\hline $1 \mathrm{a}$ & 137.2 & $\bar{C}$ & & & & & & \\
\hline 1 & 124.4 & $\mathrm{CH}$ & 7.89 & $d$ & 7.6 & 2 & $3,4 a, 13$ & $2,14 a, 14 b$ \\
\hline 2 & 130.6 & $\mathrm{CH}$ & 7.69 & $t$ & 7.3 & 1,3 & $1 \mathrm{a}, 4,4 \mathrm{a}^{*}$ & 1,3 \\
\hline 3 & 130.9 & $\mathrm{CH}$ & 7.75 & $t$ & 7.3 & 2,4 & $1,4 \mathrm{a}$ & 2,4 \\
\hline 4 & 113.9 & $\mathrm{CH}$ & 8.26 & $d$ & 7.9 & 3 & $1 \mathrm{a}, 2$ & 3,6 \\
\hline $4 \mathrm{a}$ & 141.5 & C & & & & & & \\
\hline 6 & 124 & $\mathrm{CH}$ & 9.35 & d & 3.9 & 7 & $* *$ & 4,7 \\
\hline 7 & 117.3 & $\mathrm{CH}$ & 8.82 & $d$ & 3.9 & 6 & $* *$ & 6,8 \\
\hline $7 \mathrm{a}$ & 134.8 & $\mathrm{C}$ & & & & & & \\
\hline $7 \mathrm{~b}$ & 118.9 & $\mathrm{C}$ & & & & & & \\
\hline 8 & 124.5 & $\mathrm{CH}$ & 8.37 & $d$ & 8.6 & 9 & $10,11 a$ & 7,9 \\
\hline 9 & 125.8 & $\mathrm{CH}$ & 7.63 & d & 8.5 & $8,11^{*}$ & $7 b, 10,11$ & 8 \\
\hline 10 & 126.7 & $\mathrm{C}$ & & & & & & \\
\hline 11 & 115.7 & $\mathrm{CH}$ & 8.02 & s & & $9 *$ & $7 \mathrm{~b}, 9,10,11 \mathrm{a}$ & \\
\hline $11 a$ & 145.8 & $\mathrm{C}$ & & & & & & \\
\hline $12 \mathrm{a}$ & 131.1 & C & & & & & & \\
\hline $12 b$ & 143.8 & C & & & & & & \\
\hline 13 & 77.8 & C & & & & & & \\
\hline $14 a$ & 501 & $\mathrm{CH}$ & 4.22 & d & 18.8 & $14 \mathrm{~b}$ & $1 a, 13,15$ & 1,16 \\
\hline $14 \mathrm{~b}$ & 50.1 & $\mathrm{CH}_{2}$ & 4.17 & d & 18.8 & $14 \mathrm{a}, 16^{*}$ & $1 a, 12 b, 13,15$ & 1,16 \\
\hline 15 & 204.5 & $\mathrm{C}$ & & & & & & \\
\hline 16 & 28.7 & $\mathrm{CH}_{3}$ & 1.98 & s & & $14 b^{*}$ & $13,14,15$ & $14 a, 14 b$ \\
\hline
\end{tabular}

* Long-range coupling

** Not observed 


\subsubsection{0-Bromo-6,7-dimethoxyhomofascaplysin D}

10-Bromo-6,7-dimethoxyhomofascaplysin D (65) was isolated as a yellow solid. Characteristic quasi-molecular ion clusters $\left([\mathrm{M}-\mathrm{H}]^{-}:[\mathrm{M}+2-\mathrm{H}]^{-} ; 1: 1\right)$ by negative ion mode HRESIMS again indicated the presence of bromine, which was confirmed with the molecular formula $\mathrm{C}_{23} \mathrm{H}_{20} \mathrm{~N}_{2} \mathrm{O}_{3} \mathrm{Br}\left(\mathrm{m} / \mathrm{z}\right.$ 451.0654, $\left.[\mathrm{M}-\mathrm{H}]^{-}, \Delta-0.7 \mathrm{ppm}\right)$. This molecular formula requires 14.5 double bond equivalents and thus the molecular formula $\mathrm{C}_{23} \mathrm{H}_{21} \mathrm{~N}_{2} \mathrm{O}_{3} \mathrm{Br}$ gives rise to 14 degrees of unsaturation. Consequent to the low mass of 10-bromo-6,7-dimethoxyhomofascaplysin D isolated (128 $\mu \mathrm{g})$, only a few signals were observed in the ${ }^{13} \mathrm{C}$ NMR spectrum and therefore the HSQC and HMBC experiments were depended upon for establishing the chemical shifts of the carbon resonances. The ${ }^{1} \mathrm{H}$ NMR spectrum acquired in $\mathrm{CDCl}_{3}$ revealed 12 distinct resonances which accounted for 20 of the 21 protons. The absence of one proton suggested the presence of an exchangeable. Evidence for this was provided by the presence of a singlet in the ${ }^{1} \mathrm{H}$ NMR spectrum at $\delta_{\mathrm{H}} 11.69$ $\left(\mathrm{d}_{6}-\mathrm{DMSO}\right)$, which did not correspond to any carbon in the HSQC experiment.

Prominent dissimilarities between the ${ }^{1} \mathrm{H}$ NMR spectra of 10-bromohomofascaplysin A (66) and 10-bromo-6,7-dimethoxyhomofascaplysin D (65) were noted, including the lack of the highly deshielded aromatic proton resonances above $\delta_{\mathrm{H}} 8.00$, and the emergence of four new proton resonances $\left(\delta_{\mathrm{H}} 5.85,4.98,3.36,3.29\right)$. Also, the methyl ketone proton singlet had shifted to a greater chemical shift, $\delta_{\mathrm{H}} 2.36$. The multiplicity-edited HSQC spectrum revealed seven aromatic methines, two oxymethines, two oxymethyls, one diastereotopic methylene pair, and one methyl singlet. This signified that the other ten carbons were non-protonated.

Structure elucidation was carried out in a similar fashion to that of 10-bromohomofascaplysin A (66), beginning with the aromatic proton resonances. COSY correlations were observed from $\mathrm{CH}-1\left(\delta_{\mathrm{H}} 7.68, \delta_{\mathrm{C}} 118.2\right)$ to $\mathrm{CH}-2\left(\delta_{\mathrm{H}} 7.23, \delta_{\mathrm{C}} 120.9\right)$, and $\mathrm{CH}-3\left(\delta_{\mathrm{H}} 7.32, \delta_{\mathrm{C}} 123.6\right)$ to $\mathrm{CH}-4\left(\delta_{\mathrm{H}} 7.54, \delta_{\mathrm{C}} 109.6\right)$ and between $\mathrm{CH}-2$ and $\mathrm{CH}-3$. The HMBC data showed correlations from $\mathrm{H}-1$ to $\mathrm{C}-3, \mathrm{H}-3$ to $\mathrm{C}-1$ and a mutual correlation from both protons to the non-protonated aromatic carbon $\mathrm{C}-4 \mathrm{a}\left(\delta_{\mathrm{C}} 138.6\right)$. Further correlations in the HMBC spectrum were observed from $\mathrm{H}-2$ to $\mathrm{C}-4, \mathrm{H}-4$ to $\mathrm{C}-2$ and from both protons to the non-protonated aromatic carbon $\mathrm{C}-1 \mathrm{a}\left(\delta_{\mathrm{C}} 128.3\right)$. These correlations implied a 1,2-disubstituted aromatic ring. One weak HMBC correlation was displayed from $\mathrm{H}-1$ to the non-protonated olefinic carbon $\mathrm{C}-13\left(\delta_{\mathrm{C}} 104.0\right)$. All correlations can be seen in Figure 3.7. 


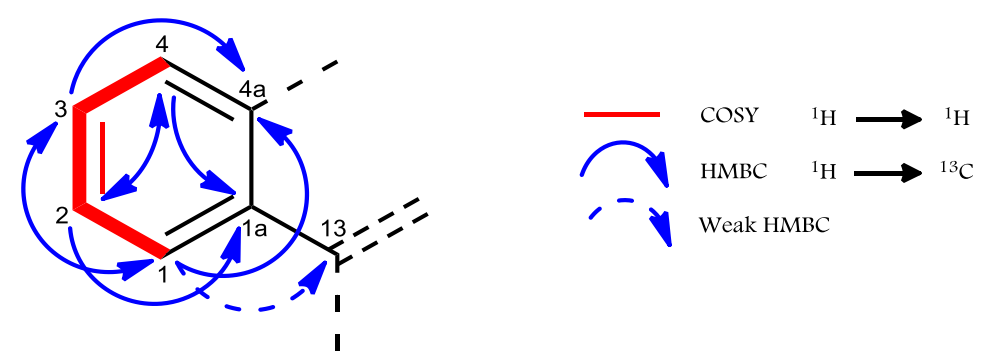

Figure 3.7. COSY and HMBC correlations establishing the connectivity between C-4a and C-13 in 10-bromo-6,7-dimethoxyhomofascaplysin D (65).

The diastereotopic methylene protons $\mathrm{CH}_{2^{-}} 14\left(\delta_{\mathrm{Ha}} 3.79, \delta_{\mathrm{Hb}} 4.22, \delta_{\mathrm{C}} 39.7\right)$ showed COSY correlations to each other and a long range coupling to the methyl singlet protons $\mathrm{CH}_{3}-16$ $\left(\delta_{\mathrm{H}} 2.36, \delta_{\mathrm{C}} 29.4\right)$. HMBC correlations were observed from $\mathrm{H}_{2}-14$ to $\mathrm{C}-16$. Both sets of protons also showed a mutual correlation to $\mathrm{C}-15\left(\delta_{\mathrm{C}} 209.1\right)$. Additionally, the $\mathrm{H}_{2}-14$ protons correlated to $\mathrm{C}-13, \mathrm{C}-1 \mathrm{a}$, and $\mathrm{C}-12 \mathrm{~b}\left(\delta_{\mathrm{C}} 126.4\right)$. These correlations provided evidence of a connection between this substructure and that outlined in Figure 3.7 to give the substructure outlined below (Figure 3.8).
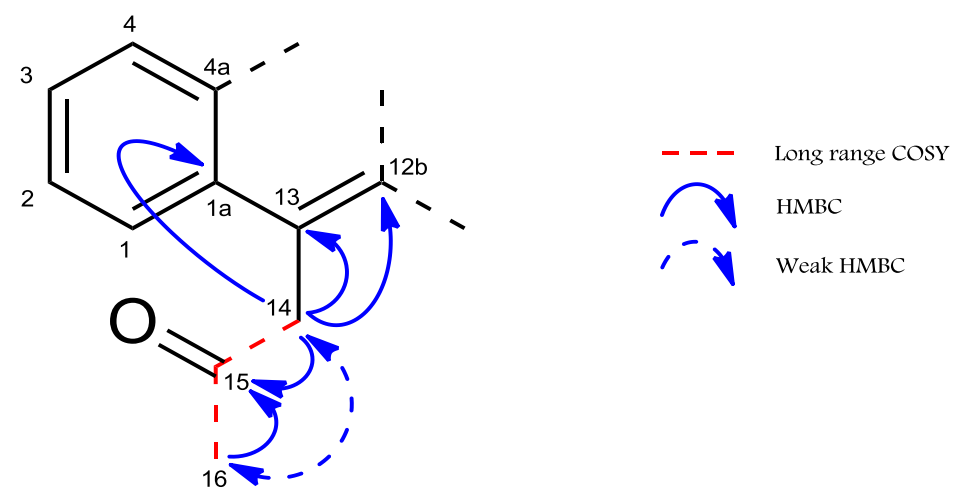

Figure 3.8. COSY and HMBC correlations establishing the connectivity between C-13 and C-16 in 10-bromo-6,7-dimethoxyhomofascaplysin D (65).

COSY correlations were observed between $\mathrm{CH}-8\left(\delta_{\mathrm{H}} 7.54, \delta_{\mathrm{C}} 119.4\right)$ and $\mathrm{CH}_{-} 9\left(\delta_{\mathrm{H}} 7.28\right.$, $\left.\delta_{\mathrm{C}} 124.1\right)$ and a long range correlation was also observed between $\mathrm{CH}-9$ and $\mathrm{CH}-11$ $\left(\delta_{\mathrm{H}} 7.73, \delta_{\mathrm{C}} 115.1\right)$. Analysis of the HMBC spectrum revealed correlations from $\mathrm{H}-8$ to two non-protonated aromatic carbons $\mathrm{C}-10\left(\delta_{\mathrm{C}} 116.0\right)$ and $\mathrm{C}-11 \mathrm{a}\left(\delta_{\mathrm{C}} 138.0\right)$, from $\mathrm{H}-9$ to $\mathrm{C}-7 \mathrm{~b}$ $\left(\delta_{\mathrm{C}} 126.8\right)$ and $\mathrm{C}-11$, and from $\mathrm{H}-11$ to $\mathrm{C}-7 \mathrm{~b}, \mathrm{C}-9$, and $\mathrm{C}-10$. The COSY and HMBC data indicated the substructure to be a 1,2,4-trisubstituted ring. Taking into consideration the structure of 10-bromohomofascaplysin A (66), the position of the bromine was assigned accordingly to this aromatic ring and deduced to be attached to $\mathrm{C}-10$, as this carbon was relatively more shielded than $\mathrm{C}-11$ a (Figure 3.9 ). 

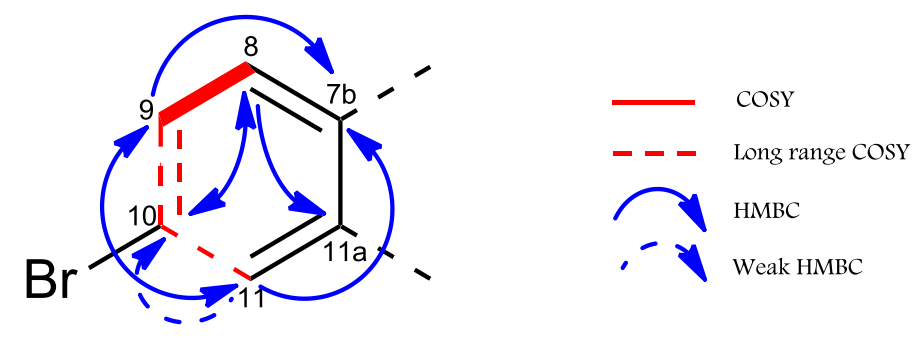

Figure 3.9. COSY and HMBC correlations establishing the connectivity between $\mathrm{C}-7 \mathrm{~b}$ and C-11a in 10-bromo-6,7-dimethoxyhomofascaplysin D (65).

In the next substructure, the highly deshielded oxymethines $\mathrm{CH}-6\left(\delta_{\mathrm{H}} 5.84, \delta_{\mathrm{C}} 83.9\right)$ and CH-7 $\left(\delta_{\mathrm{H}} 4.98, \delta_{\mathrm{C}} 72.4\right)$ displayed mutual COSY correlations to each other. HMBC correlations were observed from $\mathrm{H}-6$ to $\mathrm{C}-7$ and to the non-protonated carbons $\mathrm{C}-7 \mathrm{a}$ $\left(\delta_{\mathrm{C}} 107.1\right)$ and $\mathrm{C}-12 \mathrm{~b}$, and to the methyl singlet, $\mathrm{C}-17\left(\delta_{\mathrm{H}} 3.29, \delta_{\mathrm{C}} 56.4\right)$, and from $\mathrm{H}-7$ to non-protonated carbons $\mathrm{C}_{-} 6\left(\delta_{\mathrm{C}} 83.9\right)$, and C-12a $\left(\delta_{\mathrm{C}} 129.0\right)$, and the methyl singlet $\mathrm{C}-18$ $\left(\delta_{\mathrm{H}} 3.36, \delta_{\mathrm{C}} 56.3\right)$. The observed correlation from $\mathrm{H}-6$ to $\mathrm{C}-12 \mathrm{~b}$ indicated a connection to the substructure outlined in Figure 3.8. Furthermore, the correlations from H-6 to C-7a and from $\mathrm{H}-7$ to $\mathrm{C}-12 \mathrm{a}$ suggested the presence of a double bond within this substructure. Accounting for all the rings and double bonds thus far, gives a total of 11 of the 14 double bond equivalents. All carbons indicated by the molecular formula were accounted for and thus the remaining degrees of unsaturation could be explained by the addition of three other rings therefore suggesting again a pentacyclic system as observed in 66 . The index of hydrogen deficiency did not indicate the compound to be a charged species and so it was inferred that a tertiary nitrogen was in place adjacent to $\mathrm{CH}-6$, giving rise to a hemiaminal ether moiety (Figure 3.10). There is no literature precedent for this functionality among naturally-derived members of the fascaplysin family. Of particular significance towards the suspected functionality was the proton chemical shift of the oxymethine, $\mathrm{CH}-6$ in addition to the one-bond coupling constant $\left({ }^{1} J_{\mathrm{CH}}\right)$ of $158 \mathrm{~Hz}$, which were both unusually high for a typical oxymethine. ${ }^{76}$ Acetal functionality was considered but quickly ruled out due to two reasons: firstly, the ${ }^{13} \mathrm{C}$ chemical shift of $\mathrm{CH}-6$ was too low for an acetal carbon as they typically resonate closer to $\sim \delta_{\mathrm{c}} 100^{77}$ and secondly, all three oxygens were already assigned to the two methoxy groups and the ketone. Another postulated moiety was an epoxide, but again the methoxy groups in addition to the chemical shift of H-6 eliminated this possibility. Validation of the hemiaminal ether functionality is discussed further in section 3.4. 


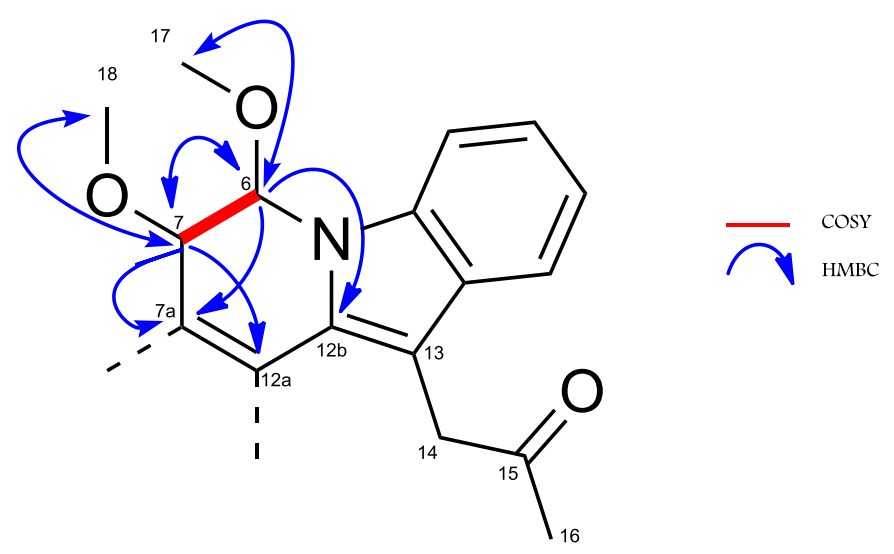

Figure 3.10. COSY and HMBC correlations establishing the connectivity between C-6 and C-12 in 10-bromo-6,7-dimethoxyhomofascaplysin D (65).

In accordance with the molecular formula, one nitrogen and one hydrogen were the final two atoms to assign within the structure. As previously mentioned, the structure was deduced to contain a pentacyclic system, determined from the number of double bond equivalents, signifying that the substructures in Figures 3.9 and 3.10 were interconnected via a ring system containing the nitrogen. In the HMBC spectrum, the exchangeable nitrogen proton $\left(\delta_{\mathrm{H}} 11.69, \mathrm{~d}_{6}-\mathrm{DMSO}\right.$ ) was found to correlate to $\mathrm{C}-7 \mathrm{a}, \mathrm{C}-7 \mathrm{~b}$ and $\mathrm{C}-12 \mathrm{a}$ confirming the placement of the nitrogen, and the connectivity between the two substructures. NOESY correlations reinforced the elucidated structure, with the most pertinent being between $\mathrm{H}-4$ and $\mathrm{H}-6, \mathrm{H}-7$ and $\mathrm{H}-8$, and $\mathrm{H}-1$ and $\mathrm{H}-14 \mathrm{a}$ (Figure 3.12).

One final analysis remained: the relative stereochemistry between $\mathrm{H}-6$ and $\mathrm{H}-7$. Usually NOE or NOESY enhancement experiments provide useful information in regards to establishing relative stereochemistry. However, these experiments were unaccommodating for this particular task due to the high level of $\mathrm{sp}^{2}$ centres within the molecule. Instead, analysis of the 3-bond proton-proton $\left({ }^{3} \mathrm{JH}_{\mathrm{HH}}\right)$ coupling constants and molecular mechanics calculations were relied on to tentatively assign the relative stereochemistry.

Interpretation of the ${ }^{3} J_{\mathrm{HH}}$ coupling constants of 1.8 and $1.6 \mathrm{~Hz}$, for $\mathrm{H}-6$ and $\mathrm{H}-7$, respectively, indicated an approximate dihedral angle of either $60^{\circ}$ or $120^{\circ}$ between the vicinal protons. An eclipsed conformation, with a proton-proton dihedral angle of $120^{\circ}$, was discounted due to considerable torsional and angle strain expected to be imposed across $\mathrm{N}-5$ through to C-7a. An equilibrium geometry optimisation using the Hartree Fock 3-21G* calculation, was performed on the cis- $\left(R^{*}, R^{*}\right)$ and trans- $\left(R^{*}, S^{*}\right)$ configurations in order to gain calculated dihedral angles (Figure 3.11). The calculation indicated the cis-configuration as having a dihedral angle closest to $60^{\circ}$ and accordingly, cis-stereochemistry is tentatively assigned to 
65. The structure of $\mathbf{6 5}$ is given in Figure 3.12, with NMR data presented in Tables 3.3 $\left(\mathrm{CDCl}_{3}\right)$ and $3.4\left(\mathrm{~d}_{6}-\mathrm{DMSO}\right)$.

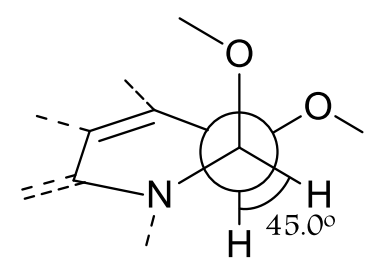

Cis- $\left(R^{*}, R^{*}\right)$

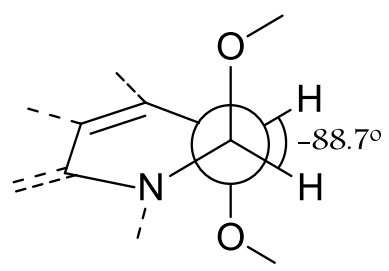

$\operatorname{Trans}-\left(R^{*}, S^{*}\right)$

Figure 3.11. Calculated dihedral angle between the vicinal protons of possible configurations as deduced from the ${ }^{3} \mathrm{HH}_{\mathrm{HH}}$ coupling constants for $\mathrm{H}-6$ and $\mathrm{H}-7$.

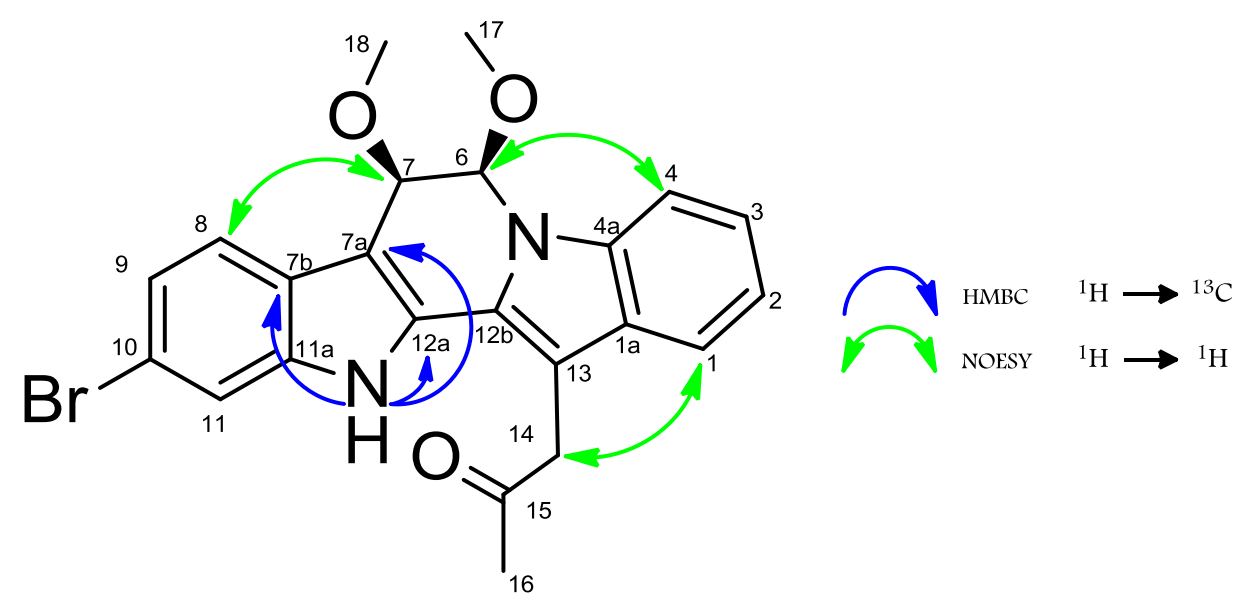

Figure 3.12. Key HMBC and NOESY correlations establishing the structure of 10-bromo-6,7dimethoxyhomofascaplysin D (65). 
Table 3.3. ${ }^{13} \mathrm{C}(150 \mathrm{MHz})$ and ${ }^{1} \mathrm{H}(600 \mathrm{MHz})$ NMR data $\left(\mathrm{CDCl}_{3}\right)$ for 10-Bromo-6,7-dimethoxyhomofascaplysin D (65).

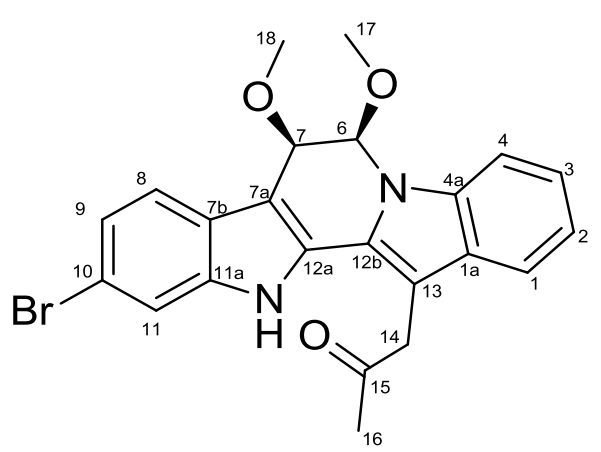

65

\begin{tabular}{|c|c|c|c|c|c|c|c|c|c|}
\hline \multirow[b]{2}{*}{ Pos } & \multicolumn{3}{|c|}{${ }^{13} \mathrm{C}$} & \multicolumn{3}{|c|}{${ }^{1} \mathrm{H}$} & \multirow{2}{*}{\multicolumn{2}{|c|}{$\begin{array}{c}\text { HMBC } \\
\left({ }^{1} \mathrm{H} \text { to }{ }^{13} \mathrm{C}\right)\end{array}$}} & \multirow[b]{2}{*}{ NOESY } \\
\hline & $\delta$ (ppm) & mult & $J(\mathrm{~Hz})$ & $\delta(\mathrm{ppm})$ & mult & $J(\mathrm{~Hz})$ & & & \\
\hline $1 \mathrm{a}$ & 128.3 & $\mathrm{C}$ & & & & & & & \\
\hline 1 & 118.2 & $\mathrm{CH}$ & 158 & 7.68 & d & 7.9 & 2 & $3,4 a, 13$ & $2,14 a, 16$ \\
\hline 2 & 120.9 & $\mathrm{CH}$ & 160 & 7.23 & $t$ & 7.1 & 1,3 & $1 \mathrm{a}, 4$ & 1,3 \\
\hline 3 & 123.6 & $\mathrm{CH}$ & 162 & 7.32 & $t$ & 7.1 & 2,4 & $1,4 a$ & 2,4 \\
\hline 4 & 109.6 & $\mathrm{CH}$ & 163 & $7.54^{* * *}$ & d & 7.3 & 3 & $1 \mathrm{a}, 2$ & 6,17 \\
\hline $4 a$ & 138.6 & $\mathrm{C}$ & & & & & & & \\
\hline 6 & 83.9 & $\mathrm{CH}$ & 159 & 5.84 & d & 1.8 & 7 & $7,7 \mathrm{a}, 12 \mathrm{~b} 17$ & $4,7,17$ \\
\hline 7 & 72.4 & $\mathrm{CH}$ & 149 & 4.98 & d & 1.6 & 6 & $6,7 \mathrm{a}, 12 \mathrm{a}, 18$ & $6,8,18$ \\
\hline $7 \mathrm{a}$ & 107.1 & $\mathrm{C}$ & & & & & & & \\
\hline $7 \mathrm{~b}$ & 126.8 & C & & & & & & & \\
\hline 8 & 119.4 & $\mathrm{CH}$ & 165 & $7.54^{* * *}$ & d & 7.3 & 9 & $10,11 \mathrm{a}$ & $7,9,18$ \\
\hline 9 & 124.1 & $\mathrm{CH}$ & 169 & 7.28 & dd & $8.5,1.6$ & $8,11^{*}$ & $7 b, 11$ & 8 \\
\hline 10 & 116.0 & $\mathrm{C}$ & & & & & & & \\
\hline 11 & 115.1 & $\mathrm{CH}$ & 166 & 7.73 & d & 1.4 & $9 *$ & $7 b, 9,10$ & \\
\hline $11 \mathrm{a}$ & 138.0 & C & & & & & & & \\
\hline $12 \mathrm{a}$ & 129.0 & C & & & & & & & \\
\hline $12 b$ & 126.4 & C & & & & & & & \\
\hline 13 & 104.0 & C & & & & & & & \\
\hline $14 \mathrm{a}$ & 397 & & 129 & 4.22 & d & 12.9 & $14 \mathrm{~b}, 16^{*}$ & $1 a, 12 b, 13,15$ & $1,14 b, 16$ \\
\hline $14 \mathrm{~b}$ & 39.7 & $\mathrm{CH}_{2}$ & 131 & 3.79 & d & 12.9 & $14 \mathrm{a}, 16^{*}$ & $1 \mathrm{a}, 12 \mathrm{~b}, 13,15,16$ & $14 \mathrm{a}, 16$ \\
\hline 15 & 209.1 & C & & & & & & & \\
\hline 16 & 29.4 & $\mathrm{CH}_{3}$ & 125 & 2.36 & $s$ & & $14 a^{*}, 14 b^{*}$ & $14 \mathrm{a}, 14 \mathrm{~b}, 15$ & $1,14 a, 14 b$ \\
\hline 17 & 56.4 & $\mathrm{CH}_{3}$ & 143 & 3.29 & s & & & 6 & 6,4 \\
\hline 18 & 56.3 & $\mathrm{CH}_{3}$ & 140 & 3.36 & $\mathrm{~s}$ & & & 7 & 7,8 \\
\hline
\end{tabular}

* Long-range coupling

**: Assignment interchangeable 
Table 3.4. ${ }^{13} \mathrm{C}(150 \mathrm{MHz})$ and ${ }^{1} \mathrm{H}(600 \mathrm{MHz})$ NMR data $\left(\mathrm{d}_{6}\right.$-DMSO) for 10-Bromo-6,7-dimethoxyhomofascaplysin D (65).

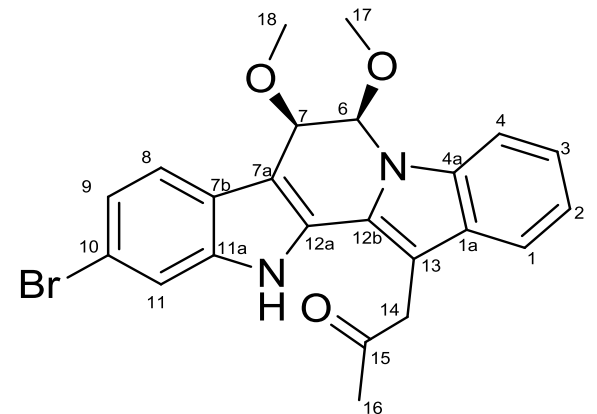

65

\begin{tabular}{|c|c|c|c|c|c|c|c|c|}
\hline \multirow[b]{2}{*}{ Pos } & \multicolumn{3}{|c|}{${ }^{13} \mathrm{C}$} & \multicolumn{3}{|c|}{${ }^{1} \mathrm{H}$} & \multirow[b]{2}{*}{ cosy } & \multirow{2}{*}{$\begin{array}{c}\text { HMBC } \\
\left({ }^{1} \mathrm{H} \text { to }{ }^{13} \mathrm{C}\right)\end{array}$} \\
\hline & $\delta(\mathrm{ppm})$ & mult & $J(\mathrm{~Hz})$ & $\delta(\mathrm{ppm})$ & mult & $J(\mathrm{~Hz})$ & & \\
\hline $1 \mathrm{a}$ & 128.9 & $\mathrm{C}$ & & & & & & \\
\hline 1 & 119.5 & $\mathrm{CH}$ & 162 & 7.47 & d & 7.1 & 2 & $3,4 a$ \\
\hline 2 & 120.4 & $\mathrm{CH}$ & 162 & 7.08 & $t$ & 7.4 & 1,3 & $1 \mathrm{a}, 4$ \\
\hline 3 & 123.5 & $\mathrm{CH}$ & 163. & $7.24 *$ & $t$ & 7.6 & 2,4 & $1,4 a$ \\
\hline 4 & 110.2 & $\mathrm{CH}$ & 162 & 7.80 & d & 8.4 & 3 & $1 \mathrm{a}, 2$ \\
\hline $4 a$ & 138.9 & C & & & & & & \\
\hline 6 & 82.9 & $\mathrm{CH}$ & 162 & 6.05 & d & 2 & 7 & $7,7 a, 12 b 17$ \\
\hline 7 & 71.6 & $\mathrm{CH}$ & 149 & 4.99 & d & 1.8 & 6 & $6,7 \mathrm{a}, 12 \mathrm{a}, 18$ \\
\hline $7 \mathrm{a}$ & 107.9 & C & & & & & & \\
\hline $7 \mathrm{~b}$ & 126.9 & C & & & & & & \\
\hline 8 & 120.3 & $\mathrm{CH}$ & 165 & 7.71 & d & 8.4 & 9 & $10,11 \mathrm{a}$ \\
\hline 9 & 123.5 & $\mathrm{CH}$ & 163 & $7.24^{*}$ & $\mathrm{dd}$ & $8.3,1.8$ & 8 & $7 b, 11$ \\
\hline 10 & 114.9 & C & & & & & & \\
\hline 11 & 114.7 & $\mathrm{CH}$ & 166 & 7.66 & d & 1.5 & & $7 b, 9,10$ \\
\hline $11 \mathrm{a}$ & 138.6 & $\mathrm{C}$ & & & & & & \\
\hline $12 \mathrm{a}$ & 129.3 & C & & & & & & \\
\hline $12 b$ & 125.4 & C & & & & & & \\
\hline 13 & 106.7 & $\mathrm{C}$ & & & & & & \\
\hline $14 \mathrm{a}$ & 39.4 & $\mathrm{CH}_{2}$ & 125 & 4.21 & d & 17.4 & $14 \mathrm{~b}$ & $1 \mathrm{a}, 12 \mathrm{~b}, 13,15$ \\
\hline $14 b$ & 39.4 & $\mathrm{CH}_{2}$ & 127 & 4.36 & d & 17.4 & $14 \mathrm{a}$ & $1 \mathrm{a}, 12 \mathrm{~b}, 13,15$ \\
\hline 15 & 206.2 & C & & & & & & \\
\hline 16 & 30.0 & $\mathrm{CH}_{3}$ & 126 & 2.36 & s & & & $14 \mathrm{a}, 14 \mathrm{~b}, 15$ \\
\hline 17 & 55.7 & $\mathrm{CH}_{3}$ & 141 & 3.29 & s & & & 6 \\
\hline 18 & 55.9 & $\mathrm{CH}_{3}$ & 142 & 3.36 & s & & & 7 \\
\hline $\mathrm{NH}$ & & & & 11.69 & $\mathrm{~s}$ & & & $7 \mathrm{a}, 7 \mathrm{~b}, 12 \mathrm{a}$ \\
\hline
\end{tabular}

* Assignment interchangeable 


\subsubsection{0-Bromo-6,7-dimethoxyhomofascaplysin C}

Negative ion mode HRESIMS of the bright yellow solid, 10-bromo-6,7dimethoxyhomofascaplysin C (64), gave rise to a quasi-molecular ion with a molecular formula $\mathrm{C}_{21} \mathrm{H}_{16} \mathrm{~N}_{2} \mathrm{O}_{3} \mathrm{Br}\left(\mathrm{m} / \mathrm{z}\right.$ 423.0348, $\left.[\mathrm{M}-\mathrm{H}]^{-}, \Delta 0.9 \mathrm{ppm}\right)$. Requiring 14.5 double bond equivalents, this indicated that the molecular formula $\mathrm{C}_{21} \mathrm{H}_{17} \mathrm{~N}_{2} \mathrm{O}_{3} \mathrm{Br}$ possesses 14 degrees of unsaturation. The presence of bromine was evidenced by the observation of a prominent $[\mathrm{M}+2-\mathrm{H}]^{-}$peak of near equal abundance to the parent quasi-molecular ion peak. The molecular formula differed to that observed for 10-bromo-6,7-dimethoxyhomofascaplysin $\mathrm{D}$ (65) by the loss of $\mathrm{C}_{2} \mathrm{H}_{4}$ and consequently suggested that the two were conceivably similar in structure. ${ }^{1} \mathrm{H}$ NMR spectroscopy revealed the presence of 13 proton resonances accounting for all 17 protons. Data acquired from the ${ }^{13} \mathrm{C}$ NMR experiment was unfortunately inadequate, showing very few of the carbon resonances due to an insufficient mass $(83 \mu \mathrm{g})$. Therefore, the HSQC and HMBC experiments were depended upon to provide information about carbon chemical shifts.

In contrast to 65 , the ${ }^{1} \mathrm{H}$ NMR spectrum of 10-bromo-6,7-dimethoxyhomofascaplysin C (64) appeared to show less resonances in the aromatic region, however, analysis of the HSQC spectrum showed that a few proton resonances were overlapping. The presence of two deshielded oxymethines and two oxymethyls, similar to those observed in $\mathbf{6 5}$ were detected. Absent from the ${ }^{1} \mathrm{H}$ NMR were the diastereotopic methylene pair, and methyl singlet while the emergence of a considerably deshielded proton singlet was observed at $\delta_{\mathrm{H}} 10.39$. One further resonance observed at $\delta_{\mathrm{H}} 11.78$ was attributed to an exchangeable proton which was confirmed by analysis of the HSQC spectrum whereby a correlation to this resonance was absent.

In addition to the two deshielded oxymethines and oxymethyls, the HSQC spectrum further revealed 7 aromatic methines, and an aldehyde whose carbon chemical shift appeared relatively shielded $\left(\delta_{\mathrm{C}} 185.1\right)$ indicating the presence of an $\alpha, \beta$-unsaturated aldehyde. The disappearance of the diastereotopic methylene pair and methyl ketone and occurrence of the aldehyde is consistent with the loss of $\mathrm{C}_{2} \mathrm{H}_{4}$ from the molecular formula of 65, suggesting that C-13 in 65, is substituted by an aldehyde in compound 64 .

Beginning with the aromatic resonances, structure elucidation was carried out similarly to that used for the previous two structures. Again, the presence of a 1,2-disubstituted and a 1,2,4-trisubstituted benzene ring was established through interpretation of HMBC and COSY 
data, and since the elucidation of these substructures has been explained in sections 3.2.1 and 3.2.2, it is unnecessary to elaborate further on the observed correlations. Like 65, a hemiaminal ether functionality was also suggested in 64, through the comparatively similar chemical shifts of oxymethines, $\mathrm{CH}-6\left(\delta_{\mathrm{H}} 5.94, \delta_{\mathrm{C}} 85.0\right)$ and $\mathrm{CH}-7\left(\delta_{\mathrm{H}} 5.06, \delta_{\mathrm{C}} 71.7\right)$, and the CH-6 ${ }^{1} J_{\mathrm{CH}}$ coupling constant $(165 \mathrm{~Hz})$. COSY correlations between H-6 and H-7 established a vicinal relationship between these two protons, while HMBC correlations from both protons to their respective oxymethyl carbons and to the non-protonated olefinic carbons $\mathrm{C}-7 \mathrm{a}\left(\delta_{\mathrm{C}} 109.7\right), \mathrm{C}-12 \mathrm{a}\left(\delta_{\mathrm{C}} 126.9\right), \mathrm{C}-12 \mathrm{~b}\left(\delta_{\mathrm{C}} 133.2\right)$ confirmed the identical nature of the carbon skeleton of the cyclic portion, to that of 65 . The only difference remaining between the two molecules was indeed the replacement of the ketone by the aldehyde. This was established through the HMBC correlations from the aldehyde, $\mathrm{H}-14\left(\delta_{\mathrm{H}} 10.39\right)$ to $\mathrm{C}-13$ $\left(\delta_{\mathrm{C}} 112.3\right)$ and $\mathrm{C}-12 \mathrm{~b}$ and further substantiated by an observed NOESY correlation from $\mathrm{H}-1$ ( $\left.\delta_{\mathrm{H}} 8.01\right)$ to $\mathrm{H}-14$ (Figure 3.13).

The relative stereochemistry of H-6 and H-7 was considered to be analogous to that of $\mathbf{6 5}$ on account of the congruent ${ }^{3} J_{\mathrm{HH}}$ coupling constants. For consistency, an equilibrium geometry optimisation using the Hartree Fock 3-21G* calculation was performed and again the cis$\left(R^{*}, R^{*}\right)$ configuration was found with the closest dihedral angle to $60^{\circ}$. Therefore, cisstereochemistry is tentatively assigned and the structure of 10-bromo-6,7-dimethoxyhomofascaplysin C (64) is given in Figure 3.13, with NMR data presented in Table 3.5 .

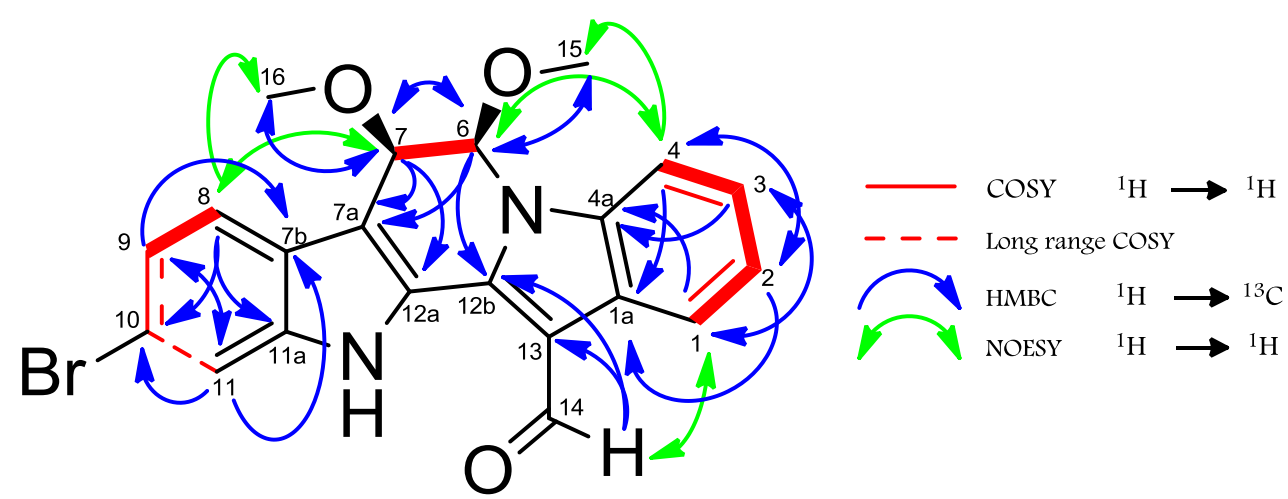

Figure 3.13. COSY, HMBC, and key NOESY correlations establishing the structure of 10-bromo-6,7-dimethoxyhomofascaplysin C (64). 
Table 3.5. ${ }^{13} \mathrm{C}(150 \mathrm{MHz})$ and ${ }^{1} \mathrm{H}(600 \mathrm{MHz})$ NMR data $\left(\mathrm{CDCl}_{3}\right)$ for 10-Bromo-6,7-dimethoxyhomofascaplysin $\mathrm{C}(64)$.

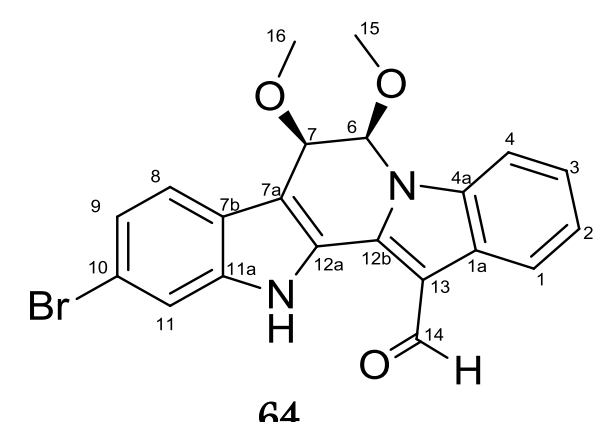

\begin{tabular}{|c|c|c|c|c|c|c|c|c|c|}
\hline \multirow[b]{2}{*}{ Pos } & \multicolumn{2}{|c|}{${ }^{13} \mathrm{C}$} & \multirow[b]{2}{*}{$J(\mathrm{~Hz})$} & \multicolumn{3}{|c|}{${ }^{1} \mathrm{H}$} & \multirow[b]{2}{*}{$\cos Y$} & \multirow{2}{*}{$\begin{array}{c}\text { HMBC } \\
\left({ }^{1} \mathrm{H} \text { to }{ }^{13} \mathrm{C}\right)\end{array}$} & \multirow[b]{2}{*}{ NOESY } \\
\hline & $\delta(\mathrm{ppm})$ & mult & & $\delta(\mathrm{ppm})$ & mult & $J(\mathrm{~Hz})$ & & & \\
\hline 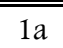 & 128.0 & & & & & & & & \\
\hline 1 & 118.2 & $\mathrm{CH}$ & 162 & 8.01 & d & 8.8 & 2 & $3,4 \mathrm{a}$ & 2,14 \\
\hline 2 & 123.6 & $\mathrm{CH}$ & 159 & 7.35 & $\mathrm{t}$ & 7.8 & 1,3 & $1 \mathrm{a}, 4$ & 1 \\
\hline 3 & 124.7 & $\mathrm{CH}$ & 159 & 7.41 & $\mathrm{t}$ & 7.8 & 2,4 & $1,4 \mathrm{a}$ & 4 \\
\hline 4 & 110.4 & $\mathrm{CH}$ & 163 & 7.61 & d & 8.1 & 3 & $1 \mathrm{a}, 2$ & $3,6,15$ \\
\hline $4 a$ & 138.8 & & & & & & & & \\
\hline 6 & 85.0 & $\mathrm{CH}$ & 160 & 5.94 & d & 1.7 & 7 & $7,7 a, 12 b, 15$ & $4,7,15$ \\
\hline 7 & 71.7 & $\mathrm{CH}$ & 149 & 5.06 & d & 1.6 & 6 & $6,7 a, 12 a, 16$ & 6,16 \\
\hline $7 \mathrm{a}$ & 109.7 & & & & & & & & \\
\hline $7 \mathrm{~b}$ & 126.4 & & & & & & & & \\
\hline 8 & 120.2 & $\mathrm{CH}$ & 164 & 7.59 & $\mathrm{~d}$ & 8.6 & 9 & $10,11 \mathrm{a}$ & 9,16 \\
\hline 9 & 124.7 & $\mathrm{CH}$ & 167 & 7.33 & $\mathrm{dd}$ & $8.3,1.4$ & $8,11^{*}$ & $7 a, 11$ & 8 \\
\hline 10 & 117.9 & & & & & & & & \\
\hline 11 & 115.6 & $\mathrm{CH}$ & 168 & 7.76 & d & 1.7 & 9* & $7 b, 9,10$ & $\mathrm{NH}$ \\
\hline $11 a$ & 137.0 & & & & & & & & \\
\hline $12 a$ & 126.9 & & & & & & & & \\
\hline $12 b$ & 133.2 & & & & & & & & \\
\hline 13 & 112.3 & & & & & & & & \\
\hline 14 & 185.1 & $\mathrm{CH}$ & 176 & 10.39 & $\mathrm{~s}$ & & & $12 b, 13$ & 1 \\
\hline 15 & 56.8 & $\mathrm{CH}_{3}$ & 144 & 3.30 & $\mathrm{~s}$ & & & 6 & 4,6 \\
\hline 16 & 56.4 & $\mathrm{CH}_{3}$ & 144 & 3.36 & $\mathrm{~s}$ & & & 7 & 7,8 \\
\hline $\mathrm{NH}$ & & & & 11.78 & $\mathrm{~s}$ & & & & 11 \\
\hline
\end{tabular}

* Long-range coupling 


\subsubsection{7-Bromoreticulatine}

7-Bromoreticulatine (63) was obtained as a brown-green solid. Like 10-bromohomofascalysin A (66) and several closely related compounds, a persistent aliphatic compound was observed in the NMR spectra. The molecular formula for 7-bromoreticulatine (63) was determined by positive ion mode HRESIMS as $\mathrm{C}_{19} \mathrm{H}_{14} \mathrm{~N}_{2} \mathrm{O}_{2} \mathrm{Br}^{+}$ $\left(\mathrm{m} / \mathrm{z} 381.0233,[\mathrm{M}]^{+}, \Delta-1.6 \mathrm{ppm}\right)$ and again, the presence of bromine was demonstrated by the distinctive $[M+2]^{+}$peak. Similarly to 66 , the molecular formula required 13.5 double bond equivalents; again this, in conjunction with an observed $[\mathrm{M}]^{+}$peak suggested that the compound was a natively charged species. Thus, the structure elucidation of 7-bromoreticulatine (63) was carried out under the assumption that the carbon framework was similar to that of 10-bromohomofascaplysin A (66).

Two resonances were of particular interest in the ${ }^{1} \mathrm{H}$ NMR spectrum: a highly deshielded aromatic proton singlet at $\delta_{\mathrm{H}} 9.78\left(\mathrm{CH}-1 ; \delta_{\mathrm{C}} 132.1\right)$, and a deshielded methoxy singlet at $\delta_{\mathrm{H}} 3.68\left(\mathrm{CH}_{3}-17 ; \delta_{\mathrm{C}} 52.8\right)$ which was slightly less shielded than the methoxy singlets present in compounds 64 and 65. In addition to these two protonated carbons, the HSQC spectrum revealed nine aromatic methines, to give a total of 13 of the 14 protons, and meant the presence of one exchangeable proton. Accounting for only 11 protonated carbons, this indicated that eight carbons were non-protonated. Six of these carbons could be identified in the ${ }^{13} \mathrm{C}$ NMR spectrum which were attributed to five non-protonated aromatic carbons $\left(\delta_{\mathrm{C}} 143.0,132.8,127.3,125.8,118.0\right)$, and an $\alpha, \beta$-unsaturated ester carbonyl (C-16; $\delta_{\mathrm{C}}$ 163.6). The chemical shifts of the two non-protonated carbons unaccounted for in the ${ }^{13} \mathrm{C}$ NMR spectrum were established from observed $\mathrm{HMBC}$ correlations, to be $\delta_{\mathrm{C}} 147.5$ and $\delta_{\mathrm{C}} 136.9$.

Structure elucidation was carried out using the same approach used for 64-66. The terminal aromatic 1,2-di- and 1,2,4-trisubstituted rings were again present in this structure, as determined by analysis of the COSY and $\mathrm{HMBC}$ data. The 1,2,4-trisubstituted ring again presented the bromine at position 4 of the aromatic ring $\left(\mathrm{C}-7, \delta_{\mathrm{C}} 118.0\right)$ and in light of the previous structures, was presumed to be a bromo-indole ring system. A new observation in the 1,2-disubstituted aromatic ring, was an $\mathrm{HMBC}$ correlation from $\mathrm{H}-12\left(\delta_{\mathrm{H}} 8.28, \delta_{\mathrm{C}} 132.5\right)$ to the $\alpha, \beta$-unsaturated ester carbonyl carbon, $\mathrm{C}-16$. Other $\mathrm{HMBC}$ correlations to $\mathrm{C}-16$ were from the deshielded methoxy, $\mathrm{CH}_{3}-17$, validating the ester functionality, and a weak fourbond HMBC correlation from $\mathrm{H}-15\left(\delta_{\mathrm{H}} 7.59, \delta_{\mathrm{C}} 128.0\right)$. These observed COSY and HMBC correlations provided the methylbenzoate substructure outlined in Figure 3.14. 


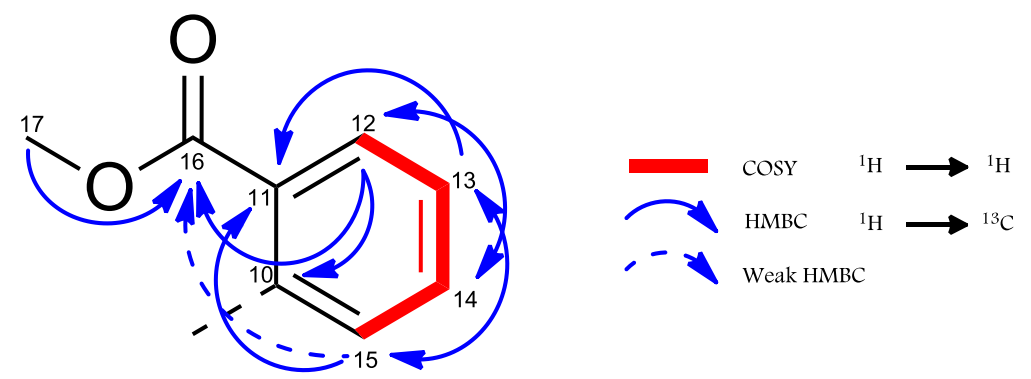

Figure 3.14. COSY and $\mathrm{HMBC}$ correlations establishing the connectivity between $\mathrm{C}-10$ and $\mathrm{CH}_{3}-17$ in 7 -bromoreticulatine (63).

A long range COSY correlation was observed between $\mathrm{H}-1$ and $\mathrm{H}-3\left(\delta_{\mathrm{H}} 8.01, \delta_{\mathrm{C}} 130.7\right)$, indicating a close proximity between the two protons. Additionally, one further strong correlation between $\mathrm{H}-3$ and $\mathrm{H} 4\left(\delta_{\mathrm{H}} 8.34 \delta_{\mathrm{C}} 115.4\right)$ was noted. Together, the COSY correlations suggested a 1,3,4-trisubstituted ring, signifying the loss of the pentacyclic ring system observed in compound 66. The ${ }^{1} J_{\mathrm{CH}}$ of $\mathrm{CH}-1$ was considerably large at $199 \mathrm{~Hz}$ and a similarly large coupling constant was observed for $\mathrm{CH}-3$ at $197 \mathrm{~Hz}$. Assuming again a pyridinium cation, the large ${ }^{1} J_{\mathrm{CH}}$ coupling constants implied that $\mathrm{H}-1$ and $\mathrm{H}-3$ were adjacent to the quaternary ammonium centre, occupying the $\alpha$-positions and further suggested a disconnection of the bond between $\mathrm{C}-12 \mathrm{~b}$ and $\mathrm{C}-13$, as found within 10-bromohomofascaplysin A (66). Observed two-bond and three-bond HMBC correlations from $\mathrm{H}-1, \mathrm{H}-3$, and $\mathrm{H}-4$, established a link to the bromo-indole substructure across the bond between $\mathrm{C}-4 \mathrm{a}$ and $\mathrm{C}-8 \mathrm{a}$. One further correlation from both $\mathrm{H}-1$ and $\mathrm{H}-3$ to non-protonated aromatic carbon $\mathrm{C}-10\left(\delta_{\mathrm{C}} 143.0\right)$ indicated connectivity to the substructure illustrated in Figure 3.14. This observation provided confirmation that the $\mathrm{C}-12 \mathrm{~b}$ to $\mathrm{C}-13$ bond had indeed been severed. In accordance with the molecular formula and the number of double bond equivalents, all requirements were satisfied. Validation towards the structure was ascertained through the NOESY data. The overall structure of 7-bromoreticulatine (63) is provided in Figure 3.15 with NMR data illustrated in Table 3.6.
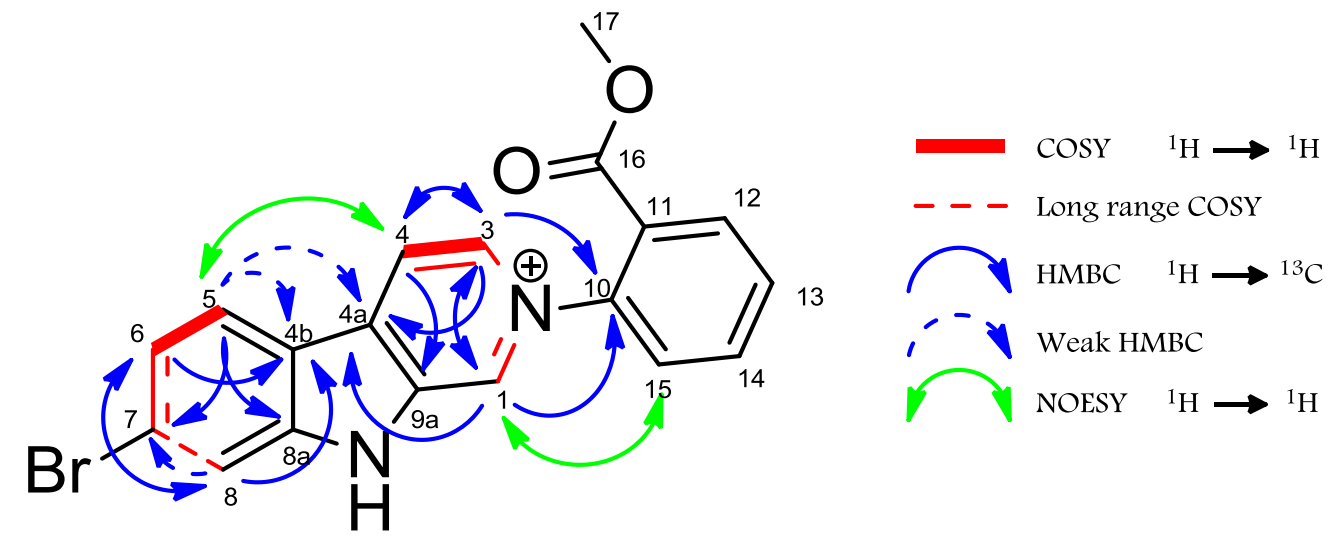

Figure 3.15. COSY, HMBC and key NOESY correlations establishing the structure of 7 -bromoreticulatine (63). 
Table 3.6. ${ }^{13} \mathrm{C}(150 \mathrm{MHz})$ and ${ }^{1} \mathrm{H}(600 \mathrm{MHz})$ NMR data $\left(\mathrm{CDCl}_{3}\right)$ for 7 -Bromoreticulatine (63).

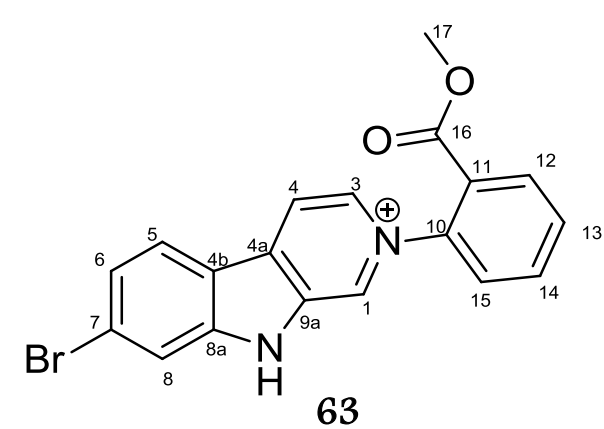

\begin{tabular}{|c|c|c|c|c|c|c|c|c|c|}
\hline \multirow[b]{2}{*}{ Pos } & \multicolumn{3}{|c|}{${ }^{13} \mathrm{C}$} & \multicolumn{3}{|c|}{${ }^{1} \mathrm{H}$} & \multicolumn{3}{|c|}{ HMBC } \\
\hline & $\delta(\mathrm{ppm})$ & mult & $J(\mathrm{~Hz})$ & $\delta(\mathrm{ppm})$ & mult & $J(\mathrm{~Hz})$ & cosy & $\left({ }^{1} \mathrm{H}\right.$ to $\left.{ }^{13} \mathrm{C}\right)$ & NOESY \\
\hline 1 & 132.1 & $\mathrm{CH}$ & 199 & 9.78 & br s & & 3* & $3,4 a, 10$ & 15 \\
\hline 3 & 130.7 & $\mathrm{CH}$ & 197 & 8.01 & d & 6.3 & $1^{*}, 4$ & $1,4,4 a, 10$ & 4 \\
\hline 4 & 115.4 & $\mathrm{CH}$ & 173 & 8.34 & d & 6.5 & 3 & $3,9 a$ & 3,5 \\
\hline $4 a$ & 132.8 & C & & & & & & & \\
\hline $4 b$ & 127.3 & C & & & & & & & \\
\hline 5 & 123.3 & $\mathrm{CH}$ & 166 & 8.08 & d & 8.5 & 6 & $4 a, 4 b, 7,8 a$ & 6 \\
\hline 6 & 125.4 & $\mathrm{CH}$ & 172 & 7.52 & $\mathrm{dd}$ & $7.8,1.4$ & 5 & $4 b, 8$ & 5 \\
\hline 7 & 118.0 & C & & & & & & & \\
\hline 8 & 117.9 & $\mathrm{CH}$ & 174 & 8.19 & s & & & $4 b, 6,7$ & \\
\hline $8 a$ & 147.5 & C & & & & & & & \\
\hline $9 a$ & 136.9 & C & & & & & & & \\
\hline 10 & 143.0 & C & & & & & & & \\
\hline 11 & 125.8 & C & & & & & & & \\
\hline 12 & 132.5 & $\mathrm{CH}$ & 172 & 8.28 & dd & $7.8,1.4$ & 13 & $10,14,16$ & 13 \\
\hline 13 & 131.6 & $\mathrm{CH}$ & 167 & 7.79 & $\mathrm{td}$ & $7.7,0.9$ & 12,14 & $11,12,15$ & 12 \\
\hline 14 & 134.3 & $\mathrm{CH}$ & 168 & 7.82 & td & $7.7,1.3$ & 13,15 & 10,12 & \\
\hline 15 & 128.0 & $\mathrm{CH}$ & 169 & 7.59 & d & 7.3 & 14 & $10,11,13,16^{*}$ & 1 \\
\hline 16 & 163.7 & C & & & & & & & \\
\hline 17 & 52.8 & $\mathrm{CH}_{3}$ & 148 & 3.68 & s & & & 16 & \\
\hline
\end{tabular}

* Long-range coupling 
A combination of $1 \mathrm{D}$ and 2D NMR experiments was successfully used to ascertain the structures of compounds 61-66. In particular, the NOESY experiment was imperative to the validation of the position of the bromine in compounds 63-66.

\subsection{Biological Activity}

7-bromoreticulatine (63), 10-bromo-6,7-dimethoxyhomofascaplysin C (64) and D (65), and10-Bromohomofascalysin A (66), and were submitted to the School of Biological Sciences, VUW for cytotoxicity analysis against human leukaemia (HL-60) cell lines. 10-Bromohomofascaplysin (66) A and 7-bromoreticulatine (63) exhibited quite potent cytotoxicity with respective $\mathrm{IC}_{50}$ values of 33.8 and $498 \mathrm{nM}$. 10-Bromo-6,7-dimethoxyhomofascaplysin C (64) and D (65) were less active displaying moderate cytotoxicities with $\mathrm{IC}_{50}$ values of 6.0 and $2.7 \mu \mathrm{M}$ respectively. In regards to the structure-activity relationship (SAR), this result perhaps suggests that the presence of the pyridinium $\mathrm{N}$-cation is required for activity.

\subsection{Hemiaminal Ether Functionality: Spectral Characteristics}

The hemiaminal ether moiety found in 64 and 65 prompts further discussion as the two compounds appear to present a new sub-class of naturally-derived compounds within the fascaplysin family. The sole $\mathrm{HMBC}$ correlation from methoxy $\mathrm{CH}_{3}-17$, to the methine $\mathrm{CH}-6$, created no reservations about a direct link between them, but certain aspects of the NMR data suggested that CH-6 was not a typical oxymethine. The highly deshielded carbon and proton resonances and the unusually large ${ }^{1} J_{\mathrm{CH}}$ value of $\mathrm{CH}-6$ encountered in both 10-bromo-6,7-dimethoxyhomofascaplysins C (64) and D (65) were salient features leading to questionable functionality. Acetal and epoxide functionalities were discounted due to reasons outlined in Chapter 3.2.2. Taking into account the molecular formulae of 64 and 65 , hemiaminal ether functionality was postulated.

\section{Comparison of the ${ }^{1} \mathrm{H}$ and ${ }^{13} \mathrm{C}$ Chemical Shifts}

The dimethoxy functionality encountered in 64 and 65 is to the author's knowledge, an unprecedented feature among related, naturally-derived compounds, though the semisynthetic analogues 67 and $68^{\dagger \dagger}$ are almost identical to 64 and 65 . The diastereoisomers, 67 
and 68 were each obtained as mixtures of inseparable enantiomers from the reaction of the related compound fascaplysin (69) with NaOMe in $\mathrm{MeOH}^{78}$ In $\mathrm{d}_{6}$-DMSO, the hemiaminal carbon and proton (CH-6) of 67 (trans-diastereoisomer), resonated at $\delta_{\mathrm{C}} 91.2$ and $\delta_{\mathrm{H}} 4.77$; compound 68 (cis-diastereoisomer) displayed a relative upfield and downfield shift for the carbon and proton respectively, at $\delta_{\mathrm{C}} 86.8$ and $\delta_{\mathrm{H}} 5.68 .^{78}$ Compound 67 shows a considerable difference in the NMR data for positions $\mathrm{CH}-6$ and $\mathrm{CH}-7$, when compared with 64 and 65, while 68 displays only a slight difference (Table 3.7). The more favourable agreement of the ${ }^{1} \mathrm{H}$ and ${ }^{13} \mathrm{C}$ NMR data $(\mathrm{CH}-6$ and $\mathrm{CH}-7)$ between 68 and compounds 64 and 65, supports the assignment of cis-stereochemistry for 64 and 65. The decreased rigidity within the fused cyclic system of compounds 67 and 68 , may potentially affect the chemical shifts and could account for the slight differences observed between the NMR data of the natural products (64 and 65) and compound 68.

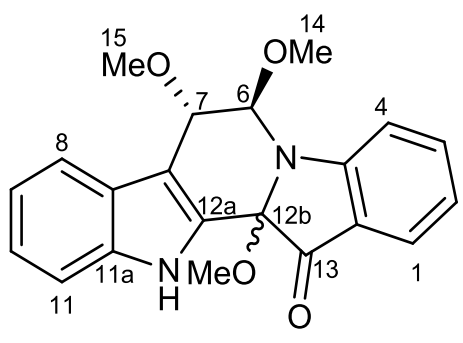

(士) 67

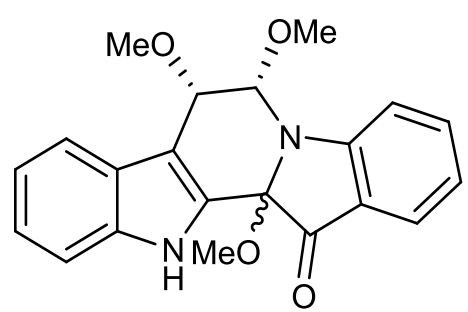

$( \pm) 68$<smiles>O=C1c2ccccc2-[n+]2ccc3c([nH]c4ccccc43)c21</smiles>

69

Table 3.7. Calculated Difference in the ${ }^{1} \mathrm{H}$ and ${ }^{13} \mathrm{C}$ NMR Chemical Shifts at Positions 6 and 7 between $64,65,67$ and 68 .

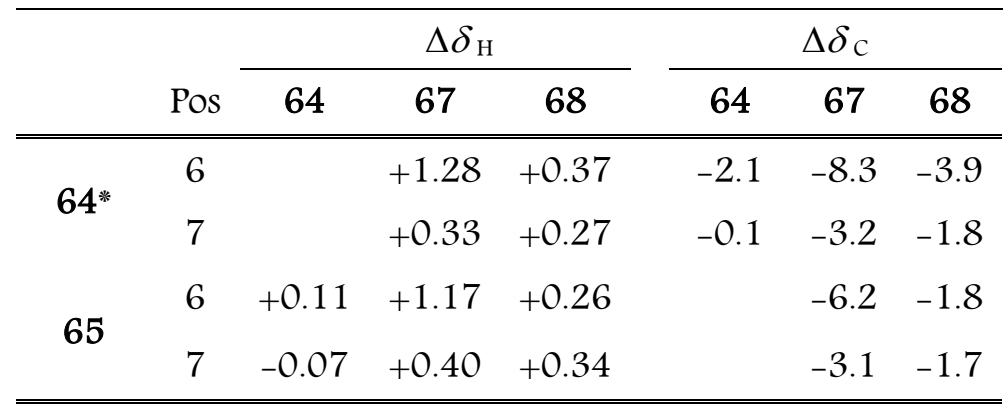

* Difference calculated from NMR data recorded in $\mathrm{d}_{6}$-DMSO

More support for the hemiaminal ether functionality is obtained from an analysis of the NMR data of the aminal and hemiaminal ether centres found in colensolide A (70). The respective ${ }^{1} \mathrm{H}$ and ${ }^{13} \mathrm{C}$ chemical shifts of the aminal centre, $\mathrm{CH}-9$ in colensolide $\mathrm{A}(70)$ are $\delta_{\mathrm{H}} 4.54$ and $\delta_{\mathrm{C}} 75.8\left(\mathrm{~d}_{6}-\mathrm{DMSO}\right)$, while the chemical shift of the quaternary hemiaminal carbon, $\mathrm{C}-13$ is significantly more deshielded at $\delta_{\mathrm{C}} 97.5 .{ }^{79}$ Thus, compound 70 demonstrates the differences

\footnotetext{
For simplicity, the structures of $\mathbf{6 7}$ and $\mathbf{6 8}$ illustrate only one of the enantiomers.
} 
in the effects of oxygen and nitrogen deshielding. Owing to a higher electronegativity, oxygen exerts a larger inductive effect than nitrogen; consequently, a hemiaminal ether carbon experiences greater deshielding than an aminal carbon. Considering this effect, it is logical to expect the chemical shift of a tertiary hemiaminal carbon, to be observed in between those reported for C-9 and C-13, in colensolide A (70). Indeed, this is found to be the case for the ${ }^{13} \mathrm{C}$ NMR chemical shift of $\mathrm{CH} 6$ in both 64 and 65 . This assumption is invalid when comparing the relative chemical shifts of aminal and hemiaminal ether protons, as protons in general are more susceptible to deshielding caused by inductive effects, as well as other factors such as anisotropic and neighbouring group effects; these effects can all cause a significant alteration in the chemical shift. ${ }^{77}, 80$ This is exemplified by the considerable difference in the proton chemical shifts observed for $\mathrm{CH}-6$, between diastereoisomers 67 and 68, and is further illustrated by the close agreement of the proton chemical shifts of the hemiaminal ether proton in 67 , and the aminal proton in colensolide A (70).

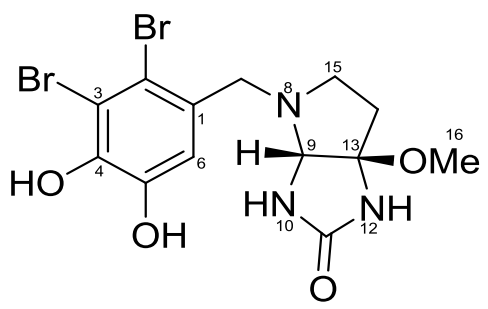

70

\section{The ${ }^{1} J_{\mathrm{CH}}$ Coupling Constant}

The one-bond proton-carbon coupling constant $\left({ }^{1} J_{\mathrm{CH}}\right)$ is a parameter that can be used in conjunction with the ${ }^{1} \mathrm{H}$ and ${ }^{13} \mathrm{C}$ NMR chemical shifts for added support towards a proposed functionality. Like chemical shifts, a given functional group typically reveals a characteristic ${ }^{1} J_{\mathrm{CH}}$ coupling constant. ${ }^{76}$ In addition to the ${ }^{1} \mathrm{H}$ and ${ }^{13} \mathrm{C}$ NMR chemical shift, the ${ }^{1} J_{\mathrm{CH}}$ value found for CH-6 in 10-bromo-6,7-dimethoxthyhomofascaplysins C (64) and D (65) suggested that the functional group was not representative of an oxymethine. A comparison against the ${ }^{1} J_{\mathrm{CH}}$ coupling constants of the hemiaminal ether centre of compounds 67 and 68 would have been ideal, however, the ${ }^{1} J_{\mathrm{CH}}$ values for these compounds were not reported. Instead, a comparison was made against the aminal ${ }^{1} J_{\mathrm{CH}}$ in colensolide A (70). The ${ }^{1} J_{\mathrm{CH}}$ coupling constant of $\mathrm{CH}_{-} 9$ in colensolide $\mathrm{A}$ is $162 \mathrm{~Hz},{ }^{79}$ which is identical to that observed for $\mathrm{CH}-6$ in $65\left(\mathrm{~d}_{6}-\mathrm{DMSO}\right)$ and extremely close to that found for $\mathrm{CH}-6$ in $64(160 \mathrm{~Hz}$, $\mathrm{CDCl}_{3}$ ). Admittedly, the comparison is made between an aminal and hemiaminal ether functional group and the similarity may not appear to be particularly applicable, especially since electron withdrawing groups increase the ${ }^{1} \mathrm{~J}_{\mathrm{CH}}$ value, ${ }^{77}$ and therefore an aminal should exhibit a lower ${ }^{1} J_{\mathrm{CH}}$ value than that of a hemiaminal ether. However, large one-bond 
coupling constants are generally observed in strained ring systems ${ }^{76}$ and the comparable ${ }^{1} J_{\mathrm{CH}}$ values could be justified by this. Given that $\mathrm{CH}_{-} 9$ in compound 70 is positioned at the junction of a strained cis-fused bicyclic system, it is likely that the ${ }^{1} J_{\mathrm{CH}}$ value exhibited by $\mathrm{CH}-9$ in colensolide $\mathrm{A}(\mathbf{7 0})$ is larger than an average aminal ${ }^{1} J_{\mathrm{CH}}$.value. As such, the observed ${ }^{1} J_{\mathrm{CH}}$ values for $\mathrm{CH}-6$ in 10-bromo-6,7-dimethoxyhomofascaplysins $\mathrm{C}(64)$ and $\mathrm{D}(65)$ are assumed to be valid for a hemiaminal ether functionality.

A search through the literature sought to determine the validity of hemiaminal ether functionality in 10-bromo-6,7-dimethoxyhomofascaplysins C (64) and D (65). The NMR data of the hemiaminal ether centres of 64 and 65 was compared against compounds 67 and 68. Compound 68 agreed more favourably with the observed NMR data for $\mathrm{CH}-6$ and $\mathrm{CH}-7$ in 64 and 65, providing support towards the proposed functionality and the tentatively assigned cis-stereochemistry. An analysis of the carbon chemical shifts of $\mathrm{CH}-9$ and $\mathrm{C}-13$ in colensolide A (70) as well as the rationalisation of the comparable ${ }^{1} J_{\mathrm{CH}}$ value for $\mathrm{CH}-9$, further supported the proposed hemiaminal ether functionality in $\mathbf{6 4}$ and $\mathbf{6 5 .}$

\subsection{Homofascaplysins: Artefacts of Isolation?}

It is possible that the methyl ketone functionality described in this report for 10-bromohomofascaplysin A (66), is the result of nucleophilic addition by acetone to 10-bromofascaplysin (71) (Scheme 3.2).
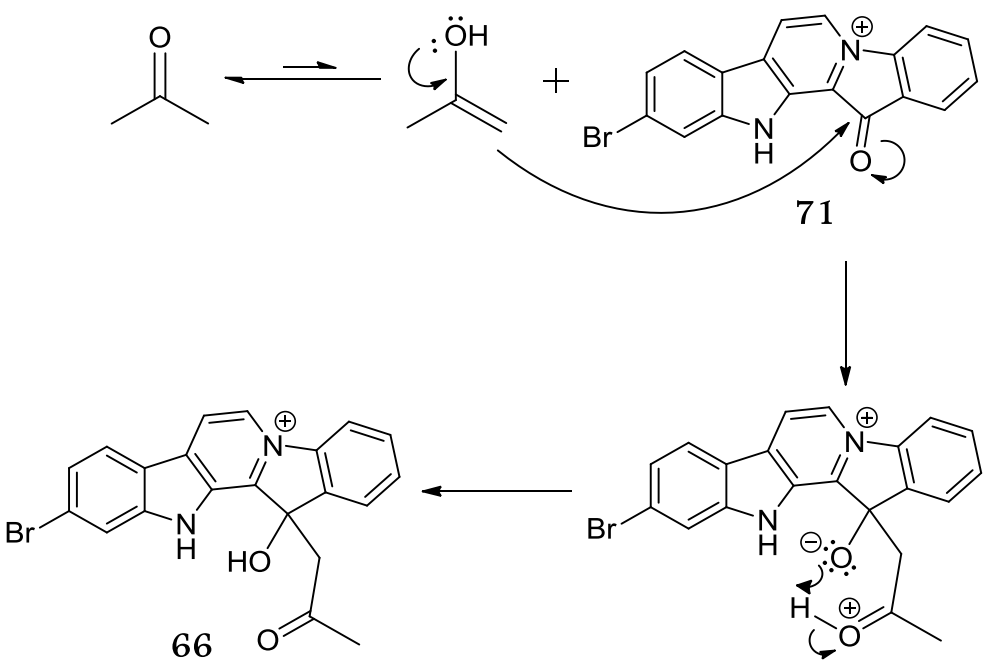

Scheme 3.2. Nucleophilic addition of acetone to 10-bromofascaplysin (71).

The non-brominated analogue of 66, homofascaplysin A (72), was first reported in 1991 together with the monoanionic sesterterpene counter-ion, dehydroluffariellolide (73) from the Fijian sponge, Fascaplysinopsis reticulata. ${ }^{81}$ Optical activity was observed for the 
compound $\left([\alpha]_{\mathrm{D}}^{20}=-9.4^{\mathrm{o}} ; c 6.4 \times 10^{-3}, \mathrm{MeOH}\right)$, indicating the absence of a racemic mixture and thereby suggesting the compound to be a natural product. ${ }^{81}$ Very recently, the brominated analogue, 3-bromohomofascaplysin A (74) was isolated from the Fijian ascidian Didemnum sp. and its specific rotation was calculated to be $[\alpha]_{\mathrm{D}}^{20}=-9.0^{\circ}(c 0.1, \mathrm{MeOH}) .{ }^{73 b}$ Neither of the purification procedures used to isolate $\mathbf{7 2}$ or $\mathbf{7 4}$ used acetone and the optical rotation suggests that homofascaplysin A is not an artefact of isolation. Surprisingly, more than a decade after the report of homofascaplysin $\mathrm{A}^{81}$ Crews et al. reported that the reexamination of a natural sample of homofascaplysin A (chloride counter-ion, 75) gave a specific rotation $[\alpha]_{D}^{20}=0^{\circ}$, indicating that a non-enzymatic reaction could afford racemic homofascaplysin A. ${ }^{75}$ As the counter ion is a chloride ion, it is assumed that the sample is not identical to the original sample of homofascaplysin A, they described in 1991.

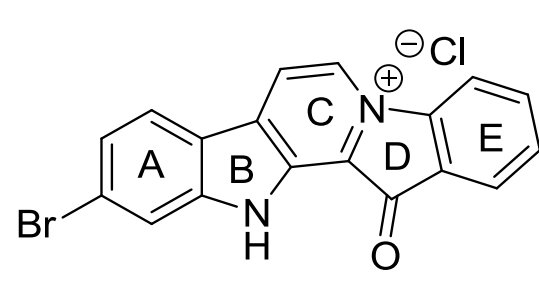

71

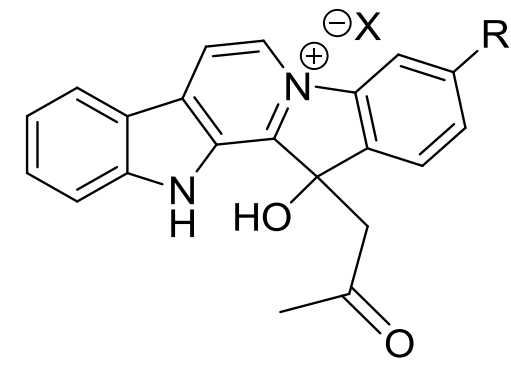

72

74

$75 \quad \mathrm{R}=\mathrm{H}$

$\mathrm{X}=73^{-}$

$\mathrm{X}=\mathrm{Cl}$

$\mathrm{X}=\mathrm{Cl}$<smiles>CC(=CCCC(=CC(=O)O)C(=O)O)CCC=C(C)CCC1=C(C)CCCC1(C)C</smiles>

73

During early purification methods, acetone was used in the isolation of 10-bromohomofascaplysin A (66). The specific rotation calculated for $66\left([\alpha]_{D}^{23}=+154^{\circ}\right.$; $\left.c 6.5 \times 10^{-3}, \mathrm{MeOH}\right)$ is markedly different from the literature values reported for $\mathbf{7 2}$ and $\mathbf{7 4}$. This discrepancy may be due to a contribution of optical activity from the impurities present in 10-bromohomofascaplysin A (66). An attempt to determine whether compound 66 is a naturally-derived product or an artefact of isolation began with the re-extraction (twice overnight in $\mathrm{MeOH}$ ) of a small amount of PTN4_O8E (20 g). The extracts were subsequently cyclic loaded onto HP2O reversed-phase packing beads and the column was batch eluted with $75 \%, 90 \% \mathrm{H}_{2} \mathrm{O} / \mathrm{MeOH}, 100 \% \mathrm{MeOH}$ and finally $100 \%$ THF. Although aromatic proton resonances were observed in the ${ }^{1} \mathrm{H}$ NMR spectra of the $100 \% \mathrm{MeOH}$ and THF fractions, they were few and were determined to be non-fascaplysin proton resonances. In contrast, the 
${ }^{1} \mathrm{H}$ NMR spectra of the $75 \%$ and $90 \% \mathrm{MeOH}$ fractions showed several aromatic proton resonances similar to those observed for the fascaplysins.

Due to the presence of a singlet close to $\delta_{\mathrm{H}} 1.90$, the $75 \%$ was selected for further purification on DIOL and the column was eluted with DCM, 20\%, 40\% DCM/MeOH, and MeOH; the ${ }^{1}$ H NMR spectra showed that the aromatic resonances were confined to the $20 \%$ and $40 \%$ $\mathrm{DCM} / \mathrm{MeOH}$ fractions. Combinations of $1 \mathrm{D}$ and 2D NMR experiments were performed on the $90 \% \mathrm{MeOH} / \mathrm{H}_{2} \mathrm{O}$ (HP2O), and 20\%, 40\% DCM/MeOH (DIOL) fractions. The NMR spectra of the $20 \% \mathrm{DCM} / \mathrm{MeOH}$ fraction revealed the familiar 1,2-di-, 1,2,4-tri- and 1,2,3,4-tetrasubstituted aromatic rings observed in compound 66, in addition to a methyl singlet and methylene which both correlated to a ketone at $\delta_{\mathrm{C}} 209.1$ in the HMBC spectrum. However, the methylene further correlated to other methylene carbons and no correlation to a quaternary carbon was observed. Analysis of the 40\% DCM/MeOH fraction NMR data, showed that the aromatic proton resonances were attributed to a compound, whose cyclic carbon framework resembled 7-bromoreticulatine (63); no ketone resonance was observed. The ketone resonance was also absent from the NMR data of the 90\% MeOH HP2O fraction. Additionally, the NMR spectra of these three fractions also lacked evidence for the $\alpha, \beta$ unsaturated ketone found in 10-bromofascaplysin. Since no evidence for the presence of either 10-bromohomofascaplysin A (66) or 10-bromofascaplysin (71) could be found in the NMR data, the answer to this question remains inconclusive.

As mentioned earlier, 10-bromo-6,7-dimethoxyhomofascaplysins C (64) and D (65) represent a new sub-class within the fascaplysin family. The closest analogues that exist in the literature are the semi-synthetic compounds, 67 and $68{ }^{78}$ Although methanol was used extensively throughout the isolation protocol, it seems unlikely that the relatively mild conditions of the PSDVB and DIOL packing materials used for purification were enough to induce methoxy addition. Furthermore, if these compounds were susceptible to this addition under mild conditions, there would surely be precedence for this functionality among the reported fascaplysin derivatives, since methanol has been used just as extensively in the isolation of all compounds reported thus far. ${ }^{72,73,75,81,82}$ Nonetheless, it cannot be stated with absolute certainty that $\mathbf{6 4}$ and $\mathbf{6 5}$ are indeed natural products. Despite the specific rotation calculated for 65 being $[\alpha]_{D}^{23}=0^{\circ}\left(c 3.0 \times 10^{-4}, \mathrm{CHCl}_{3}\right)$, this result is unreliable due to such a low concentration and the specific rotation calculated for 64 , is irrational and invalid $\left([\alpha]_{D}^{23}=-2222^{\circ} ; c 5.0 \times 10^{-4}, \mathrm{CHCl}_{3}\right)$ also due to the low concentration. More work is required to determine the answer to this question, whereby the sponge should be reextracted and purification methods carried out in the absence of methanol. Ethanol would 
provide a convenient substitute, as ethoxy substituents would be expected to replace the methoxy groups if compounds 64 and 65 are indeed artefacts.

\subsection{Related Bis-indole Alkaloids}

Fascaplysin (69) is an intensely red pigmented bis-indole alkaloid reported in 1988 by Clardy et al., along with the known compound luffarielolide (62) from the Fijian sponge Fascaplysinopsis sp., Berquist. ${ }^{72}$ Prior to this, Fascaplysinopsis reticulata was well known for the monomeric tryptophan derived compound, aplysinopsin (76) but the $12 H$-pyrido[1,2-a;3,4- $b^{7}$ ]diindole system of fascaplysin $(69)$ presented a new precedent to natural products. X-ray diffraction analysis gave the complete structure of fascaplysin after NMR could not effectively eliminate other potential structures due to the unfavourable ratio $\mathrm{H}: \mathrm{CNO}$ of 0.52 providing ambiguous assignments. ${ }^{72}$ A total of 24 related compounds have subsequently been isolated from Fascaplysinopsis sp., Hyrtios sp., and Thorectandra sp. sponges and Didemnum sp. tunicates. ${ }^{73 a}$ Sponges representing the genus Fascaplysinopisis have provided several of these unusual bis-indole alkaloids.

F. reticulata collected from Fiji, yielded fascaplysin A (77), homofascaplysin A (72), and reticulatine (78) alongside the sesterterpenoids dehydroluffariellolide (73) and isodehydroluffariellolide (79). As with $\mathbf{7 2}$, compound 77 was also accompanied by the monoanionic form of the sesterterpene compound 73. Subsequent purification of fascaplysin A (77) on anion exchange resin (DOWEX-1, chloride) afforded fascaplysin (69). Unlike fascaplysin (69) and fascaplysin A (77) the literature does not attempt to make a distinction between the names of the two forms of homofascaplysin A (one containing the chloride counter ion and the other a sesterterpene counter ion). A thorough investigation of the sponge led to the isolation of neutral compounds homofascaplysin B (80), homofascaplysin C (81), and secofascaplysin A (82). ${ }^{81,82}$ More than a decade later, the same research group reported the isolation of reticulatate (83) from a different collection of F.reticulata. ${ }^{75}$ Reticulatate (83) had been reported a year earlier as an isolate from a Palauan sponge identified as a Thorectandra sp., ${ }^{82 \mathrm{~b}}$ though a synthetically derived zwitter-ionic analogue obtained from the reaction of fascaplysin (69) with $1 \mathrm{M} \mathrm{NaOH}$ or with $30 \%$ aqueous $\mathrm{NH}_{4} \mathrm{OH}$ was the first to appear in the literature. ${ }^{78}$ Continued investigations of 12 separate sponge specimens of $F$. reticulata collected from various sites off the coasts of Fiji and Indonesia provided the congeners homofascaplysate A (84), reticulatol (85) along with brominated analogues of those mentioned: 10-bromofascaplysin (71), 3-bromofascaplysin (86), 3,10-dibromofascaplysin (87), 14-bromoreticulatine (88), 7,14-dibromoreticulatine (89), 
14-bromoreticulatate (90), 14-bromoreticulatol (91), and 3-bromosecofascaplysins A and B (92 and 93 , respectively). ${ }^{73 a}, 75$

The genus Fascaplysinopsis has clearly yielded many fascaplysin derivatives, but they have not been exclusively found within this genus. Both homofascaplysin A (75) and fascaplysin (69) have been isolated from a Fijian collection of the sponge Hyrtios cf. erecta. ${ }^{83}$ Investigations on the sponge Thorectandra sp. resulted in the isolation of thorectandramine (94) alongside fascaplysin (69), reticulatine (78), and reticulatate (83). ${ }^{82 \mathrm{~b},} 82 \mathrm{c}$ Thorectandramine (94) is unlike other analogues of fascaplysin, as it bears a sixth aromatic ring substituted on C-13. Didemnum sp. ascidians have additionally yielded fascaplysin (69), homofascaplysin C (81), homofascaplysate A (84), and 3-bromofascaplysin (86). ${ }^{73 a}$ The fascaplysin derivatives, 3-bromohomofascaplysin A (74), 3-bromohomofascaplysin B (95), 3-bromohomofascaplysin C (96), homofascaplysin B-1 (97), and 3-bromohomofascaplysin B-1 (98) were also isolated from Didemnum sp. ascidians and are yet to be discovered from sponges. $^{73}$

One feature that appears to be rare among the group of fascaplysin derivatives is monobromination on the A-ring. Of the 24 compounds documented in the literature, 11 are brominated analogues, yet only three display A-ring bromination. A closer inspection shows that of these three, just one is monobrominated. The sponge investigated in this research provided only A-ring monobrominated analogues and may hold prospective for the isolation of several more structures of this kind.<smiles>CN1C(=N)N(C)C(=Cc2c[nH]c3ccccc23)C1=O</smiles>

76

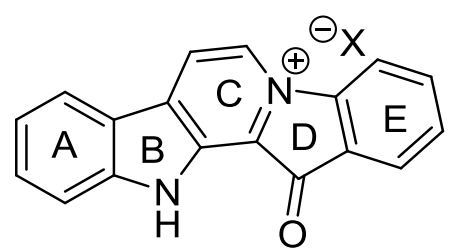

$77 \mathrm{X}=73^{-}$<smiles></smiles>

78<smiles>CC(=CCCC1CCOC1=O)CCC=C(C)CCC1=C(C)C(=O)CCC1(C)C</smiles>

79 
<smiles>[R]c1ccc2c([R])c3c4[nH]c5ccccc5c4ccn3c2c1</smiles>

$80 \mathrm{R}=\mathrm{H} \quad \mathrm{R}_{1}=\mathrm{COCOOCH}_{3}$

$81 \mathrm{R}=\mathrm{H} \quad \mathrm{R}_{1}=\mathrm{CHO}$<smiles>[R]c1ccccc1-[n+]1ccc2c(c1)[nH]c1ccccc12</smiles>

$83 \mathrm{R}=\mathrm{COOH}$

$85 \mathrm{R}=\mathrm{OH}$

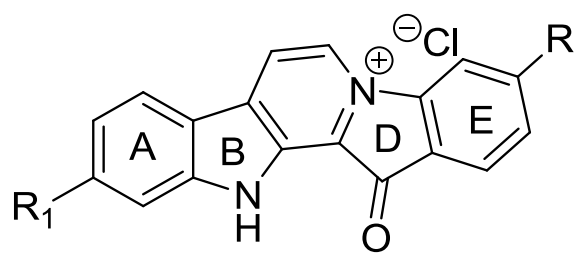

$86 \mathrm{R}=\mathrm{Br} \quad \mathrm{R}_{1}=\mathrm{H}$

$87 \mathrm{R}=\mathrm{Br} \quad \mathrm{R}_{1}=\mathrm{Br}$

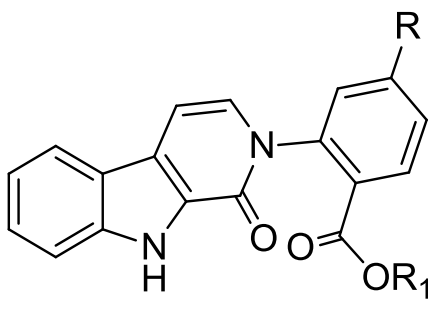

$92 \mathrm{R}=\mathrm{Br} \quad \mathrm{R}_{1}=\mathrm{CH}_{3}$

$93 \mathrm{R}=\mathrm{Br} \quad \mathrm{R}_{1}=\mathrm{H}$

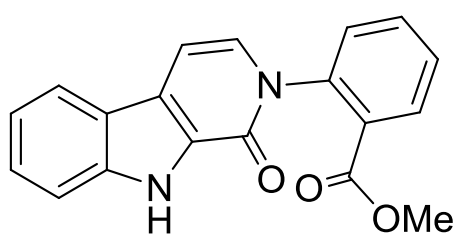

82

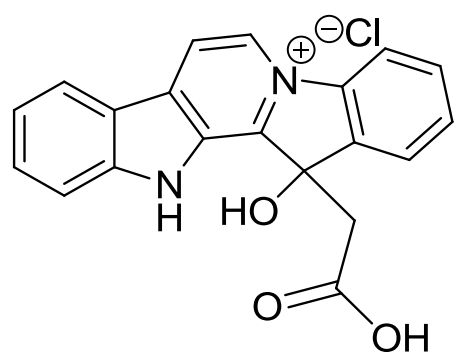

84

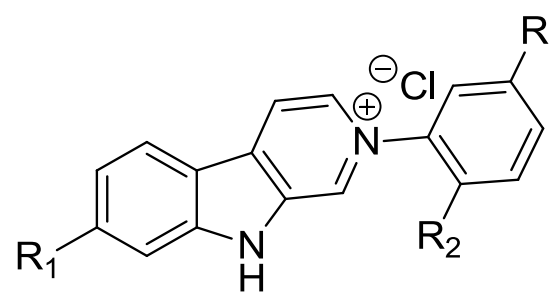

$88 \mathrm{R}=\mathrm{Br} \quad \mathrm{R}_{1}=\mathrm{H} \quad \mathrm{R}_{2}=\mathrm{COOCH}_{3}$

$89 \mathrm{R}=\mathrm{Br} \quad \mathrm{R}_{1}=\mathrm{Br} \quad \mathrm{R}_{2}=\mathrm{COOCH}_{3}$

$90 \quad \mathrm{R}=\mathrm{Br} \quad \mathrm{R}_{1}=\mathrm{H} \quad \mathrm{R}_{2}=\mathrm{COOH}$

$91 \mathrm{R}=\mathrm{Br} \quad \mathrm{R}_{1}=\mathrm{H} \quad \mathrm{R}_{2}=\mathrm{OH}$

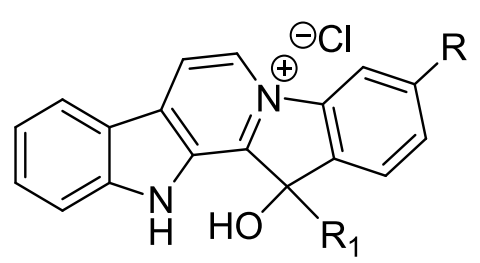

$94 \mathrm{R}=\mathrm{H}$<smiles>[R]c1ccc2c([R])c3c4[nH]c5ccccc5c4ccn3c2c1</smiles>

$95 \mathrm{R}=\mathrm{Br} \quad \mathrm{R}_{1}=\mathrm{COCOOCH}_{3}$

$96 \mathrm{R}=\mathrm{Br} \quad \mathrm{R}_{1}=\mathrm{CHO}$

$97 \quad \mathrm{R}=\mathrm{H} \quad \mathrm{R}_{1}=\mathrm{COCOOCH}_{2} \mathrm{CH}_{3}$

$98 \mathrm{R}=\mathrm{Br} \quad \mathrm{R}_{1}=\mathrm{COCOOCH}_{2} \mathrm{CH}_{3}$ 
All compounds have shown varying degrees of bioactivity, in a number of different biological assays. Given that several compounds have been re-isolated, by more than one research group and hence a variety of bioassays performed, only the few which have shown to exhibit cytotoxicity will be discussed. An in vitro disk diffusion soft agar assay was used to identify solid-tumour selectivity of fascaplysin (69), 10-bromofascaplysin (71), reticulatine (78) reticulatate (83), reticulatol (85), 3-bromofascaplysin (86), 14-bromoreticulatine (88), 7,14-bromoreticulatine (89), 14-bromoreticulatate (90), and 14-bromoreticulatol (91). ${ }^{73 a}$ The cytotoxicity against murine and human solid-tumour, leukaemia and normal cells was measured for each compound and solid-tumour selectivity was determined by calculating the difference in cytotoxicity between solid-tumour and leukaemia, and solid-tumour and normal cells; compounds with a difference equal to or greater than the standard used in the assay were considered as "tumour selective". ${ }^{73 a}$ Fascaplysin (69) was found to be the most cytotoxic and showed selectivity towards murine solid-tumour cell lines (0.4 $\mu \mathrm{g} /$ disk). Reticulatine (78) also displayed selectivity towards murine solid-tumour cell lines although at a concentration 45 times higher (18 $\mu \mathrm{g} /$ disk) than that observed for fascaplysin (69). Conversely, selectivity towards human solid-tumour cell lines was found from 10-bromofascaplysin (71) (0.8 $\mu \mathrm{g} /$ disk) while 3-bromofascaplysin (86) displayed no selectivity in either the murine or human cell lines $(6.4 \mu \mathrm{g} / \mathrm{disk})$. This result suggested that the placement of the bromine within the fascaplysin framework plays a role in the activity. Compared with reticulatine (78), the presence of the bromine in 14-bromoreticulatine $(\mathbf{8 8})$, and 7,14-bromoreticulatine (89) caused a significant decrease in the cytotoxicity and a loss of selectivity (200 and $84 \mu g /$ disk, respectively). Reticulatate (83) was observed to be selective for both murine and human solid-tumour cell lines (64 $\mu \mathrm{g} /$ disk) while 14-bromoreticulatate (90) was not selective towards either (64 $\mu \mathrm{g} /$ disk). Interestingly, reticulatol (85) and 14-bromoretulatol (91) exhibited selectivity towards human leukaemia (64 and $84 \mu \mathrm{g} / \mathrm{disk}$, respectively). ${ }^{73 a}$ Fascaplysin (69), fascaplysin A (77), and 3-bromofascaplysin (86) were also tested for in vitro antitumour activity against 60 human cancer cell lines. The overall results showed 69 and 77 to be approximately equally active, but surprisingly, in many cell lines where fascaplysin (69) was inactive, the presence of the sesterterpene anion in fascaplysin A (77) caused activity. In contrast, 3-bromofascaplysin (86) was found to be more cytotoxic than 69 and 77 but was inactive in cell lines that were sensitive to 69 and $77 .^{73 a}$ Reticulatine (78) was also found to be moderately active against breast (MCF-7) and ovarian cancer (OVCAR-3) cell lines with $\mathrm{IC}_{50}$ values of 1.5 and $2.2 \mathrm{mg} / \mathrm{mL}$, respectively; reticulatate (83) displayed moderate activity against the $\mathrm{MCF}-7$ cell line only $\left(\mathrm{IC}_{50} 5.9 \mathrm{mg} / \mathrm{mL}\right){ }^{82 \mathrm{~b}}$ There appears to be no information on the cytotoxicity of homofascaplysin A (75) in the literature although it is reported to display growth inhibition against the chloroquine- and 
pyrimethamine-resistant Plasmodium falciparum (malaria inducing parasite) strain K1, with an $\mathrm{IC}_{50}$ value of $38 \mathrm{nM}^{73 b}$

\subsection{Biogenetic Relationship between Fascaplysins}

A biogenesis for compounds 63-66 cannot be postulated without proposing a biogenesis on closely related compounds. Currently, there are 24 closely related compounds documented in the literature, and thus a biogenesis would be elaborate and beyond the scope of this report. A simple biogenetic pathway linking certain members of the fascaplysin family has been proposed by Crews et al., which was based upon the general acceptance that they are tryptophan-derived secondary metabolites. ${ }^{73 a}$ Therefore, this report will not attempt to propose a biogenesis but will give a brief depiction of where compounds 63-66 may fit into this proposed pathway.

The putative biogenetic pathway proposed by Crews et al. (Scheme 3.3) provides a relationship between the fascaplysin derivatives isolated in that particular study ${ }^{73 a}$ and fails to include homofascaplysin A (75) and thorectandramine (94), despite the Crews research group providing the original report of homofascaplysin A. ${ }^{81}$ Certainly, 7-bromoreticulatine (63) can be easily incorporated within the proposed biogenetic pathway, as the only modification from reticulatine (78), is the addition of bromine. It is possible that 10-bromo-6,7-dimethoxyhomofascaplayin $C$ (64) is derived from a hypothetical 10-bromohomofascaplysin C. The non-brominated analogue, homofascaplysin C (81) is thought to arise from the postulated $\alpha$-keto acid (Scheme 3.3). ${ }^{73 a}$ The methyl ketone functional group present in 10-bromo-6,7-dimethoxyhomofascaplysin D (65) suggests a close biogenetic relationship with 10-bromohomofascaplysin A (66). Homofascaplysate A (84) is proposed to arise from fascaplysin (69), although how this might occur is uncertain and as such is not depicted in the pathway. ${ }^{73 a}$ Since homofascaplysin A (75) and homofascaplysate A (84) differ only by the carbonyl functional group at C-16, it is assumed that the brominated analogue of 69, 10-bromofascaplysin (71), acts as the precursor to 10-bromohomofascaplysin A (66), either enzymatically or non-enzymatically. The link between 66 and 10-bromo-6,7dimethoxyhomofascaplysin D (65) could possibly occur through a hypothetical 10-bromohomofascaplysin D derivative. The overall proposed biogenesis adapted from Crews et al. illustrated in Scheme 3.3, includes the new fascaplysin derivatives isolated in this study and illustrates hypothetical compounds in blue. 


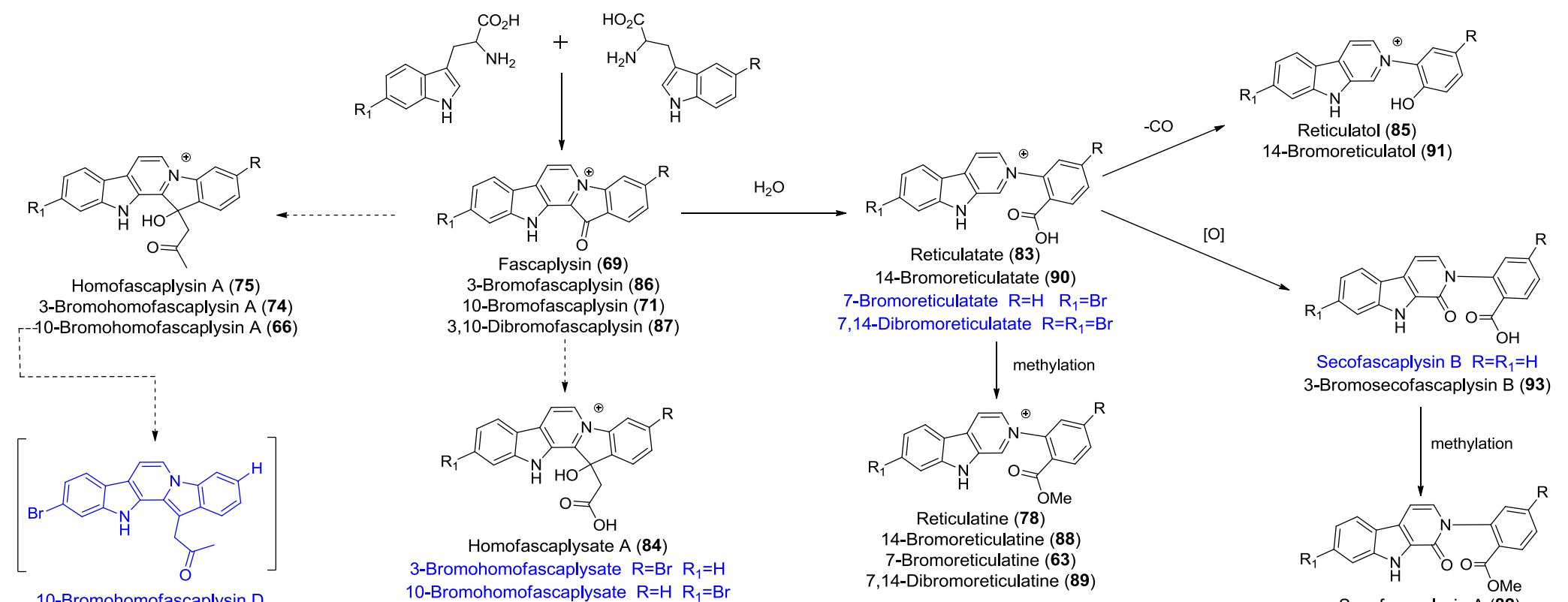

10-Bromohomofascaplysin D 0-Bromohomofascaplysate $\mathrm{R}=\mathrm{H} \quad \mathrm{R}_{1}=$

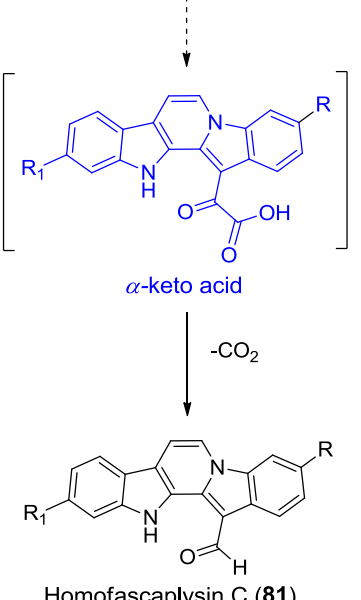

Homofascaplysin C (81)

3- Bromohomofascaplysin $C$ (96)

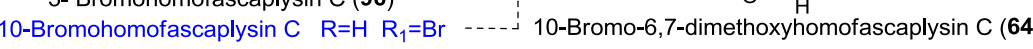

Scheme 3.3. Putative biogenetic relationship between fascaplysin derivatives. Adapted from Crews et al. ${ }^{73 a}$ 


\section{Chapter 4}

\section{Conclusion}

Over the last five decades, complex bioactive marine natural products have attracted the attention of researchers from many scientific disciplines. The oceans remain a largely untapped resource and will continue to supply a considerable number of new and novel, architecturally interesting bioactive compounds, with potential as pharmaceutical drugs and drug leads, for many years to come.

This study began with the investigation of four common Tongan holothurians to determine whether the antifungal activity exhibited by saponins isolated from Australostichopus mollis is unique to the New Zealand sea cucumber, or a generic feature. The Tongan holothurian saponins were found to exhibit similar antifungal activity against Saccharomyces cerevisiae, to that observed for the A. mollis saponin, neothyonidioside (44), suggesting the antifungal activity to be a general characteristic. Since the mechanism of action of neothyonidioside (44) in yeast has since been investigated, this result is not surprising, as other saponins are likely to have the same mechanism of action. ${ }^{67}$

An investigation of Tongan marine sponges involved the screening of five sponge specimens using the VUW MNP laboratory NMR spectroscopy screening protocol. By this method, two topologically dissimilar sponges were found to be identical early in the investigation which may not have been identified until a later stage in a bioassay guided isolation protocol. Purification of an unidentified sponge extract resulted in the isolation of three known euryspongiol congeners which were found to be mixtures. A thorough investigation of a Dictyoceratid sponge yielded four new members of the fascaplysin family. The derivatives all contained bromination of the A-ring, which appears to be a rare feature among members of the fascaplysin family. The NOESY experiment was essential to the confirmation of the 
bromine position. Perhaps further investigations of a larger collection of this sponge may provide additional A-ring brominated analogues to those isolated in this research. Certainly, there remains potential for other fascaplysin derivatives to be discovered from the sponge which could subsequently enable SAR analyses to be performed.

Several challenges were encountered during the isolation of these compounds, notably with respect to their purification. A long-chain alkyl moiety impurity was persistently present and appears to be a common, albeit undesirable feature found alongside the fascaplysin derivatives. The isolation of 10-bromo-6,7-dimethoxyhomofascaplysins $\mathrm{C}$ and D (64 and 65 , respectively) present a new sub-class of naturally-derived fascaplysin congeners whose NMR chemical shifts and ${ }^{1} J_{\mathrm{CH}}$ in particular, were key factors to the indication of hemiaminal ether functionality at CH-6. It remains uncertain whether compounds 64-66 are artefacts of isolation, and this must be further investigated to establish the answer to this question. In the case of compounds 64 and 65, this answer may be found by re-extraction of the sponge specimen but in all instances where methanol is typically used, ethanol should be substituted. For compound 66, acetone should be avoided.

The nanomolar cytotoxicity exhibited by 10-bromohomofascaplysin A (66) and 7-bromoreticulatine $(63)$ is motivation for their re-isolation, so that their biological properties can be thoroughly investigated. Interestingly, compound $\mathbf{6 6}$ displayed cytotoxicity approximately 200 times greater than 64 and 90 times greater than 65; 63 was roughly 12 and 5 times more cytotoxic than 64 and 65, respectively. This result suggests that the presence of the pyridinium cation may be required for activity. It is important to note, that the utilisation of a bioassay guided isolation protocol may have shrouded the isolation of 64 and 63 as a result of the substantial cytotoxicity exhibited by 63 and 66 . 


\section{Chapter 5}

\section{Experimental}

\subsection{General Experimental}

All NMR spectra were recorded using a $600 \mathrm{MHz}$ Varian Direct Drive spectrometer (600 $\mathrm{MHz}$ for ${ }^{1} \mathrm{H}$ nuclei, and $150 \mathrm{MHz}$ for ${ }^{13} \mathrm{C}$ nuclei) equipped with a triple resonance $\mathrm{HCN}$ cryogenic probe operating at $25 \mathrm{~K}$. The residual solvent peak was used as an internal reference for ${ }^{1} \mathrm{H}$ and ${ }^{13} \mathrm{C}$ chemical shifts. ${ }^{84}$ Quantification of ${ }^{1} \mathrm{H}$ NMR samples was performed using the acquisition parameters described by $\mathrm{West}^{57}$ with an internal $\mathrm{CH}_{3} \mathrm{NO}_{2}$ standard. HRESIMS data were obtained from a Waters Q-TOF Premier Tandem Mass spectrometer located at Industrial Research Limited. UV-vis spectra were recorded on an Agilent Diode Array spectrophotometer. Optical rotations were run on a Rudolph Research Analytical Autopol II Automatic polarimeter.

Solvent mixtures for all chromatography are reported as \% v/v. HPLC purifications were carried out using a Rainan Dynamax SD-200 solvent delivery system with $25 \mathrm{~mL}$ pump heads. A Varian Prostar 335 Diode Array detector was used for UV detection of all HPLC runs. Solvents utilised in HPLC were of HPLC grade and $\mathrm{H}_{2} \mathrm{O}$ was glass distilled and deionised using a Millie system. Normal-phase HPLC was performed using a custom-packed Phenomenex analytical $(5.0 \times 250 \mathrm{~mm}, 5 \mu \mathrm{m})$ or semi-preparative $(10 \times 250 \mathrm{~mm}, 5 \mu \mathrm{m})$ dihydroproproxypropyl-derivatised silica (DIOL) column. Reversed-phase HPLC was performed using a Phenomenex Prodigy $C_{18}$ analytical $(4.6 \times 250 \mathrm{~mm}, 5 \mu \mathrm{m})$ or semipreparative $(10 \times 250 \mathrm{~mm}, 10 \mu \mathrm{m})$ column. Normal-phase flash column chromatography was performed using YMC Co. Ltd DIOL chromatographic resin. Reversed-phase chromatography was carried out using Supelco HP20 and HP20ss. Solvents used for bench- 
top chromatography were either glass distilled or of HPLC grade. TLC analyses were performed on Machery-Nagel Alugram SIL G/UV $\mathrm{UV}_{254}$ plates. Analysis of TLC plates was carried out by visualisation of (1) absorbance and fluorescence under UV light $(\lambda=254 \mathrm{~nm}$ and $350 \mathrm{~nm}$ respectively), and (2) dipping in $5 \% \mathrm{H}_{2} \mathrm{SO}_{4} / \mathrm{MeOH}$ followed by dipping in $0.1 \%$ vanillin/EtOH (\% w/v) then heating.

\subsection{Isolation of Euryspongiols A1, A2 and B from an Unidentified Sponge}

The unidentified sponge PTN4_14B was collected by hand using SCUBA at a depth of $\sim 23 \mathrm{~m}$, Northern Vava'u Island, Tonga (18 $36.8^{\prime}$ S, $174^{\circ}$ 01.3' W) in late November 2009, after which it was immediately frozen and stored at $-18{ }^{\circ} \mathrm{C}$ until extraction. A voucher sample was prepared in EtOH and is kept at $-18{ }^{\circ} \mathrm{C}$ at the School of Physical and Chemical Sciences, Victoria University of Wellington, New Zealand.

The sponge (22g; wet weight) was extracted twice overnight with $\mathrm{MeOH}$ (100 mL) and subsequently cyclic loaded onto a $40 \mathrm{~mL} \mathrm{HP} 20$ column and then washed with $\mathrm{H}_{2} \mathrm{O}(60 \mathrm{~mL})$. The column was eluted with $60 \mathrm{~mL}$ of the following: (1) $30 \% \mathrm{Me}_{2} \mathrm{CO} / \mathrm{H}_{2} \mathrm{O}$ (2) $75 \%$ $\mathrm{Me}_{2} \mathrm{CO} / \mathrm{H}_{2} \mathrm{O}$ and (3) $100 \% \mathrm{Me}_{2} \mathrm{CO}$. The $100 \% \mathrm{Me}_{2} \mathrm{CO}$ fraction was concentrated to dryness under reduced pressure to provide $52.5 \mathrm{mg}$ of material, while the $30 \%$ and $75 \% \mathrm{Me}_{2} \mathrm{CO} / \mathrm{H}_{2} \mathrm{O}$ fractions were backloaded onto individual columns packed with HP2O $(20 \mathrm{~mL})$. Each column was then eluted with $\mathrm{Me}_{2} \mathrm{CO}$ to give $5.5 \mathrm{mg}$ of the $30 \%$ fraction and $33.9 \mathrm{mg}$ of the $75 \%$ fraction.

The $75 \%$ fraction was cyclic loaded onto HP20ss and then eluted with $20 \mathrm{~mL}$ portions of $\mathrm{MeOH} / \mathrm{H}_{2} \mathrm{O}$, beginning with $30 \%$ and increasing in $10 \%$ increments, until the final elution with $100 \% \mathrm{MeOH}$. Each fraction was concentrated by rotary evaporation then any remaining water was removed by first freezing with liquid $\mathrm{N}_{2}$ and then by lyophilisation. Based on a combination of TLC (20\% MeOH/DCM) and NMR analyses, the $70 \%-100 \%$ fractions were combined and chromatographed on a DIOL column $(10 \mathrm{~mL})$. The column was eluted with $20 \mathrm{~mL}$ solutions of DCM, 2.5\%, 5\%, 7.5\%, 10\%, 20\%, 50\% EtOAc/DCM, then $50 \%$ $\mathrm{DCM} / \mathrm{MeOH}$, however no separation was achieved. All fractions were combined and an attempt to purify approximately half of the sample on silica $(10 \mathrm{~mL})$ was ineffective as the majority of the sample did not elute from the silica column. Chromatography on a DIOL column $(10 \mathrm{~mL})$ was re-attempted, using the remainder of the $75 \% \mathrm{Me}_{2} \mathrm{CO} / \mathrm{H}_{2} \mathrm{O}$ fraction. The column was eluted with the following: EtOAc, 1\%, 2\%, 5\%, 7.5\% 10\%, 20\% 50\% $\mathrm{MeOH} / \mathrm{EtOAC}$ and finally $\mathrm{Me}_{2} \mathrm{CO}$. Fractions were combined based on TLC analysis with the mobile phase $20 \% \mathrm{MeOH} / \mathrm{DCM}$. The polar fraction (eluting from 20\% MeOH/EtOAc) was 
further purified on an analytical $\mathrm{C}_{18} \mathrm{HPLC}$ column eluting with $60 \% \mathrm{H}_{2} \mathrm{O} / \mathrm{MeCN}$ at a flow rate of $1 \mathrm{~mL} / \mathrm{min}$. Four fractions were collected and two fractions each contained a mixture of closely related compounds. Fraction 2 (retention time $3.5 \mathrm{~min}$ ) gave $0.2 \mathrm{mg}$ of material containing a mixture of euryspongiol A1 (51) and another compound believed to be closely related to 51 (approximate ratio 1.6:1, respectively) though spectral data was either far too weak or absent to allow for structure elucidation of the second compound. Fraction 3 contained $1.3 \mathrm{mg}$ of sample which was a mixture of euryspongiols A2 (52) and B (53) in an approximate ratio of $2: 1$, respectively.

Euryspongiol A1 (51): White solid; NMR data in agreement with those published. ${ }^{69}$

Euryspongiol A2 (52): White solid; NMR data in agreement with those published. ${ }^{69}$

Euryspongiol B (53): White solid; all NMR data in agreement with those published. ${ }^{69}$

\subsection{Isolation of Bis-indole Alkaloids from a Dictyoceratid Sponge}

Two separate collections of the same sponge, PTN4_08E and PTN4_10B, were obtained by hand using SCUBA at a depth of approximately $15 \mathrm{~m}$, from Fakafotulā Island, Vava'u, Tonga (18 39.6' S, $174^{\circ}$ O4.2' $\left.\mathrm{W}\right)$ in late November 2009 . The specimens were frozen immediately and stored at $-18^{\circ} \mathrm{C}$ until extraction. A voucher sample is kept at the School of Chemical and Physical Sciences, Victoria University of Wellington, New Zealand, stored in EtOH at $-18{ }^{\circ} \mathrm{C}$.

The sponge (92 g; wet weight) was cut into small pieces and extracted twice overnight with $\mathrm{MeOH}(2 \times 500 \mathrm{~mL})$. The extracts were cyclic loaded onto a glass column packed with HP2O beads $(200 \mathrm{~mL})$ and the column was subsequently washed with $\mathrm{H}_{2} \mathrm{O}(600 \mathrm{~mL})$. Elution of the column was performed with $300 \mathrm{~mL}$ of each of the following: (1) $30 \% \mathrm{Me}_{2} \mathrm{CO} / \mathrm{H}_{2} \mathrm{O}$, (2) $75 \%$ $\mathrm{Me}_{2} \mathrm{CO} / \mathrm{H}_{2} \mathrm{O}$ and (3) $100 \% \mathrm{Me}_{2} \mathrm{CO}$. Fractions 1 and 2 were backloaded onto separate columns packed with HP2O beads $(100 \mathrm{~mL})$ and subsequently eluted with $\mathrm{Me}_{2} \mathrm{CO}(250 \mathrm{~mL})$. The three organic eluents were concentrated to dryness under reduced pressure to afford $108.0 \mathrm{mg}$ of fraction $1,296.2 \mathrm{mg}$ of fraction 2, and $677.1 \mathrm{mg}$ of fraction 3. Each fraction was analysed by TLC and NMR, the latter revealing interesting aromatic resonances confined to the $100 \% \mathrm{Me}_{2} \mathrm{CO} \mathrm{HP} 20$ fraction.

Fraction 3 was loaded onto DIOL $(60 \mathrm{~mL})$ and the column was eluted with the following: $20 \mathrm{~mL}$ mixtures of pet. ether, $1 \%, 2 \%, 5 \%, 10 \%, 20 \%, 50 \%$ DCM/pet. ether, DCM, $1 \%, 2 \%, 5 \%$, 10\%, 20\%, 50\% EtOAC/DCM, EtOAc, 1\%, 2\%, 5\%, 10\%, 20\%, MeOH/EtOAc, and $400 \mathrm{~mL}$ of 
$50 \% \mathrm{MeOH} / \mathrm{DCM}$. The DIOL remained coloured and was consequently eluted with $10 \%$ $\mathrm{H}_{2} \mathrm{O} / \mathrm{MeOH}$ ( 1 L) over 3 days. Fractions were combined based on TLC evidence.

By ${ }^{1} \mathrm{H}$ NMR analysis, ambliol B $(61,4.5 \mathrm{mg})$ was found in the combined fractions eluted from $20 \% \mathrm{DCM} /$ pet. ether and luffariellolide $(62,147.6 \mathrm{mg})$ was discovered in the fractions eluted from $5 \%$ EtOAc/DCM. The $10 \% \quad \mathrm{H}_{2} \mathrm{O} / \mathrm{MeOH}$ fraction contained $5.1 \mathrm{mg}$ of 7-bromoreticulatine (63). The 50\% MeOH/DCM DIOL fraction was revealed by ${ }^{1} \mathrm{H}$ NMR to contain more of the aromatic resonances of interest and further purification was continued on DIOL $(10 \mathrm{~mL})$, eluting with $30 \mathrm{~mL}$ portions of DCM, 20\%, 40\%, 80\% MeOH/DCM and finally $\mathrm{MeOH}$. Again the fractions were combined on the basis of TLC analysis.

Purification of the combined fractions eluting from the DIOL column from 20\% MeOH/DCM was attempted on an analytical $\mathrm{C}_{18} \mathrm{HPLC}$ column, eluting with $50 \% \mathrm{MeCN} / 0.1 \mathrm{M} \mathrm{HCOOH}$ (aq), then $40 \% \mathrm{MeCN} / 0.1 \mathrm{M} \mathrm{HCOOH}_{(\mathrm{aq})}$, followed by 25\% MeCN/0.05 M HCOOH. These conditions proved to be unsuitable, determined by the UV trace which showed the chromophore streaking. Consequently, the sample was purified on an analytical DIOL HPLC column and eluted with $20 \% \mathrm{IPA} / n$-hexane at a flow rate of $1 \mathrm{~mL} / \mathrm{min}$, then stripped with $80 \%$ IPA/n-hexane. Three fractions were collected, fraction 1 (retention time $6.4 \mathrm{~min}$ ) afforded 10-bromo-6,7-dimethoxyhomofascaplysin C $(64,128 \mu g)$, and fraction 2 (retention time $7.5 \mathrm{~min}$ ) yielded 10-bromo-6,7-dimethoxyhomofascaplysin D $(65,83 \mu \mathrm{g})$. The final fraction which eluted from $80 \%$ IPA/ $n$-hexane was re-chromatographed on an analytical $\mathrm{C}_{18}$ HPLC column and eluted from $30 \% \mathrm{MeCN} / 0.5 \mathrm{M} \mathrm{HCOOH}_{(\mathrm{aq})}$ at a flow rate of $1 \mathrm{~mL} / \mathrm{min}$. One fraction was collected (retention time $2.5 \mathrm{~min}$ ) which was subsequently cyclic loaded onto HP2Oss and eluted with $15 \mathrm{~mL} \mathrm{MeOH}$ to yield $651 \mu \mathrm{g}$ of 10-bromohomofascaplysin A (66).

Ambliol B (61): Red-brown oil; $[\alpha]_{D}^{23}=+67.6^{\circ}\left(c 5.9 \times 10^{-2}, \mathrm{CHCl}_{3}\right)$; all spectroscopic data were in agreement with those previously published. ${ }^{70}$

Luffariellolide (62): Brown oil; $[\alpha]_{D}^{23}=+4.9^{\circ}\left(c\right.$ 1.0, $\left.\mathrm{CHCl}_{3}\right)$; all spectroscopic data were in agreement with those previously published..$^{71}$

10-Bromohomofascaplysin A (63): Yellow solid; $[\alpha]_{D}^{23}=+154^{\circ}\left(c 6.5 \times 10^{-3}, \mathrm{MeOH}\right)$; UV $(\mathrm{MeOH}) \lambda_{\max }(\log \varepsilon) 215 \mathrm{~nm}$ (4.54), $264 \mathrm{~nm}$ (4.41), $347 \mathrm{~nm}$ (4.32); NMR data presented in Tables 3.1 \& 3.2; HRESIMS obsd. $m / z$ 407.0395:409.0382 (1:1, $\left.[\mathrm{M}]^{+}:[\mathrm{M}+2]^{+}\right)$, $\mathrm{C}_{21} \mathrm{H}_{16} \mathrm{~N}_{2} \mathrm{O}_{2} \mathrm{Br}^{+}$, calcd. 407.0395 : 409.0370, $\Delta 0.0$ ppm. 
10-Bromo-6,7-dimethoxyhomofascaplysin C (64): Yellow solid; $[\alpha]_{D}^{23}=-2222^{\circ}\left(c 5.0 \times 10^{-4}\right.$, $\mathrm{CHCl}_{3}$ ); UV (MeOH) $\lambda_{\max }(\log \varepsilon) 6.38 \times 10-6242 \mathrm{~nm}(4.64), 355 \mathrm{~nm}(4.50), 375 \mathrm{~nm}$ (4.52); NMR data presented in Table 3.5; HRESIMS obsd. $m / z 423.0348: 425.0347$ (1: $1,[\mathrm{M}-\mathrm{H}]^{-}$: $\left.[\mathrm{M}+2-\mathrm{H}]^{-}\right), \mathrm{C}_{21} \mathrm{H}_{16} \mathrm{~N}_{2} \mathrm{O}_{3} \mathrm{Br}$, calcd. $423.0344: 425.0329, \Delta 0.9 \mathrm{ppm}$.

10-Bromo-6,7-dimethoxyhomofascaplysin D (65): Yellow solid; $[\alpha]_{D}^{23}=0^{\circ}\left(c 3.0 \times 10^{-4}\right.$, $\mathrm{CHCl}_{3}$ ); UV (MeOH) $\lambda_{\max }(\log \varepsilon) 228 \mathrm{~nm}$ (4.62), $260 \mathrm{~nm}$ (4.44), $393 \mathrm{~nm}$ (4.33); NMR data presented in Tables 3.3 \& 3.4; HRESIMS obsd $m / z$ 451.0654:453.0664 (1:1, $\left.[\mathrm{M}-\mathrm{H}]^{-}:[\mathrm{M}+2-\mathrm{H}]^{-}\right), \mathrm{C}_{23} \mathrm{H}_{20} \mathrm{~N}_{2} \mathrm{O}_{3}$ Br calcd. $451.0657: 453.0642, \Delta-0.7$ ppm.

7-Bromoreticulatine (66): Brown-yellow oil; UV (MeOH) $\lambda_{\max }(\log \varepsilon) 207 \mathrm{~nm}(4.88), 252 \mathrm{~nm}$ (4.62), $322 \mathrm{~nm}$ (4.43); NMR data presented in Table 3.6; HRESIMS obsd. $\left.m / z 381.0233: 383.0215(1: 1, M]^{+}:[\mathrm{M}+2]^{+}\right), \mathrm{C}_{19} \mathrm{H}_{14} \mathrm{~N}_{2} \mathrm{O}_{2} \mathrm{Br}^{+}$, calcd. 381.0239:383.0213, $\Delta-1.6 \mathrm{ppm}$.

\subsubsection{Re-extraction of a Specimen of Sponge PTN4_08B in the Search for 10-bromohomofascaplysin A}

A small specimen (21.5 g; wet weight) of PTN4_08E was cut from the parent specimen and extracted twice in MeOH overnight $(100 \mathrm{~mL})$. The extracts were cyclic loaded onto an HP2O column $(40 \mathrm{~mL})$ and washed with $\mathrm{H}_{2} \mathrm{O}(60 \mathrm{~mL})$. Elution of the column was carried out with $60 \mathrm{~mL}$ of (1) $75 \% \mathrm{MeOH} / \mathrm{H}_{2} \mathrm{O}$ (2) $90 \% \mathrm{MeOH} / \mathrm{H}_{2} \mathrm{O}$ (3) $100 \% \mathrm{MeOH}$ and then (4) $100 \mathrm{~mL}$ of THF. The $75 \%-100 \% \mathrm{MeOH} / \mathrm{H}_{2} \mathrm{O}$ fractions yielded yellow eluents and were concentrated by rotary evaporation, then remaining $\mathrm{H}_{2} \mathrm{O}$ was frozen with liquid $\mathrm{N}_{2}$ and the samples were freeze dried to give $17.3,18.8,27.0 \mathrm{mg}$ of material of the $75 \%, 90 \% \mathrm{MeOH} / \mathrm{H}_{2} \mathrm{O}$ and $100 \%$ $\mathrm{MeOH}$ fractions, respectively. The THF fraction provided a dark green eluent which was backloaded onto an HP2O column $(20 \mathrm{~mL})$ and the column was washed with $\mathrm{H}_{2} \mathrm{O}$. The HP2O beads were transferred to a round bottom flask $(100 \mathrm{~mL})$ and freeze dried. Once dry, the beads were washed with DCM $(100 \mathrm{~mL})$ by filtration into a Buchner flask $(250 \mathrm{~mL})$ providing a yellow filtrate that was concentrated under reduced pressure to afford $83.7 \mathrm{mg}$ of material.

The $75 \% \mathrm{MeOH} / \mathrm{H}_{2} \mathrm{O}$ fraction was further purified on a DIOL column $(10 \mathrm{~mL})$, eluting with $30 \mathrm{~mL}$ portions of DCM, 20\%, 40\% MeOH/DCM and 100\% MeOH. The ${ }^{1} \mathrm{H}$ NMR spectra revealed the aromatic resonances as being confined to the $20 \%$ and $40 \% \mathrm{MeOH} / \mathrm{DCM}$ fractions, however analysis of the 2D NMR data acquired for these fractions lacked evidence for the presence of 10-bromohomofascaplysin A (66) and 10-bromofascaplysin (71). 1D and 
2D NMR data were acquired for the $90 \% \mathrm{MeOH} / \mathrm{H}_{2} \mathrm{O} \mathrm{HP} 2 \mathrm{O}$ fraction which also showed no evidence for either of these compounds. 


\section{Appendix $A$}

\section{Existing Marine Chemistry Screening Protocol}

\section{Required apparatus}

- $1 \times$ Screen column loaded with $40 \mathrm{~mL}$ HP2O for Tongan specimens, $80 \mathrm{~mL}$ for New Zealand specimens, equilibrated in $\mathrm{MeOH}$

- $1 \times$ Backloading column loaded with $20 \mathrm{~mL}$ HP20 for Tongan specimens, $40 \mathrm{~mL}$ for New Zealand specimens, equilibrated in $\mathrm{MeOH}$

\section{Preparation of Nitromethane Quantification Standard}

- Prepare a $0.01 \%$ solution (\% v/v) by transferring $100 \mu \mathrm{L} \mathrm{CH}_{3} \mathrm{NO}_{2}$ into a $10 \mathrm{~mL}$ volumetric flask and topping up to $10 \mathrm{~mL}$ with $d$-chloroform.

\section{Procedure}

\section{Preparation of Voucher Sample}

- Take a voucher specimen of approximately $10 \mathrm{~g}$ of sponge, ensuring that it is representative of both the ectoderm and endoderm.

- Label and store the voucher sample in 75\% isopropanol in water.

\section{Extraction}

- Extract approximately $20 \mathrm{~g}$ of crude sponge material in $100 \mathrm{~mL} \mathrm{MeOH}$ overnight (100 g for New Zealand Marine organisms in $400 \mathrm{~mL} \mathrm{MeOH}$ ).

- Filter the extract and set aside. Re-extract the sponge material (and any filter paper/celite) in $100 \mathrm{~mL} \mathrm{MeOH}$ overnight.

- Filter the second extract. 
- Keep all sponge material (including filter paper/celite) until the screen is complete at which time it may be discarded.

\section{Cyclic Loading}

- Pass the second extract through the screen column with a flow rate of approximately $10 \mathrm{~mL} / \mathrm{min}$.

- Pass the first extract through the screen column with a flow rate of approximately $10 \mathrm{~mL} / \mathrm{min}$. Combine the eluent with that of the second extract.

- Dilute the combined eluents with $200 \mathrm{~mL}$ of distilled water. Pass the diluted eluents back through the screen column at a flow rate of approximately $10 \mathrm{~mL} / \mathrm{min}$.

- Dilute the eluent with $400 \mathrm{~mL}$ of distilled water. Pass the diluted eluent back through the screen column at a flow rate of approximately $10 \mathrm{~mL} / \mathrm{min}$.

- The eluent should be kept until the screen is complete at which time it may be discarded.

\section{Elution}

- Elute the screen column with $100 \mathrm{~mL}$ of distilled water at a flow rate of approximately $10 \mathrm{~mL} / \mathrm{min}$. The water eluent can be discarded immediately.

- Elute the screen column with $100 \mathrm{~mL}$ of $30 \%$ acetone in distilled water at a flow rate of approximately $10 \mathrm{~mL} / \mathrm{min}$.

- Elute the screen column with $100 \mathrm{~mL}$ of $75 \%$ acetone in distilled water at a flow rate of approximately $10 \mathrm{~mL} / \mathrm{min}$.

- Elute the screen column with $100 \mathrm{~mL}$ of $100 \% \mathrm{Me}_{2} \mathrm{CO}$ at a flow rate of approximately $10 \mathrm{~mL} / \mathrm{min}$.

\section{Backloading the $75 \%$ Acetone Fraction}

- Dilute the $75 \%$ acetone fraction with $100 \mathrm{~mL}$ of distilled water. Pass the diluted eluent through the backloading column at a flow rate of approximately $8 \mathrm{~mL} / \mathrm{min}$. 
- Dilute the eluent with $200 \mathrm{~mL}$ of distilled water. Pass the eluent back through the backloading column at a flow rate of approximately $8 \mathrm{~mL} / \mathrm{min}$.

- The eluent should be kept until the screen is complete at which time it may be discarded.

- Elute the backloading column with $100 \%$ acetone.

\section{Processing the $75 \%$ Acetone Fraction}

- Concentrate the acetone eluent to dryness by rotary-evaporation then transfer to a pre-weighed sample vial. If solvent was used for the transfer, concentrate to dryness and record the mass.

- If sufficient mass is obtained, sub-sample approximately $30 \mathrm{mg}$ for NMR analysis.

- In a $5 \mathrm{~mm}$ NMR tube, prepare an NMR sample by dissolving the sub-sample in $500 \mu \mathrm{L}$ of $\mathrm{CD}_{3} \mathrm{OD}$.

- Add $10 \mu \mathrm{L}$ of the nitromethane standard to the NMR tube.

\section{NMR Analysis of the $75 \%$ Acetone Fraction}

- Run a ${ }^{1} \mathrm{H}$ NMR spectrum of the sample on the $600 \mathrm{MHz}$ instrument using the standard 'Screen $1 \mathrm{H}$ ' parameter set (experiment time approximately 4 mins).

- Make a note "standard added" in the sample text.

- Run a COSY spectrum of the sample using the standard 'ScreenCOSY' parameter set (experiment time approximately 20 mins).

- Run an HSQC NMR spectrum of the sample using the standard 'ScreenHSQC' parameter set (experiment time approximately $5.5 \mathrm{~h}$ ).

\section{Backloading the $30 \%$ Acetone Fraction}

- Dilute the $30 \%$ acetone fraction with $100 \mathrm{~mL}$ of distilled water. Pass the diluted eluent through the backloading column at a flow rate of approximately $8 \mathrm{~mL} / \mathrm{min}$. 
- Dilute the eluent with $200 \mathrm{~mL}$ of distilled water. Pass the eluent back through the backloading column at a flow rate of approximately $8 \mathrm{~mL} / \mathrm{min}$.

- The eluent should be kept until the screen is complete at which time it may be discarded.

- Elute the backloading column with $100 \%$ acetone.

\section{Processing the $30 \%$ Acetone Fraction}

- Concentrate the acetone eluent to dryness by rotary-evaporation then transfer to a pre-weighed sample vial. If solvent was used in the transfer, concentrate to dryness and record the mass.

- If sufficient mass is obtained, sub-sample approximately $30 \mathrm{mg}$ for NMR analysis.

- Prepare an NMR sample in $500 \mu \mathrm{L}$ of $\mathrm{CD}_{3} \mathrm{OD}$ in a $5 \mathrm{~mm}$ NMR tube.

10. NMR Analysis of the $30 \%$ Acetone Fraction

- Run a ${ }^{1} \mathrm{H}$ NMR spectrum of the sample using the standard 'Screen $1 \mathrm{H}^{\prime}$ ' parameter set.

\section{Processing the $100 \%$ Acetone Fraction}

- Concentrate the acetone eluent to dryness by rotary-evaporation then transfer to a pre-weighed sample vial. If solvent was used in the transfer, concentrate to dryness and record the mass.

- Prepare an NMR sample in $700 \mu \mathrm{L} \mathrm{CDCl}_{3}$ in a $5 \mathrm{~mm}$ NMR tube.

\section{NMR Analysis of the $100 \%$ Acetone Fraction}

- Run a ${ }^{1} \mathrm{H}$ NMR spectrum of the sample using the standard 'Screen $1 \mathrm{H}^{\prime}$ ' parameter set. 


\section{Appendix $B$}

${ }^{1} \mathrm{H}$ and ${ }^{13} \mathrm{C}$ NMR Spectra of Known Compounds

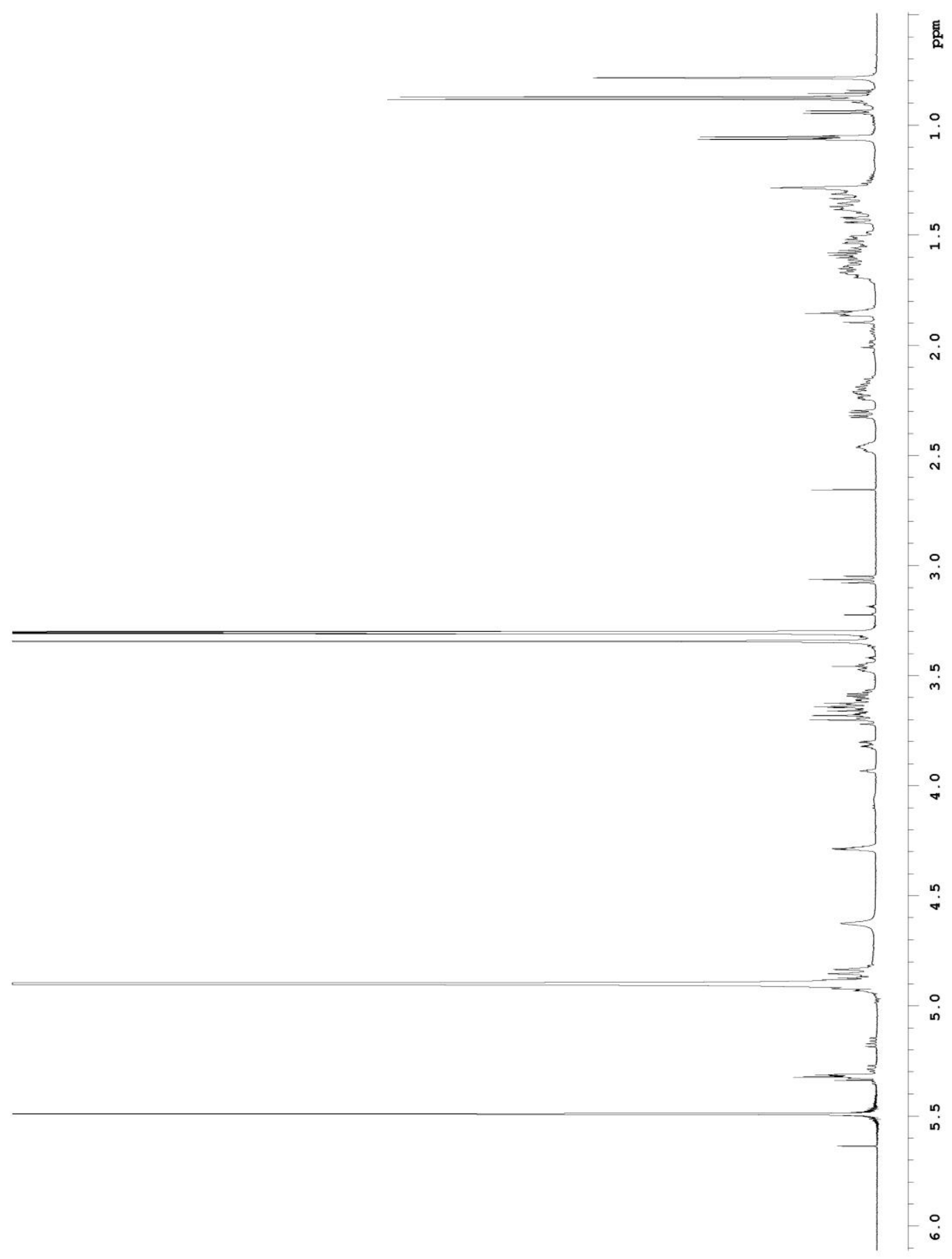

${ }^{1} \mathrm{H}$ NMR spectrum of Euryspongiol A1 (51) (MeOD, $600 \mathrm{MHz}$ ) 


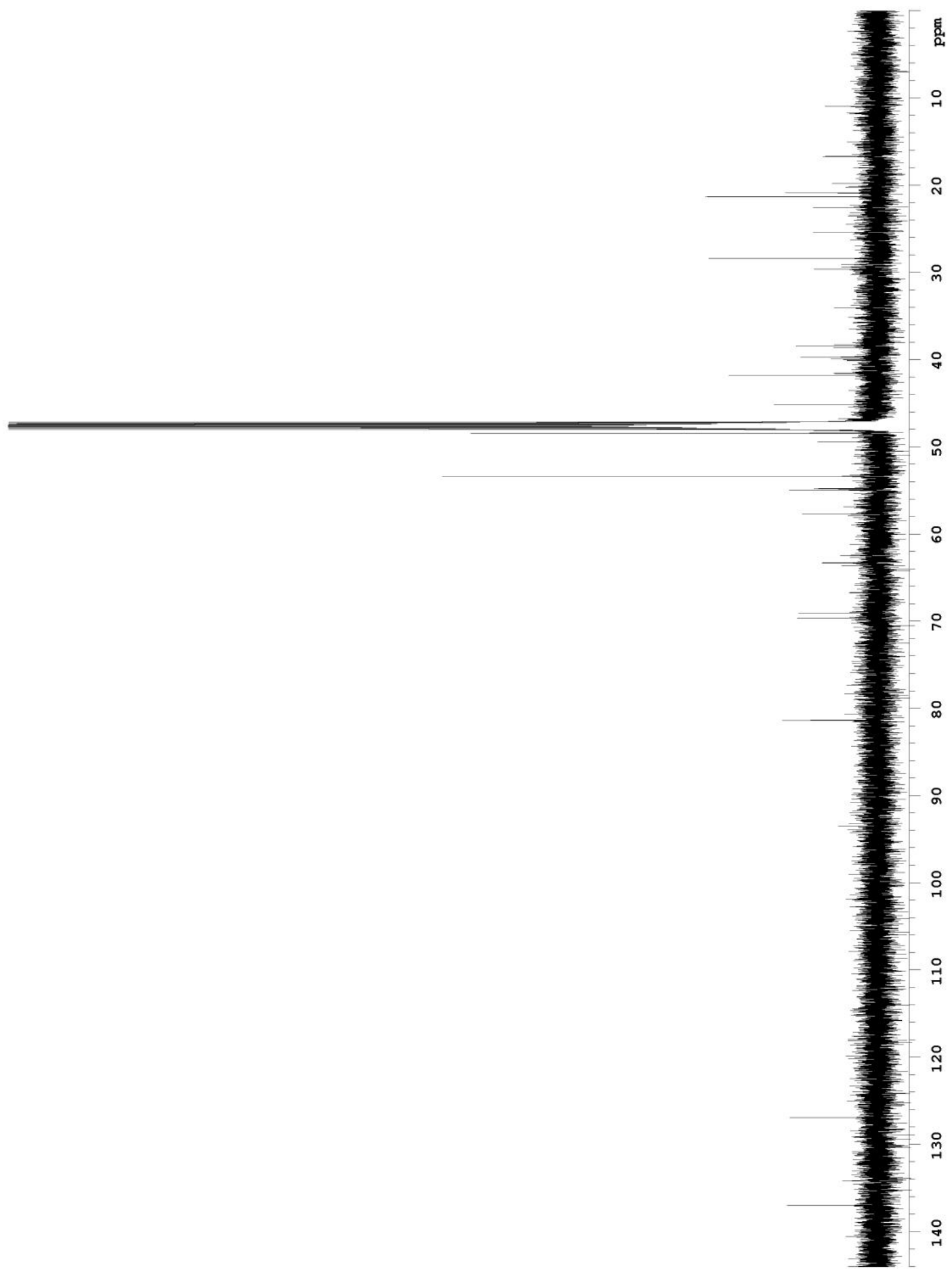

${ }^{13} \mathrm{C}$ NMR spectrum of Euryspongiol A1 (51) (MeOD, $600 \mathrm{MHz}$ ) 


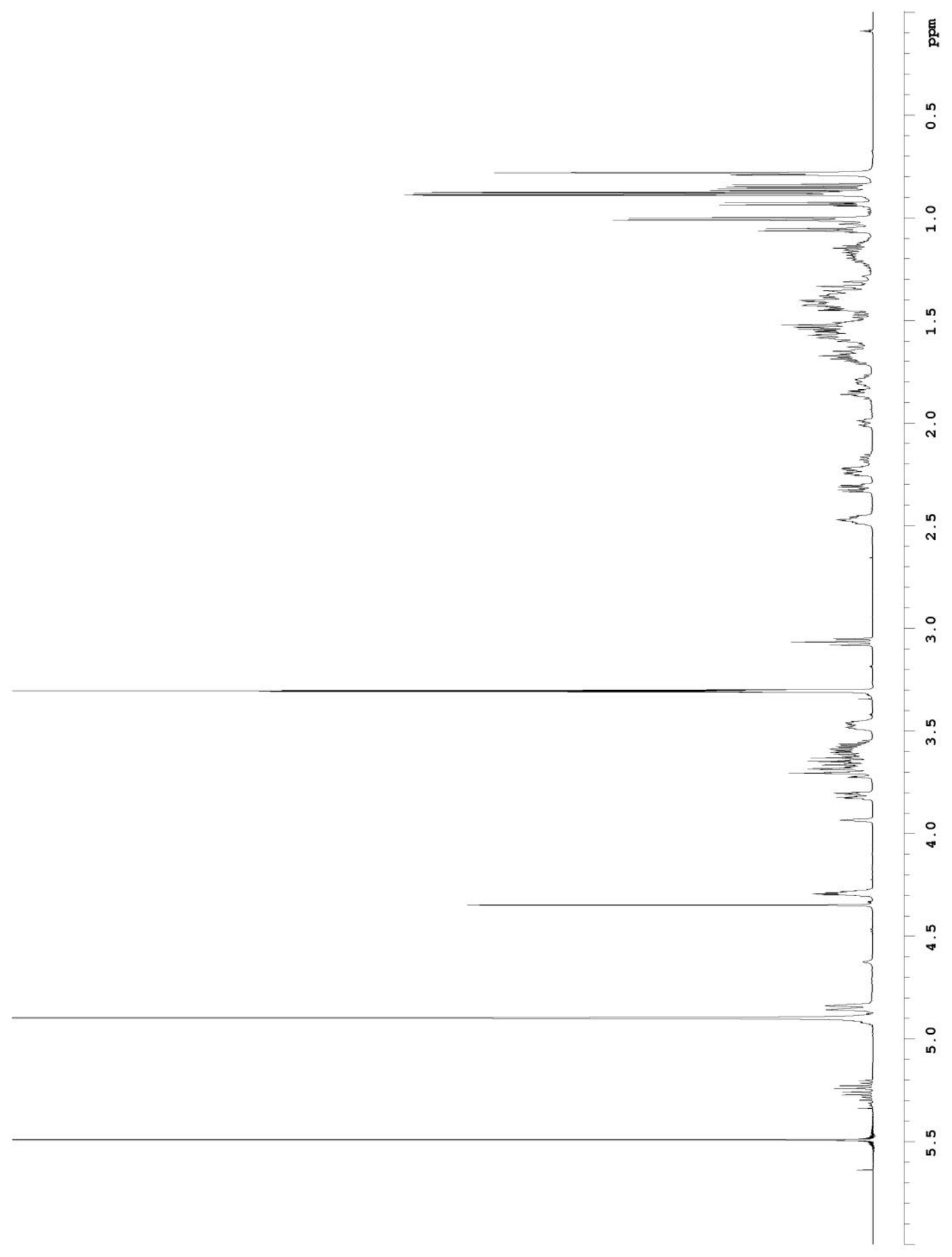

${ }^{1} \mathrm{H}$ NMR spectrum of Euryspongiols A2 (52; major) and B (53; minor) (MeOD, $\left.600 \mathrm{MHz}\right)$ 


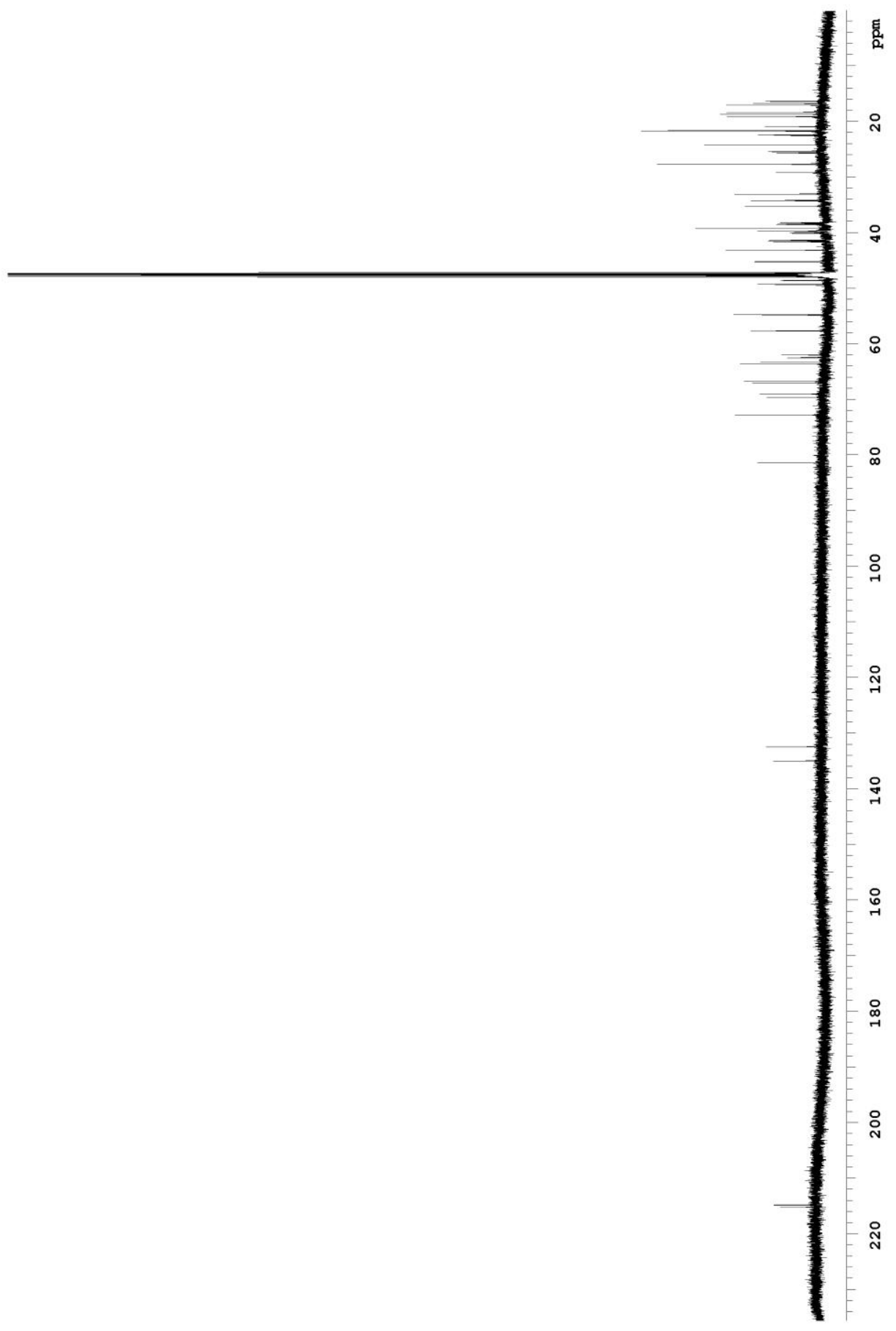

${ }^{13} \mathrm{C}$ NMR spectrum of Euryspongiols A2 (52; major) and B (53; minor) (MeOD, $600 \mathrm{MHz}$ ) 


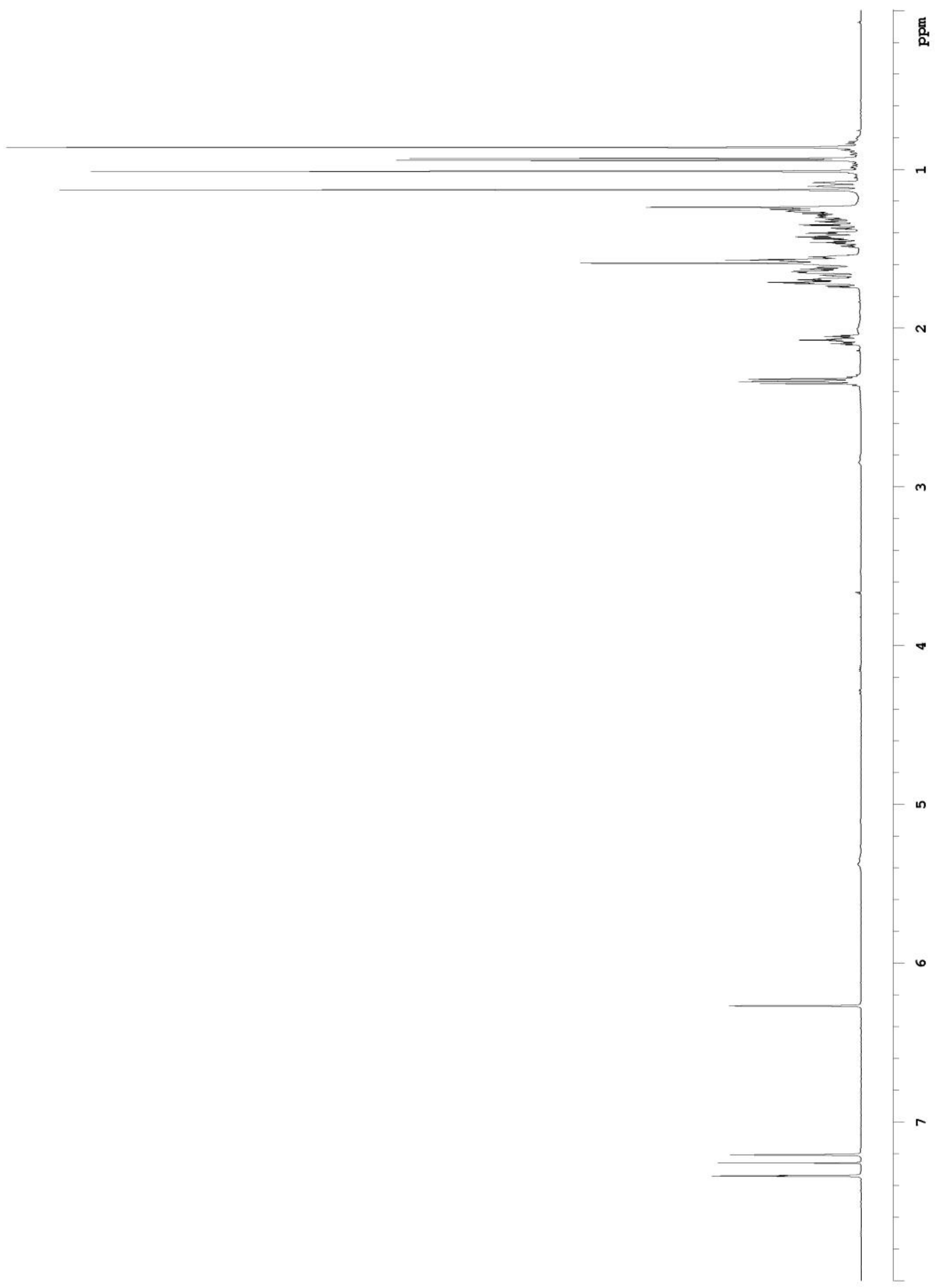

${ }^{1} \mathrm{H}$ NMR spectrum of ambliol B $(61)\left(\mathrm{CDCl}_{3}, 600 \mathrm{MHz}\right)$ 


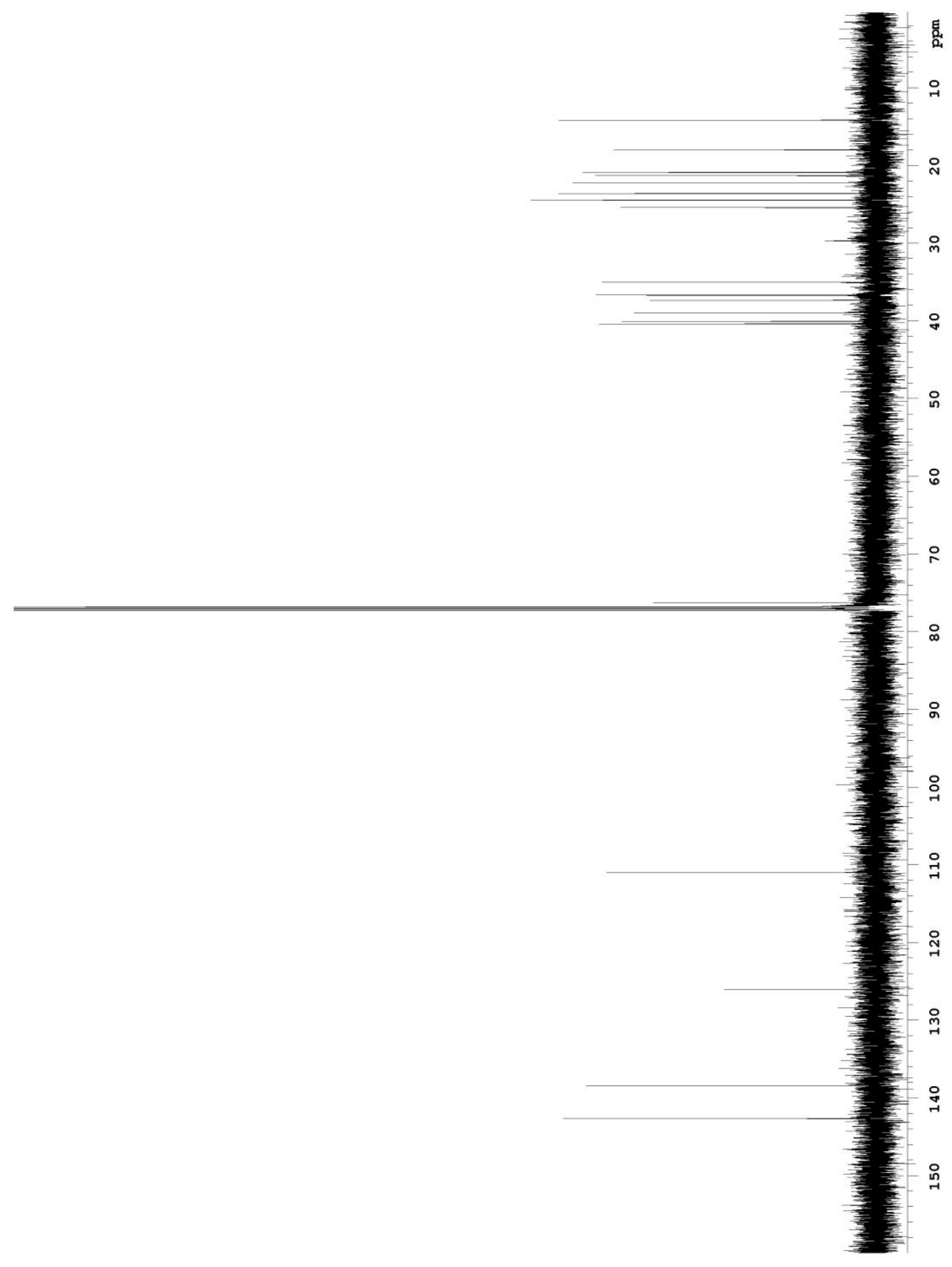

${ }^{13} \mathrm{C}$ NMR spectrum of ambliol B $(61)\left(\mathrm{CDCl}_{3}, 600 \mathrm{MHz}\right)$ 


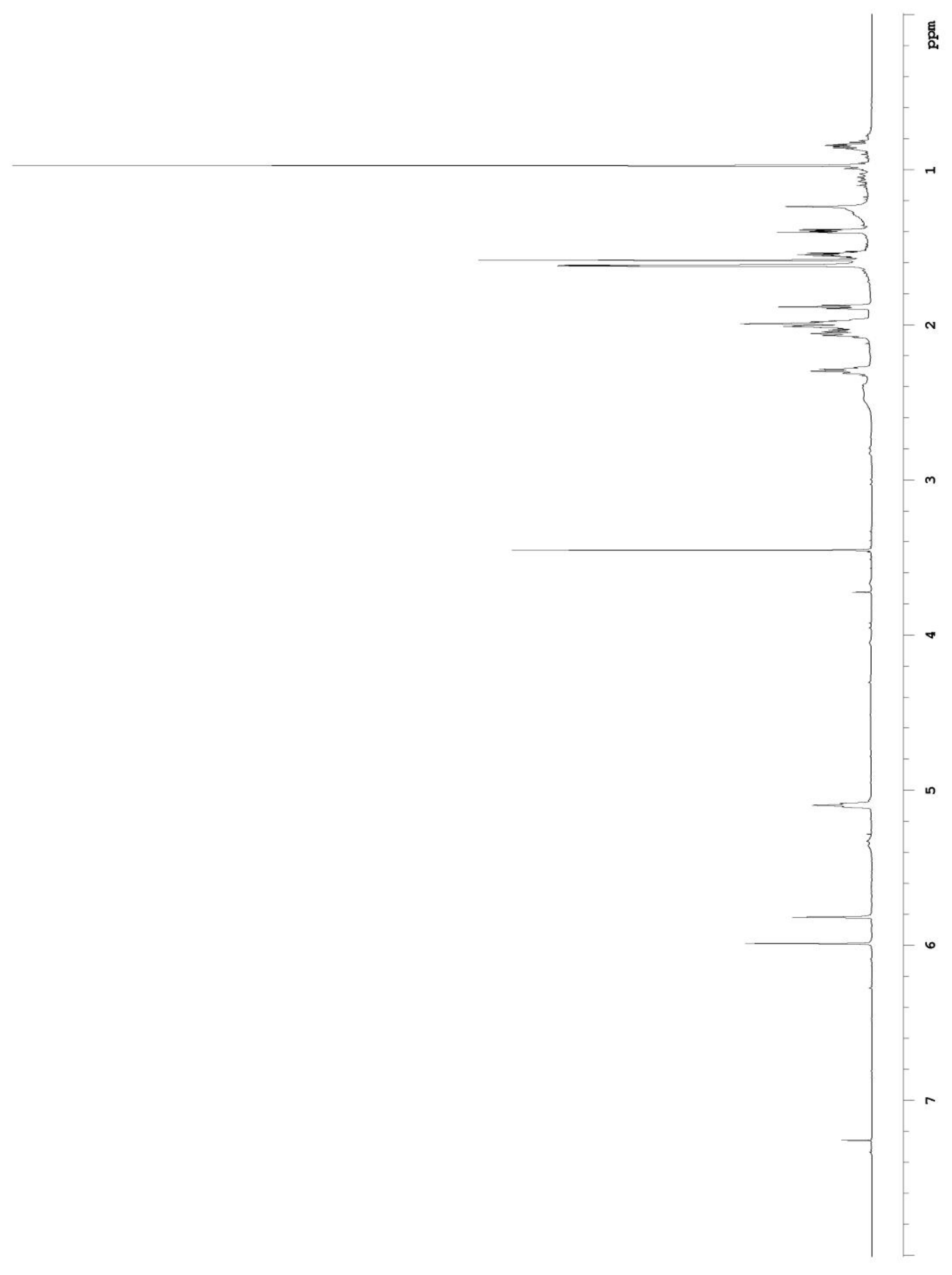

${ }^{1} \mathrm{H}$ NMR spectrum of luffariellolide (62) $\left(\mathrm{CDCl}_{3}, 600 \mathrm{MHz}\right)$ 


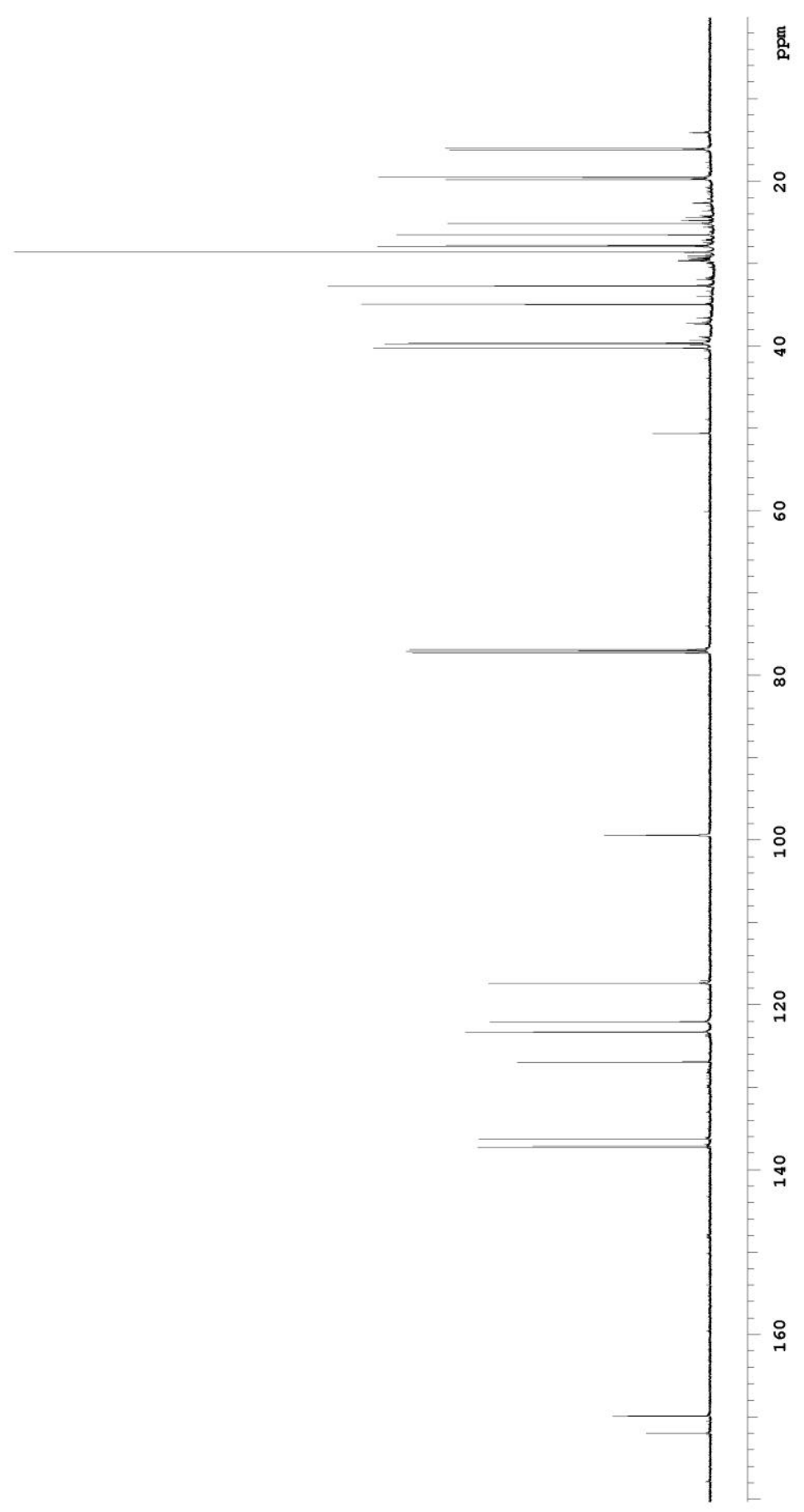

${ }^{13} \mathrm{C}$ NMR spectrum of luffariellolide $(62)\left(\mathrm{CDCl}_{3}, 600 \mathrm{MHz}\right)$ 
Appendix $C$

7-Bromoreticulatine Spectra

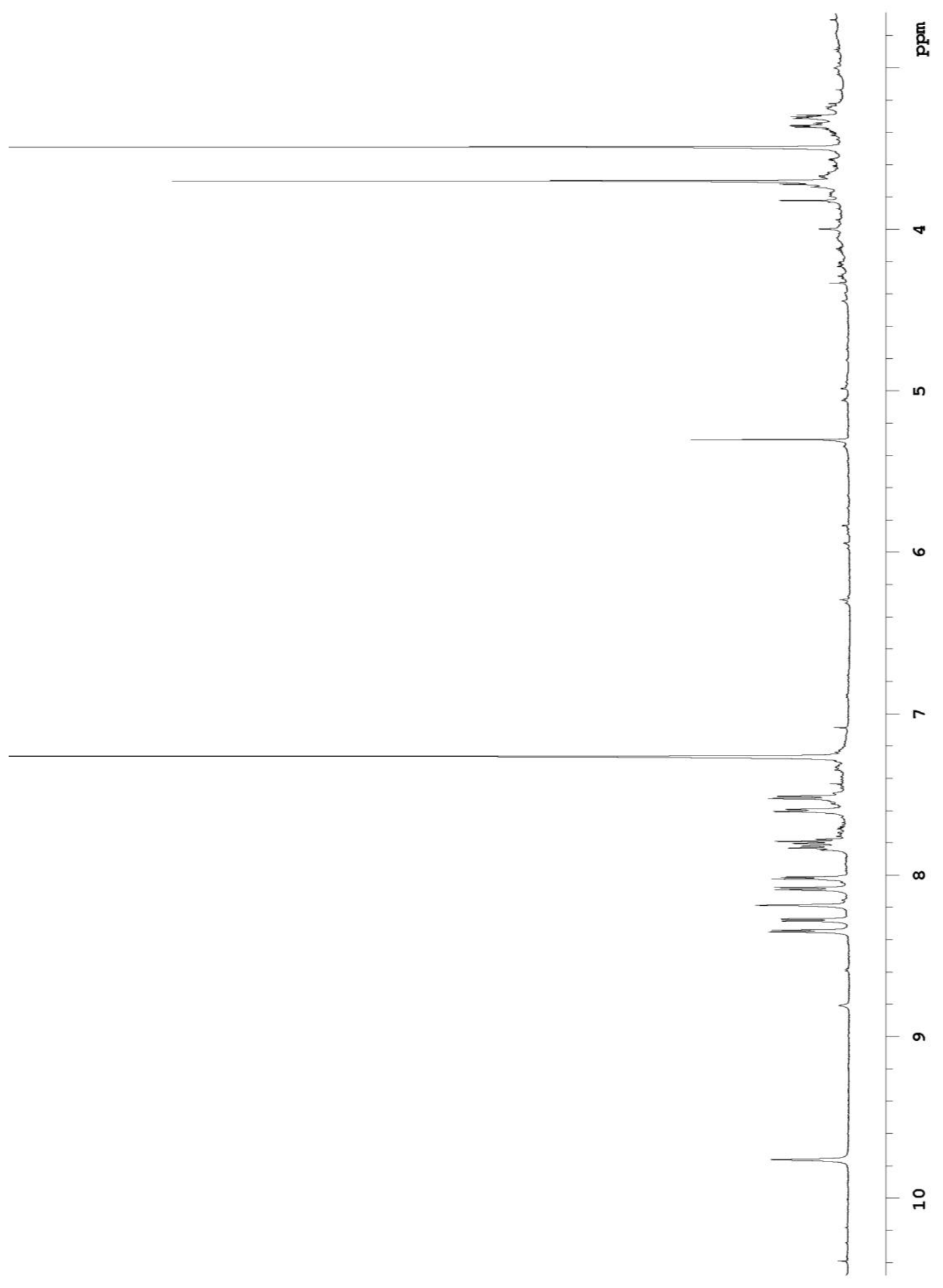

${ }^{1} \mathrm{H}$ NMR spectrum of 7-bromoreticulatine (63) $\left(\mathrm{CDCl}_{3}, 600 \mathrm{MHz}\right)$ 


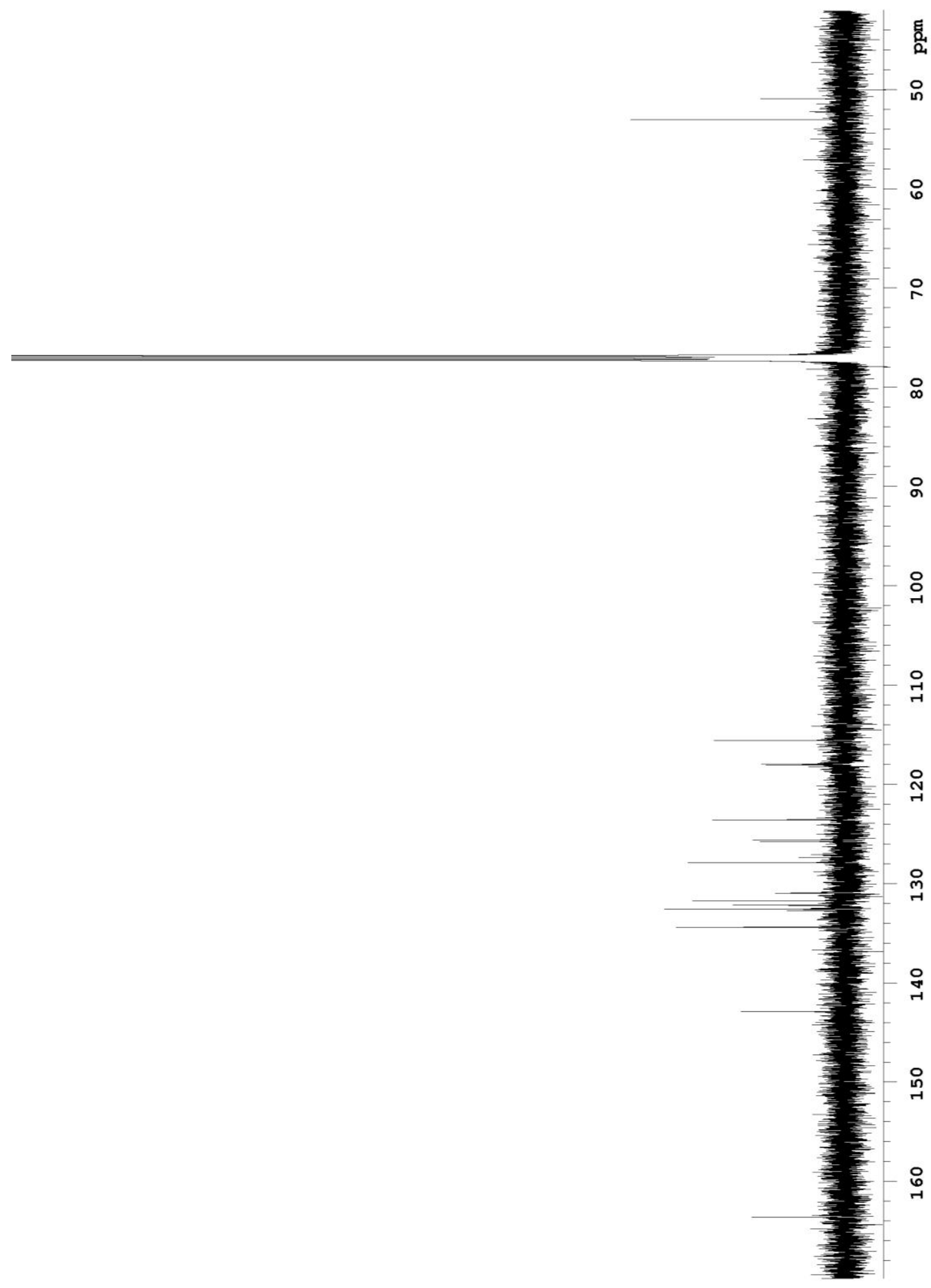

${ }^{13} \mathrm{C}$ NMR spectrum of 7 -bromoreticulatine $(63)\left(\mathrm{CDCl}_{3}, 600 \mathrm{MHz}\right)$ 


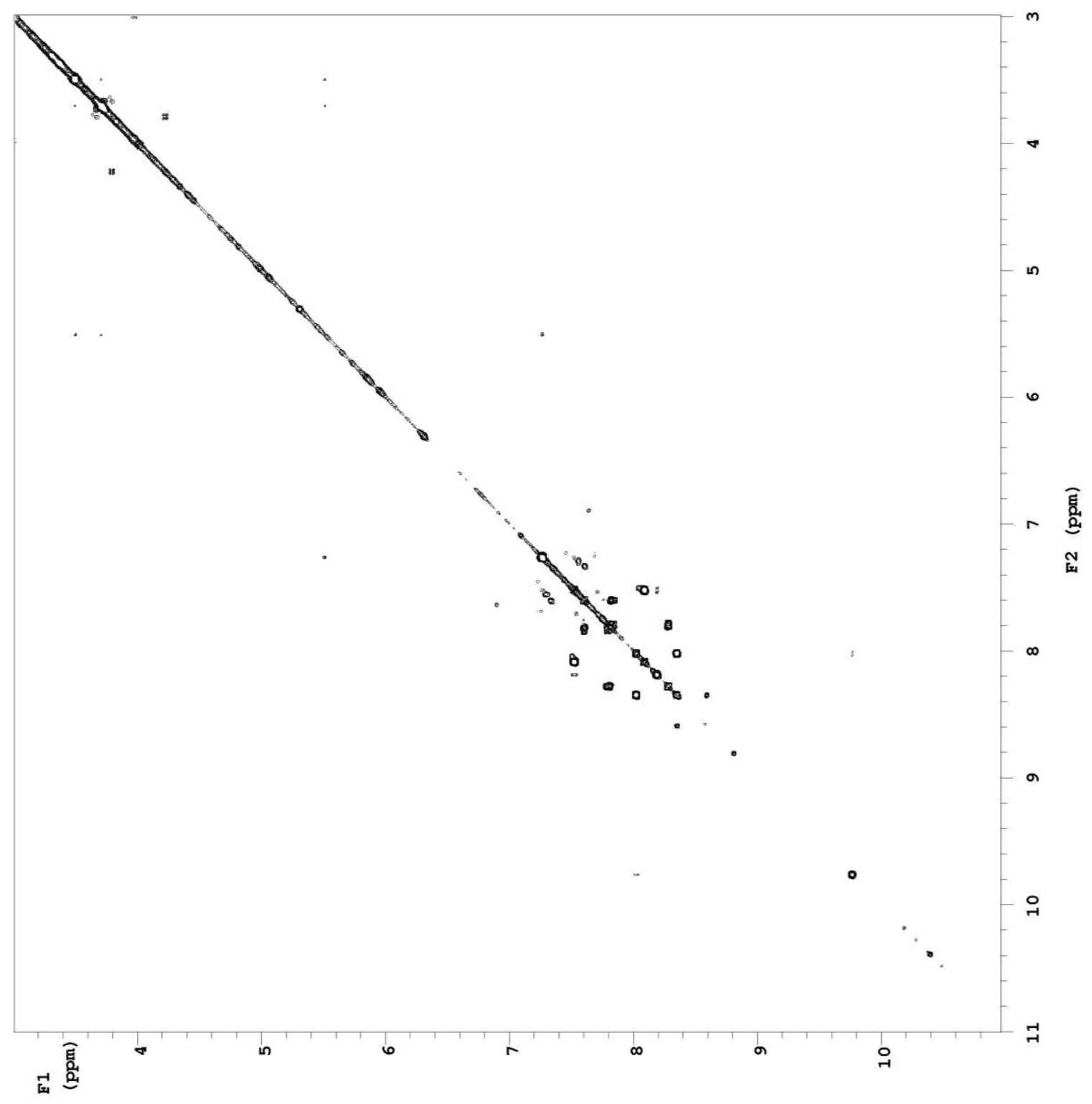

COSY spectrum of 7-bromoreticulatine (63) $\left(\mathrm{CDCl}_{3}, 600 \mathrm{MHz}\right)$ 


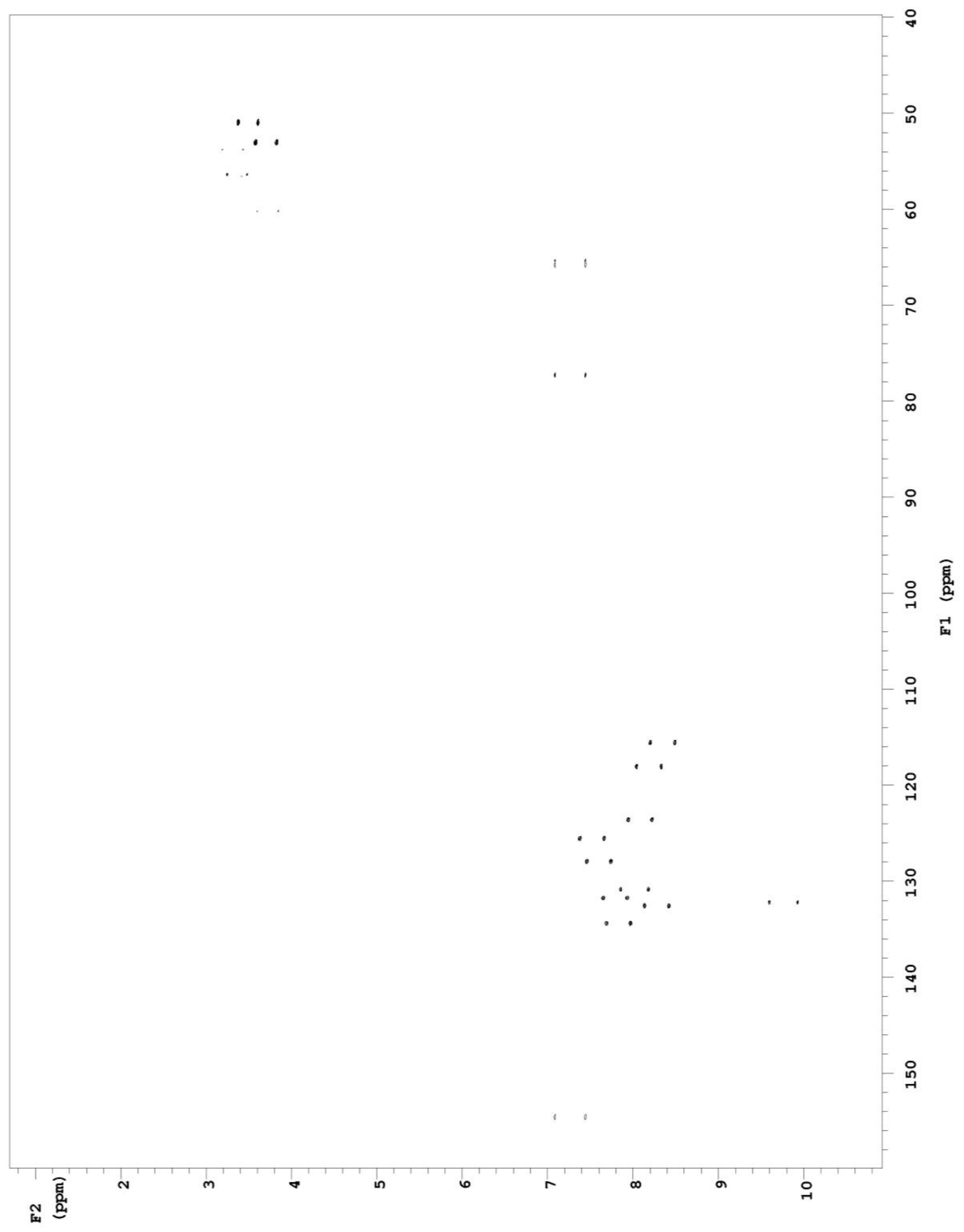

HSQC (coupled) spectrum of 7-bromoreticulatine (63) $\left(\mathrm{CDCl}_{3}, 600 \mathrm{MHz}\right)$ 


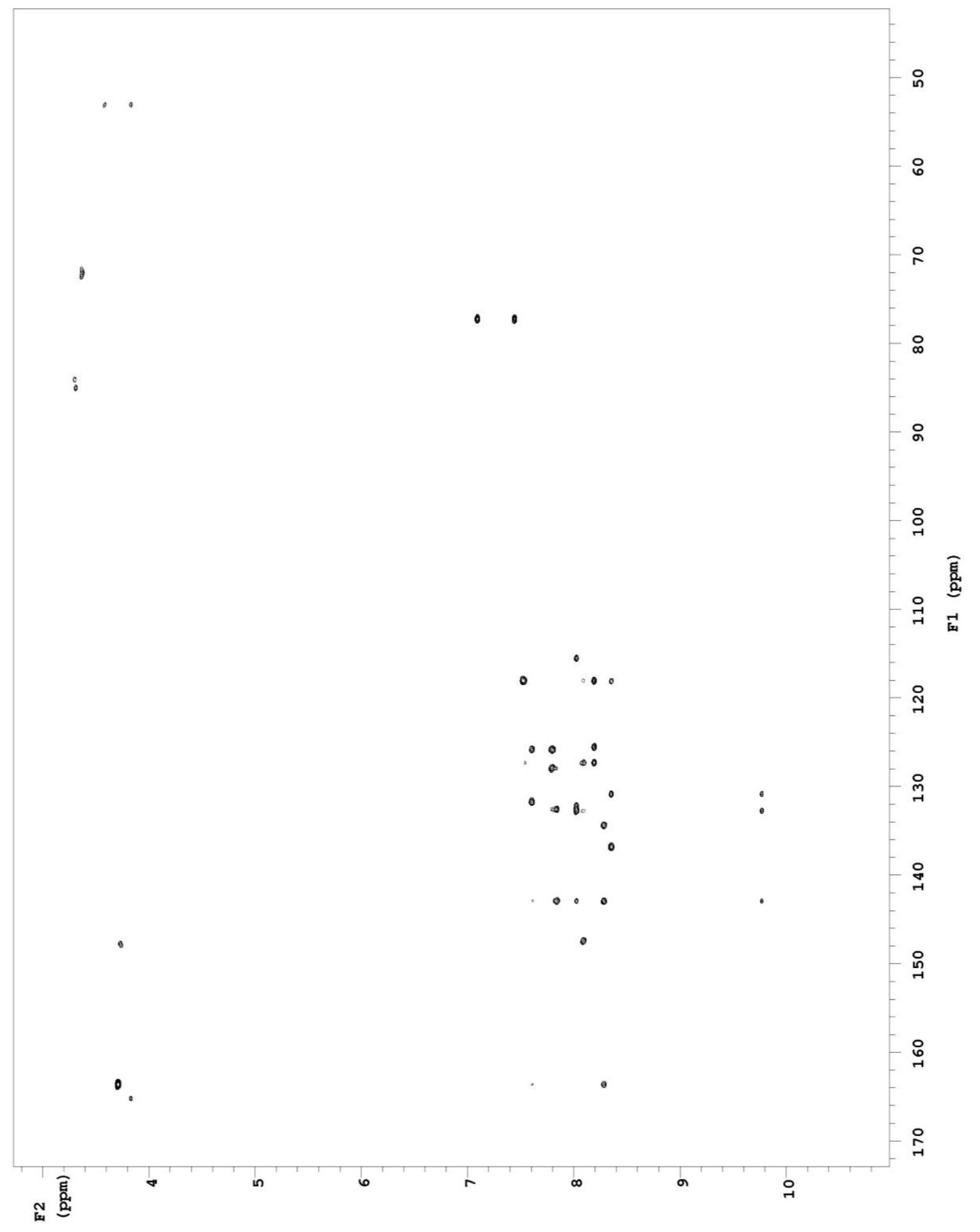

$\mathrm{HMBC}$ spectrum of 7-bromoreticulatine $(63)\left(\mathrm{CDCl}_{3}, 600 \mathrm{MHz}\right)$ 


\section{Appendix D}

10-Bromo-6,7-dimethoxyhomofascaplysin C Spectra

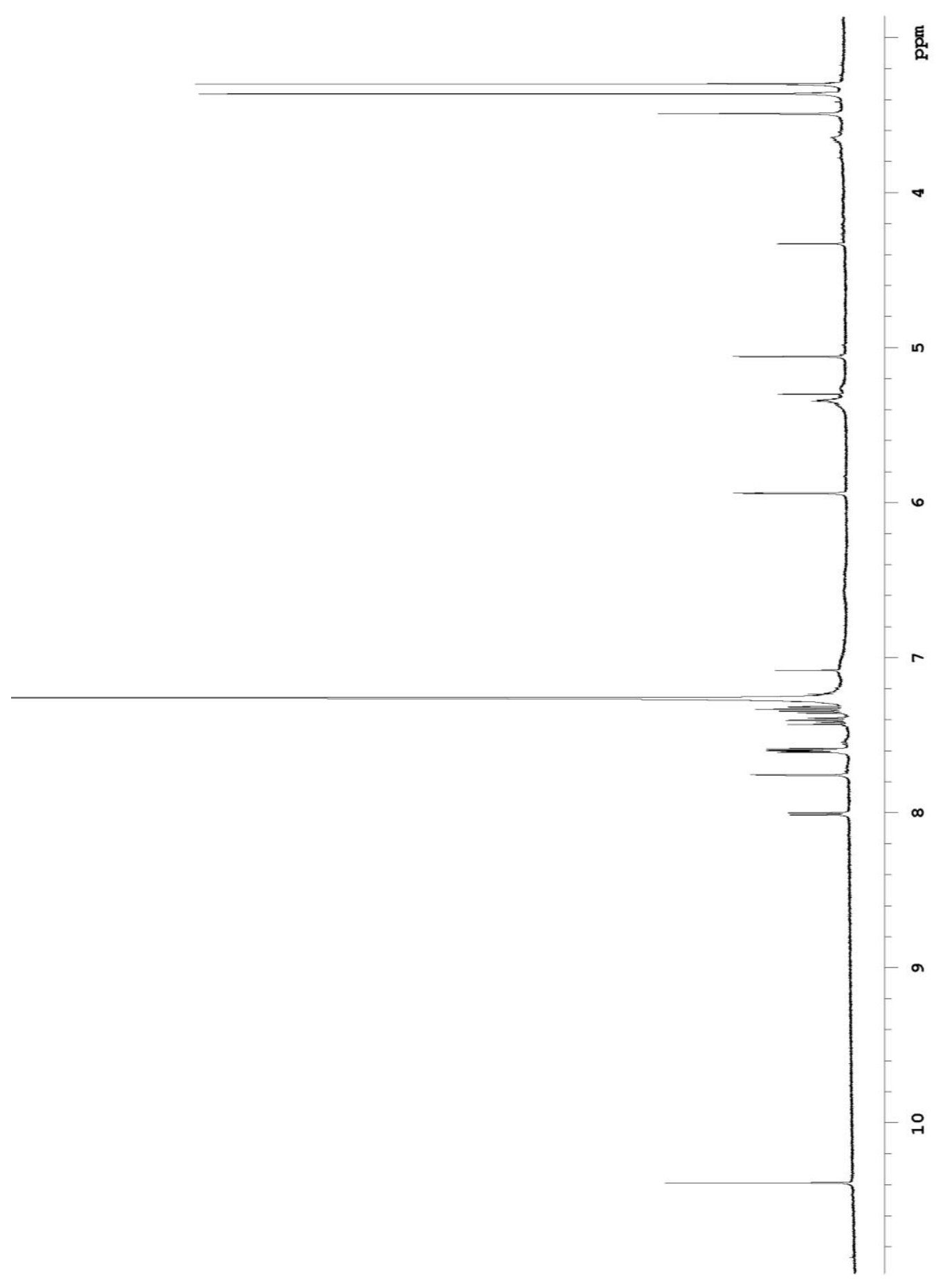

${ }^{1} \mathrm{H}$ NMR spectrum of 10-bromo-6,7-dimethoxyhomofascaplysin C $(64)\left(\mathrm{CDCl}_{3}, 600 \mathrm{MHz}\right)$ 


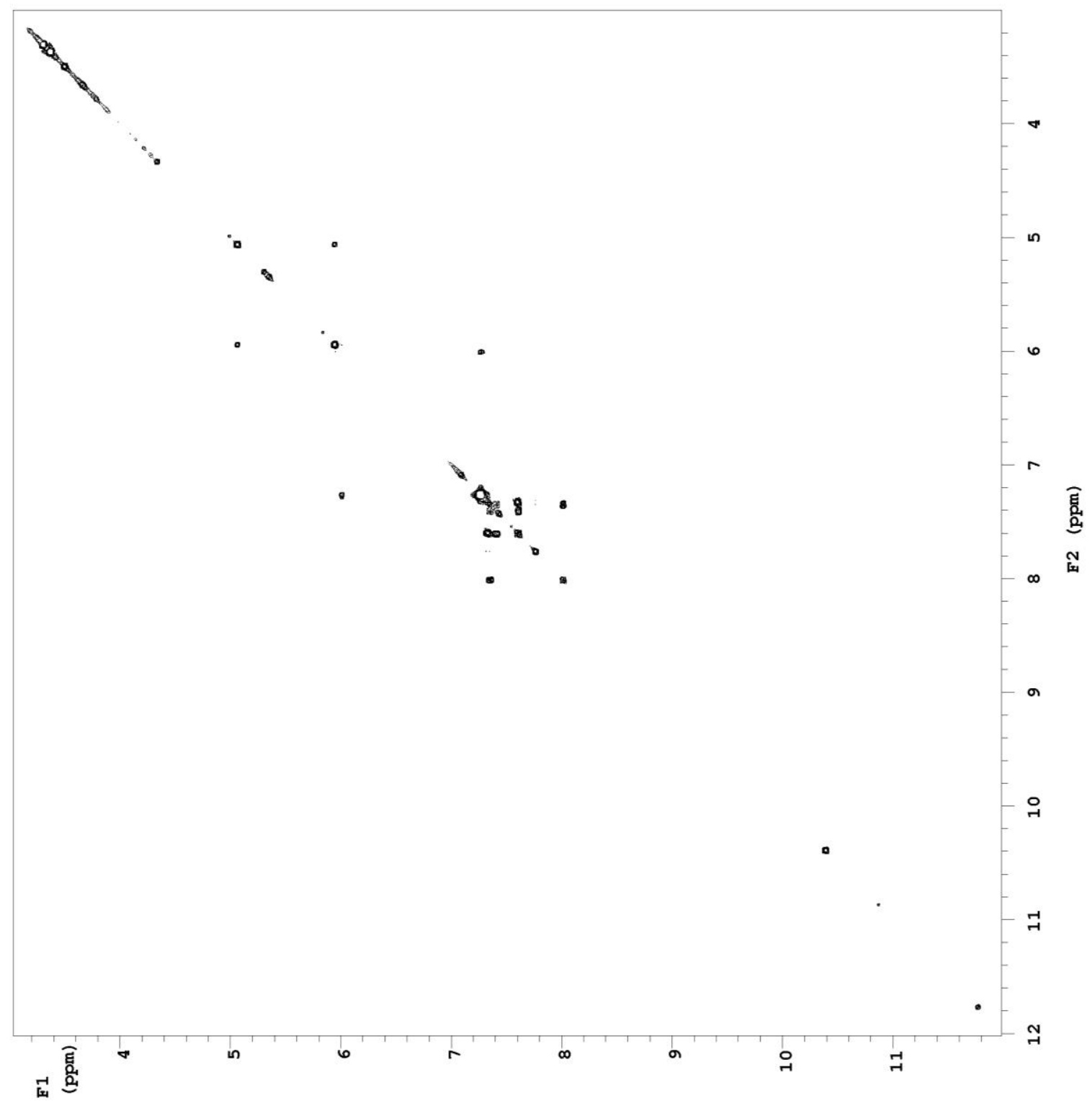

COSY spectrum of 10-bromo-6,7-dimethoxyhomofascaplysin C (64) $\left(\mathrm{CDCl}_{3}, 600 \mathrm{MHz}\right)$ 


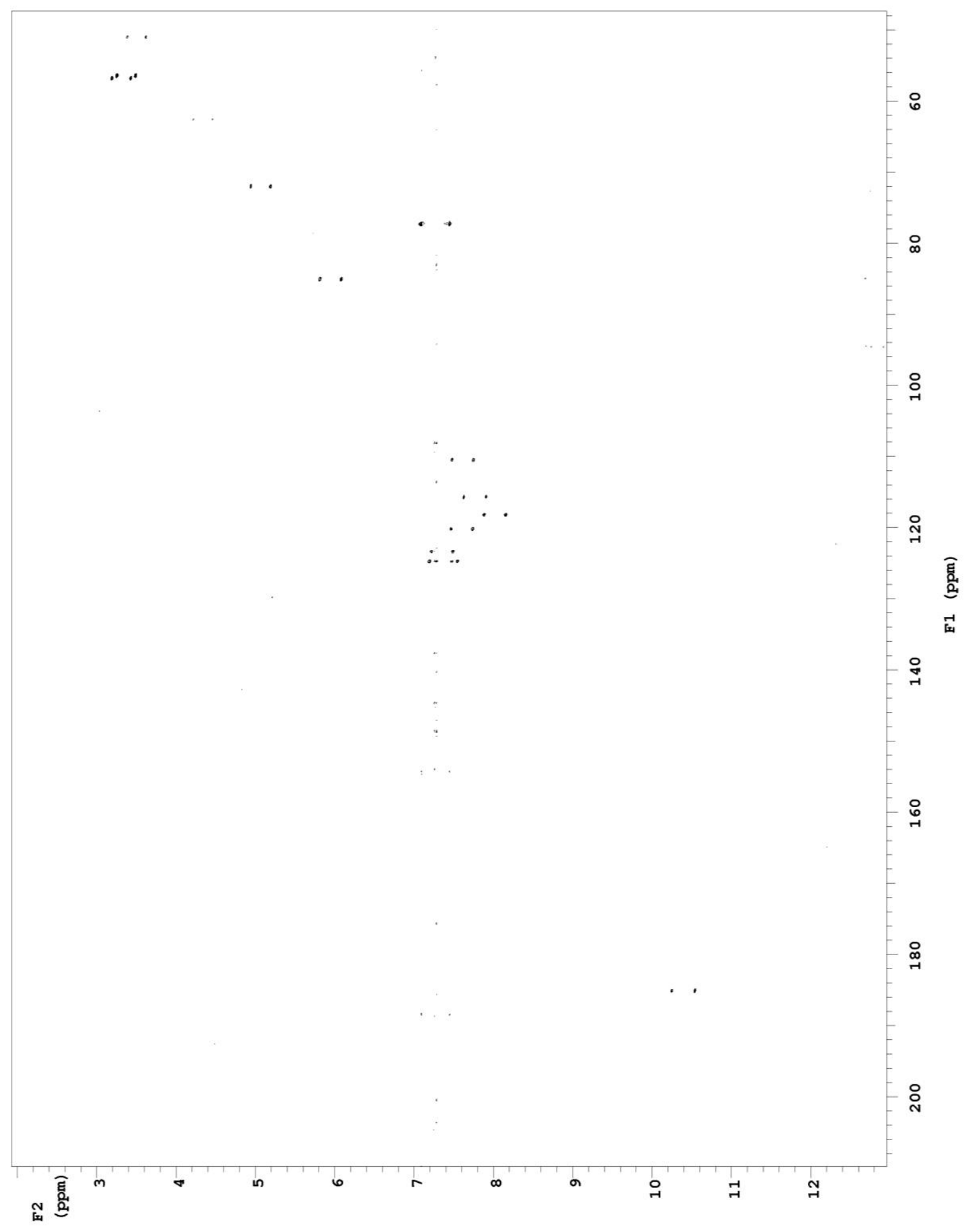

HSQC (coupled) spectrum of 10-bromo-6,7-dimethoxyhomofascaplysin C (64) $\left(\mathrm{CDCl}_{3}, 600 \mathrm{MHz}\right)$ 


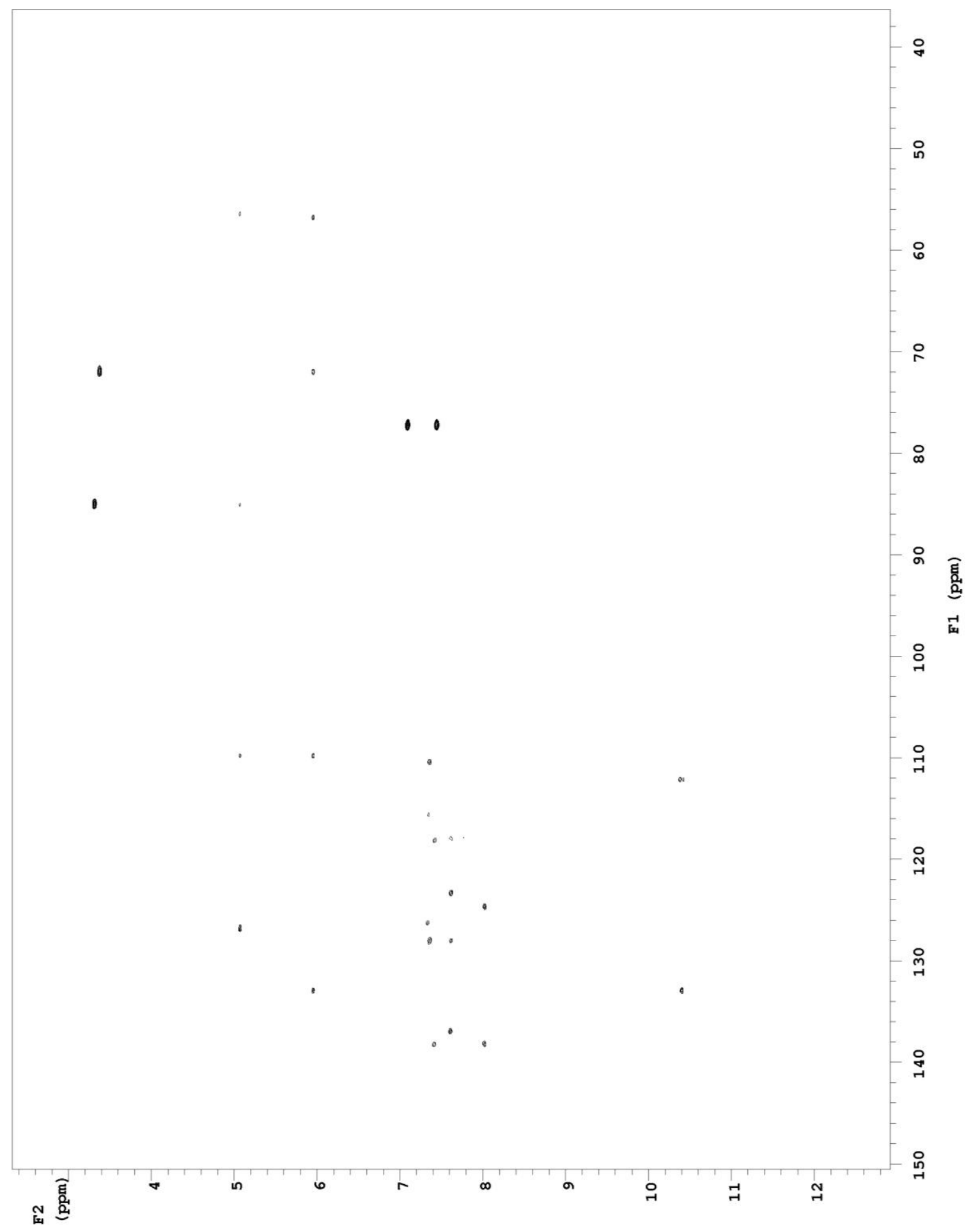

HMBC spectrum of 10-bromo-6,7-dimethoxyhomofascaplysin $\mathrm{C}(64)\left(\mathrm{CDCl}_{3}, 600 \mathrm{MHz}\right)$ 


\section{Appendix $E$}

10-Bromo-6,7-dimethoxyhomofascaplysin D Spectra

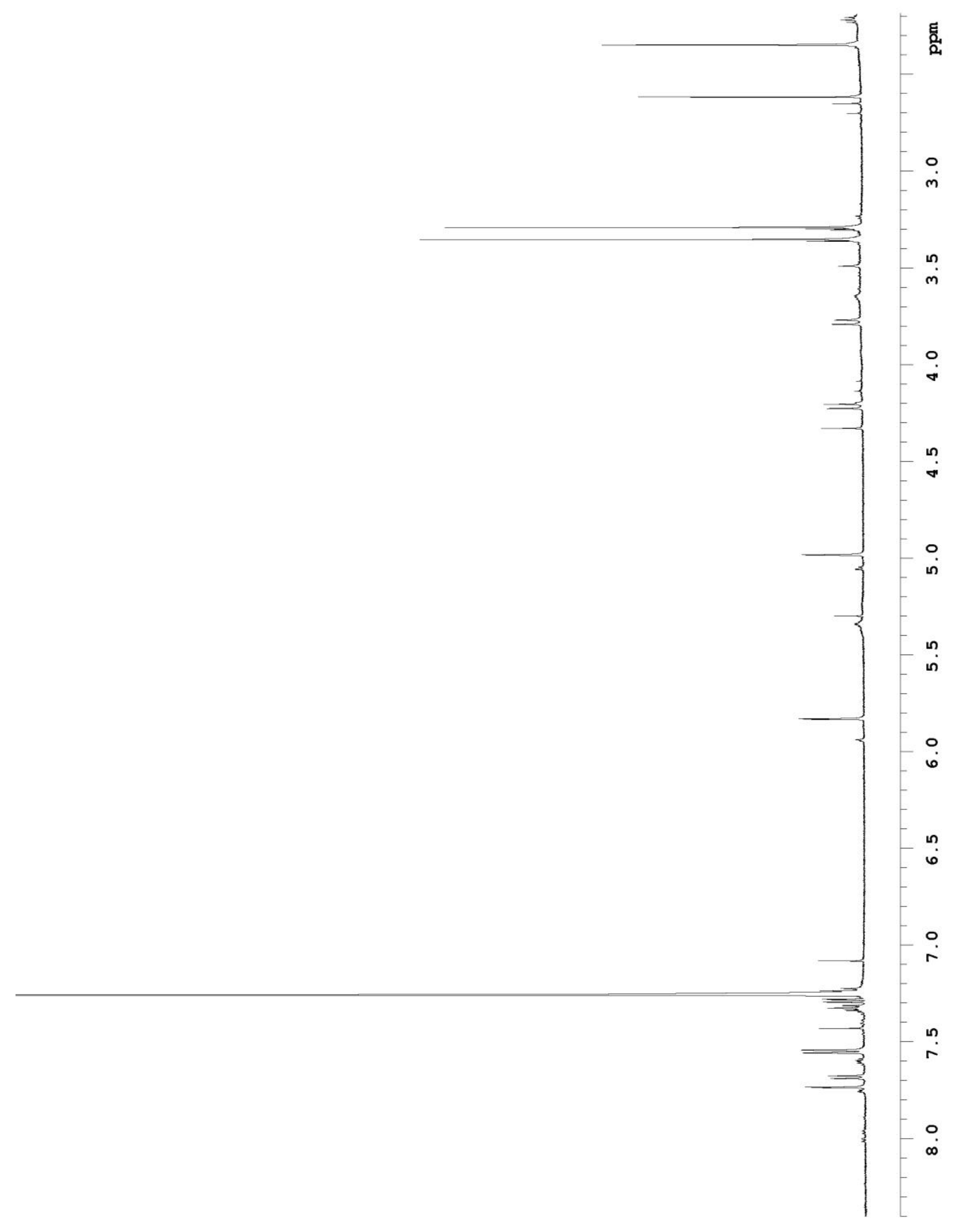

${ }^{1} \mathrm{H}$ NMR spectrum of 10-bromo-6,7-dimethoxyhomofascaplysin D (65) $\left(\mathrm{CDCl}_{3}, 600 \mathrm{MHz}\right)$ 


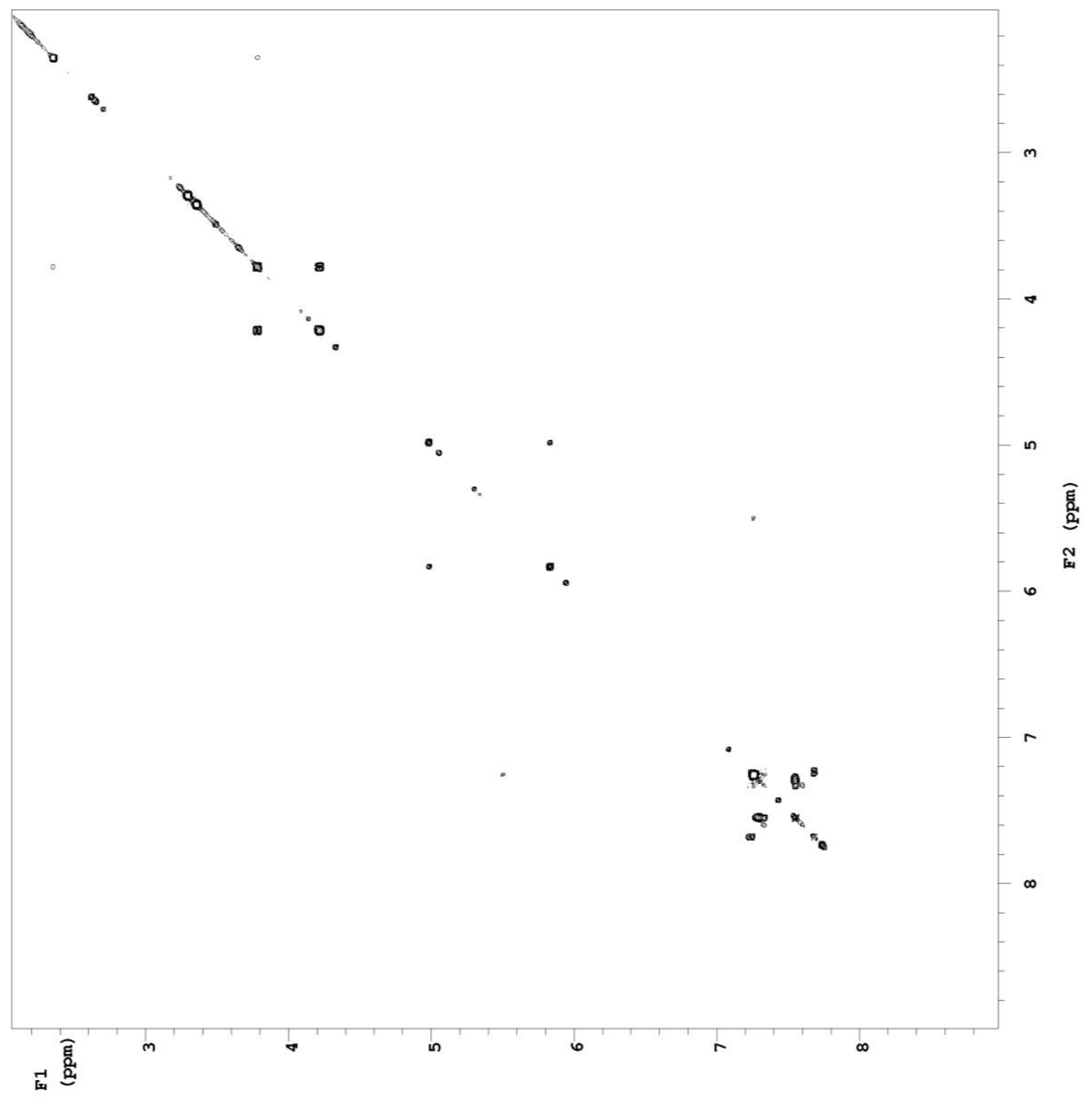

COSY spectrum of 10-bromo-6,7-dimethoxyhomofascaplysin D (65) $\left(\mathrm{CDCl}_{3}, 600 \mathrm{Mz}\right)$ 


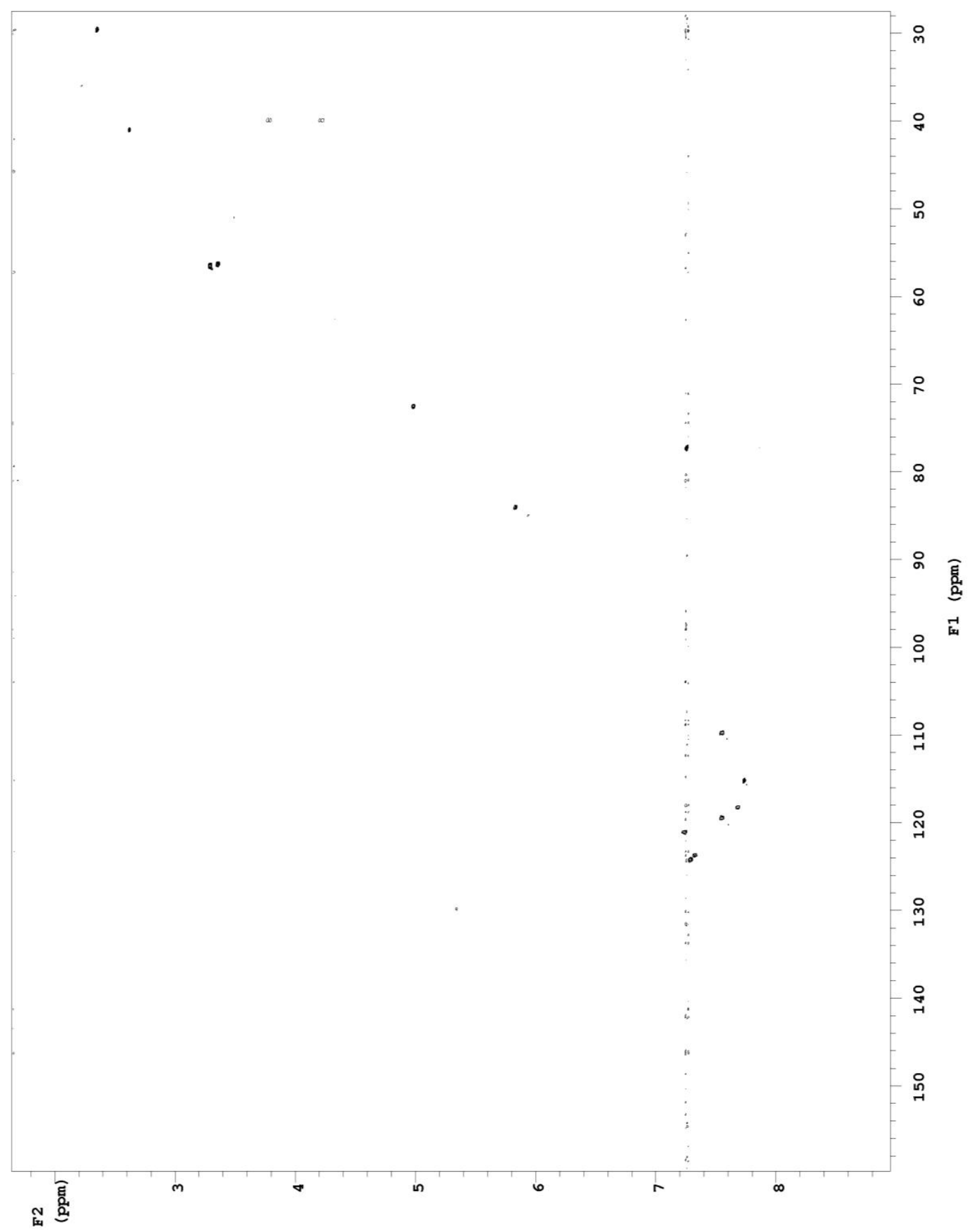

HSQC (decoupled) spectrum of 10-bromo-6,7-dimethoxyhomofascaplysin D (65) ( $\left.\mathrm{CDCl}_{3}, 600 \mathrm{Mz}\right)$ 


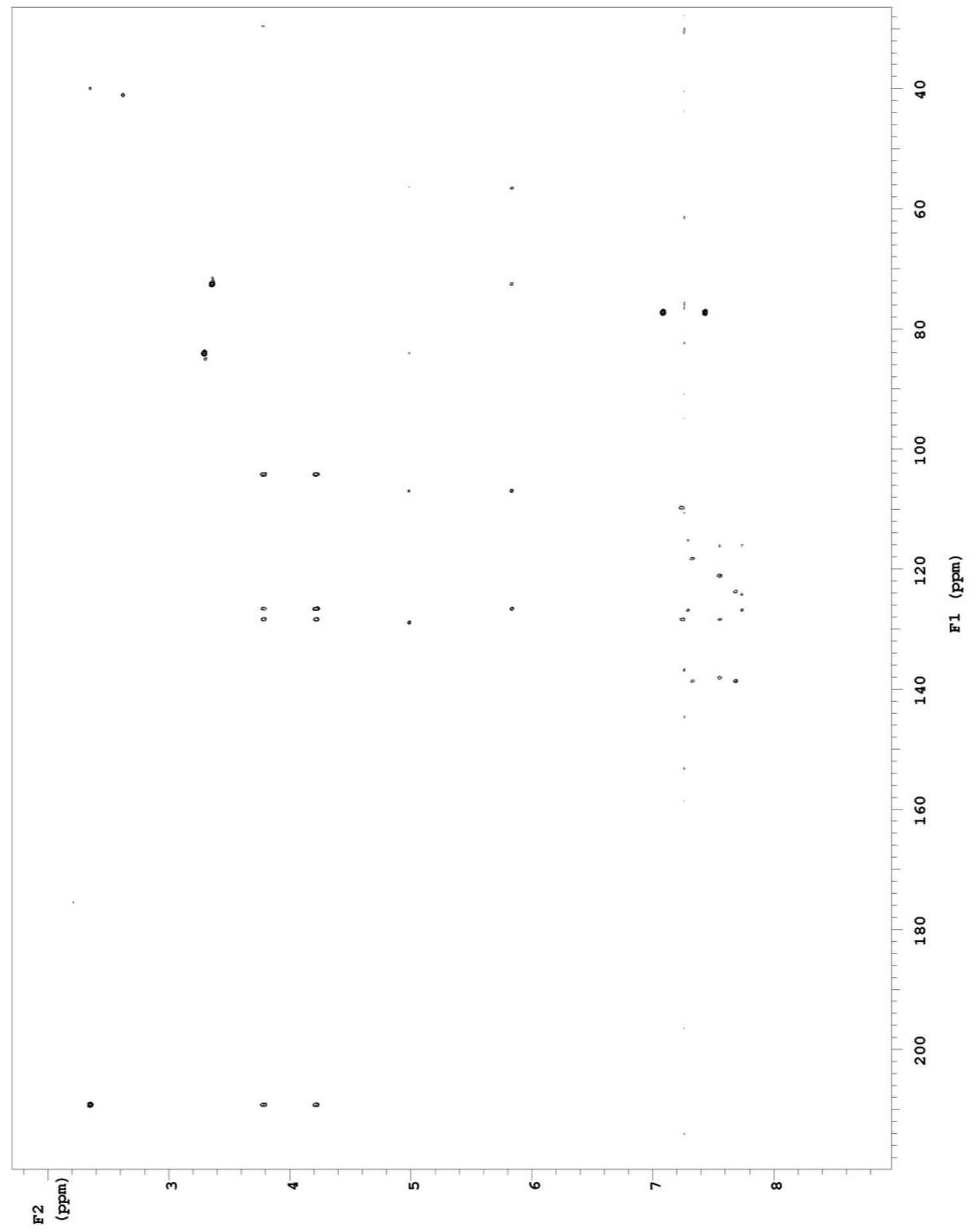

HMBC spectrum of 10-bromo-6,7-dimethoxyhomofascaplysin D (65) $\left(\mathrm{CDCl}_{3}, 600 \mathrm{Mz}\right)$ 


\section{Appendix $F$}

10-Bromohomofascaplysin A Spectra

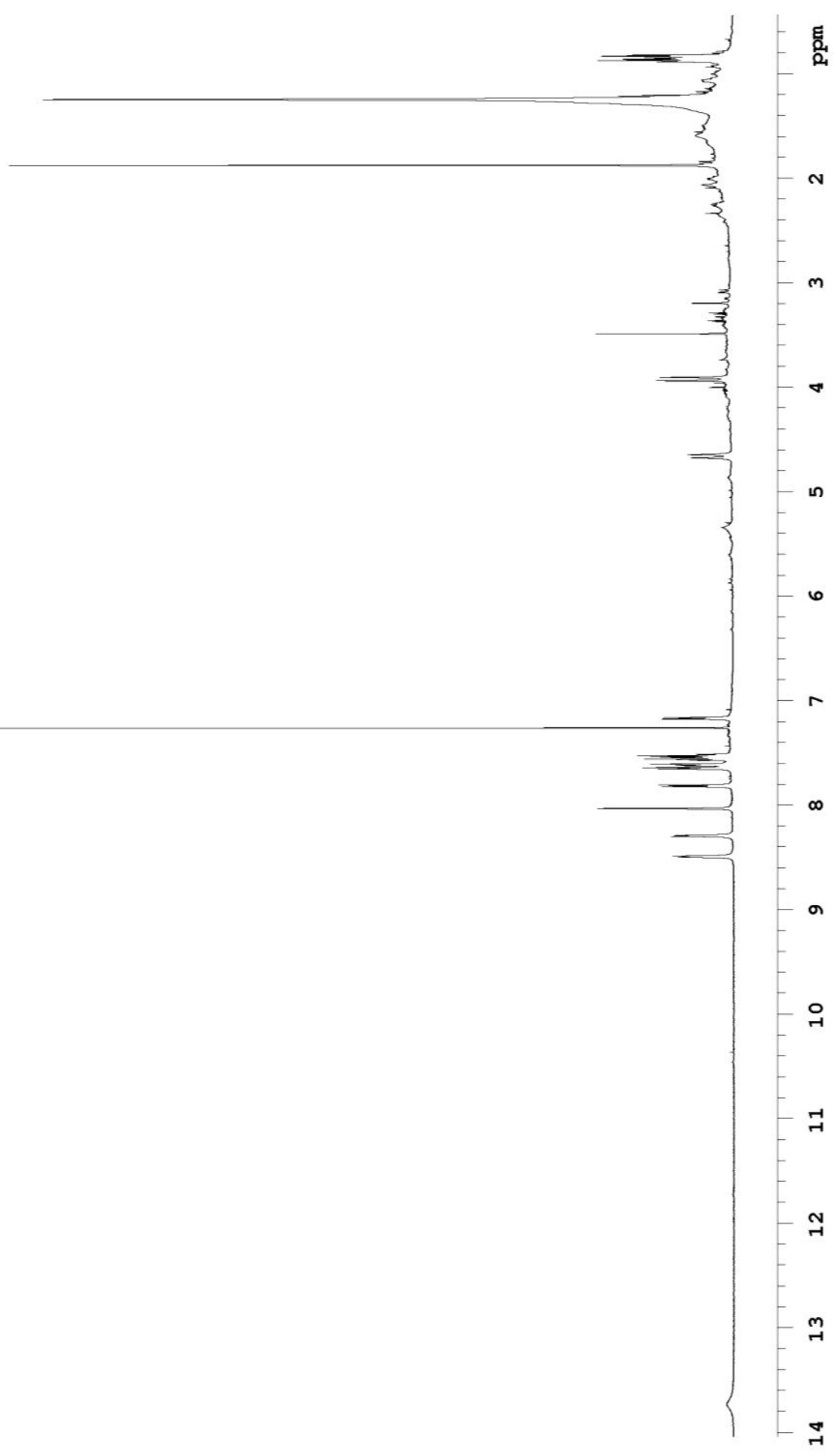

${ }^{1} \mathrm{H}$ NMR spectrum of 10-bromohomofascaplysin A (66) $\left(\mathrm{CDCl}_{3}, 600 \mathrm{MHz}\right)$ 


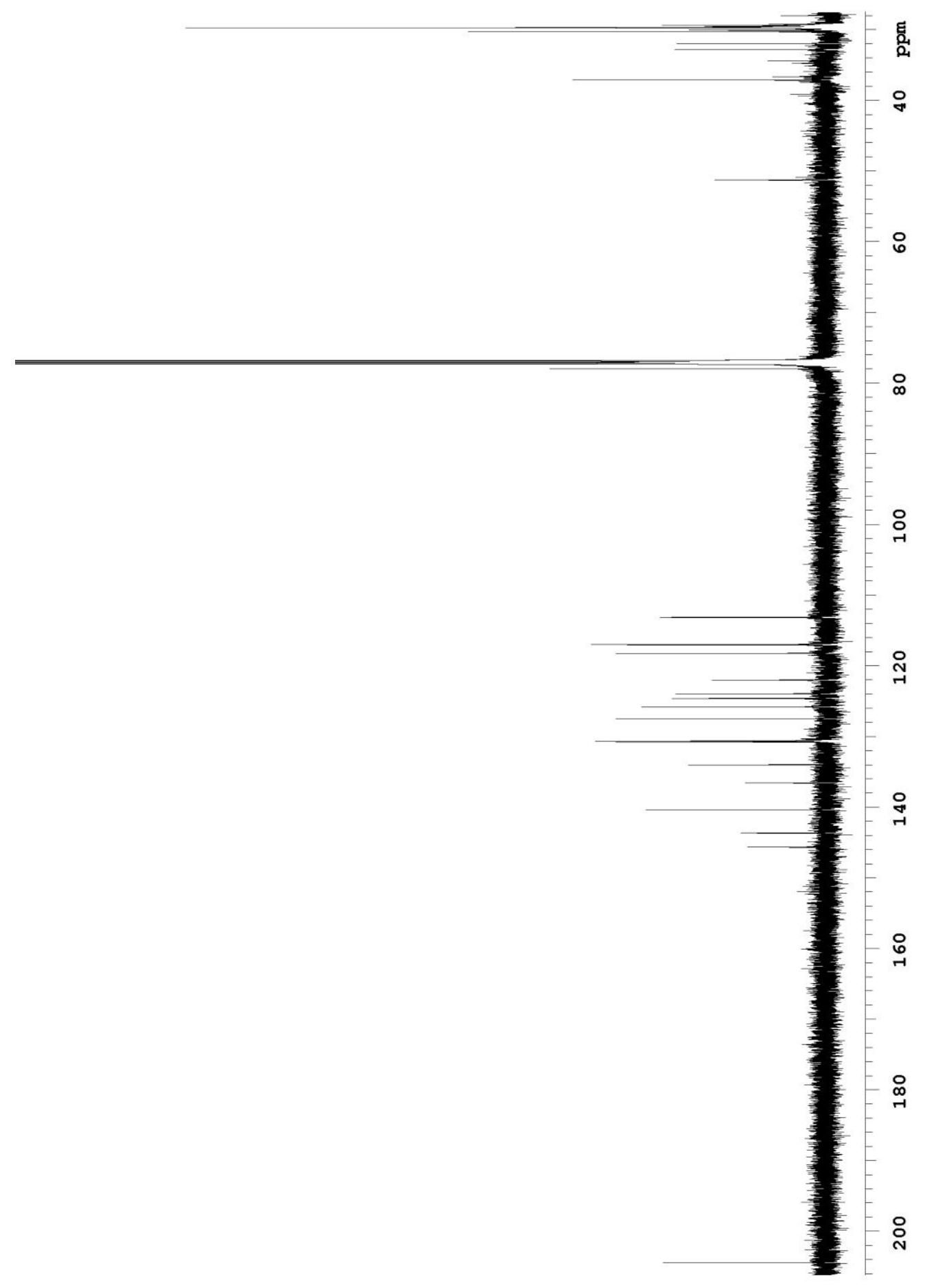

${ }^{13} \mathrm{C}$ NMR spectrum of 10-bromohomofascaplysin A (66) $\left(\mathrm{CDCl}_{3}, 150 \mathrm{MHz}\right)$ 


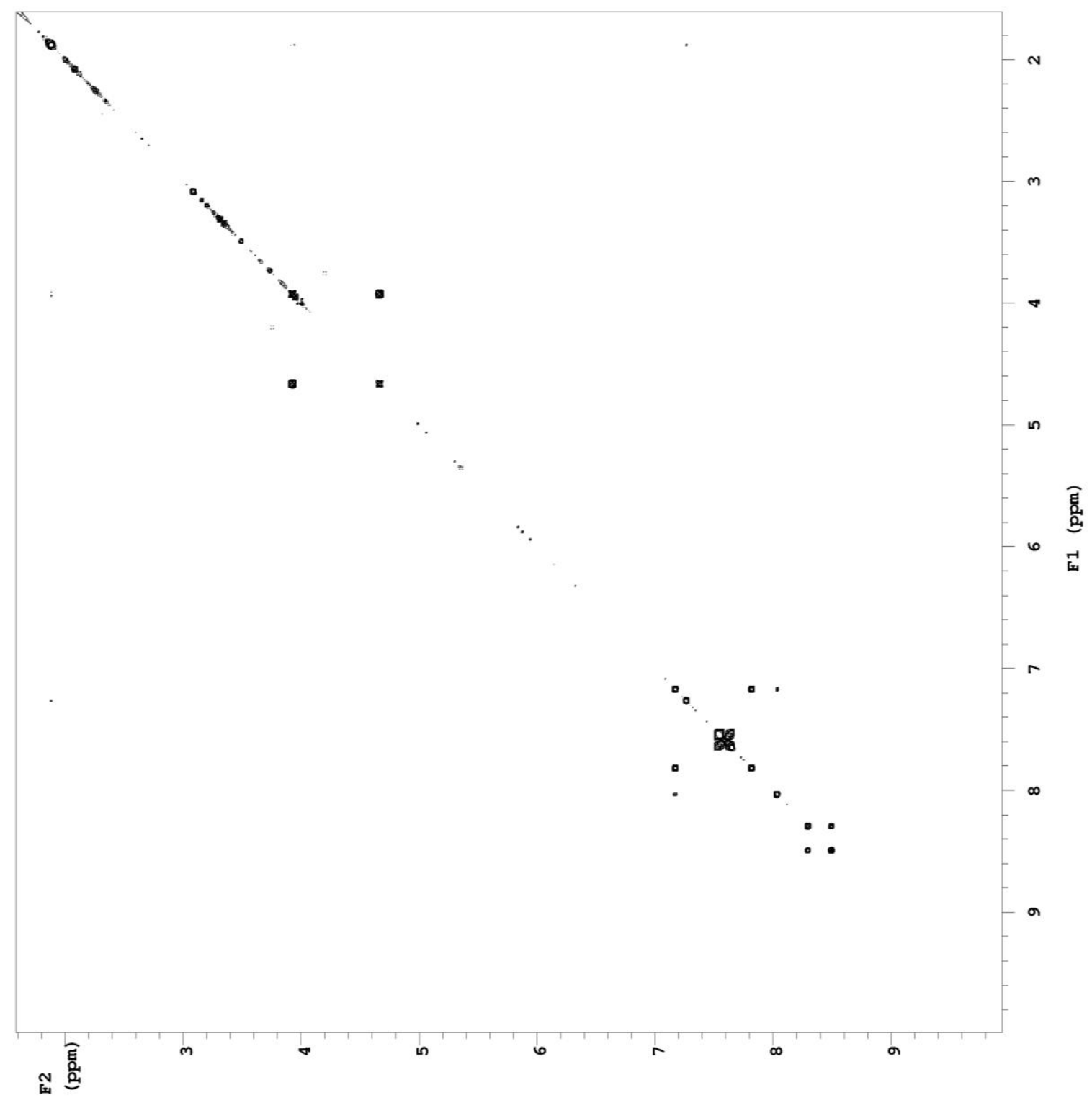

COSY spectrum of 10-bromohomofascaplysin A (66) $\left(\mathrm{CDCl}_{3}, 600 \mathrm{MHz}\right)$ 


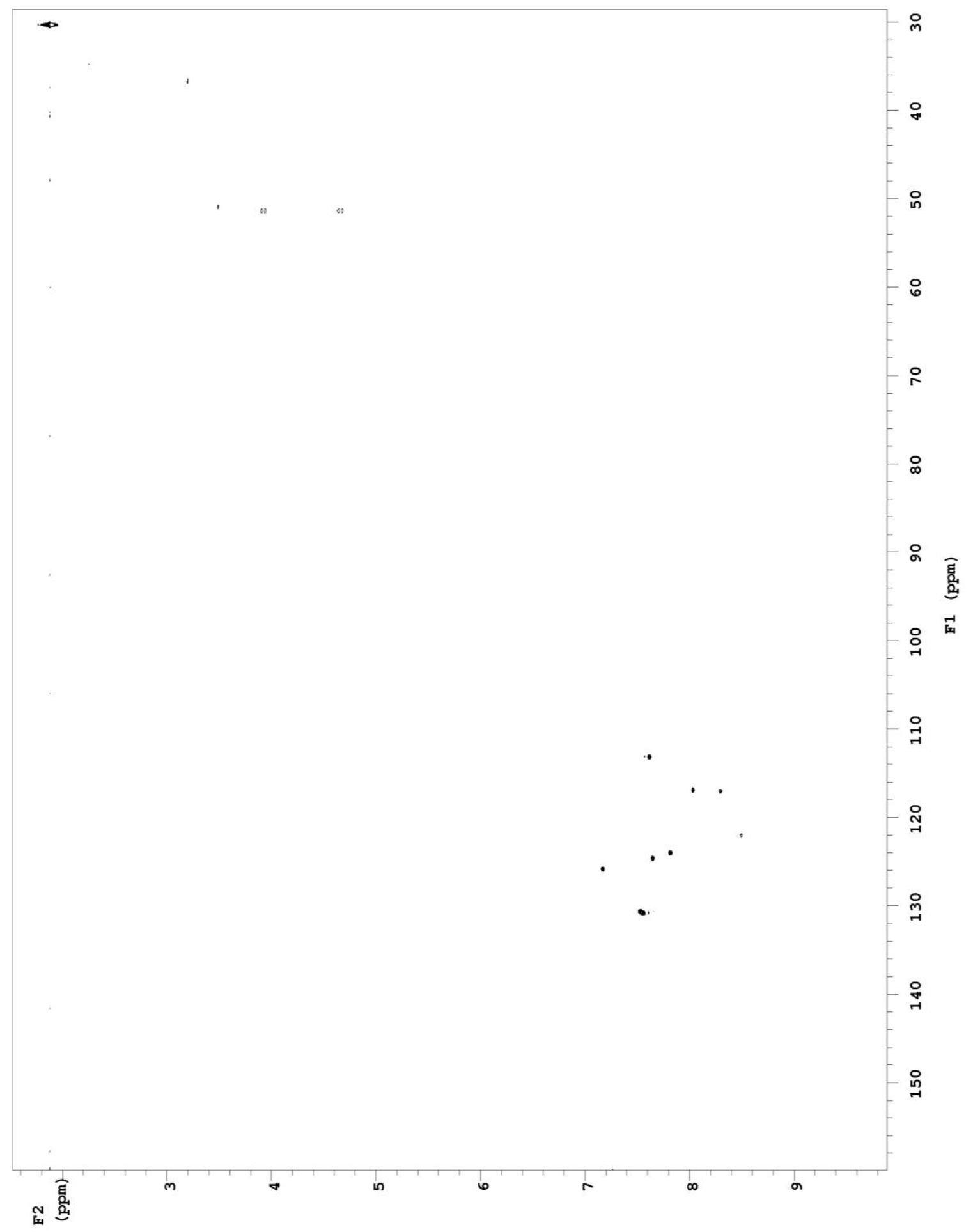

HSQC (decoupled) spectrum of 10-bromohomofascaplysin A (66) ( $\left.\mathrm{CDCl}_{3}, 600 \mathrm{MHz}\right)$ 


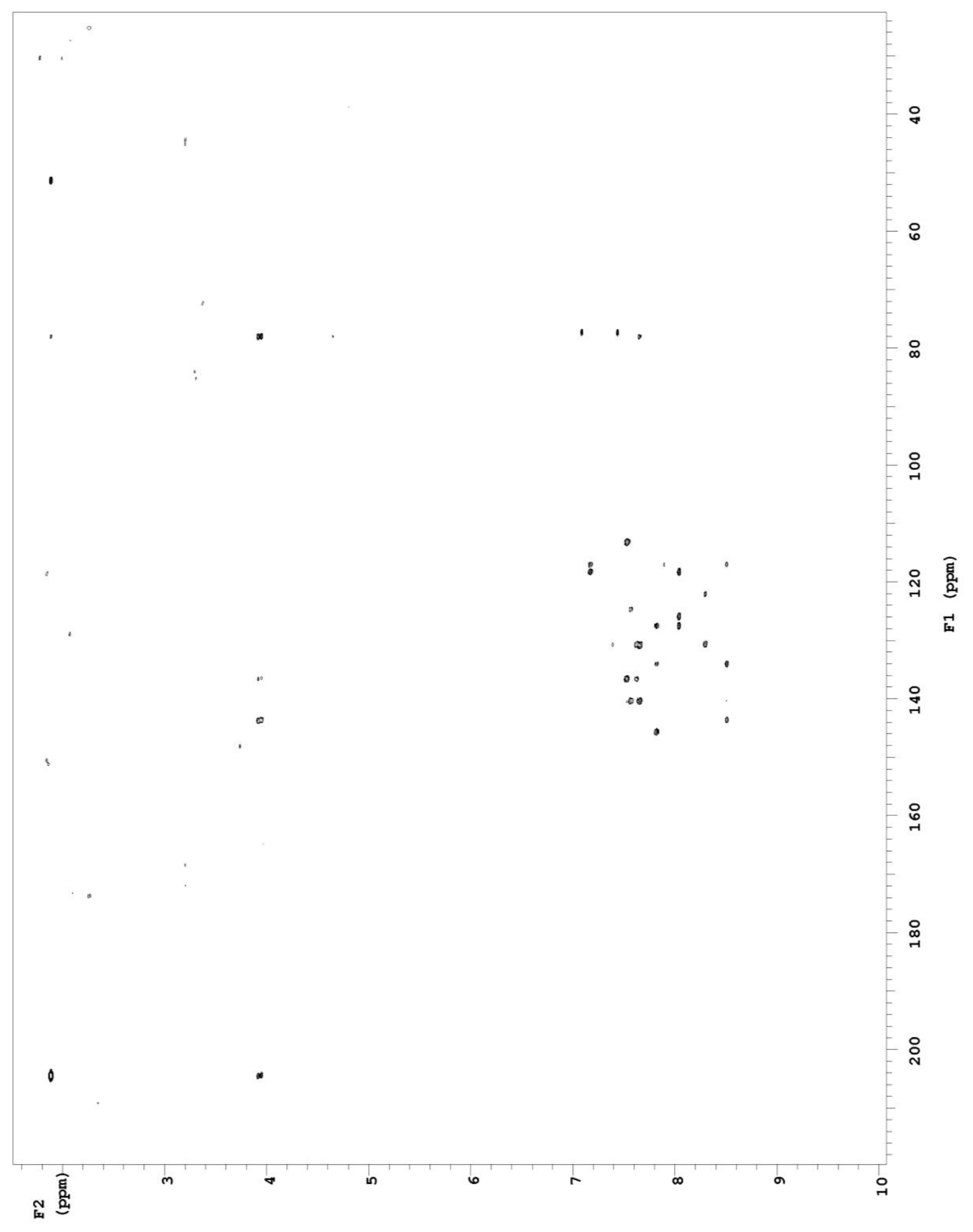

HMBC spectrum of 10-bromohomofascaplysin A (66) $\left(\mathrm{CDCl}_{3}, 600 \mathrm{MHz}\right.$ 


\section{References}

1. Newman, D. J.; Cragg, G. M.; Snader, K. M., Nat. Prod. Rep., 2000, 17 (3), 215-234.

2. Stone, M. J.; Williams, D. H., Mol. Microbiol., 1992, 6(1), 29-34.

3. Cragg, G. M.; Grothaus, P. G.; Newman, D. J., Chem. Rev., 2009, 109 (7), 3012 3043.

4. Demain, A. L., Med. Res. Rev., 2009, 29 (6), 821-842.

5. Vignesh, S.; Raja, A.; Arthur James, R., Int. J. Pharmacol., 2011, 7(1), 22-30.

6. (a) Wani, M. C.; Taylor, H. L.; Wall, M. E.; Coggon, P.; McPhail, A. T., J. Am. Chem. Soc., 1971, 93 (9), 2325-2327; (b) Wall, M. E.; Wani, M. C., J. Ethnopharmacol., 1996, $51(1-3), 239-254$.

7. Lam, K. S., Trends Microbiol., 2007, 15 (6), 279-289.

8. (a) Service, R. F., Science 1996, 272 (5266), 1266-1268; (b) Messeguer, A.; Cortes, N., Clin.Transl. Oncol., 2007, 9 (2), 83-92.

9. Kennedy, J. P.; Williams, L.; Bridges, T. M.; Daniels, R. N.; Weaver, D.; Lindsley, C. W., J. Comb. Chem., 2008, 10 (3), 345-354.

10. Cragg, G. M.; Newman, D. J., Phytochemistry Rev., 2009, 8(2), 313-331.

11. Newman, D. J.; Cragg, G. M.,. J. Nat. Prod., 2007, 70 (3), 461-477.

12. Carter, G. T., Nat. Prod. Rep., 2011, (28), 1783 - 1789.

13. (a) Dalisay, D. S.; Rogers, E. W.; Edison, A. S.; Molinski, T. F., J. Nat. Prod., 2009, 72 (4), 732-738; (b) Dalisay, D. S.; Molinski, T. F., J. Nat. Prod., 2009, 72 (4), 739-744; (c) Dalisay, D. S.; Molinski, T. F., Org. Lett., 2009, 11 (9), 1967-1970; (d) Dalisay, D. S.; Molinski, T. F., J. Nat. Prod., 2010, 73 (4), 679-682.

14. S. M. Kupchan, In Adv. in Chem., 1971; Vol. 108, pp 1-13.

15. Napolitano, J. G.; Daranas, A. H.; Norte, M.; Fernández, J. J., Anti-Cancer Agents Med. Chem., 2009, 9 (2), 122-137.

16. (a) Haefner, B., Drug Disc. Today 2003, 8 (12), 536-544; (b) Marris, E., Nature 2006, 443 (7114), 904-905.

17. Ebada, S. S.; Edrada, R. A.; Lin, W.; Proksch, P., Nat. Protoc., 2008, 3 (12), 18201831.

18. Villa, F. A.; Gerwick, L., Immunopharmacol Immunotoxicol., 2010, 32 (2), 228237.

19. (a) Bergmann, W.; Feeney, R. J., J. Am. Chem. Soc., 1950, 72 (6), 2809-2810; (b) Bergmann, W.; Burke, D. C., J. Org. Chem., 1955, 20 (11), 1501-1507.

20. (a) Sipkema, D.; Franssen, M. C. R.; Osinga, R.; Tramper, J.; Wijffels, R. H., Mar. Biotechnol., 2005, 7 (3), 142-162; (b) Vasconcelos, T. R. A.; Ferreira, M. L.; Gonçalves, R. S. B.; Da Silva, E. T.; De Souza, M. V. N., J. Sulfur Chem., 2008, 29 (5), 559-571.

21. Newman, D. J.; Cragg, G. M., J. Nat. Prod., 2004, 67(8), 1216-1238. 
22. Marinlit: Marine Literature Database. vpc15.5; University of Cantebury: Christchurch, 2011.

23. Kita, M.; Uemura, D., Chem. Rec., 2010, 10(1), 48-52.

24. Imhoff, J. F.; Labes, A.; Wiese, J., Biotechnol. Adv., 2011, 29 (5), 468-482.

25. Mayer, A. M. S.; Glaser, K. B.; Cuevas, C.; Jacobs, R. S.; Kem, W.; Little, R. D.; McIntosh, J. M.; Newman, D. J.; Potts, B. C.; Shuster, D. E., Trends Pharmacol. Sciences 2010, 31 (6), 255-265.

26. Cortes, J.; Montero, A. J.; Glück, S., Cancer Treat. Rev., 2011.

27. Jain, S.; Vahdat, L. T., Clin. Cancer Res., 2011, 17 (21), 6615-6622.

28. Braekman, J. C.; Daloze, D., Phytochemistry Rev., 2004, 3(3), 275-283.

29. (a) Blunt, J. W.; Copp, B. R.; Munro, M. H. G.; Northcote, P. T.; Prinsep, M. R., Nat. Prod. Rep., 2010, 27 (2), 165-237; (b) Blunt, J. W.; Copp, B. R.; Munro, M. H. G.; Northcote, P. T.; Prinsep, M. R., Nat. Prod. Rep., 2011, 28 (2), 196-268; (c) Blunt, J. W.; Copp, B. R.; Keyzers, R. A.; Munro, M. H. G.; Prinsep, M. R., Nat. Prod. Rep. 2012, $29(2), 144-222$.

30. Hooper, J. N. A.; Van Soest, R. W. M., Systema Porifera: A Guide to the Classification of Sponges. Kluwer Academic/Plenum Publishers New York: 2002; Vol. 1.

31. Koopmans, M.; Martens, D.; Wijffels, R. H., Mar. Drugs 2009, 7 (4), 787-802.

32. Page, M.; West, L.; Northcote, P.; Battershill, C.; Kelly, M., J. Chem. Ecol., 2005, 31 (5), 1161-1174

33. Abdo, D.; Motti, C.; Battershill, C.; Harvey, E., J. Chem. Ecol., 2007, 33 (8), 16351645.

34. Ruzicka, R.; Gleason, D. F., Oecologia, 2008, 154 (4), 785-794.

35. Becerro, M. A.; Thacker, R. W.; Turon, X.; Uriz, M. J.; Paul, V. J., Oecologia, 2003, 135(1), 91-101.

36. (a) Blunt, J. W.; Copp, B. R.; Hu, W. P.; Munro, M. H. G.; Northcote, P. T.; Prinsep, M. R., Nat. Prod. Rep., 2009, 26 (2), 170-244; (b) Blunt, J. W.; Copp, B. R.; Hu, W. P.; Munro, M. H. G.; Northcote, P. T.; Prinsep, M. R., NatProd. Rep., 2008, 25(1), 35-94.

37. Pawson, D. L.; Pawson, D. J.; King, R. A., Zootaxa, 2010, (2449), 1-48.

38. (a) Stonik, V. A.; Kalinin, V. I.; Avilov, S. A., J. Nat. Toxins 1999, 8, 235-247; (b) Halstead, B. W., Poisonous and Venomous Marine Animals of the World. Darwin Press, New Jersey: 2004.

39. Wing, S., Subtidal invertebrates of New Zealand. Cantebury University Press: 2008.

40. Moraes, G.; Northcote, P. T.; Kalinin, V. I.; Avilov, S. A.; Silchenko, A. S.; Dmitrenok, P. S.; Stonik, V. A.; Levin, V. S., Biochem. Syst. Ecol., 2004, 32 (7), 637-650.

41. Hostettmann, K.; Marston, A., Saponins. Cambridge University Press: Great Britain, 1995.

42. Van Dyck, S.; Gerbaux, P.; Flammang, P., Compar. Biochem. Physiol. Part B: Biochem. Mol. Biol., 2009, 152 (2), 124-134. 
43. Liu, B. S.; Yi, Y. H.; Li, L.; Sun, P.; Han, H.; Sun, G. Q.; Wang, X.-H.; Wang, Z. L., Chem. Biodiv., 2008, 5(7), 1425-1433.

44. Chanley, J. D.; Ledeen, R.; Wax, J.; Nigrelli, R. F.; Sobotka, H., J. Am. Chem. Soc., $1959,81(19), 5180-5183$.

45. Kitagawa, I.; Nishino, T.; Matsuno, T.; Akutsu, H.; Kyogoku, Y., S Tetrahedron Lett., 1978, $19(11), 985-988$.

46. Han, H.; Xu, Q. Z.; Yi, Y. H.; Gong, W.; Jiao, B. H., Chem. Biodiv., 2010, 7 (1), 158 167.

47. Sashidhara, K. V.; White, K. N.; Crews, P., J. Nat. Prod., 2009, 72 (3), 588-603.

48. Quiñoá, E.; Crews, P., Tetrahedron Lett., 1987, 28 (28), 3229-2323.

49. Crews, P.; Bescansa, P.; Bakus, G. J., Experientia, 1985, 41 (5), 690-1.

50. Crews, P.; Bescansa, P., J. Nat. Prod., 1986, 49 (6), 1041-1052.

51. Barber, J. M.; Quek, N. C. H.; Leahy, D. C.; Miller, J. H.; Bellows, D. S.; Northcote, P. T., J. Nat. Prod., 2011, 74 (4), 809-815.

52. Field, J. J.; Singh, A. J.; Kanakkanthara, A.; Halafihi, T. I.; Northcote, P. T.; Miller, J. H., J. Med. Chem. 2009, 52 (22), 7328-7332.

53. Tanaka, J.-i.; Higa, T., Tetrahedron Lett., 1996, 37 (31), 5535-5538.

54. Sticher, O., Nat. Prod. Rep., 2008, 25 (3), 517-554.

55. Popplewell, W. L., PhD Thesis, Victoria University of Wellington, Wellington, 2008.

56. Blunt, J. W.; Calder, V. L.; Fenwick, G. D.; Lake, R. J.; McCombs, J. D.; Munro, M. H. G.; Perry, N. B., J. Nat. Prod., 1987, 50 (2), 290-292.

57. West, L. M., PhD Thesis, Victoria University of Wellington, Wellington, 2001.

58. Moraes, G., PhD Thesis, Victoria University of Wellington, Wellington, 2006.

59. Harvey, A. L., Drug Disc. Today, 2008, 13(19-20), 894-901.

60. Keyzers, R. A. PhD Thesis, Victoria University of Wellington, Wellington, 2003.

61. Koehn, F. E., Prog. Drug Res., 2008, 65, 176-210.

62. (a) Ryan, J. M., PhD Thesis, Victoria University of Wellington, Wellington 2007; (b) Wojnar, J., PhD Thesis, Victoria University of Wellington, Wellington, 2008.

63. Singh, A. J., PhD Thesis, Victoria University of Wellington, Wellington, 2012.

64. (a) Kalinin, V. I.; Silchenko, A. S.; Avilov, S. A.; Stonik, V. A.; Smirnov, A. V., Phytochemistry Rev., 2005, 4 (2-3), 221-236; (b) Hirashima, M.; Tsuda, K.; Hamada, T.; Okamura, H.; Furukawa, T.; Akiyama, S. I.; Tajitsu, Y.; Ikeda, R.; Komatsu, M.; Doe, M.; Morimoto, Y.; Shiro, M.; Van Soest, R. W. M.; Takemura, K.; Iwagawa, T., J. Nat. Prod., 2010, 73 (9), 1512-1518; (c) Antonov, A. S.; Kalinovskii, A. I.; Dmitrenok, P. S.; Stonik, V. A., Russ. J. Bioorg. Chem., 2002, 28 (3), 183-188; (d) Antonov, A. S.; Kalinovsky, A. I.; Stonik, V. A.; Afiyatullov, S. S.; Aminin, D. L.; Dmitrenok, P. S.; Mollo, E.; Cimino, G., J. Nat. Prod., 2007, 70 (2), 169-178; (e) Afiyatullov, S. S.; Kalinovsky, A. I.; Antonov, A. S.; Ponomarenko, L. P.; Dmitrenok, P. S.; Aminin, D. L.; Krasokhin, V. B.; Nosova, V. M.; Kisin, A. V., J. Nat. Prod., 2007, 70 (12), 1871-1877. 
65. Careaga, V. P.; Muniain, C.; Maier, M. S., Chem. Biodiv., 2011, 8(3), 467-475.

66. Moraes, G.; Northcote, P. T.; Silchenko, A. S.; Antonov, A. S.; Kalinovsky, A. I.; Dmitrenok, P. S.; Avilov, S. A.; Kalinin, V. I.; Stonik, V. A., J. Nat. Prod., 2005, 68 (6), 842-847.

67. Yibmantasiri, P.; Leahy, D. C.; Busby, B. P.; Angermayr, S. A.; Sorgo, A. G.; Boeger, K.; Heathcott, R.; Barber, J. M.; Moraes, G.; Matthews, J. H.; Northcote, P. T.; Atkinson, P. H.; Bellows, D. S., Mol. BioSyst., 2012, 8(3), 902-912.

68. Keukens, E. A. J.; de Vrije, T.; van den Boom, C.; de Waard, P.; Plasman, H. H.; Thiel, F.; Chupin, V.; Jongen, W. M. F.; de Kruijff, B., Biochim. Biophys. Acta (BBA) Biomembr., 1995, 1240(2), 216-228.

69. Dopeso, J.; Quiñoá, E.; Riguera, R.; Debitus, C.; Bergquist, P. R., Tetrahedron, 1994, $50(12), 3813-3828$.

70. Walker, R. P.; Faulkner, D. J., J. Org. Chem., 1981, 46 (6), 1098-102.

71. Albizati, K. F.; Holman, T.; Faulkner, D. J.; Glaser, K. B.; Jacobs, R. S., Experientia, 1987, $43(8), 949-50$.

72. Roll, D. M.; Ireland, C. M.; Lu, H. S. M.; Clardy, J., J. Org. Chem., 1988, 53 (14), 3276-3278.

73. (a) Segraves, N. L.; Robinson, S. J.; Garcia, D.; Said, S. A.; Fu, X.; Schmitz, F. J.; Pietraszkiewicz, H.; Valeriote, F. A.; Crews, P., J. Nat. Prod., 2004, 67 (5), 783-792;

(b) Lu, Z.; Ding, Y.; Li, X.-C.; Djigbenou, D. R.; Grimberg, B. T.; Ferreira, D.; Ireland, C. M.; Van Wagoner, R. M., Bioorg. Med. Chem., 2011, In Press, Corrected Proof.

74. Levy, G. C., Carbon-13 Nuclear Magnetic Resonance for Organic Chemists WileyInterscience, New York: 1972.

75. Segraves, N. L.; Lopez, S.; Johnson, T. A.; Said, S. A.; Fu, X.; Schmitz, F. J.; Pietraszkiewicz, H.; Valeriote, F. A.; Crews, P., Tetrahedron Lett., 2003, 44 (17), 3471-3475.

76. Voelter, W.; Bretmaier, E., Carbon-13 NMR Spectroscopy: High-Resolution Methods and Applications in Organic Chemistry and Biochemistry. 3rd ed.; VCH, New York: 1987.

77. Silverstein, R. M.; Webster, F. X.; Kiemle, D. J., Spectrometric Identification of Organic Compounds. 7th Ed. ed.; John Wiley \& Sons, Inc.: 2005.

78. Fretz, H.; Ucci-Stoll, K.; Hug, P.; Schoepfer, J.; Lang, M., Helv. Chim. Acta, 2001, 84 (4), 867-873.

79. Popplewell, W. L.; Northcote, P. T., Tetrahedron Lett. 2009, 50 (49), 6814-6817.

80. Hore, P. J., Nuclear Magnetic Resonance. Oxford University Press Inc., New York: 1995.

81. Jimenez, C.; Quiñoá, E.; Adamczeski, M.; Hunter, L. M.; Crews, P., J. Org. Chem., 1991, 56(10), 3403-3410.

82. (a) Jimenez, C.; Quiñoá, E.; Crews, P., Tetrahedron Lett., 1991, 32 (16), 1843-1846;

(b) Charan, R. D.; McKee, T. C.; Boyd, M. R., Nat. Prod. Res., 2004, 18(3), 225-229;

(c) Charan, R. D.; McKee, T. C.; Gustafson, K. R.; Pannell, L. K.; Boyd, M. R., Tetrahedron Lett., 2002, 43 (29), 5201-5204; (d) Foderaro, T. A.; Barrows, L. R.; Lassota, P.; Ireland, C. M., J. Org. Chem., 1997, 62 (17), 6064-6065; (e) Schmidt, E. W.; Faulkner, D. J., Tetrahedron Lett. 1996, 37 (23), 3951-3954. 
83. Kirsch, G.; Kong, G. M.; Wright, A. D.; Kaminsky, R., J. Nat. Prod., 2000, 63 (6), 825829.

84. Gottlieb, H. E.; Kotlyar, V.; Nudelman, J. Org. Chem., 1997, 62 (21), 7512-7515 